\title{
A Promising Cathode for Li-ion Batteries: $\mathrm{Li}_{3} \mathrm{~V}_{2}\left(\mathrm{PO}_{4}\right)_{3}$
}

Chaofeng Liu ${ }^{1}$, Robert Massé ${ }^{2}$, Xihui Nan ${ }^{1}$, Guozhong Cao ${ }^{1,2} *$

${ }^{1}$ Beijing Institute of Nanoenergy and Nanosystems, Chinese Academy of Sciences, Beijing 100083, China

${ }^{2}$ Department of Materials Science and Engineering, University of Washington, Seattle, Washington 98195, USA

Corresponding Author: Prof. Guozhong Cao (gzcao@u.washington.edu) 


\section{A Promising Cathode for Li-ion Batteries: $\mathrm{Li}_{3} \mathrm{~V}_{2}\left(\mathrm{PO}_{4}\right)_{3}$}

\section{Content}

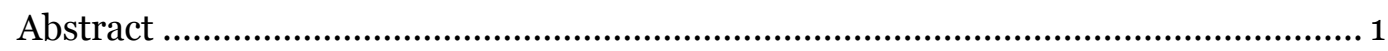

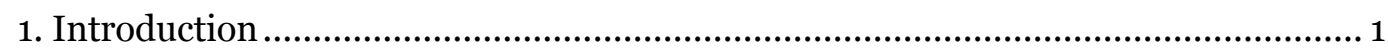

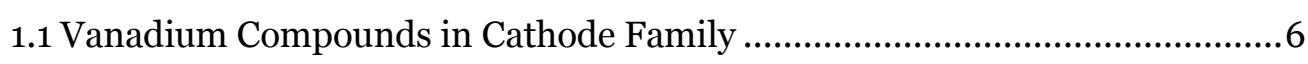

1.2 Comparison in Phosphates Electrode Materials..............................................11

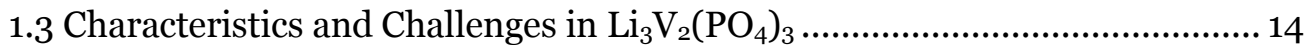

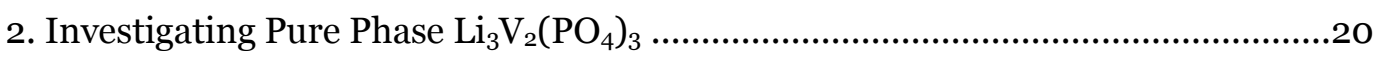

3. Doping: the Effect from Foreign Atoms ..............................................................26

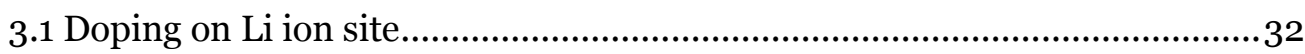

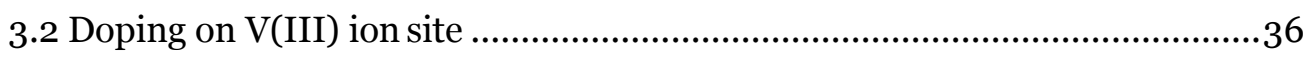

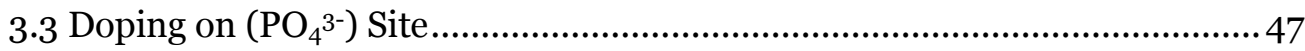

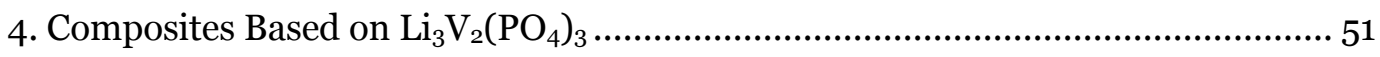

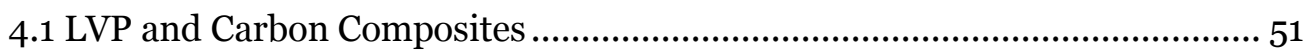

4.2 LVP Combined with Other Electrode Materials.............................................70

4.3 LVP-Metal Composites............................................................................... 79

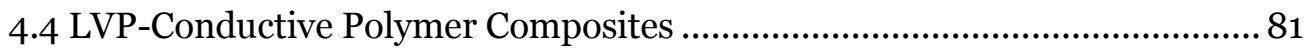

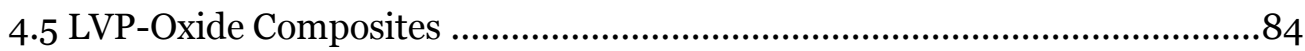

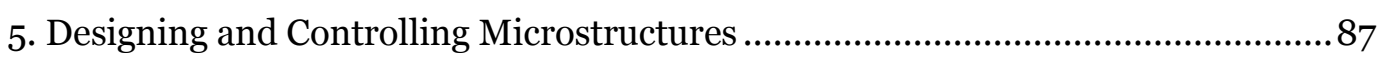

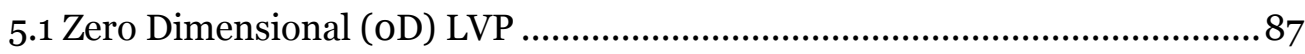

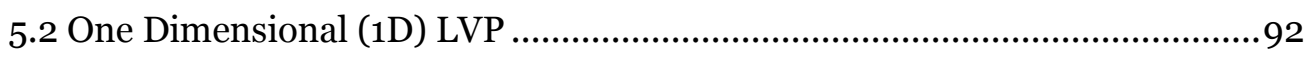

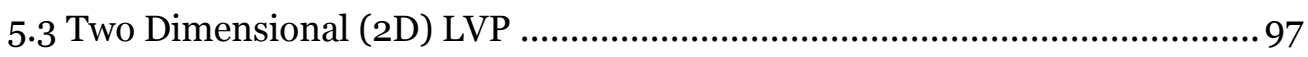

5.4 Three Dimensional (3D) LVP …............................................................100

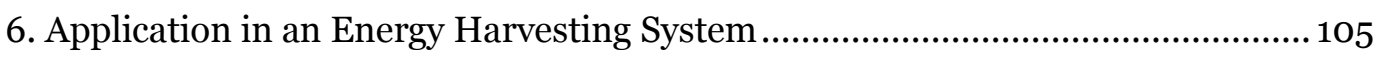

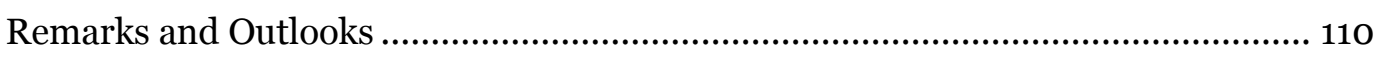

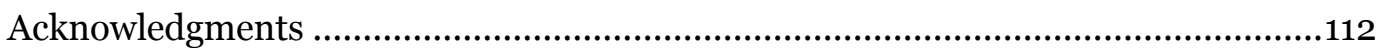

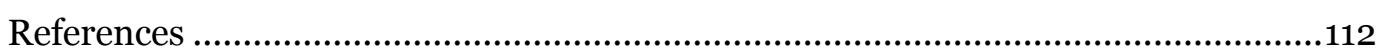




\begin{abstract}
Lithium ion batteries are essential energy storage devices that power the electronics that let us share information and connect with people anywhere at any time. As the demand for uninterrupted energy performance rises, corresponding challenges need to be overcome in both industry and academia. Currently, cathode performance limits energy-power density in Li-ion batteries. Materials chemists and scientists have devoted much effort to explore cathodes with higher capacities and electrochemical potentials. Lithium vanadium phosphate, a rising star in the cathode family, has attracted more attention in recent years because it can display a high average potential $(>4.0 \mathrm{~V})$ and specific capacity $(197 \mathrm{mAh} / \mathrm{g})$ with excellent structural stability during cycling. However, the separated $\mathrm{VO}_{6}$ octahedra intrinsically limit electrical conductivity, which hurts the rate capability. This review focuses on the fundamental issues in lithium vanadium phosphate and summarizes its crystal structure, ion diffusion, and electrochemical characteristics. Three synthetic aspects are described carefully: doping, composite and designing microstructures. At the same time, some rules are distilled from the report results, which may be referred to in order to tune the electrochemical performance in electrode materials.
\end{abstract}

\title{
1. Introduction
}

Energy has been supporting and driving the evolution of civilization in the human history, and fossil fuels such as coal, oil and natural gas are the main power sources 
that have powered industrial development and improved peoples' quality of life in the past decades. However, negative impacts stemming from the combustion of fossil fuels hurt the natural environment and public health. For example, $\mathrm{CO}_{2}$ emissions are correlated with the greenhouse effect and floating dust induced pulmonary diseases. Currently, the challenges we confront are greater than in the past because population growth demands more energy. With the expected increase of the world population from 7 to 10 billion by 2050 , energy consumption will double from 14 TW to 28 TW $[1,2]$. However, a large energy deficit will eventually appear as fossil fuels are depleted and energy consumption outpaces production. Therefore, harvesting renewable energies, such as solar, wind, and biomass energy, have become hot research topics and great efforts have been devoted to develop the corresponding technologies. The intermittent character of these renewable energies brings energy management challenges; thus efficient and useful solutions are essential to advance renewable energies. As of now, energy storage mainly depends on batteries and supercapacitors, and each has strong points. Supercapacitors rely on charge accumulation at the interfaces between electrode materials and electrolyte, thus the specific surface area in electrode materials determines the capacity of devices. The charge sorption/desorption mechanism endows supercapacitors with the ultrahigh power density $\left(\sim 10^{4} \mathrm{~W} / \mathrm{Kg}\right)$ since all charges can be released within millisecond. In practice, the limited surface area in electrode materials yield devices with lower energy density $(<10 \mathrm{Wh} / \mathrm{Kg})$. In contrast, batteries work using redox reactions in electrode materials accompanied by mass diffusion. In particular, Li-ion batteries have 
competitive operating voltages and reasonably low cost to make commercially viable energy packages. The crystal lattices in materials provide sufficient positions for ion insertion or extraction during charge/discharge processes, which deliver high specific capacities. Thus, batteries have the higher energy densities $(>100 \mathrm{Wh} / \mathrm{Kg})$, but solid-state mass diffusion hinders fast charge/discharge. Improving the power and energy densities and enhance the capacities in electrode materials are the main challenges for satisfying growing market demand. Before considering how to crack the nuts, we should take a glance at the configuration, working principle and the characteristics of battery components. Figure 1a shows an illustration of a Li-ion battery which contains a cathode, anode, separator film, electrolyte and current collectors. During the charging process, Li ions are extracted from cathode lattice sites and pass through the porous separator to insert into the anode lattices accompanied by electrons that move from cathode to anode through an external circuit. In reverse, $\mathrm{Li}$ ions come back to cathode and electrons drive the apparatus in the external circuit. As seen from the schematic, robust crystal structures in the cathode and anode are required to ensure long-term safety and reversibility. Figure $1 \mathrm{~b}$ exhibits the profiles in cathode and anode during the battery charge or discharge. The cathode potential increases and the anode potential decreases during charging, and the charge process is stopped at a set potential difference between the electrodes. The area encompassed by the potential curves of cathode and anode is the stored energy density of the battery. During discharge, the potential of the cathode decreases and that of the anode increases, and the battery runs down when the potential difference is 
lower than a certain value between two electrodes. The area between the potential discharge curves stands for the released energy density. The ratio between discharge and charge area represents the battery energy efficiency. Based on these foundations, it is understood that a cathode with a higher potential and an anode with a lower potential benefits the fabrication of a higher voltage battery. At the same time potential plateaus are essential in electrodes, especially the anode. With these design rules, graphite, silicon and $\mathrm{Li}$ metal are applicable anodes for commercial Li-ion batteries. Although $\mathrm{Li}_{4} \mathrm{Ti}_{5} \mathrm{O}_{12}$ has an ideal potential plateau and excellent structural stability, the higher potential position decreases the working voltage of battery. Beyond the electrode potential, specific capacity is also a limiting factor to enhance the energy density in battery. Compared with the commercial graphite anode, cathode materials confront with more challenges, such as improving the specific capacity, enhancing the electrochemical potential, and promoting the cycling stability. Exploring new cathode categories and improving the known materials are the main approaches in both industry and academia. The rules for exploring new materials have been summarized in several review articles [3-6]. Nowadays, the cathodes focus on V-, Fe-, Co-, Ni-, and Mn-based materials. For example, $\mathrm{LiFePO}_{4}$ as a cathode displays a potential plateau at $3.45 \mathrm{~V}$, but the phosphate groups separate the $\mathrm{FeO}_{6}$ octahedrons leading to an inferior electrical conductivity $\left(10^{-9}-10^{-10} \mathrm{~S} / \mathrm{cm}\right)$ [7]. $\mathrm{LiCoO}_{2}$ is the earliest commercial cathode with an average potential at $3.9 \mathrm{~V}$, but cobalt is both toxic and expensive which stimulates researchers to find new candidates [8]. The dissolution of $\mathrm{Mn}^{2+}$ from $\mathrm{LiMn}_{2} \mathrm{O}_{4}$ and chemical reactions with the electrolyte in 
$\mathrm{LiNiO}_{2}$ hinder their safety and stability in practical applications [9]. Conversely, Vanadium compounds are promising cathodes that have attracted researchers' interest due to their unique voltage plateaus, high theoretical capacities and excellent stabilities. In this review, we compare the characteristics of vanadium-based cathodes and concentrate in particular on the advancements in lithium vanadium phosphate $\left(\mathrm{Li}_{3} \mathrm{~V}_{2}\left(\mathrm{PO}_{4}\right)_{3}\right)$.

(a)

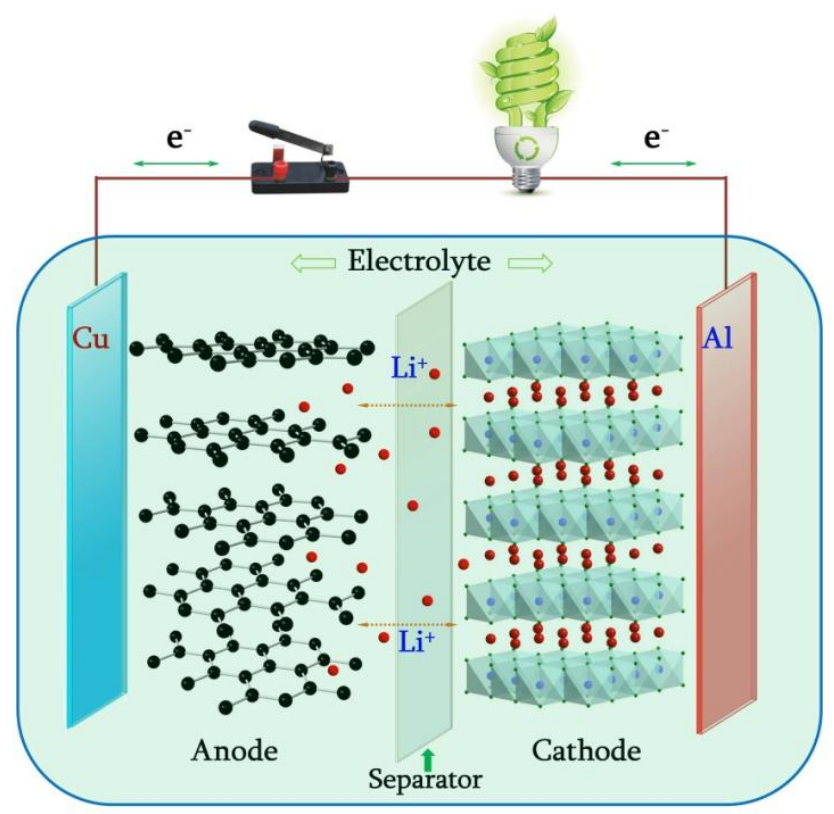

(b)

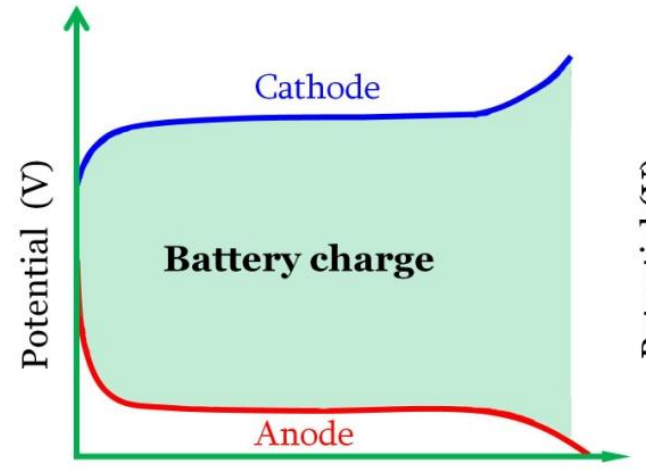

Specific capacity $(\mathrm{mAh} / \mathrm{g})$

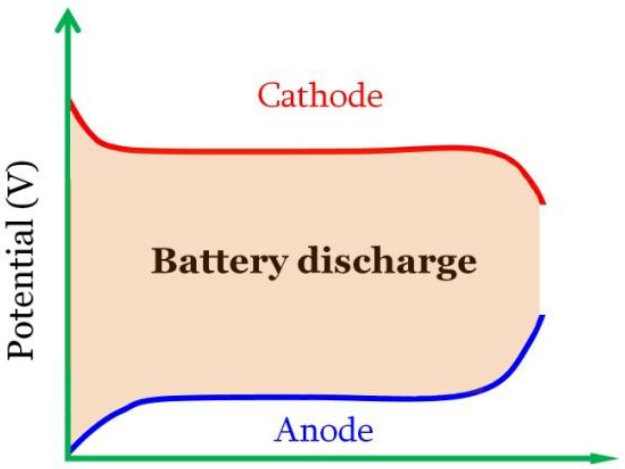

Specific capacity $(\mathrm{mAh} / \mathrm{g})$

Figure 1. (a) Schematic Li-ion battery configuration [5]. The main components are the cathode, anode, separator, electrolyte and current collectors. $\mathrm{Li}$ ions move forwards and backwards between cathode and anode and electrons travel in the external circuit when the battery works. Robust 
materials in electrodes ensure battery safety and stability. (b) The potential curves in the cathode and anode during battery operation. Upon charging, $\mathrm{Li}$ ions are extracted from the cathode lattice and inserted into the anode while the potential increases in the cathode and decreases in the anode. In reverse, $\mathrm{Li}$ ions come back and the potential decreases in the cathode. The area between the potential curves indicates the energy density of the battery in the charged or discharged state, and the ratio of the area between the discharged and charged state represents the battery efficiency. Beyond the specific capacity of materials, the potential difference between electrodes also corresponds to the energy density in battery, especially the potential plateau in anode. Thus, in a full battery, the expected cathode should has a high potential plateau, and the anode has a low potential plateau within the working window of electrolyte.

\subsection{Vanadium Compounds in Cathode Family}

Vanadium, atomic number 23 , is a first-row transition metal whose electron configuration is $[\mathrm{Ar}] 3 \mathrm{~d}^{3} 4 \mathrm{~s}^{2}$. Metallic vanadium exhibits physical characteristics that include hardness, silvery grey color, ductility and malleability, and its electrical conductivity reaches up to $5.13 \times 10^{4} \mathrm{~S} / \mathrm{cm}$. The element is found only in chemical compounds in nature, but once isolated artificially, the formation of an oxide layer somewhat stabilizes the free metal against further oxidation [10]. The element vanadium has a considerable abundance of $190 \mathrm{ppm}$ in continental crust (Figure 2) and the abundance rank is $20^{\text {th }}$ in all known elements [11], leading to a relatively low cost for practical applications. With the increasingly development of energy technology, vanadium compounds, such as $\mathrm{V}_{2} \mathrm{O}_{5}, \mathrm{LiV}_{3} \mathrm{O}_{8}$ and $\mathrm{Li}_{3} \mathrm{~V}_{2}\left(\mathrm{PO}_{4}\right)_{3}$, have been studied as cathode materials in secondary batteries, including Li- [12-15], Na- [16-18] and Mg-ion [19-21] batteries due to their stable crystal structures, high theoretical capacities and excellent cycling stabilities. 
Figure 3 compares the crystal structures and discharge curves in three vanadium compounds: $\mathrm{V}_{2} \mathrm{O}_{5}, \mathrm{LiV}_{3} \mathrm{O}_{8}$ and $\mathrm{Li}_{3} \mathrm{~V}_{2}\left(\mathrm{PO}_{4}\right)_{3} . \mathrm{V}_{2} \mathrm{O}_{5}$ has a layered structure and each vanadium atom is encompassed by five coordinative oxygens to build a square pyramid. All square pyramids share edges to construct two dimensional layers and the spaces between layers provide active sites for storing $\mathrm{Li}$ ions. These active sites have different sites energies which result in the sloping potential curves [5]. Although a high theoretical specific capacity of $441 \mathrm{mAh} / \mathrm{g}$ was calculated for the reversible insertion of three $\mathrm{Li}$ ions in $\mathrm{V}_{2} \mathrm{O}_{5}$, this capacity is difficult to achieve in practice because the structural stability of $\mathrm{V}_{2} \mathrm{O}_{5}$ can be destroyed when intercalation occurred with three $\mathrm{Li}$ ions [22]. While $\mathrm{LiV}_{3} \mathrm{O}_{8}$ consists of $\mathrm{VO}_{6}$ octahedrons and $\mathrm{VO}_{5}$ trigonal bipyramids, these polyhedrons connect each other through corner-sharing oxygens to form the $\left(\mathrm{V}_{3} \mathrm{O}_{8}\right)^{-}$layers oriented along an axis. Lithium ions reside in the interlayer octahedral sites as a chain to connect the layers [12]. Three Li ions can be inserted in the matrix lattice with a high specific capacity of $279 \mathrm{mAh} / \mathrm{g}$ delivered, but the structural $\mathrm{Li}$ ion in $\mathrm{LiV}_{3} \mathrm{O}_{8}$ cannot be removed, implying that $\mathrm{LiV}_{3} \mathrm{O}_{8}$ is akin to $\mathrm{V}_{2} \mathrm{O}_{5}$ as a cathode without removable $\mathrm{Li}$ ions in the matrix. $\mathrm{Li}_{3} \mathrm{~V}_{2}\left(\mathrm{PO}_{4}\right)_{3}$ exhibits distinct advantages compared with $\mathrm{LiV}_{3} \mathrm{O}_{8}$ and $\mathrm{V}_{2} \mathrm{O}_{5}$, such as three removable $\mathrm{Li}$ ions in the lattice, a higher discharge potential of $4.0 \mathrm{~V}$ and a robust crystal structure for reversibly inserting $\mathrm{Li}$ ions without destroying the lattice. These merits in $\mathrm{Li}_{3} \mathrm{~V}_{2}\left(\mathrm{PO}_{4}\right)_{3}$ derive from the unique crystal structure in which $\mathrm{PO}_{4}$ tetrahedrons and $\mathrm{VO}_{6}$ octahedrons construct the rigid framework, which experiences no appreciable volume change during ion insertion or extraction. Table 1 compares several key parameters on 
these vanadium compounds as cathodes in $\mathrm{Li}$ ion batteries. $\mathrm{Li}_{3} \mathrm{~V}_{2}\left(\mathrm{PO}_{4}\right)_{3}$ has a very high number of removable $\mathrm{Li}$ ions, average potential, energy density and Li ion diffusion coefficient. Although the theoretical capacity in $\mathrm{Li}_{3} \mathrm{~V}_{2}\left(\mathrm{PO}_{4}\right)_{3}$ is lower than $\mathrm{V}_{2} \mathrm{O}_{5}$ and $\mathrm{LiV}_{3} \mathrm{O}_{8}$, it is also higher than commercial cathodes, such as $\mathrm{LiCoO}_{2}(137$ mAh/g from 0.5 Li) [8], $\mathrm{LiMn}_{2} \mathrm{O}_{4}(148 \mathrm{mAh} / \mathrm{g})$ [9] and $\mathrm{LiFePO}_{4}(170 \mathrm{mAh} / \mathrm{g})$ [23]. The greatest advantages for $\mathrm{Li}_{3} \mathrm{~V}_{2}\left(\mathrm{PO}_{4}\right)_{3}$ are the high average potential and $\mathrm{Li}$ ion diffusion coefficient, the former in part determines the energy density (which is the product of average potential and specific capacity), and the latter affects the rate capability of materials since the diffusion rate of $\mathrm{Li}$ ions corresponds to the speed at which energy is stored or released. Therefore, $\mathrm{Li}_{3} \mathrm{~V}_{2}\left(\mathrm{PO}_{4}\right)_{3}$ can deliver a high energy density of $\sim 800 \mathrm{Wh} / \mathrm{kg}$ in practice that is superior to $\mathrm{LiV}_{3} \mathrm{O}_{8}(740 \mathrm{Wh} / \mathrm{kg})$ [24]. The calculated theoretical energy density of $\mathrm{V}_{2} \mathrm{O}_{5}$ is as high as $\sim 1100 \mathrm{Wh} / \mathrm{kg}$ [25], however, the specific capacity can only display half of the theoretical value in practice, so the energy density cannot currently exceed $600 \mathrm{Wh} / \mathrm{kg}$ in $\mathrm{V}_{2} \mathrm{O}_{5}$ cathode materials.

Apart from three vanadium compounds mentioned above, several other vanadium compounds were also studied as cathodes for Li-ion batteries, such as $\mathrm{V}_{6} \mathrm{O}_{13}, \mathrm{VO}_{2}$ and $\mathrm{H}_{2} \mathrm{~V}_{3} \mathrm{O}_{8}$, but less competitive when compared with the three compounds described in the last paragraph. For example, $\mathrm{V}_{6} \mathrm{O}_{13}$ belongs to the layered compounds and can deliver a high initial specific capacity of $400 \mathrm{mAh} / \mathrm{g}$ at the initial with the potential window of 1.5-4.0 V, however, the inferior cycling stability limits the applications [26]. Nanostructured $\mathrm{V}_{6} \mathrm{O}_{13}$ can enhance the cycling stability, but the specific capacity 
decreases to $100 \mathrm{mAh} / \mathrm{g}$ at $500 \mathrm{~mA} / \mathrm{g}$ in the potential window of $1.0-4.0 \mathrm{~V}$, leading to the losing competitiveness [27]. $\mathrm{VO}_{2}(\mathrm{~B})$, a metastable crystal, can only be produced by the transformation of closely related materials at low temperature. Although designing the microstructure can enhance the reactive kinetics, the low average potential $\left(\sim 2.5 \mathrm{~V}\right.$ vs $\left.\mathrm{Li} / \mathrm{Li}^{+}\right)$counteracts the strength from the specific capacity $[28,29]$. $\mathrm{H}_{2} \mathrm{~V}_{3} \mathrm{O}_{8}$ consists of $\mathrm{V}_{3} \mathrm{O}_{8}$ layers held together by hydrogen bonds, and can display a specific capacity exceeding $200 \mathrm{mAh} / \mathrm{g}$. However, the low average potential ( 2.6 V vs $\mathrm{Li} / \mathrm{Li}^{+}$) limits the energy density [30,31]. More importantly, the low average potentials of these compounds imply the limitation in practical batteries because the working voltage window will narrow down when commercial anodes, such as carbon or silicon, are used. Besides, and no removable Li-ion in these vanadium compounds also limits their practical applications, some attempts have been carried out to overcome this barriers, though [32,33]. In view of the facts above, $\mathrm{Li}_{3} \mathrm{~V}_{2}\left(\mathrm{PO}_{4}\right)_{3}$ has the possibility to utilize in full batteries as the cathode in practical applications.

The drawbacks in $\mathrm{Li}_{3} \mathrm{~V}_{2}\left(\mathrm{PO}_{4}\right)_{3}$ should be addressed and some effective approaches are needed to overcome these barriers. The most important issue is that $\mathrm{Li}_{3} \mathrm{~V}_{2}\left(\mathrm{PO}_{4}\right)_{3}$ has an inferior electrical conductivity of $2.4 \times 10^{-7} \mathrm{~S} / \mathrm{cm}$ because the transition metal ions are separated by the phosphate groups [34]. Thus, improving the electrical conductivity has become an essential research topic and some great efforts were devoted to it. In addition, enhancing the practical capacity and rate capability are also pivotal issues for expanding the applications in various surroundings conditions, thus 
the effects from foreign atoms, composites, surface modifications and microstructure design have been investigating extensively. More details related to the characteristics of $\mathrm{Li}_{3} \mathrm{~V}_{2}\left(\mathrm{PO}_{4}\right)_{3}$ and the effects of materials design strategies mentioned above will be reviewed carefully in the following sections.

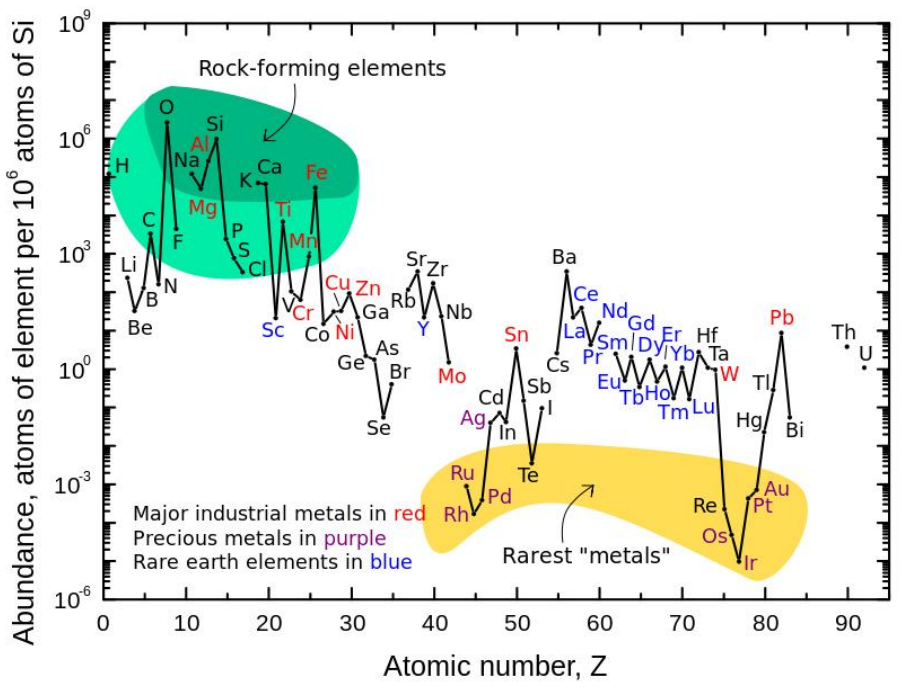

Figure 2. Abundance (atom fraction) of the chemical elements in Earth's upper continental crust as a function of atomic number [11]. The element vanadium has a considerable abundance of 190 ppm in continental crust and the abundance rank is $20^{\text {th }}$ in all known elements.

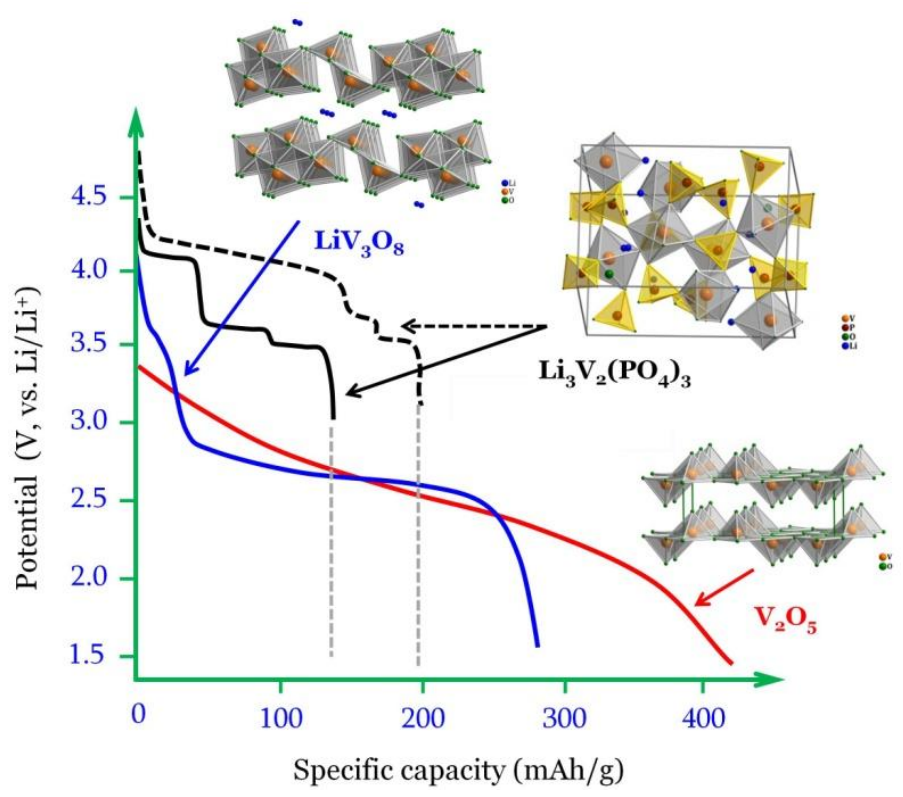


Figure 3. The profiles of potential curves and crystal structures of vanadium compounds. $\mathrm{V}_{2} \mathrm{O}_{5}$ and $\mathrm{LiV}_{3} \mathrm{O}_{8}$ have similar potential profiles and approximate average potentials, but $\mathrm{Li}_{3} \mathrm{~V}_{2}\left(\mathrm{PO}_{4}\right)_{3}$ displays a higher average potential of $4.0 \mathrm{~V}$ in the electrochemical range of 3.0-4.8 $\mathrm{V}$. The difference in potential profiles stems from the difference in site energies; the occupation of Li ions at different crystallographic sites correspond to the various voltage plateaus [35]. The blue, red and black lines correspond to the potential profiles of $\mathrm{LiV}_{3} \mathrm{O}_{8}, \mathrm{~V}_{2} \mathrm{O}_{5}$ and $\mathrm{Li}_{3} \mathrm{~V}_{2}\left(\mathrm{PO}_{4}\right)_{3}$, respectively, and the relating crystal structures are pointed out with the same color arrows. The solid and dashed curves of potential profiles for $\mathrm{Li}_{3} \mathrm{~V}_{2}\left(\mathrm{PO}_{4}\right)_{3}$ stand for the working potential windows of 3.0-4.3 and 3.0-4.8 V, respectively.

Table 1. Performances comparison of some common vanadium compounds

\begin{tabular}{cccc}
\hline Materials & $\mathrm{V}_{2} \mathrm{O}_{5}$ & $\mathrm{LiV}_{3} \mathrm{O}_{8}$ & $\mathrm{Li}_{3} \mathrm{~V}_{2}\left(\mathrm{PO}_{4}\right)_{3}$ \\
\hline $\begin{array}{c}\text { Average potential } \\
\left(\mathrm{V} . \text { v } s \mathrm{Li} / \mathrm{Li}^{+}\right)\end{array}$ & $\sim 2.5$ & $\sim 2.8$ & $\sim 4.0$ \\
Theoretical specific capacity & $147(1 \mathrm{Li})$ & & $133(2 \mathrm{Li})$ \\
$(\mathrm{mAh} / \mathrm{g})$ & $294(2 \mathrm{Li})$ & $279(3 \mathrm{Li})$ & $197(3 \mathrm{Li})$ \\
Theoretical energy density & $441(3 \mathrm{Li})$ & & $\sim 800$ \\
$(\mathrm{Wh} / \mathrm{Kg})$ & $\sim 1100$ & $\sim 740$ & $10^{-9}-10^{-10}$ \\
Li ion diffusion coefficient & $10^{-12}-10^{-13}$ & $2-8 \times 10^{-10}$ & \\
$(\mathrm{~cm} / \mathrm{s})$ & & & $2.4 \times 10^{-7}$ \\
Electrical conductivity & $10^{-2}-10^{-3}$ & $3.52 \times 10^{-6}$ & {$[39,40]$} \\
References & {$[25,36]$} & {$[37,38]$} & \\
\hline
\end{tabular}

Note: The theoretical specific capacities correspond to the number of Li ions inserted as shown in the following brackets.

\subsection{Comparison in Phosphates Electrode Materials}

Beyond the advantages of vanadium compounds, $\mathrm{Li}_{3} \mathrm{~V}_{2}\left(\mathrm{PO}_{4}\right)_{3}$ also has competitive strengths associated with phosphate electrode materials. Phosphate materials consist of $\mathrm{PO}_{4}{ }^{3-}$ groups and $\mathrm{MO}_{6}(\mathrm{M}=$ transition metal ions $)$ octahedrons to build robust crystal structures that can bear and buffer the volume change during the process of Li-ion insertion or extraction. Besides, the excellent chemical stability of $\mathrm{PO}_{4}{ }^{3-}$ groups endows the electrode materials with the best thermal safety out of lithium transition 
metal oxides category [41]. Figure 4 shows the discharge curves in the phosphate family, and divided into two categories, olivine and monoclinic, based on crystal structure. The structure difference leads to the distinct difference in discharge curves. For example, olivine materials, such as $\mathrm{LiMnPO}_{4}$ and $\mathrm{LiFePO}_{4}$, exhibit a single continuous discharge plateau because the removable $\mathrm{Li}$ ions have the equivalent sites that imply the same site energy. Whereas, monoclinic materials have at least two removable Li ions that occupy different sites, leading to the nonequivalent site energy and step-type discharge plateaus. Specific capacity and average potential are two essential factors to evaluate suitability for practical applications. Table 2 compares some key parameters in phosphate materials. $\mathrm{LiFePO}_{4}$ cathodes are used in commercial secondary batteries due to the superior chemical and thermal stability, but the relatively low electrochemical potential of $3.45 \mathrm{~V}$ limits the energy density compared to commercial $\mathrm{LiCoO}_{2}$ cathode in full batteries [23]. $\mathrm{LiMnPO}_{4}$ displays the highest average potential $(4.10 \mathrm{~V})$, but Jahn-Teller deformation of $\mathrm{Mn}^{3+}$ induces huge polarization during the electrochemical reaction and causes a dramatic degradation of electrochemical performance [42]. At the same time $\mathrm{LiNiPO}_{4}$ and $\mathrm{LiCoPO}_{4}$ present higher charge potentials of 4.8 and $5.1 \mathrm{~V}$ in Li-ion half cells, respectively. While this would provide a very high energy density in theory, this voltage is so high that in practice no suitable electrolyte currently exists that withstand this powerfully oxidizing environment. Besides, the cycling stability is also an essential issue to overcome [43]. $\mathrm{Li}_{3} \mathrm{Fe}_{2}\left(\mathrm{PO}_{4}\right)_{3}$ and $\mathrm{LiTi}_{2}\left(\mathrm{PO}_{4}\right)_{3}$ possess monoclinic structures like $\mathrm{Li}_{3} \mathrm{~V}_{2}\left(\mathrm{PO}_{4}\right)_{3}$ but exhibit lower discharge plateaus and specific capacities. Much worse, 
the $\mathrm{Li}$ ions in these crystal lattices cannot participate in the electrochemical reactions during the energy storage $[44,45]$. Additionally, the electrical conductivities $\left(<10^{-8}\right.$ S/cm) and ionic diffusion coefficients $\left(<10^{-14} \mathrm{~cm}^{2} / \mathrm{s}\right)$ in $\mathrm{Li}_{3} \mathrm{Fe}_{2}\left(\mathrm{PO}_{4}\right)_{3}$ and $\mathrm{LiTi}_{2}\left(\mathrm{PO}_{4}\right)_{3}$ are also lower than the values in $\mathrm{Li}_{3} \mathrm{~V}_{2}\left(\mathrm{PO}_{4}\right)_{3}$. In addition, the $\mathrm{Li}$ ion diffusion coefficient in $\mathrm{Li}_{3} \mathrm{~V}_{2}\left(\mathrm{PO}_{4}\right)_{3}$ ranges from $10^{-9}$ to $10^{-10} \mathrm{~cm}^{2} / \mathrm{s}$, which is five orders of magnitude higher than for the commercial polyanionic cathode $\mathrm{LiFePO}_{4}$ (i.e., $10^{-14}$ to $10^{-16} \mathrm{~cm}^{2} / \mathrm{s}$ ) [39]. By contrast, $\mathrm{Li}_{3} \mathrm{~V}_{2}\left(\mathrm{PO}_{4}\right)_{3}$ displays competitive values in all electrochemical parameters among the phosphate materials.

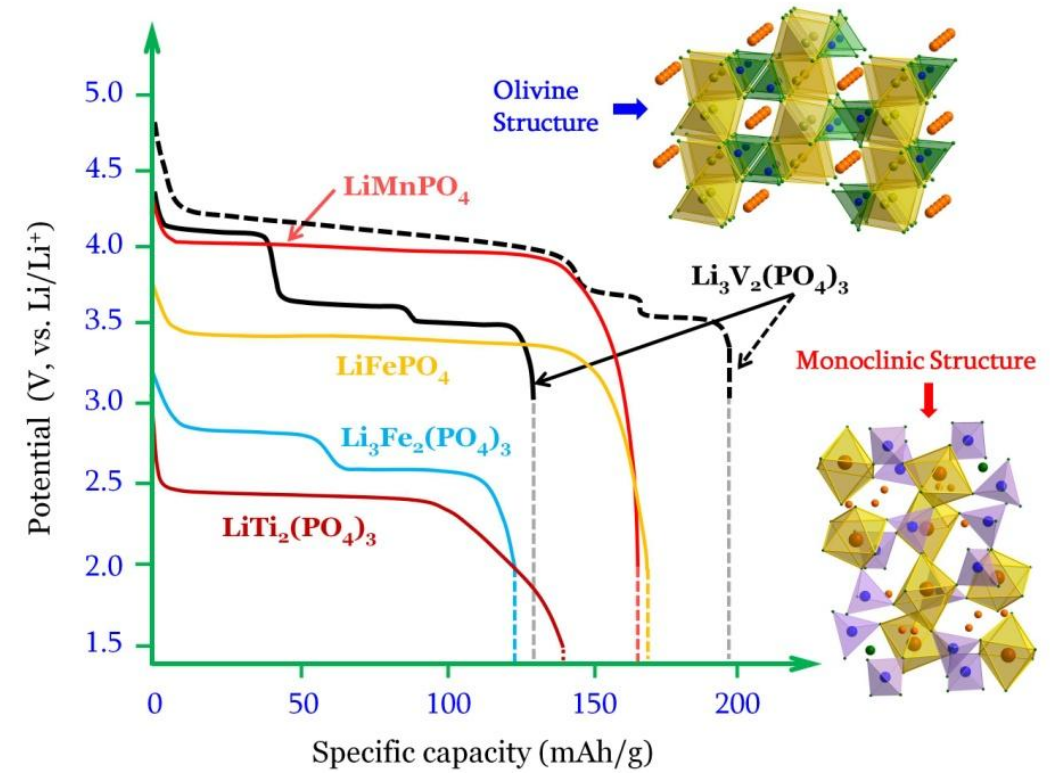

Figure 4. Comparisons of normal discharge curves in several phosphate materials. The phosphate materials can be divided into two categories based on crystal structure: olivine $\left(\mathrm{LiMPO}_{4}\right)$ and monoclinic $\left(\mathrm{Li}_{3} \mathrm{M}_{2}\left(\mathrm{PO}_{4}\right)_{3}\right)$. Olivine materials contain one removable $\mathrm{Li}$ ion, but the monoclinic electrodes have at least two removable $\mathrm{Li}$ ions. The inserted $\mathrm{Li}$ ion number determines the specific capacity of materials, and the occupation sites of $\mathrm{Li}$ ions control the electrochemical potentials. For example, olivine materials have one equivalent site that suggests the same site energy for $\mathrm{Li}$ ion, resulting that a single continuous discharge plateau. However, monoclinic structures possess more removable ions and these ions have different site energy so that the discharge plateaus have several steps. 
Table 2. Comparisons in Phosphate Materials

\begin{tabular}{|c|c|c|c|c|c|}
\hline Materials & $\mathrm{LiFePO}_{4}$ & $\mathrm{LiMnPO}_{4}$ & $\mathrm{LiTi}_{2}\left(\mathrm{PO}_{4}\right)_{3}$ & $\mathrm{Li}_{3} \mathrm{Fe}_{2}\left(\mathrm{PO}_{4}\right)_{3}$ & $\mathrm{Li}_{3} \mathrm{~V}_{2}\left(\mathrm{PO}_{4}\right)_{3}$ \\
\hline $\begin{array}{l}\text { Number of removable } \\
\text { Li ions in matrix lattices }\end{array}$ & 1 & 1 & 0 & 0 & 3 \\
\hline $\begin{array}{l}\text { Average potential } \\
\left.\text { (V. vs } \mathrm{Li} / \mathrm{Li}^{+}\right)\end{array}$ & 3.45 & 4.10 & 2.50 & 2.80 & 4.00 \\
\hline $\begin{array}{l}\text { Theoretical specific } \\
\text { capacity }(\mathrm{mAh} / \mathrm{g})\end{array}$ & $170(1 \mathrm{Li})$ & $171(1 \mathrm{Li})$ & $138(2 \mathrm{Li})$ & $128(2 \mathrm{Li})$ & $\begin{array}{l}133(2 \mathrm{Li}) \\
197(3 \mathrm{Li})\end{array}$ \\
\hline $\begin{array}{l}\text { Theoretical energy } \\
\text { density }(\mathrm{Wh} / \mathrm{Kg})\end{array}$ & 585 & 700 & 345 & 360 & 800 \\
\hline $\begin{array}{c}\text { Li ion diffusion } \\
\text { coefficient }\left(\mathrm{cm}^{2} / \mathrm{s}\right)\end{array}$ & $10^{-14}-10^{-16}$ & $10^{-13}-10^{-17}$ & $\sim 10^{-14}$ & - & $10^{-9}-10^{-10}$ \\
\hline $\begin{array}{l}\text { Electrical conductivity } \\
\qquad(\mathrm{S} / \mathrm{cm})\end{array}$ & $10^{-9}-10^{-10}$ & $10^{-10}-10^{-11}$ & $\sim 10^{-8}$ & $<10^{-8}$ & $2.4 \times 10^{-7}$ \\
\hline References & {$[7,23]$} & [46-48] & {$[49,50]$} & {$[44,51]$} & {$[39,40]$} \\
\hline
\end{tabular}

Note: All the data in $\mathrm{Li}$ ion diffusion for these materials are collected from the reported results and the size effect is not considered. However, The $\mathrm{Li}$ ion diffusion coefficient in $\mathrm{LiFePO}_{4}$ was believed to be as high as $\sim 10^{-8} \mathrm{~cm}^{2} / \mathrm{s}$ along [010] in nanosized particles through calculations [52].

\subsection{Characteristics and Challenges in $\mathrm{Li}_{3} \mathrm{~V}_{2}\left(\mathrm{PO}_{4}\right)_{3}$}

Lithium vanadium phosphate $\left(\mathrm{Li}_{3} \mathrm{~V}_{2}\left(\mathrm{PO}_{4}\right)_{3}, \mathrm{LVP}\right)$, a promising cathode candidate and a hot research topic in the field of Li-ion batteries, comprises both mobile lithium ions and redox-active transition metal ions within a rigid phosphate framework. It exhibits outstanding electrochemical and thermal stability as well as a high operating potential and reliable safety, all of which are required to satisfy the requirements of practical commercial applications. LVP has two crystal structures, rhombohedral and monoclinic, that consist of $\mathrm{PO}_{4}$ tetrahedra and $\mathrm{VO}_{6}$ octahedra connected in different ways. The rhombohedral structure is also known as NASICON-type LVP (space group $\mathrm{R} \overline{3}, \mathrm{a}=8.316 \AA$ and $\mathrm{c}=22.484 \AA$ ) in which $\mathrm{PO}_{4}$ tetrahedra and $\mathrm{VO}_{6}$ octahedra are interconnected through their vertices to form a "lantern" unit framework [53]. While the monoclinic LVP (space group P2 $1 / n, a=8.605 \AA, b=8.591 \AA$, c $=12.038$ 
$\AA$ and $\beta=90.6^{\circ}$ ) has a more dense stacked structure than NASICON-type LVP $[15,54]$. The three dimensional network of monoclinic LVP is linked by slightly distorted $\mathrm{VO}_{6}$ octahedra and $\mathrm{PO}_{4}$ tetrahedra through sharing of the apical oxygens to form a $(\mathrm{V}-\mathrm{O}-\mathrm{P}-\mathrm{O})_{\mathrm{n}}$ bonding arrangement [15] where each $\mathrm{VO}_{6}$ octahedron is surrounded with six $\mathrm{PO}_{4}$ tetrahedra, whereas each $\mathrm{PO}_{4}$ tetrahedron is surrounded by four $\mathrm{VO}_{6}$ octrahedra (Figure 5a). Table 2 lists the crystallographic atomic positions consistent with the crystal structure shown in Figure 5a. The structural difference between rhombohedral and monoclinic LVP determines their different electrochemical properties. Rhombohedra LVP, however, exhibits one voltage plateau around $3.7 \mathrm{~V}$ vs. $\mathrm{Li} / \mathrm{Li}^{+}$relating to a two-phase transition between $\mathrm{Li}_{3} \mathrm{~V}_{2}\left(\mathrm{PO}_{4}\right)_{3}$ and $\mathrm{LiV}_{2}\left(\mathrm{PO}_{4}\right)_{3}$. Regrettably, rhombohedra LVP must be synthesized by ion exchange from the corresponding sodium analog, $\mathrm{Na}_{3} \mathrm{~V}_{2}\left(\mathrm{PO}_{4}\right)_{3}$, and thus limited work have been done on this structure $[53,55,56]$. Thus, this review focuses on the advancement of monoclinic LVP. In monoclinic LVP, there are three different Li sites, denoted Li(1), $\operatorname{Li}(2)$ and $\mathrm{Li}(3)$. Each site has a different coordination environment: $\operatorname{Li}(1)$ is coordinated by four oxygens, whereas $\operatorname{Li}(2)$ and $\operatorname{Li}(3)$ are coordinated by five (Figure 5b) $[57,58]$. These Li ions also have different ionic mobility, leading to several phase transitions as the material is electrochemically cycled between 3.0 and $4.8 \mathrm{~V}$ versus $\mathrm{Li} / \mathrm{Li}^{+}$. The theoretical capacity in this potential range based on three $\mathrm{Li}$ ions extracted is $197 \mathrm{mAh} / \mathrm{g}$, which is the highest of all phosphate cathode materials [41]. In the potential range between 3.0 and $4.3 \mathrm{~V}$ vs. $\mathrm{Li} / \mathrm{Li}^{+}$, based on the $\mathrm{V}^{3+} / \mathrm{V}^{4+}$ redox couple, a reversible capacity of $133 \mathrm{mAh} / \mathrm{g}$ can still be obtained [15]. The phase transitions 
during the process of insertion and removal of Li ions in LVP has been studied systematically and described by Morcrette and coworkers [55]. However, it is important that the potential curves agree with Li ions occupations in the LVP structure. $\mathrm{Li}(1)$ resides in a stronger confined field or surroundings due to only four coordinated oxygens to form a tetrahedron, whereas $\operatorname{Li}(2)$ and $\operatorname{Li}(3)$ are located at pseudotetrahedral sites that are comprised of five oxygens to build the highly distorted tetrahedral environments [34]. Thus, high-energy $\operatorname{Li}(3)$ (Figure 5b) is extracted preferentially, while $\operatorname{Li}(2)$ shifts to a tetrahedral site that is similar to the $\operatorname{Li}(1)$ site. The ordering in $\mathrm{V}^{3+} / \mathrm{V}^{4+}$ induces $\mathrm{Li}(3)$ extraction with two steps [59], occurring at 3.6 and $3.7 \mathrm{~V}$. The subsequent extraction of $\operatorname{Li}(1)$ occurs at $4.1 \mathrm{~V}$, and involves a phase transition from $\mathrm{Li}_{2} \mathrm{~V}_{2}\left(\mathrm{PO}_{4}\right)_{3}$ to $\mathrm{LiV}_{2}\left(\mathrm{PO}_{4}\right)_{3}$ and full oxidation of $\mathrm{V}^{3+}$ to $\mathrm{V}^{4+}$. The potential for this process is higher because the repulsion energy between $\operatorname{Li}(1)$ and $\mathrm{V}(1)$ endows $\mathrm{Li}(1)$ a higher energy compared to that of $\mathrm{Li}(2)$ [60]. The last lithium, $\mathrm{Li}(2)$, is the most stable and therefore is extracted at higher voltage $4.6 \mathrm{~V}$, accompanied by a phase transformation between $\mathrm{LiV}_{2}\left(\mathrm{PO}_{4}\right)_{3}$ and $\mathrm{V}_{2}\left(\mathrm{PO}_{4}\right)_{3}$. The whole process obeys the energy rules that the removable Li ion with highest site energy is extracted preferentially. Moreover, this process occurs at the lowest electrochemical potential because the least energy is consumed in the extraction. In contrast, when Li ion is located at the lowest energy sites, more energy is exhausted when it is dragged out, which corresponds to a higher electrochemical potential plateau. These energy rules are consistent with the change in Gibbs energy in the phase transformation [61]. In practice, the charging potential stages are instinct, but 
the discharging potential profile exhibits a sloping curve in the window of 3.0-4.8 V.

The reason is that the valence ordering disappears when the $\mathrm{V}_{2}\left(\mathrm{PO}_{4}\right)_{3}$ framework is completely delithiated, and the solid solution behavior occurs in the process of Li-ions insertion. Once the valence ordering is restored, the charging potential stages appear again due to the phase transitions $[60,62]$.

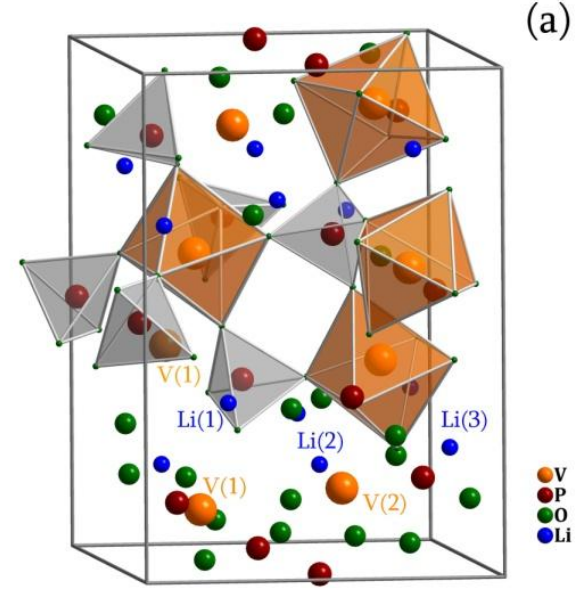

Figure 5. (a) Lattice structure and (b) $\mathrm{Li}$ atomic coordination environments of $\mathrm{Li}_{3} \mathrm{~V}_{2}\left(\mathrm{PO}_{4}\right)_{3}$ [58]. $\operatorname{Li}(1)$ is surrounded by four oxygen atoms to form a tetrahedron, and $\operatorname{Li}(2)$ and $\operatorname{Li}(3)$ occupy highly distorted tetrahedral environments with different Li-O bond lengths. $\mathrm{Li}(3)$ with the highest site energy can be extracted easily at the lowest electrochemical potential of $3.6 \mathrm{~V}$, and $\operatorname{Li}(2)$ resides in the lowest energy site, causing the corresponding potential is the highest at $4.6 \mathrm{~V}$. Energy rules dominate the order of ions extraction, lower site energy, higher electrochemical potential displayed [35].

Table 2. Atomic coordinates and isotropic displacement factors obtained by Rietveld refinements of neutron diffraction data for LVP [54].

\begin{tabular}{|c|c|c|c|c|c|c|}
\hline \multirow{2}{*}{ Atoms } & \multirow{2}{*}{ Sites } & \multicolumn{3}{|c|}{ Wyckoff positions } & \multirow{2}{*}{$\mathrm{B}_{\text {iso }}\left(\AA^{2}\right)$} & \multirow{2}{*}{ Occupancy } \\
\hline & & $x$ & $y$ & $z$ & & \\
\hline V1 & $4 \mathrm{e}$ & 0.2461 & 0.1072 & 0.4606 & 0.61 & 1 \\
\hline $\mathrm{V} 2$ & $4 \mathrm{e}$ & 0.7534 & 0.3943 & 0.4703 & 0.59 & 1 \\
\hline $\mathrm{P} 1$ & $4 \mathrm{e}$ & $0.1068(9)$ & $0.1489(8)$ & $0.1014(11)$ & $1.4(2)$ & 1 \\
\hline P2 & $4 \mathrm{e}$ & $0.6004(9)$ & $0.3493(7)$ & $0.1164(11)$ & $1.5(2)$ & 1 \\
\hline P3 & $4 \mathrm{e}$ & $0.0349(9)$ & $0.4924(7)$ & $0.2474(12)$ & $1.1(2)$ & 1 \\
\hline $\mathrm{O} 1$ & $4 \mathrm{e}$ & $0.4257(9)$ & $0.3305(6)$ & $0.0915(9)$ & $1.5(2)$ & 1 \\
\hline $\mathrm{O} 2$ & $4 \mathrm{e}$ & $0.9262(9)$ & $0.1471(6)$ & $0.1108(10)$ & $1.3(2)$ & 1 \\
\hline
\end{tabular}




\begin{tabular}{lllllll}
\hline O3 & $4 \mathrm{e}$ & $0.3547(8)$ & $0.2607(6)$ & $0.4799(8)$ & $1.2(2)$ & 1 \\
$\mathrm{O} 4$ & $4 \mathrm{e}$ & $0.8041(9)$ & $0.2185(7)$ & $0.4952(9)$ & $1.5(2)$ & 1 \\
$\mathrm{O} 5$ & $4 \mathrm{e}$ & $0.1727(10)$ & $0.0394(7)$ & $0.0518(8)$ & $1.6(2)$ & 1 \\
$\mathrm{O} 6$ & $4 \mathrm{e}$ & $0.6435(9)$ & $0.4747(6)$ & $0.0883(9)$ & $1.2(2)$ & 1 \\
$\mathrm{O} 7$ & $4 \mathrm{e}$ & $0.4500(8)$ & $0.0667(5)$ & $0.3688(9)$ & $0.9(2)$ & 1 \\
$\mathrm{O} 8$ & $4 \mathrm{e}$ & $0.9277(9)$ & $0.4033(6)$ & $0.3196(9)$ & $1.0(2)$ & 1 \\
$\mathrm{O} 9$ & $4 \mathrm{e}$ & $0.1697(9)$ & $0.4291(6)$ & $0.1697(9)$ & $1.4(2)$ & 1 \\
$\mathrm{O} 10$ & $4 \mathrm{e}$ & $0.6098(9)$ & $0.0750(6)$ & $0.1346(10)$ & $1.6(2)$ & 1 \\
$\mathrm{O} 11$ & $4 \mathrm{e}$ & $0.1660(9)$ & $0.1862(7)$ & $0.2670(9)$ & $1.5(2)$ & 1 \\
$\mathrm{O} 12$ & $4 \mathrm{e}$ & $0.6399(9)$ & $0.3176(6)$ & $0.2868(9)$ & $1.1(2)$ & 1 \\
$\mathrm{Li} 1$ & $4 \mathrm{e}$ & $0.292(3)$ & $0.328(2)$ & $0.298(2)$ & $0.5(4)$ & 1 \\
$\mathrm{Li} 2$ & $4 \mathrm{e}$ & $0.571(3)$ & $0.195(2)$ & $0.421(3)$ & $2.9(6)$ & 1 \\
$\mathrm{Li} 3$ & $4 \mathrm{e}$ & $0.911(4)$ & $0.233(3)$ & $0.305(4)$ & $4.7(8)$ & 1 \\
\hline
\end{tabular}

As mentioned in the section above, polyanionic materials like LVP suffer from inferior electronic conductivity $\left(2.4 \times 10^{-7} \mathrm{~S} / \mathrm{cm}\right)$ [34] and lower specific capacity compared with those in $\mathrm{V}_{2} \mathrm{O}_{5}$ and $\mathrm{LiV}_{3} \mathrm{O}_{8}$ shown in Table 1. Thus, improving the electronic conductivity, as well as specific capacity and cycling stability are the hottest topics in this research field. In the past years, more than 500 research papers related to LVP have been published. A column chart is exhibited in Figure 6a, where the data for 2015 runs through December. With respect to the family of phosphates, the studies focus on $\mathrm{LiFePO}_{4}$, and much less effort has been devoted to other phosphates materials (Figure 6b). However, as seen from Figure 6a, the number of studies on LVP is rapidly rising, implying that research enthusiasm on LVP was evoked in recent years, perhaps because of the excellent structural stability, high electrochemical potential and superior rate capability. Based on different targets, researchers put emphasis on various aspects, such as pure phases, doping, composites and designed nanostructures (inset of Figure 6a). The research on pure phases focuses on the crystal structure, ion diffusion, electrical conductivity, intercalation mechanism 
and synthesis methods. Introduction of foreign atoms is also an effective approach to optimize the electrochemical performance because the modulated lattice parameters and energy levels determine the ion diffusion and operating potential of electrode materials. Composites combine the strengths of the component materials to maximize their favorable factors, and LVP is no exception. For example, great efforts concentrate on carbon and LVP composites because the excellent intrinsic conductivity in carbon enhances the electrical conductivity in the whole system, which improves the rate capability of the LVP host. In addition, composites comprised of LVP and other electrode materials, such as $\mathrm{LiFePO}_{4}$ and $\mathrm{LiCoO}_{2}$, are also promising research directions that focus on how to improve the comprehensive performance of LVP in extreme operating environments. Besides, designing nanostructures are always the hot topic in the field of functional materials; tailoring nanostructures on LVP shortens or improves the ionic and electronic transport pathways, which helps achieve some of the expected performance targets. The following review carefully concentrates on these aspects. 
(a)

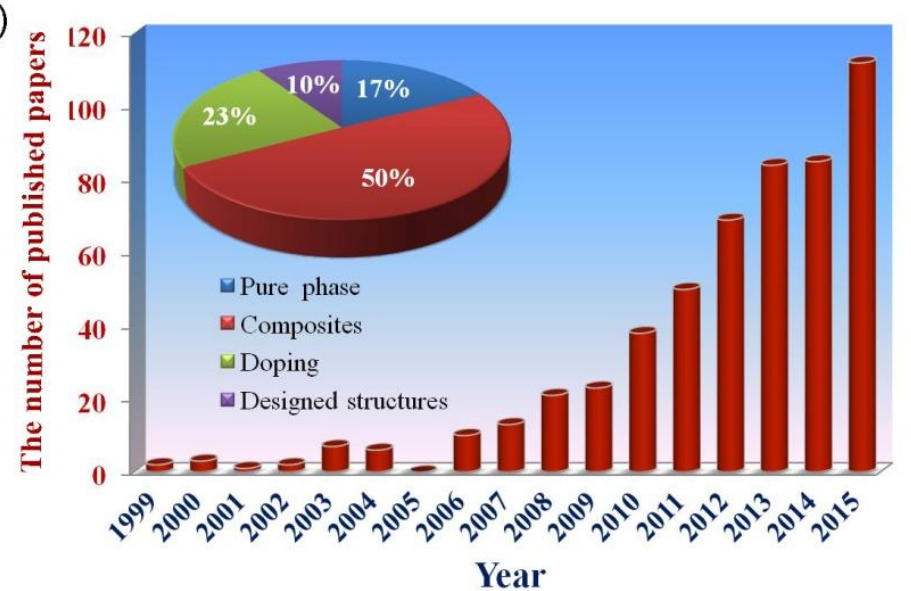

(b)

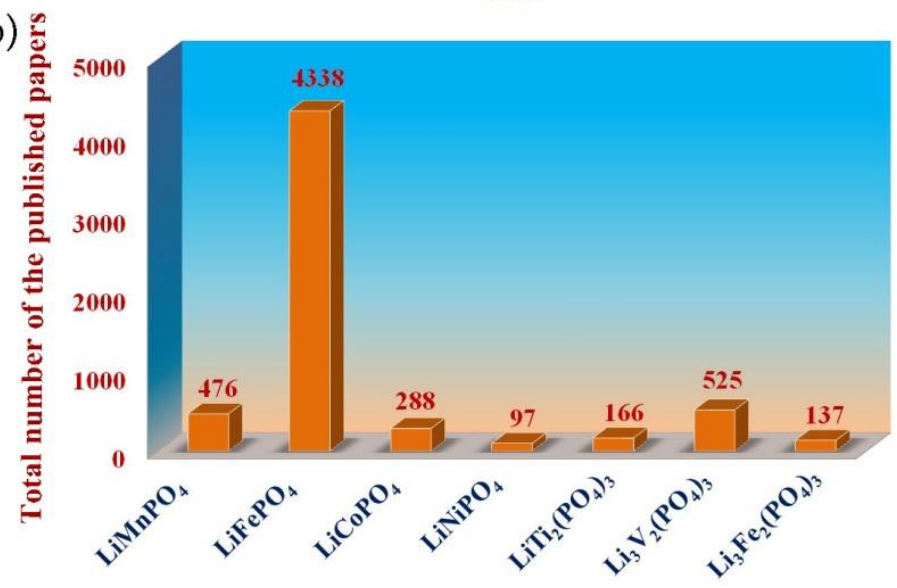

Figure 6. (a) A statistical breakdown of published papers in the past years plus the percentage of research emphasis on four different aspects in LVP. On the pie chart, composites have the highest proportion; in particular, many papers involve composites with carbon and only a small fraction deals with the fundamental understanding and solving practical challenges. Doping can tune the energetics of the host atoms and serves to improve the electrochemical performance of LVP. Although investigations on pure phases have been reported in the same proportion as doping, some studies on pure phases can be divided into carbon composites because some raw materials provide carbon sources to LVP matrix, such as oxalic acid [39]. (b) The total number of published papers in phosphate electrode materials in the past. $\mathrm{LiFePO}_{4}$ has been studied most extensively, but other phosphates have become rising hot topics recently. Although the number of reported LVP studies is quickly rising, the total number is lower compared to $\mathrm{LiFePO}_{4}$. The source papers were collected from Thomson Reuters and the keywords were the chemical formulas of the electrode materials. The data was collected on January 5. 2016.

\section{Investigating Pure Phase $\mathrm{Li}_{3} \mathrm{~V}_{2}\left(\mathrm{PO}_{4}\right)_{3}$}

The studies on pure-phase LVP focus on the crystal structure determination, 
transferring path of ions, chemical diffusion coefficient, synthesis methods, and the operating potential range. As described above, the details about the crystal structure, atom occupancy, and the order of ion extraction from LVP were acquired from Rietveld refinement of neutron diffraction data [54]. The order of ion extraction during the electrochemical reaction was further supported using energetic calculations and classical molecular dynamics simulations [63] and was verified through nuclear magnetic resonance (NMR) studies [34]. In addition, infrared spectra were recorded at different states of charge. This information reflects stretching and bending of bonds in LVP [56] and supports the same conclusion as the NMR data.

Although the order of Li ion transfer was established by NMR, the activation energy for solid ionic conduction must also be understood [64]. The activation (or migration) energy for $\mathrm{Li}^{+}$ions diffusion in monoclinic LVP was systematically calculated using a simple vacancy hopping mechanism. The position of the highest potential energy along the migration path is the transition state position, which corresponds to the stationary point with a single negative eigenvalue for the Hessian matrix. The rational functional optimization (RFO) method implemented in the GULP code was used to search for the point [63]. Figure 7a exhibits the possible migration pathways in LVP, and the low migration energies $(<0.8 \mathrm{eV})$ for paths of $\mathrm{A}-\mathrm{D}, \mathrm{G}$, and $\mathrm{J}$ suggest high $\mathrm{Li}$ ion mobility in this material. In particular, the preferred migration paths are along the quasi [100] directions (paths A, B, and C) whereas the other directions have relatively high migration energies [63]. As a result, the mobility of Li ion is highly anisotropic, 
even though LVP has three dimensional (3D) diffusion channels. Based on molecular dynamics, the calculated diffusion coefficient and the corresponding activation energy for $\mathrm{Li}^{+}$at $298 \mathrm{~K}$ are $3.65 \times 10^{-11} \mathrm{~cm}^{2} / \mathrm{s}$ and $0.42 \mathrm{eV}$, respectively [63]. The galvanostatic intermittent titration technique (GITT) is an effective approach that is utilized to investigate $\mathrm{Li}$ ion diffusion in electrode materials $[65,66]$. This technique was first developed using dense planar electrodes where the electrochemical reaction only occurs at the interface between the electrode and the electrolyte [67]. However, porous electrodes in Li ion batteries are not sufficiently planar. With the development of analytical theory for GITT [66] let us estimate Li ion diffusion coefficients in LVP and the ranges from $10^{-7}$ to $10^{-13} \mathrm{~cm}^{2} / \mathrm{s}$ within the operating potential range (Figure 7b). Remarkably, the diffusion coefficients are different at various potentials; for example, the potentials at phase transitions lead to relatively low diffusion coefficients that indicate high energy barriers, especially in the charge process.

Beyond the investigations on $\mathrm{Li}$ ion diffusion, the interface between LVP and the electrolyte also requires more attention, especially given the wide working potential range of 3.0 to $4.8 \mathrm{~V}$. Solid electrolyte interphases (SEI) are formed on the surface of cathode [68] due to the solvents in electrolyte are oxidized by cathode at the high electrochemical potential zone. A capacity loss for LVP is observed in the initial cycle [62,69]. This irreversible capacity loss is attributed to the side reaction between LVP material and electrolyte components because the organic electrolyte is oxidized to form $\mathrm{CO}_{2}$ gas and the SEI film. Chen and coworkers studied the evolution of the SEI 
on LVP through ex-situ HRTEM measurements [69]. When the charge potential exceeds $4.3 \mathrm{~V}$, SEI spots begin to partially cover the surface, and grow during the charge/discharge cycles so that a continuous SEI layer evolves after 20 cycles (Figure 7c). Fourier transform infrared spectroscopy (FTIR) was used to study the chemical composition of the SEI (Figure 7d). All observed IR bands in the sample before cycling are assigned to the internal vibrations of the $\mathrm{PO}_{4}{ }^{3-}$ anions, the relatively weak bands between $450 \mathrm{~cm}^{-1}$ and $750 \mathrm{~cm}^{-1}$ stems from the intramolecular stretching modes of $\mathrm{PO}_{4}{ }^{3-}$, and the strong bands between $750 \mathrm{~cm}^{-1}$ and $1350 \mathrm{~cm}^{-1}$ originate from the intramolecular bending modes of $\mathrm{PO}_{4}{ }^{3-}$. The positions of these original $\mathrm{PO}_{4}{ }^{3-}$ peaks remain almost unchanged after cycling. However, the intensities of these $\mathrm{PO}_{4}{ }^{3-}$ peaks become weaker with charge-discharge cycles, indicating that the SEI film on the electrode surface screens the IR signals from the LVP bulk. Besides, some new peaks are detected in the $1850-1700 \mathrm{~cm}^{-1}, 1500-1300 \mathrm{~cm}^{-1}, 1150-950 \mathrm{~cm}^{-1}$, and $900-800$ $\mathrm{cm}^{-1}$ regions which are assigned to $\mathrm{C}=\mathrm{O}\left(1803,1768,1075 \mathrm{~cm}^{-1}\right), \mathrm{C}-\mathrm{H}\left(1404 \mathrm{~cm}^{-1}\right)$ and P-O-C $\left(974 \mathrm{~cm}^{-1}\right)$ vibrations, respectively. The species thus formed includes some organic compounds such as $\mathrm{ROCO}_{2} \mathrm{Li}, \mathrm{RCO}_{2} \mathrm{Li}$, and aliphatic compounds that result from the decomposition of solvent molecules. In the $900-800 \mathrm{~cm}^{-1}$ region, the new peak at $870 \mathrm{~cm}^{-1}$ is assigned to the $\mathrm{CO}_{3}$ bending of $\mathrm{Li}_{2} \mathrm{CO}_{3}$, and the peak at $830 \mathrm{~cm}^{-1}$ may reflect the P-F bond of the $\mathrm{Li}_{x} \mathrm{PF}_{y}$ or $\mathrm{Li}_{x} \mathrm{PO}_{y} \mathrm{~F}_{z}$ species [69]. Based on these results, Membreño and coworkers have studied the formation of SEI on LVP by X-ray photoelectron spectroscopy (XPS) spectra in both potential window of 3.0-4.2 and 3.0-4.8 V [62]. By contrasting the XPS spectra at different cycles in the LVP/PVDF, 
carbon/PVDF and LVP composite electrodes with or without potential bias, it was found that the SEI on LVP electrode originated from the carbon additive rather than the LVP matrix, because the V element has no catalysis effect and oxygen in phosphate is less basic or reactive. However, the shadowing effect derived from the surface roughness of electrode intervenes in the signal intensities of XPS that results in the quantitative analysis impossibly, thus SEI on LVP needs to be studied further as the authors pointed out at the end of the article. Furthermore, it is worth noting that the irreversible changes in crystallinity and unit cell volume also lead to inferior cycling performance in LVP within the 3.0 to $4.8 \mathrm{~V}$ range. Thus, the structural evolution of LVP/C was cycled in different potential ranges. No marked expansion of unit cell volume was observed when the upper potential limit was reduced from $4.8 \mathrm{~V}$ to $4.6 \mathrm{~V}$. Therefore, the best operating potential region is $3.0-4.6 \mathrm{~V}$ for the practical applications of LVP because the sample can delivers extra 17-37 mAh/g specific capacity over that of 3.0-4.3 V [70] without side reactions in electrode. 
(a)

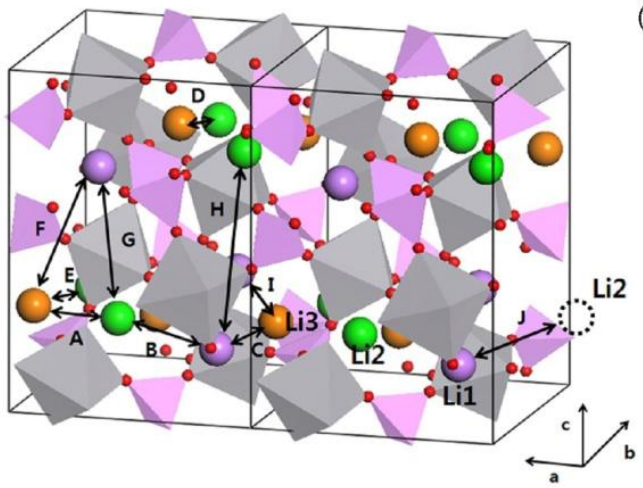

(c)

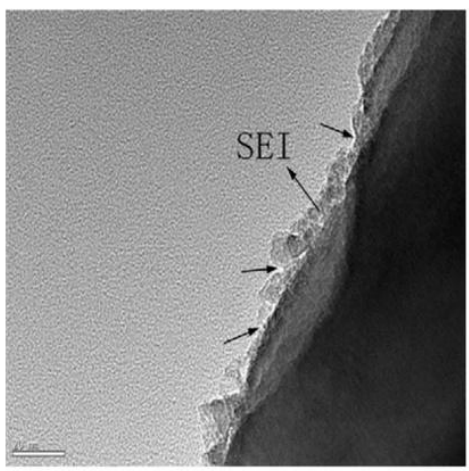

(b)

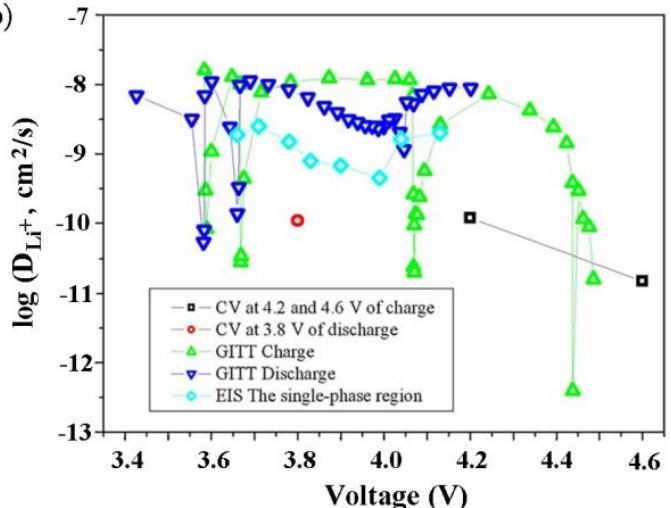

(d)

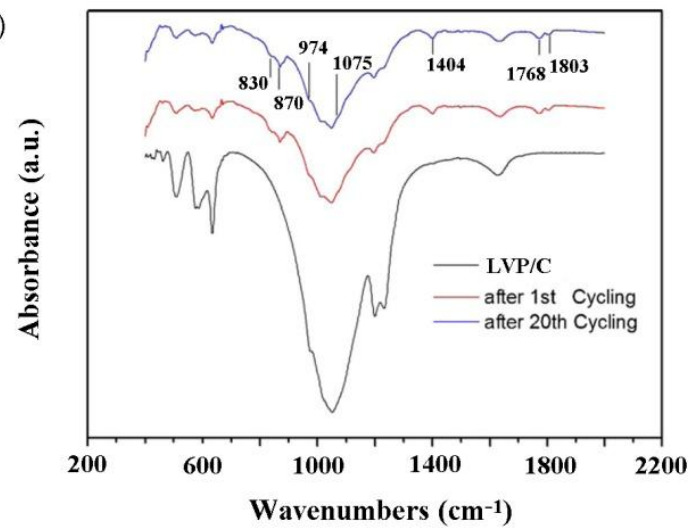

Figure 7. (a)Schematic illustration of possible $\mathrm{Li}^{+}$ion migration paths $(\mathrm{A}-\mathrm{J})$ [63]. Migration energies determine the orientations for ions transfer. Thus, the mobility of $\mathrm{Li}$ ions is highly anisotropic, even though LVP has 3D diffusion pathways. (b) Comparison of chemical diffusion coefficient of LVP determined by CV, GITT and EIS [71]. (c) Typical HRTEM images of LVP/C after twenty cycles [69], and (d) FTIR spectra of the as-prepared LVP/C, together with those after the first charge and twenty cycles.

Synthesis methods and the corresponding reaction kinetics are also essential topics in the studies on pure-phase LVP. The main synthesis methods for LVP include combustion reactions [72], microwave methods [73], sol-gel [74,75], rheological phase methods [76], solid state reactions [77], hydrothermal and solvothermal methods [78] and electrospinning [79]. These methods and related results were summarized by Rui [80]. In one case, thermogravimetric/ differential thermal analyses (TG/DTA) was used to analyze the LVP phase transformation during solid-state 
preparation. The whole solid-state reaction process could be divided into four stages, and the nucleation of $\mathrm{LiVP}_{2} \mathrm{O}_{7}$ is the rate-determining step. The values of the free energy $\left(\Delta \mathrm{G}^{*}\right)$, enthalpy $\left(\Delta \mathrm{H}^{*}\right)$, and entropy $\left(\Delta \mathrm{S}^{*}\right)$ of activation are $99.24 \mathrm{~kJ} / \mathrm{mol}$, $199.97 \mathrm{~kJ} / \mathrm{mol}$, and $136.30 \mathrm{~J} /(\mathrm{mol} \cdot \mathrm{K})$, respectively [77]. These values of the apparent activation energy are the largest of all four stages, implying that the phase transformation is determined by the stage with the highest energy barriers.

\section{Doping: the Effect from Foreign Atoms}

Introduction of foreign atoms varies the physical and chemical surroundings of the host lattice, and directly changes the electrochemical performance. Doping is always an effective way to improve the rate capability or cycling performance in electrode materials with the phosphate framework, such as $\mathrm{LiFePO}_{4}[81]$ and $\mathrm{LiMnPO}_{4}[42]$. Up to now, 26 chemical elements shown in Figure 8 have been chosen as dopants for LVP and three sites $\left(\mathrm{Li}^{+}, \mathrm{V}^{3+}\right.$ and $\left.\mathrm{PO}_{4}{ }^{3-}\right)$ can be substituted. Various effects have been induced and the effects on electrochemical properties are listed in Table 3. Doping in LVP serves the following functions: (1) foreign ions distort the crystal structure, which changes the structural and thermal stability of LVP [82]; (2) lightweight elements substituted for $\mathrm{V}^{3+}$ increase the theoretical capacity of LVP [83-85]; (3) defects or new phases produced by doping enhance the ionic or electronic conductivity of host materials $[84,86]$; (4) the reasonable substitution changes the profiles of charge/discharge curves of LVP; for example three plateaus were reduced to one step $[87,88]$. Thus, ion doping has been regarding as an effective way to 
improve the electrochemical performance of LVP and the effects of doping at the three substituted sites are summarized below.

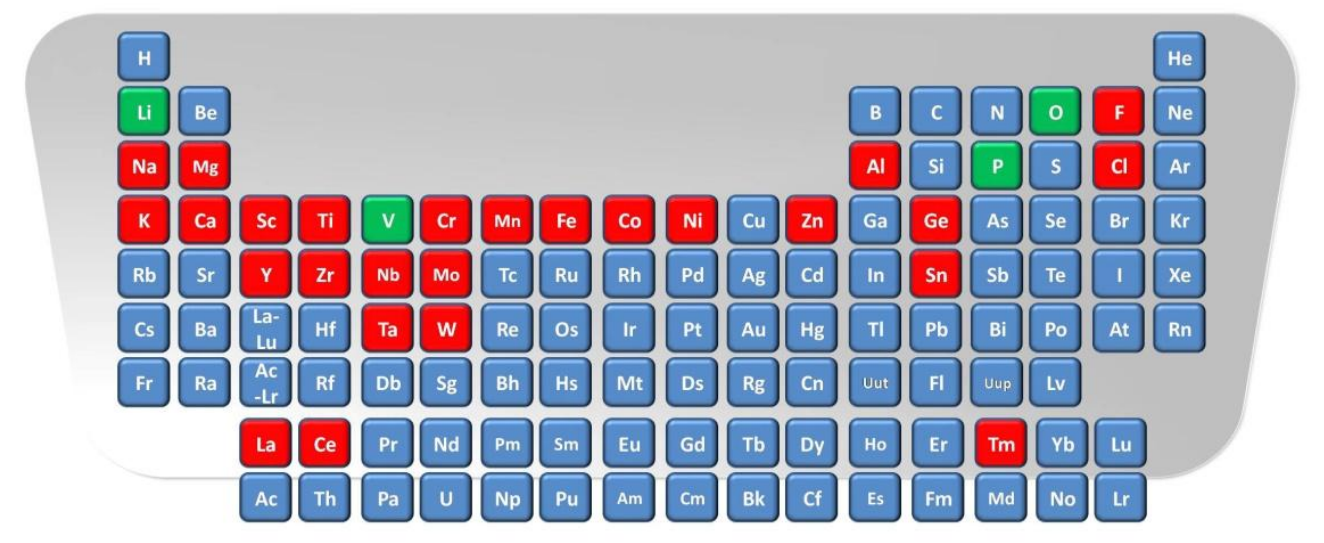

Figure 8. The doping map of LVP in the element periodic table. Up to now, 26 chemical elements (red) were introduced into the host lattice of LVP, yielding various effects on the electrochemistry of LVP. 
Table 3. The Effect of Heteroatom Doping on the Electrochemical Performance

\begin{tabular}{|c|c|c|c|c|c|c|}
\hline Dopants & Optimized composition & Conductivity & Initial discharge capacity & Rate capability & Cycling performance & $\begin{array}{c}\text { Refere } \\
\text { nce }\end{array}$ \\
\hline $\mathrm{Na}^{+}$ & $\begin{array}{l}\mathrm{Li}_{2.97} \mathrm{Na}_{0.03} \mathrm{~V}_{2}\left(\mathrm{PO}_{4}\right)_{3} / \mathrm{C}(6.5 \\
\text { wt.\%) }\end{array}$ & $\begin{array}{l}6.74 \times 10^{-3} \mathrm{~S} / \mathrm{cm} \\
\text { (electrical) }\end{array}$ & $\begin{array}{l}170 \mathrm{mAh} / \mathrm{g} \text { at } 39.4 \mathrm{~mA} / \mathrm{g} \text { in } 3.0-4.8 \\
\mathrm{~V}\end{array}$ & $118.9 \mathrm{mAh} / \mathrm{g}$ at $2 C$ & $105.6 \mathrm{mAh} / \mathrm{g}$ at $2 C$ after 80 cycles & [89] \\
\hline $\mathrm{Na}^{+}$ & $\begin{array}{l}\mathrm{Li}_{2.95} \mathrm{Na}_{0.05} \mathrm{~V}_{2}\left(\mathrm{PO}_{4}\right)_{3} / \mathrm{C}(2.9 \\
w t . \%)\end{array}$ & & $187 \mathrm{mAh} / \mathrm{g}$ at $0.2 C$ in $3.0-4.8 \mathrm{~V}$ & $173.1 \mathrm{mAh} / \mathrm{g}$ at $1 C$ & $\begin{array}{l}178.2 \text { and } 157.5 \mathrm{mAh} / \mathrm{g} \text { at } 0.2 \text { and } 1 \\
C \text { after } 30 \text { cycles, respectively }\end{array}$ & [90] \\
\hline $\mathrm{Na}^{+}$ & $\begin{array}{l}\mathrm{Li}_{2.95} \mathrm{Na}_{0.05} \mathrm{~V}_{2}\left(\mathrm{PO}_{4}\right)_{3} / \mathrm{C}(2.9 \\
w t . \%)\end{array}$ & & $131.1 \mathrm{mAh} / \mathrm{g}$ at $0.1 C$ in $3.0-4.2 \mathrm{~V}$ & & $123.6 \mathrm{mAh} / \mathrm{g}$ at $0.1 C$ after 30 cycles & [91] \\
\hline $\mathrm{Na}^{+}$ & $\mathrm{Li}_{2.9} \mathrm{Na}_{0.1} \mathrm{~V}_{2}\left(\mathrm{PO}_{4}\right)_{3}$ & & $122.3 \mathrm{mAh} / \mathrm{g}$ at $0.2 C$ in $3.0-4.3 \mathrm{~V}$ & $\begin{array}{l}120.57 \text { and } 113.95 \mathrm{mAh} / \mathrm{g} \text { at } 0.5 \\
\text { and } 2 C \text {, respectively }\end{array}$ & $\begin{array}{l}117.95 \mathrm{mAh} / \mathrm{g} \text { at } 0.5 C \text { after } 50 \\
\text { cycles }\end{array}$ & [92] \\
\hline $\mathrm{Na}^{+}$ & $\begin{array}{l}\mathrm{Li}_{2} \mathrm{NaV}_{2}\left(\mathrm{PO}_{4}\right)_{3} / \mathrm{C}(7.87 \text { wt. } \%) \\
\text { (rhombohedral) }\end{array}$ & & $119.1 \mathrm{mAh} / \mathrm{g}$ at $0.05 C$ in $3.0-4.4 \mathrm{~V}$ & $\begin{array}{l}105 \text { and } 95 \mathrm{mAh} / \mathrm{g} \text { at } 5 \text { and } 10 C \text {, } \\
\text { respectively }\end{array}$ & $\begin{array}{l}\sim 100 \mathrm{mAh} / \mathrm{g} \text { at } 1 C \text { after } 100 \\
\text { cycles }\end{array}$ & [93] \\
\hline $\mathrm{Na}^{+}$ & $\begin{array}{l}\mathrm{Li}_{2} \mathrm{NaV}_{2}\left(\mathrm{PO}_{4}\right)_{3} / \mathrm{C} \\
\text { (rhombohedral) }\end{array}$ & & $\sim 122 \mathrm{mAh} / \mathrm{g}$ at $0.1 \mathrm{C}$ in $3.0-4.3 \mathrm{~V}$ & $\begin{array}{l}80 \text { and } 68 \mathrm{mAh} / \mathrm{g} \text { at } 5 \text { and } 10 C, \\
\text { respectively }\end{array}$ & $\sim 75 \mathrm{mAh} / \mathrm{g}$ at $2 C$ after 500 cycles & [87] \\
\hline $\begin{array}{l}\mathrm{Na}^{+} \text {and } \\
\mathrm{Ni}^{2+}\end{array}$ & $\mathrm{Li}_{2.5} \mathrm{Na}_{0.5} \mathrm{~V}_{1.98} \mathrm{Ni}_{0.03}\left(\mathrm{PO}_{4}\right)_{3} / \mathrm{C}$ & & $108 \mathrm{mAh} / \mathrm{g}$ at $1 C$ in $3.0-4.3 \mathrm{~V}$ & & $\begin{array}{l}99 \% \text { capacity retention at } 1 C \text { after } \\
50 \text { cycles }\end{array}$ & [88] \\
\hline $\mathrm{Mg}^{2+}$ & $\begin{array}{l}\mathrm{Li}_{3} \mathrm{~V}_{1.95} \mathrm{Mg}_{0.05}\left(\mathrm{PO}_{4}\right)_{3} / \mathrm{C}(11.41 \\
w t . \%)\end{array}$ & & $\sim 166 \mathrm{mAh} / \mathrm{g}$ at $0.1 C$ in $3.0-4.8 \mathrm{~V}$ & $138.5 \mathrm{mAh} / \mathrm{g}$ at $5 \mathrm{C}$ & $123 \mathrm{mAh} / \mathrm{g}$ at $5 \mathrm{C}$ after 100 cycles & [84] \\
\hline $\mathrm{Mg}^{2+}$ & $\begin{array}{l}\mathrm{Li}_{3} \mathrm{~V}_{1.8} \mathrm{Mg}_{0.30}\left(\mathrm{PO}_{4}\right)_{3} / \mathrm{C}(4.4 \\
w t . \%)\end{array}$ & & $\sim 130 \mathrm{mAh} / \mathrm{g}$ at $0.2 C$ in $3.0-4.5 \mathrm{~V}$ & $\sim 127 \mathrm{mAh} / \mathrm{g}$ at $1 C$ & $118 \mathrm{mAh} / \mathrm{g}$ at $0.2 C$ after 100 cycles & [94] \\
\hline $\begin{array}{l}\mathrm{Mg}^{2+} \text { and } \\
\mathrm{Ti}^{4+}\end{array}$ & $\mathrm{Li}_{3} \mathrm{Mg}_{0.1} \mathrm{Ti}_{0.1} \mathrm{~V}_{1.8}\left(\mathrm{PO}_{4}\right)_{3} / \mathrm{C}$ & & $82 \mathrm{mAh} / \mathrm{g}$ at $0.1 C$ in $3.0-4.8 \mathrm{~V}$ & & $67 \mathrm{mAh} / \mathrm{g}$ at $0.1 C$ after 20 cycles & [95] \\
\hline $\mathrm{Al}^{3+}$ & $\mathrm{Li}_{3} \mathrm{~V}_{1.95} \mathrm{Al}_{0.05}\left(\mathrm{PO}_{4}\right)_{3} / \mathrm{C}$ & $\begin{array}{l}1.9 \times 10^{-6} \mathrm{~S} / \mathrm{cm} \\
\text { (electrical) }\end{array}$ & $129 \mathrm{mAh} / \mathrm{g}$ at $0.5 C$ in $3.0-4.2 \mathrm{~V}$ & & $\begin{array}{l}119 \text { and } 110 \mathrm{mAh} / \mathrm{g} \text { at } 1 \text { and } 2 \mathrm{C} \\
\text { after } 30 \text { cycles, respectively }\end{array}$ & [96] \\
\hline $\mathrm{Al}^{3+}$ & $\mathrm{Li}_{3} \mathrm{~V}_{1.98} \mathrm{Al}_{0.02}\left(\mathrm{PO}_{4}\right)_{3} / \mathrm{C}(0.38$ & & $182 \mathrm{mAh} / \mathrm{g}$ at $0.1 \mathrm{C}$ in $3.0-4.8 \mathrm{~V}$ & $173,167,149,140$ and $119 \mathrm{mAh} / \mathrm{g}$ & $\sim 120 \mathrm{mAh} / \mathrm{g}$ at $20 \mathrm{C}$ after 100 & [97] \\
\hline
\end{tabular}




\begin{tabular}{|c|c|c|c|c|c|c|}
\hline & $w t \%)$ & & & $\begin{array}{l}\text { at } 0.5,1,5,10 \text { and } 20 C \text {, } \\
\text { respectively }\end{array}$ & cycles & \\
\hline $\mathrm{Al}^{3+}$ & $\begin{array}{l}\mathrm{Li}_{3} \mathrm{~V}_{1.92} \mathrm{Al}_{0.08}\left(\mathrm{PO}_{4}\right)_{3} / \mathrm{C}(4.67 \\
w t . \%)\end{array}$ & & $191.5 \mathrm{mAh} / \mathrm{g}$ at $0.1 C$ in $3.0-4.8 \mathrm{~V}$ & & $178 \mathrm{mAh} / \mathrm{g}$ at $0.5 C$ after 200 cycles & [98] \\
\hline $\mathrm{Al}^{3+}$ and & $\mathrm{Li}_{3} \mathrm{~V}_{1.98} \mathrm{Al}_{0.02}\left(\mathrm{PO}_{4}\right)_{2.99} \mathrm{Cl}_{0.01}$ & & $178 \mathrm{mAh} / \mathrm{g}$ at $0.02 \mathrm{~mA} / \mathrm{cm}^{2}$ in & & 143 and $103 \mathrm{mAh} / \mathrm{g}$ at 0.05 and 15 & [99] \\
\hline $\mathrm{Cl}^{-}$ & & & $3.0-4.8 \mathrm{~V}$ & & $C$ after 100 cycles, respectively. & \\
\hline $\mathrm{K}^{+}$ & $\mathrm{Li}_{2.85} \mathrm{~K}_{0.15} \mathrm{~V}_{2}\left(\mathrm{PO}_{4}\right)_{3} / \mathrm{C}$ & & $95 \mathrm{mAh} / \mathrm{g}$ at $0.1 C$ in $3.0-4.8 \mathrm{~V}$ & & $75 \mathrm{mAh} / \mathrm{g}$ at $0.1 C$ after 20 cycles & [95] \\
\hline $\mathrm{Ca}^{2+}$ & $\mathrm{Li} 2.96 \mathrm{Ca} 0.02 \mathrm{~V} 2(\mathrm{PO} 4) 3 / \mathrm{C}$ & & $127 \mathrm{mAh} / \mathrm{g}$ at $0.1 \mathrm{C}$ in $3.0-4.8 \mathrm{~V}$ & $80 \mathrm{mAh} / \mathrm{g}$ at $5 C$ & $95 \mathrm{mAh} / \mathrm{g}$ at $1 C$ after 200 cycles & [100] \\
\hline $\mathrm{Sc}^{3+}$ & $\mathrm{Li}_{3} \mathrm{~V}_{1.85} \mathrm{Sc}_{0.15}\left(\mathrm{PO}_{4}\right)_{3} / \mathrm{C}$ & & $150 \mathrm{mAh} / \mathrm{g}$ at $0.1 C$ in $3.0-4.8 \mathrm{~V}$ & $93 \mathrm{mAh} / \mathrm{g}$ at $5 C$ & $105 \mathrm{mAh} / \mathrm{g}$ at $1 C$ after 200 cycles & [100] \\
\hline $\mathrm{Sc}^{3+}$ & $\mathrm{Li}_{3} \mathrm{~V}_{1.8} \mathrm{Sc}_{0.2}\left(\mathrm{PO}_{4}\right)_{3} / \mathrm{C}$ & & $117 \mathrm{mAh} / \mathrm{g}$ at $0.1 C$ in $3.0-4.8 \mathrm{~V}$ & & $111 \mathrm{mAh} / \mathrm{g}$ at $0.1 C$ after 20 cycles & {$[95]$} \\
\hline $\mathrm{Ti}^{4+}$ & $\mathrm{Li}_{2.8}\left(\mathrm{~V}_{0.9} \mathrm{Ti}_{0.1}\right)_{2}\left(\mathrm{PO}_{4}\right)_{3}$ & (inoic) & $130 \mathrm{mAh} / \mathrm{g}$ at $0.5 \mathrm{C}$ in $3.0-4.3 \mathrm{~V}$ & & $116 \mathrm{mAh} / \mathrm{g}$ at $0.5 C$ after 100 cycles & [101] \\
\hline $\begin{array}{l}\mathrm{Ti}^{4+} \text { and } \\
\mathrm{Mg}^{2+}\end{array}$ & $\mathrm{Li}_{3} \mathrm{~V}_{1.9} \mathrm{Ti}_{0.05} \mathrm{Mg}_{0.05}\left(\mathrm{PO}_{4}\right)_{3}$ & & $175 \mathrm{mAh} / \mathrm{g}$ at $0.2 C$ in $3.0-4.8 \mathrm{~V}$ & $\begin{array}{l}150,137 \text { and } 120 \mathrm{mAh} / \mathrm{g} \text { at } 0.5,1,2 \\
C \text {, respectively }\end{array}$ & $\begin{array}{l}125 \text { and } 100 \mathrm{mAh} / \mathrm{g} \text { at } 0.5 \text { and } 2 C \\
\text { after } 200 \text { cycles, respectively }\end{array}$ & {$[85]$} \\
\hline $\mathrm{Fi}^{2+}$ & $\begin{array}{l}\mathrm{Li}_{3} \mathrm{~V}_{1.9} \mathrm{Ti}_{0.05} \mathrm{Fe}_{0.05}\left(\mathrm{PO}_{4}\right)_{3} / \mathrm{C} \\
(4.16 \text { wt. } \%)\end{array}$ & & $176 \mathrm{mAh} / \mathrm{g}$ at $0.1 \mathrm{C}$ in $3.0-4.8 \mathrm{~V}$ & $\begin{array}{l}138,126,118 \text { and } 90 \mathrm{mAh} / \mathrm{g} \text { at } 1,5, \\
10 \text { and } 20 \mathrm{C} \text {, respectively }\end{array}$ & $\begin{array}{l}105 \text { and } 98 \mathrm{mAh} / \mathrm{g} \text { at } 5 \text { and } 10 \mathrm{C} \\
\text { after } 160 \text { cycles, respectively }\end{array}$ & [102] \\
\hline $\mathrm{Cr}^{3+}$ & $\mathrm{Li}_{3} \mathrm{~V}_{1.9} \mathrm{Cr}_{0.1}\left(\mathrm{PO}_{4}\right)_{3}$ & & $163 \mathrm{mAh} / \mathrm{g}$ at $0.2 C$ in $3.0-4.8 \mathrm{~V}$ & $\begin{array}{l}150,139 \text { and } 120 \mathrm{mAh} / \mathrm{g} \text { at } 0.5,1 \\
\text { and } 2 C \text {, respectively }\end{array}$ & $\begin{array}{l}145 \text { and } 110 \mathrm{mAh} / \mathrm{g} \text { at } 0.5 \text { and } 2 C \\
\text { after } 50 \text { cycles, respectively }\end{array}$ & [103] \\
\hline $\mathrm{Cr}^{3+}$ & $\mathrm{Li}_{3} \mathrm{~V}_{1.9} \mathrm{Cr}_{0.1}\left(\mathrm{PO}_{4}\right)_{3} / \mathrm{C}$ & $\begin{array}{l}2.63 \times 10^{-3} \mathrm{~S} / \mathrm{cm} \\
\text { (electrical) }\end{array}$ & $\begin{array}{l}171.4 \text { and } 130.2 \mathrm{mAh} / \mathrm{g} \text { at } 0.2 \text { and } 4 \\
C \text { in } 3.0-4.8 \mathrm{~V}\end{array}$ & $\begin{array}{l}140,127 \text { and } 118 \text { at } 1,3 \text { and } 5 C \text {, } \\
\text { respectively }\end{array}$ & $\begin{array}{l}78.6 \% \text { capacity retention after } 100 \\
\text { cycles at } 0.2 \mathrm{C} \text { rate }\end{array}$ & [104] \\
\hline $\mathrm{Mn}^{2+}$ & $\mathrm{Li}_{3} \mathrm{~V}_{1.8} \mathrm{Mn}_{0.2}\left(\mathrm{PO}_{4}\right)_{3}$ & & $196 \mathrm{mAh} / \mathrm{g}$ at $0.1 \mathrm{C}$ in $3.0-4.8 \mathrm{~V}$ & $\begin{array}{l}190,152,143,132 \text { and } 118 \mathrm{mAh} / \mathrm{g} \\
\text { at } 0.1,1,2,5 \text { and } 10 \mathrm{C} \text {, respectively }\end{array}$ & $160 \mathrm{mAh} / \mathrm{g}$ at $0.1 C$ after 50 cycles & [105] \\
\hline $\mathrm{Mn}^{2+}$ & $\mathrm{Li}_{3} \mathrm{~V}_{1.94} \mathrm{Mn}_{0.09}\left(\mathrm{PO}_{4}\right)_{3} / \mathrm{C}$ & & 158.8 at $0.2 C$ in $3.0-4.8 \mathrm{~V}$ & $\begin{array}{l}150.8 \text { and } 146.4 \mathrm{mAh} / \mathrm{g} \text { at } 0.5 \text { and } \\
1 C \text {, respectively }\end{array}$ & $\begin{array}{l}120.4,110.6 \text { and } 107.5 \\
\mathrm{mAh} / \mathrm{g} \text { at } 0.2,0.5 \text { and } 1 C \text { after } 100 \\
\text { cycles, respectively }\end{array}$ & [106] \\
\hline $\mathrm{Mn}^{3+}$ & $\mathrm{Li}_{3} \mathrm{~V}_{1.8} \mathrm{Mn}_{0.2}\left(\mathrm{PO}_{4}\right)_{3}$ & & $185 \mathrm{mAh} / \mathrm{g}$ at $0.1 \mathrm{C}$ in $3.0-4.8 \mathrm{~V}$ & 130 and $126 \mathrm{mAh} / \mathrm{g}$ at $5 \mathrm{C}$ and $10 C$, & $95 \%$ and $96 \%$ retention of the & [107] \\
\hline
\end{tabular}




\begin{tabular}{|c|c|c|c|c|c|c|}
\hline & & & & respectively & $\begin{array}{l}\text { initial capacities at } 5 \text { and } 10 C \text { after } \\
100 \text { cycles ,respectively }\end{array}$ & \\
\hline $\mathrm{Fe}^{3+}$ & $\mathrm{Li}_{3} \mathrm{~V}_{1.98} \mathrm{Fe}_{0.02}\left(\mathrm{PO}_{4}\right)_{3}$ & $\begin{array}{l}1.6 \mathrm{~S} / \mathrm{cm} \\
\text { (electrical) }\end{array}$ & $177 \mathrm{mAh} / \mathrm{g}$ at $0.2 \mathrm{C}$ in $3.0-4.9 \mathrm{~V}$ & & $126 \mathrm{mAh} / \mathrm{g}$ at $0.2 C$ after 80 cycles & [108] \\
\hline $\mathrm{Fe}^{3+}$ & $\begin{array}{l}\mathrm{Li}_{3} \mathrm{~V}_{1.95} \mathrm{Fe}_{0.05}\left(\mathrm{PO}_{4}\right)_{3} / \mathrm{C}(3.4 \\
w t . \%)\end{array}$ & $\begin{array}{l}2.22 \times 10^{-2} \mathrm{~S} / \mathrm{cm} \\
\text { (electrical) }\end{array}$ & $168.6 \mathrm{mAh} / \mathrm{g}$ at $0.5 \mathrm{C}$ in $3.0-4.8 \mathrm{~V}$ & $\begin{array}{l}137,123 \text { and } 102 \mathrm{mAh} / \mathrm{g} \text { at } 1,2 \text { and } \\
5 \mathrm{C} \text {, respectively }\end{array}$ & $\begin{array}{l}130.9 \mathrm{mAh} / \mathrm{g} \text { at } 0.5 C \text { after } 50 \\
\text { cycles }\end{array}$ & [109] \\
\hline $\mathrm{Fe}^{3+}$ & $\mathrm{Li}_{3} \mathrm{~V}_{1.95} \mathrm{Fe}_{0.05}\left(\mathrm{PO}_{4}\right)_{3} / \mathrm{C}$ & & $175 \mathrm{mAh} / \mathrm{g}$ at $0.1 C$ in $3.0-4.8 \mathrm{~V}$ & $\begin{array}{l}141,119 \text { and } 110 \mathrm{mAh} / \mathrm{g} \text { at } 1,5 \text { and } \\
10 \mathrm{C} \text {, respectively }\end{array}$ & $168 \mathrm{mAh} / \mathrm{g}$ at $0.1 C$ after 50 cycles & [110] \\
\hline $\mathrm{Co}^{3+}$ & $\mathrm{Li}_{3} \mathrm{~V}_{1.90} \mathrm{Co}_{0.10}\left(\mathrm{PO}_{4}\right)_{3} / \mathrm{C}$ & & $178 \mathrm{mAh} / \mathrm{g}$ at $0.1 C$ in $3.0-4.8 \mathrm{~V}$ & $\begin{array}{l}159,135 \text { and } 128 \mathrm{mAh} / \mathrm{g} \text { at } 1,5 \text { and } \\
10 \mathrm{C} \text {, respectively }\end{array}$ & $169 \mathrm{mAh} / \mathrm{g}$ at $0.1 C$ after 50 cycles & [110] \\
\hline $\mathrm{Co}^{3+}$ & $\begin{array}{l}\mathrm{Li}_{3} \mathrm{~V}_{1.85} \mathrm{Co}_{0.15}\left(\mathrm{PO}_{4}\right)_{3} / \mathrm{C}(7.33 \\
w t . \%)\end{array}$ & $\begin{array}{l}2.05 \times 10^{-4} \mathrm{~S} / \mathrm{cm} \\
\text { (electrical) }\end{array}$ & $163.3 \mathrm{mAh} / \mathrm{g}$ at $0.1 \mathrm{C}$ in $3.0-4.8 \mathrm{~V}$ & & $\begin{array}{l}73.4 \% \text { retention of the initial } \\
\text { capacities at } 0.1 C \text { after } 100 \text { cycles }\end{array}$ & [111] \\
\hline $\mathrm{Ni}^{2+}$ & $\mathrm{Li}_{3} \mathrm{Ni}_{0.04} \mathrm{~V}_{1.96}\left(\mathrm{PO}_{4}\right)_{3} / \mathrm{C}$ & & $127 \mathrm{mAh} / \mathrm{g}$ at $5 C$ in $3.0-4.8 \mathrm{~V}$ & $\begin{array}{l}122.5 \text { and } 107.4 \mathrm{mAh} / \mathrm{g} \text { at } 0.5 \text { and } \\
10 C \text {, respectively }\end{array}$ & $124.3 \mathrm{mAh} / \mathrm{g}$ at $5 C$ after 200 cycles & [112] \\
\hline $\mathrm{Ni}^{2+}$ & LVP-1wt\% Ni & & $128 \mathrm{mAh} / \mathrm{g}$ at $0.1 C$ in $3.0-4.3 \mathrm{~V}$ & $\begin{array}{l}128,127,126,120 \text { and } 114 \mathrm{mAh} / \mathrm{g} \\
\text { at } 0.1,0.2,0.5,1.0 \text { and } 2.0 \mathrm{C}, \\
\text { respectively }\end{array}$ & & [113] \\
\hline $\mathrm{Ni}^{2+}$ & $\mathrm{Li}_{3} \mathrm{~V}_{1.9} \mathrm{Ni}_{0.1}\left(\mathrm{PO}_{4}\right)_{3} / \mathrm{C}$ & & $128 \mathrm{mAh} / \mathrm{g}$ at $0.1 C$ in $3.0-4.3 \mathrm{~V}$ & $\begin{array}{l}121,110 \text { and } 86 \mathrm{mAh} / \mathrm{g} \text { at } 0.5,1 \text { and } \\
2 C \text {, respectively }\end{array}$ & $127 \mathrm{mAh} / \mathrm{g}$ at $0.1 C$ after 20 cycles & [114] \\
\hline $\mathrm{Zn}^{2+}$ & $\mathrm{Li}_{3} \mathrm{~V}_{1.97} \mathrm{Zn}_{0.05}\left(\mathrm{PO}_{4}\right)_{3} / \mathrm{C}$ & & $131.2 \mathrm{mAh} / \mathrm{g}$ at $0.2 C$ in $3.0-4.3 \mathrm{~V}$ & $122.6 \mathrm{mAh} / \mathrm{g}$ at $1 C$ & $121.7 \mathrm{mAh} / \mathrm{g}$ at $1 C$ after 20 cycles & [115] \\
\hline $\mathrm{Ge}^{4+}$ & $\mathrm{Li}_{2.8}\left(\mathrm{~V}_{0.9} \mathrm{Ge}_{0.1}\right)_{2}\left(\mathrm{PO}_{4}\right)_{3}$ & & $131 \mathrm{mAh} / \mathrm{g}$ at $13 \mathrm{~mA} / \mathrm{g}$ in $3.0-4.2 \mathrm{~V}$ & $88 \mathrm{mAh} / \mathrm{g}$ at $1 C$ & & [116] \\
\hline $\mathrm{Y}^{3+}$ & $\mathrm{Li}_{3} \mathrm{~V}_{1.97} \mathrm{Y}_{0.03}\left(\mathrm{PO}_{4}\right)_{3}$ & & $124 \mathrm{mAh} / \mathrm{g}$ at $0.5 C$ in $3.0-4.2 \mathrm{~V}$ & & $117 \mathrm{mAh} / \mathrm{g}$ at $0.5 C$ after 30 cycles & {$[117]$} \\
\hline $\mathrm{Zr}^{4+}$ & $\begin{array}{l}\mathrm{Li}_{3} \mathrm{~V}_{1.95} \mathrm{Zr}_{0.05}\left(\mathrm{PO}_{4}\right)_{3} / \mathrm{C} \\
(0.3-0.6 w t . \%)\end{array}$ & $\begin{array}{l}10^{-5} \mathrm{~S} / \mathrm{cm} \\
\text { (inoic) }\end{array}$ & $\begin{array}{l}162 \text { and } 118 \mathrm{mAh} / \mathrm{g} \text { at } 0.1 C \text { in } \\
3.0-4.3 \text { and } 3.0-4.8 \mathrm{~V} \text {, respectively }\end{array}$ & & $138 \mathrm{mAh} / \mathrm{g}$ at $0.2 C$ after 50 cycles & [86] \\
\hline $\mathrm{Nb}^{5+}$ & $\begin{array}{l}\mathrm{Li}_{3} \mathrm{~V}_{1.97} \mathrm{Nb}_{0.03}\left(\mathrm{PO}_{4}\right)_{3} / \mathrm{C}(2.10 \\
w t . \%)\end{array}$ & $\begin{array}{l}1.12 \times 10^{-4} \mathrm{~S} / \mathrm{cm} \\
\text { (electrical) }\end{array}$ & $181.5 \mathrm{mAh} / \mathrm{g}$ at $0.1 C$ in $3.0-4.8 \mathrm{~V}$ & $\begin{array}{l}160,125 \text { and } 86 \mathrm{mAh} / \mathrm{g} \text { at } 1,5 \text { and } \\
10 C \text {, respectively }\end{array}$ & $\begin{array}{l}153.7 \mathrm{mAh} / \mathrm{g} \text { at } 0.1 C \text { after } 50 \\
\text { cycles }\end{array}$ & [118] \\
\hline
\end{tabular}




\begin{tabular}{|c|c|c|c|c|c|}
\hline $\mathrm{Nb}^{5+}$ & $\mathrm{Li}_{3} \mathrm{~V}_{1.85} \mathrm{Nb}_{0.15}\left(\mathrm{PO}_{4}\right)_{3} / \mathrm{C}$ & $162.4 \mathrm{mAh} / \mathrm{g}$ at $0.5 C$ in $3.0-4.8 \mathrm{~V}$ & & $\begin{array}{l}140.6 \mathrm{mAh} / \mathrm{g} \text { at } 0.5 C \text { after } 50 \\
\text { cycles }\end{array}$ & [82] \\
\hline $\mathrm{Nb}^{5+}$ & $\mathrm{Li}_{3} \mathrm{~V}_{1.95} \mathrm{Nd}_{0.05}\left(\mathrm{PO}_{4}\right)_{3} / \mathrm{C}$ & $129.2 \mathrm{mAh} / \mathrm{g}$ at $1 C$ in $3.0-4.3 \mathrm{~V}$ & & $\begin{array}{l}100 \% \text { retention rate after } 100 \\
\text { cycles in } 3.0-4.3 \mathrm{~V} \text { at } 1 C \text { rate, }\end{array}$ & [119] \\
\hline $\mathrm{Mo}^{6+}$ & $\mathrm{Li}_{3} \mathrm{Mo}_{0.03} \mathrm{~V}_{1.97}\left(\mathrm{PO}_{4}\right)_{3} / \mathrm{C}$ & $125.0 \mathrm{mAh} / \mathrm{g}$ at $5 C$ in $3.0-4.3 \mathrm{~V}$ & $\begin{array}{l}122.8 \mathrm{mAh} / \mathrm{g} \text { and } 117.6 \mathrm{mAh} / \mathrm{g} \text { at } \\
10 \text { and } 20 \mathrm{C} \text {, respectively }\end{array}$ & $125 \mathrm{mAh} / \mathrm{g}$ at $5 C$ after 100 cycles & [120] \\
\hline $\mathrm{Sn}^{4+}$ & $\mathrm{Li}_{3} \mathrm{~V}_{1.95} \mathrm{Sn}_{0.05}\left(\mathrm{PO}_{4}\right)_{3} / \mathrm{C}$ & $136 \mathrm{mAh} / \mathrm{g}$ at $0.5 C$ in $2.5-4.5 \mathrm{~V}$ & & $124 \mathrm{mAh} / \mathrm{g}$ at $0.5 C$ after 80 cycles & [121] \\
\hline $\mathrm{La}^{3+}$ & $\mathrm{Li}_{3} \mathrm{~V}_{1.98 \mathrm{La} 0.02\left(\mathrm{PO}_{4}\right)_{3}}$ & $153.3 \mathrm{mAh} / \mathrm{g}$ at $0.2 C$ in $3.0-4.8 \mathrm{~V}$ & & $\begin{array}{l}142.5 \mathrm{mAh} / \mathrm{g} \text { at } 0.2 C \text { after } 30 \\
\text { cycles }\end{array}$ & [122] \\
\hline $\mathrm{Ce}^{4+}$ & $\mathrm{Li}_{3} \mathrm{~V}_{1.95} \mathrm{Ce}_{0.05}\left(\mathrm{PO}_{4}\right)_{3}$ & $120 \mathrm{mAh} / \mathrm{g}$ at $0.2 C$ in $3.0-4.3 \mathrm{~V}$ & $\begin{array}{l}108,102,97 \text { and } 88.6 \mathrm{mAh} / \mathrm{g} \text { at } 1,2, \\
5 \text { and } 10 \mathrm{C} \text {, respectively }\end{array}$ & $83.5 \mathrm{mAh} / \mathrm{g}$ at $10 C$ after 100 cycles & [123] \\
\hline $\mathrm{Ce}^{4+}$ & $\begin{array}{l}\mathrm{Li}_{3} \mathrm{~V}_{1.98} \mathrm{Ce}_{0.02}\left(\mathrm{PO}_{4}\right)_{3} / \mathrm{C}(10.68 \\
w t . \%)\end{array}$ & $180.7 \mathrm{mAh} / \mathrm{g}$ at $0.2 C$ in $3.0-4.8 \mathrm{~V}$ & $\begin{array}{l}171.3,165.2 \text { and } 120.4 \mathrm{mAh} / \mathrm{g} \text { at } 1, \\
2 \text { and } 10 \mathrm{C} \text {, respectively }\end{array}$ & $\begin{array}{l}171.6 \mathrm{mAh} / \mathrm{g} \text { at } 0.2 C \text { after } 100 \\
\text { cycles }\end{array}$ & [124] \\
\hline $\mathrm{Ta}^{5+}$ & & $138.2 \mathrm{mAh} / \mathrm{g}$ at $0.1 C$ in $3.0-4.8 \mathrm{~V}$ & & $\begin{array}{l}114.3 \mathrm{mAh} / \mathrm{g} \text { at } 0.2 \mathrm{C} \text { after } 50 \\
\text { cycles }\end{array}$ & [125] \\
\hline $\mathrm{Tm}^{3+}$ & & $181.2 \mathrm{mAh} / \mathrm{g}$ at $0.1 C$ in $3.0-4.8 \mathrm{~V}$ & $\begin{array}{l}141,123 \mathrm{mAh} / \mathrm{g} \text { at } 5 \text { and } 10 \mathrm{C} \text {, } \\
\text { respectively }\end{array}$ & & {$[126$} \\
\hline $\mathrm{F}^{-}$ & $\mathrm{Li}_{3} \mathrm{~V}_{2}\left(\mathrm{PO}_{4}\right)_{2.90} \mathrm{~F}_{0.10}$ & $128 \mathrm{mAh} / \mathrm{g}$ at $1 C$ in $3.0-4.2 \mathrm{~V}$ & $\begin{array}{l}125 \text { and } 119 \mathrm{mAh} / \mathrm{g} \text { at } 5 \text { and } 10 C \text {, } \\
\text { respectively }\end{array}$ & $117 \mathrm{mAh} / \mathrm{g}$ at $10 C$ after 30 cycles & [127] \\
\hline $\mathrm{Cl}^{-}$ & $\begin{array}{l}\mathrm{Li}_{3} \mathrm{~V}_{2}\left(\mathrm{PO}_{4}\right)_{2.90} \mathrm{Cl}_{0.10} / \mathrm{C}(3.11 \\
w t . \%)\end{array}$ & $125.1 \mathrm{mAh} / \mathrm{g}$ at $0.1 C$ in $3.0-4.3 \mathrm{~V}$ & $\begin{array}{l}117.2,110.5,101.4,90.7 \text { and } 72.3 \\
\mathrm{mAh} / \mathrm{g} \text { at } 0.5,1,2,5 \text { and } 10 C, \\
\text { respectively }\end{array}$ & & [128] \\
\hline $\mathrm{Cl}^{-}$ & $\mathrm{Li}_{3} \mathrm{~V}_{2}\left(\mathrm{PO}_{4}\right)_{2.99} \mathrm{Cl}_{0.01}$ & $176 \mathrm{mAh} / \mathrm{g}$ at $0.1 C$ in $3.0-4.3 \mathrm{~V}$ & $\begin{array}{l}164,155,125,106 \text {, and } 72 \mathrm{mAh} / \mathrm{g} \text { at } \\
0.5,1,2,10 \text { and } 20 C \text {, respectively }\end{array}$ & $146 \mathrm{mAh} / \mathrm{g}$ at $0.1 C$ after 50 cycles & [129] \\
\hline $\mathrm{Cl}^{-}$ & $\mathrm{Li}_{3} \mathrm{~V}_{2}\left(\mathrm{PO}_{4}\right)_{2.88} \mathrm{Cl}_{0.12} / \mathrm{C}$ & $123.79 \mathrm{mAh} / \mathrm{g}$ at $0.5 C$ in $3.0-4.3 \mathrm{~V}$ & & $113.58 \mathrm{mAh} / \mathrm{g}$ after 80 cycles at $5 C$ & [130] \\
\hline
\end{tabular}




\subsection{Doping on $\mathrm{Li}$ ion site}

$\mathrm{Na}$ ion is the main dopant at the $\mathrm{Li}$ ion site and the amount of $\mathrm{Na}$ ion directly affects the LVP crystal structure, resulting in a remarkable change in the charge/discharge profiles. The chemical formula of $\mathrm{Na}^{+}$-doped LVP is written as $\mathrm{Li}_{3-x} \mathrm{Na}_{x} \mathrm{~V}_{2}\left(\mathrm{PO}_{4}\right)_{3}$. If $x$ $\leq 0.1$, the crystal structure of LVP remains monoclinic [89-91]. But when $x \geq 0.5$, the host phase is transformed to rhombohedral $[87,88,93]$. In general, rhombohedral LVP is derived from $\mathrm{Na}_{3} \mathrm{~V}_{2}\left(\mathrm{PO}_{4}\right)_{3}$ using the ion exchange method [53,131]. Thus, $\mathrm{Li}$ ion substituted excessively by $\mathrm{Na}$ ion will induce a monoclinic to rhombohedral phase transition in LVP. It is significant that these phases strongly determine the electrochemical performance of doped LVP.

As mentioned above, the monoclinic structure is retained when the doping amount of $\mathrm{Na}$ ion is smaller than or equal to $0.1\left(\mathrm{Li}_{3-x} \mathrm{Na}_{x} \mathrm{~V}_{2}\left(\mathrm{PO}_{4}\right)_{3}, x \leq 0.1\right)$. Introduction of small amount of $\mathrm{Na}$ ion forms monoclinic $\mathrm{Li}_{2.97} \mathrm{Na}_{0.03} \mathrm{~V}_{2}\left(\mathrm{PO}_{4}\right)_{3}$ in which the lattice constants $a, b$ and $c$ increase nearly linearly by $18.2 \%, 3.2 \%$ and $20.8 \%$ per substituted sodium, respectively [89]. Besides, $\mathrm{Li}_{2.97} \mathrm{Na}_{0.03} \mathrm{~V}_{2}\left(\mathrm{PO}_{4}\right)_{3}$ has an enhanced electronic conductivity of $6.74 \times 10^{-3} \mathrm{~S} / \mathrm{cm}$, which is over an order of magnitude higher than that of LVP $\left(2.16 \times 10^{-4} \mathrm{~S} / \mathrm{cm}\right)$. This increase arises because Na-doping expands the LVP lattice and distorts the V positions in such a way that the band gap narrows. The distortion of the LVP crystal structure shortens Li-Li distances and lengthens Li-O bonds, which leads to low Li activation energies for diffusion and improves the 
ionic conductivity in the phosphate framework. While the lattice parameters for $a$ and $b$ increase, the $c$ axis compresses as the amount of $\mathrm{Na}$ ions is increased [90]. Furthermore, the radius of $\mathrm{Na}$ ion $(95 \mathrm{pm})$ is larger than that of $\mathrm{Li}$ ion $(60 \mathrm{pm})$, resulting in larger channels that reduce polarization during lithiation/delithiation and favor fast Li-ion diffusion. The higher Li-diffusivity of Na-doped LVPs leads to a slightly larger discharge capacity compared to pure LVP (Figure 9a). This result is further supported by Li-ion diffusion coefficients (Figure 9b) calculated from GITT curves, which show that $\mathrm{Li}_{2.95} \mathrm{Na}_{0.05} \mathrm{~V}_{2}\left(\mathrm{PO}_{4}\right)_{3} / \mathrm{C}$ composites have a higher diffusion coefficient. Impedance measurements also demonstrated that $\mathrm{Li}_{2.95} \mathrm{Na}_{0.05} \mathrm{~V}_{2}\left(\mathrm{PO}_{4}\right)_{3} / \mathrm{C}$ has a smaller charge transfer resistance than that of LVP/C [91,92]. These results reveal that $\mathrm{Na}$ ion positively affects ionic diffusion and charge transfer in LVP. In addition, it also improves the electrochemical performance; for example, $\mathrm{Li}_{2.9} \mathrm{Na}_{0.1} \mathrm{~V}_{2}\left(\mathrm{PO}_{4}\right)_{3} / \mathrm{C}$ delivers a discharge capacity of $112.2 \mathrm{mAh} / \mathrm{g}$ at $5 C$ after 80 cycles, but LVP/C only displays $100.8 \mathrm{mAh} / \mathrm{g}$ under the same conditions [92]. 

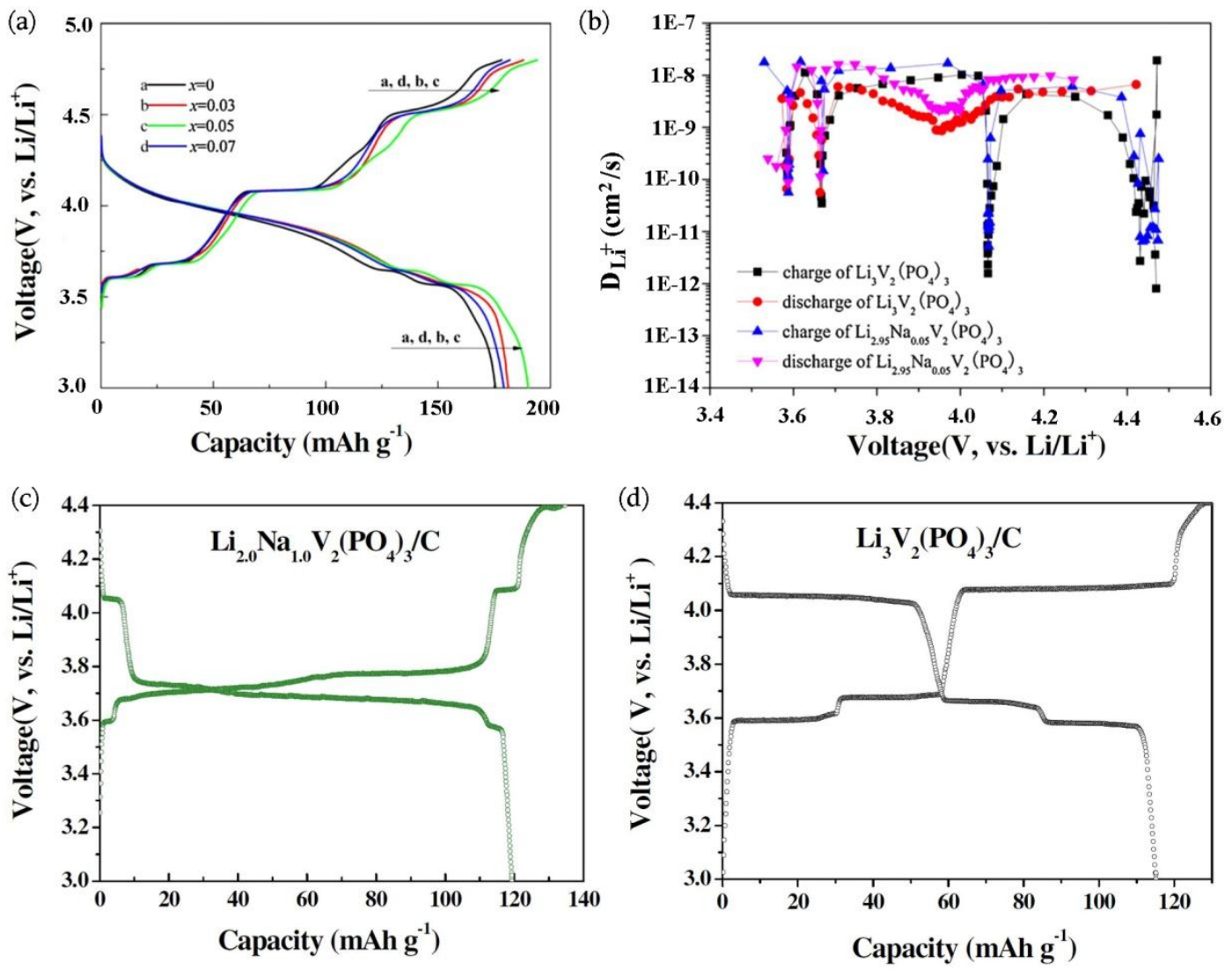

Figure 9. (a) Initial charge/discharge profiles of $\mathrm{Li}_{3-} \mathrm{Na}_{x} \mathrm{~V}_{2}\left(\mathrm{PO}_{4}\right)_{3} / \mathrm{C}$ composites $(\mathrm{x}=0,0.03,0.05$ and 0.07 ) at $0.2 C$ in the voltage range of 3.0-4.8 V. Na-doped LVP shows increased specific capacity. (b)The $\mathrm{Li}$ ion diffusion coefficients of $\mathrm{LVP} / \mathrm{C}$ and $\mathrm{Li}_{2.95} \mathrm{Na}_{0.05} \mathrm{~V}_{2}\left(\mathrm{PO}_{4}\right)_{3} / \mathrm{C}$ electrodes calculated from GITT curves as a function of cell voltage during charge and discharge [90]. The first charge/discharge curves of (c) $\mathrm{Li}_{2} \mathrm{NaV}_{2}\left(\mathrm{PO}_{4}\right)_{3} / \mathrm{C}$ and (d) $\mathrm{LVP} / \mathrm{C}$ tested at $0.05 C$ between 3.0 and 4.4 V [93]. Controlled Na doping remarkably changes the charge/discharge profile compared to LVP.

With the increase of the amount of doped Na, the phase in LVP partially [93] or fully $[87,131]$ transforms from monoclinic to rhombohedral, causing a clear plateau near 3.7 $\mathrm{V}$ in the discharge curve (Figure 9c), rather than three plateaus at 4.1, 3.7 and 3.6 V (Figure 9d). Different studies found different constituent phases and electrochemical performances in $\mathrm{Li}_{2} \mathrm{NaV}_{2}\left(\mathrm{PO}_{4}\right)_{3}$. Goodenough [131] argued that $\mathrm{Na}$ ions prefer to reside immobilized in the $\mathrm{A}(1)$ site of the rhombohedral-NASICON structure during electrochemical cycling, suggesting a direct $\mathrm{A}(2)-\mathrm{A}(2)$ lithium 
transport mechanism. It is worth noting that the $\mathrm{A}(1)$ and $\mathrm{A}(2)$ differ from $\mathrm{Li}(1)$ and Li(2) mentioned above, because the atoms occupation are totally different in rhombohedral and monoclinic LVP. The single rhombohedral $\mathrm{Li}_{2} \mathrm{NaV}_{2}\left(\mathrm{PO}_{4}\right)_{3}$ presents great high-rate capability $(80 \mathrm{mAh} / \mathrm{g}$ at $5 C$ and $68 \mathrm{mAh} / \mathrm{g}$ at $10 C$ ) and excellent cyclability, (about $93 \%$ of the initial capacity is retained after 500 cycles at 2 C) because no fundamental change occurs in the three-dimensional host framework [87]. However, it is believed that $\mathrm{Li}_{2} \mathrm{NaV}_{2}\left(\mathrm{PO}_{4}\right)_{3}$ consists of two [87] or three [93] phases based on refinement calculations. Tang et al. [93] obtained a novel $\mathrm{Li}_{2} \mathrm{NaV}_{2}\left(\mathrm{PO}_{4}\right)_{3}$ composite which was made up of rhombohedral $\mathrm{Li}_{3} \mathrm{~V}_{2}\left(\mathrm{PO}_{4}\right)_{3}(59 \%)$, monoclinic $\mathrm{Li}_{3} \mathrm{~V}_{2}\left(\mathrm{PO}_{4}\right)_{3}(10 \%)$ and rhombohedral $\mathrm{Na}_{3} \mathrm{~V}_{2}\left(\mathrm{PO}_{4}\right)_{3}(31 \%)$. To be more precise, it is a compound mixture. It is remarkable that one plateau appears in the charge/discharge curve near 3.7 V (Figure 9c), where the rhombohedral phase reaction contributes $93.6 \%$ of the observed capacity and the remainder comes from monoclinic LVP. The short plateaus at 3.65 and $4.1 \mathrm{~V}$ could play a useful role to indicate the end of charging and discharging. All of these characteristics distinguish it from LVP/C, which contains three plateaus [15,132] (Figure 9d). Shao and coworkers [133] obtained a phase diagram for Na-doped LVP (from $\mathrm{Na}=0$ to 3 ) and systematically investigated the evolution of the charge/discharge profiles.

In addition to $\mathrm{Na}^{+}$, other ions like $\mathrm{Mg}^{2+}, \mathrm{K}^{+}$and $\mathrm{Ca}^{2+}$ can reside in the $\mathrm{Li}$ ionsite and improve the electrochemical performance of $\mathrm{LVP} .\left(\mathrm{Li}_{0.95} \mathrm{Mg}_{0.025}\right)_{3} \mathrm{~V}_{2}\left(\mathrm{PO}_{4}\right)_{3}$ displayed a considerable discharge capacity of $156 \mathrm{mAh} / \mathrm{g}$ at $35 \mathrm{~mA} / \mathrm{g}$ between $3.0-4.8 \mathrm{~V}$, and a 
capacity retention of $70 \%$ after 50 cycles [134]. It is worth noting that the discharge plateaus also transform from three plateaus to one, which is similar to results for $\mathrm{Na}^{+}$ $[87,93,131]$ and $\mathrm{K}^{+}[95]$ doped LVP. $\mathrm{Ca}^{2+}$-doped LVP still retains three plateaus in its discharge curves and displays excellent rate capability and cycling performance, which is attributed to stabilization of the monoclinic LVP structure [100]. In comparison with other cations doped on Li ion site, K-doped LVP exhibits a worse cyclic performance [95]. Although great efforts are devoted on the doping in $\mathrm{Li}$ ion sites, it is not clear why some ions improve performance and others do not, why some ions change the crystal structure and others do not in LVP. In addition, Li-ion has three sites in the LVP lattice, it is not clear which site will be replaced, and is there a significant difference caused by the doping sites? Therefore, some fundamental issues need to be explored further on the doping on Li-ion sites.

\subsection{Doping on V(III) ion site}

Foreign atoms doping studies concentrate on the $\mathrm{V}^{3+}$ site in order to produce defects that improve the properties of LVP. As seen from the LVP doping map on the periodic table (Figure 8), 21 metallic ions have been doped on the $\mathrm{V}^{3+}$ site, which includes $\mathrm{Mg}^{2+}[94,134,135], \mathrm{Al}^{3+}[83,96-98,136], \mathrm{Ca}^{2+}[100], \mathrm{Sc}^{3+}[100], \mathrm{Ti}^{4+}$ $[85,95,101,102], \mathrm{Cr}^{3+}[103,104], \mathrm{Mn}^{2+} / \mathrm{Mn}^{3+}[105-107,137,138], \mathrm{Fe}^{3+}[108,109], \mathrm{Co}^{3+}$ [110,111], $\mathrm{Ni}^{2+}$ [112-114], $\mathrm{Zn}^{2+}[115], \mathrm{Ge}^{4+}[116], \mathrm{Y}^{3+}$ [117], $\mathrm{Zr}^{4+}[86,139], \mathrm{Nb}^{5+}$ $[82,118,119], \mathrm{Mo}^{6+}[120], \mathrm{Sn}^{4+}[121], \mathrm{La}^{3+}[122], \mathrm{Ce}^{4+}[123,124], \mathrm{Tm}^{3+}[126]$ and $\mathrm{Ta}^{5+}$ [125]. There are five aspects to $\mathrm{V}^{3+}$ site doping: (a) improving the electronic and 
ionic conductivity of LVP host, (b) mitigating particle growth, (c) tuning the discharging curves and (d) modifying the specific capacity and rate capability.

\subsubsection{Improvements on Electronic and Ionic Conductivity}

Three factors contribute to improving the electronic and ionic conductivity in cation-doped LVP.

First, doping cations introduce defects, such as vacancies and holes, which counteract the imbalance of electrical neutrality in crystal lattice. For example, Figure 10a shows the variation of electronic conductivity in $\mathrm{Li}_{3} \mathrm{~V}_{2-\mathrm{x}} \mathrm{Mg}_{\mathrm{x}}\left(\mathrm{PO}_{4}\right)_{3}$ samples. Electronic conductivity increases by more than one order of magnitude when the dopant content increases in the range of $0<x<0.05 . \mathrm{Mg}^{2+}$ substitution at the $\mathrm{V}^{4+}$ site generates two holes to preserve charge balance in the host. As charge carriers, these holes increase conductivity. When $x>0.05$, conductivity increases slowly with the $x$ value [84], which may be attributed to the recombination of unlike defects. A similar phenomenon is observed in $\mathrm{Al}^{3+}$-doped LVP in which substitution results in a significant increase in the electronic conductivity of $\mathrm{Li}_{3} \mathrm{Al}_{0.05} \mathrm{~V}_{1.95}\left(\mathrm{PO}_{4}\right)_{3}$, which reaches $1.9 \times 10^{-6} \mathrm{~S} / \mathrm{cm}$, about a factor of 100 higher than $\mathrm{Li}_{3} \mathrm{~V}_{2}\left(\mathrm{PO}_{4}\right)_{3}[96] . \mathrm{Ni}^{2+}$ - or $\mathrm{Co}^{2+}$-substituted $\mathrm{V}^{3+}$ changes the cation valence electron energy distribution [114] and like $\mathrm{Mg}^{2+}$, results p-type conductivity [135] in LVP. These defects enhance the conductivity and reversibility of the samples, leading to improved cycling performance [114]. However, Ni-O has a higher bond energy $(391.6 \mathrm{~kJ} / \mathrm{mol})$ than 
Co-O $(368 \mathrm{~kJ} / \mathrm{mol})$, at the same time the Ni-O bond length is longer than the Co-O bond, which implies that Ni doping would provide more stable structure of P-O bond than $\mathrm{Co}^{2+}$ doping in LVP [112]. Furthermore, the effect of $\mathrm{Co}^{2+}$ in LVP was systematically studied and the initial capacities of $\mathrm{Li}_{3} \mathrm{~V}_{2-x} \mathrm{Co}_{x}\left(\mathrm{PO}_{4}\right)_{3}$ compounds directly depend on the $\mathrm{Co}^{2+}$ content [111] (Figure 10b). With the increase of Co content, the initial specific capacity decreases, and then for $x>0.10$ the capacity increases monotonically. The discharge capacity reached $163.3 \mathrm{mAh} / \mathrm{g}$ as the Co content was increased to 0.15 (109.4\% of the initial capacity of the undoped LVP. The solid line in Figure $10 \mathrm{~b}$ is a quadratic fitted curve of the experimental values. Seen from the curve, a transition point is located at approximately $x=0.07$. Unfortunately the fundamental origin of the trend in the initial capacity was not well understood and needs more research. Similar results were also observed in Fe-, Mn-, Mo- and Sn-doped LVP $[120,121,140]$. In addition, $\mathrm{Ti}^{4+}$-doped LVP demonstrated that lithium sites are partially unoccupied. Doped LVP exhibits a superior ionic conductivity of $10^{-5} \mathrm{~S} / \mathrm{cm}$, or three orders of magnitudes higher than LVP $\left(\sim 10^{-8}\right.$ $\mathrm{S} / \mathrm{cm}$ ). The enhanced ionic conductivity derives from the disorder of lithium ions in the host [101].

Second, a new phase with high conductivity is generated in the doped LVP. $\mathrm{Zr}^{4+}$ provides an essential example. $\mathrm{Zr}^{4+}$-doped LVP impregnates a new phase, $\mathrm{LiZr}_{2}\left(\mathrm{PO}_{4}\right)_{3}$ (LZP), on the surface of LVP. NASICON-type LZP is used as Li-ion solid electrolytes due to its excellent Li-ion conductivity $\left(\sim 10^{-5} \mathrm{~S} / \mathrm{cm}\right)$ [86]. Superionic channels form to 
enhance the ionic diffusion in $\mathrm{Zr}$-doped LVP by more than four orders of magnitude compared to pristine $\operatorname{LVP}\left(10^{-9}\right.$ to $\left.10^{-10} \mathrm{~cm}^{2} / \mathrm{s}\right)$ [139]. Generating superionic conductors in LVP has only been found with $\mathrm{Zr}^{4+}$ doping, and insulating phases often appear with other dopants $[84,102]$. One pivotal issue should be pointed out: what makes Zr special? Which element can combine with LVP to produce new phase with high ionic conductivity, and which factor determines this special result?

Third, the host LVP lattice is distorted and the bond strength is tuned when the $\mathrm{V}^{3+}$ site is occupied by foreign cations. This is accompanied with bigger space or superionic channels in the host that facilitate Li-ion transportation and results in an enhanced ionic diffusion coefficient. For example, doped $\mathrm{Mg}^{2+}$ in LVP counteracts the volume change during reversible $\mathrm{Li}^{+}$extraction/insertion and enhances the cycling stability. The expansion of the crystal lattice allows more space for lithium insertion and de-insertion. During the de-insertion process, the lattice is prevented from shrinking by the $\mathrm{Mg}^{2+}$ dopant ions, whose radius is unchangeable [94]. $\mathrm{Tm}^{3+}, \mathrm{Fe}^{2+}$ or $\mathrm{Ti}^{4+}-\mathrm{Fe}^{2+}$ co-doping plays a similar role as $\mathrm{Mg}^{2+}$ in LVP $[102,108,126]$. Replacing $\mathrm{V}^{3+}$ with $\mathrm{Mo}^{6+}$ induces a stronger bond between Mo-O than $\mathrm{V}-\mathrm{O}$, which weakens the interaction between $\mathrm{Li}$ and $\mathrm{O}$, resulting in a higher $\mathrm{Li}^{+}$mobility in $\mathrm{Li}_{3} \mathrm{Mo}_{0.03} \mathrm{~V}_{1.97}\left(\mathrm{PO}_{4}\right)_{3} / \mathrm{C}$ [120]. On the basis of these reports, foreign metallic ions doped at the $\mathrm{V}^{3+}$ site create defects or induces lattice distortions that enhance the electronic and ionic conductivities of LVP, but it is difficult to generate new phases with superior ionic conductivity, except for $\mathrm{Zr}^{4+}$-doped LVP. 

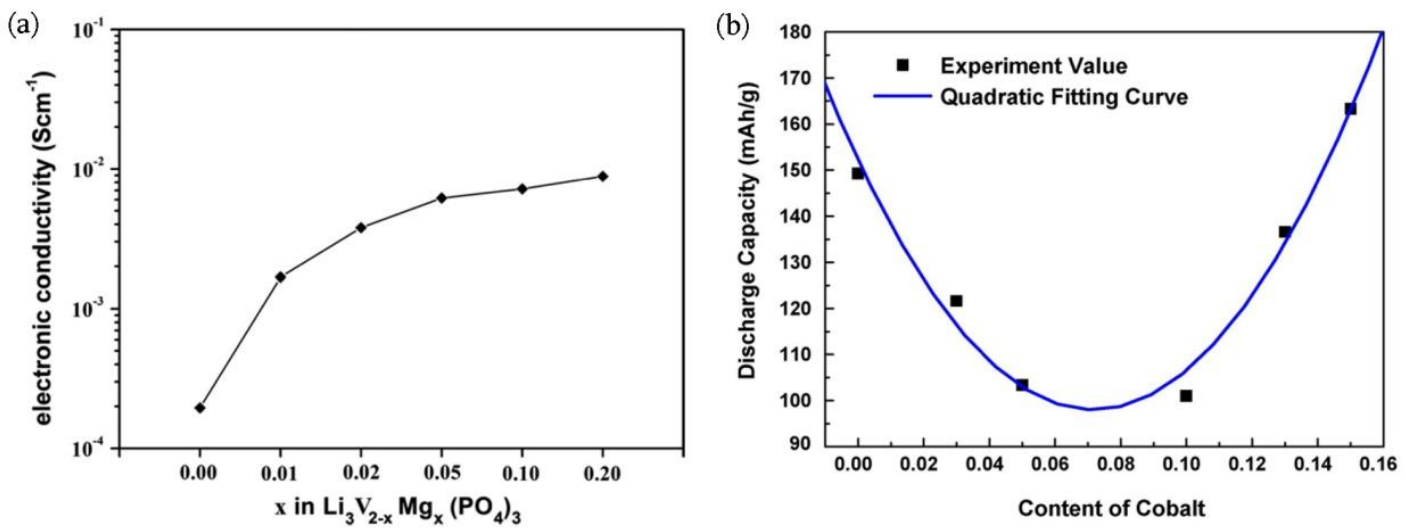

Figure 10. (a) Variation of electronic conductivity of $\mathrm{Li}_{3} \mathrm{~V}_{2-x} \mathrm{Mg}_{x}\left(\mathrm{PO}_{4}\right)_{3}$ samples with increasing $\mathrm{Mg}$ content [84]. (b) The initial discharge capacity of $\mathrm{Li}_{3} \mathrm{~V}_{2-x} \mathrm{Co}_{x}\left(\mathrm{PO}_{4}\right)_{3}(x=0.00,0.03,0.05,0.10$, 0.13 and 0.15 ), and the quadratic fitted curve based on the experimental values [111].

\subsubsection{Mitigating the Growth of LVP Particles and Stabilizing Crystal Structure}

The rate of lithium insertion/extraction increases as the Li transport dimension within the particles is reduced. The characteristic time constant for ionic diffusion is defined by $t=L^{2} / D$, where $L$ is the diffusion length and $D$ the diffusion constant. The time $t$ for ion insertion/extraction varies with the square of the particle size [141]. Thus, controlling the particles size is also a significant aspect in doped LVP. Figure 11 shows the morphologies of LVP and co-doped samples. The samples are comprised of irregular particles with broad particle size distributions. The particle sizes of $\mathrm{Li}_{3} \mathrm{~V}_{1.9} \mathrm{Ti}_{0.05} \mathrm{Fe}_{0.05}\left(\mathrm{PO}_{4}\right)_{3}$ (LVTFP) (Figure 11a) are smaller than for LVP (Figure 11b). A smaller particle size shortens the solid-state diffusion path and enlarges the surface area available for charge transfer reactions; LVTFP delivered a higher capacity than LVP at $10 C$ within the electrochemical window of $3.0-4.8 \mathrm{~V}(\sim 120 \mathrm{mAh} / \mathrm{g}$ vs. $\sim 90$ $\mathrm{mAh} / \mathrm{g}$ ) [102]. It is clear whether the reduction in particle size is solely due to the 
incorporation of dopants. When $\mathrm{Ca}^{2+}$ and $\mathrm{Sc}^{3+}$ ions were incorporated into the LVP lattice, the (020) diffraction peaks shifted to lower angles, indicating expanded lattice parameters and unit cell volume. At the same time, the larger radii of $\mathrm{Ca}^{2+}(1.00 \AA)$ and $\mathrm{Sc}^{3+}(0.73 \AA)$ compared to $\mathrm{V}^{3+}(0.68 \AA)$ help to stabilize the monoclinic structure of LVP. These cations buffer the volume change during charge and discharge [100]. As a result, $\mathrm{Ca}$ - and Sc-doped LVP/C showed an enhanced rate capability than that of the pristine $\mathrm{LVP} / \mathrm{C}$ electrode.

X-ray absorption near edge structure (XANES) spectroscopy was used to examine the oxidation states and local environments of $\mathrm{V}$ in a series of $\mathrm{Zn}$-doped LVP samples. The non-dipole transition from $1 s$ to the $3 d$ state in $\mathrm{V}$ was reflected by the pre-edge feature (Figure 11c) that is sensitive to the vanadium oxidation state and the symmetry [142]. The peak with low energy stems from $\mathrm{V}^{3+}$ with $O_{\mathrm{h}}$ symmetry and the peak at higher energy position originates from $\mathrm{V}$ with higher oxidation states and/or different geometries [143]. The second pre-edge peaks at $5469 \mathrm{eV}$ display the reduced intensities in the Zn-doped samples, suggesting that the less hybridization between $\mathrm{V}$ $3 d$ and $\mathrm{O} p$ orbitals. Therefore, the $\mathrm{V}-\mathrm{O} O_{\mathrm{h}}$ group has a less distortion that may have enhanced the structural stability in LVP/C [115]. Meanwhile, the irreversible volume and $c$-axis expansion were calculated and found to decreases markedly with increasing dopant amount (Figure 11d). For $x=0.15$, the irreversible expansion in the $c$ axis and the unit cell volume increase by only $0.41 \%$ and $0.17 \%$, respectively. This indicated the highest reversibility and agreed well with the displayed cycling performance [115]. The inhibited growth of doped LVP particles may stem from the 
size effect of dopants larger than $\mathrm{V}^{3+}$, such that mass transportation is inhibited and the growth of host particles is suppressed. At the same time volume expansion is buffered by dopants substituted on the $\mathrm{V}^{3+}$ site, and the LVP structure becomes more robust during the process of Li-ion insertion and extraction. As widely reported, the stabilized crystal structure and reduced particles size are beneficial to improve the rate capability of LVP host $[85,108,109,115,118]$. The inhibiting effect on particles size by doping is not conclusive, as material, such as citric acid monohydrate [102], could also impact on particle growth.

(a)

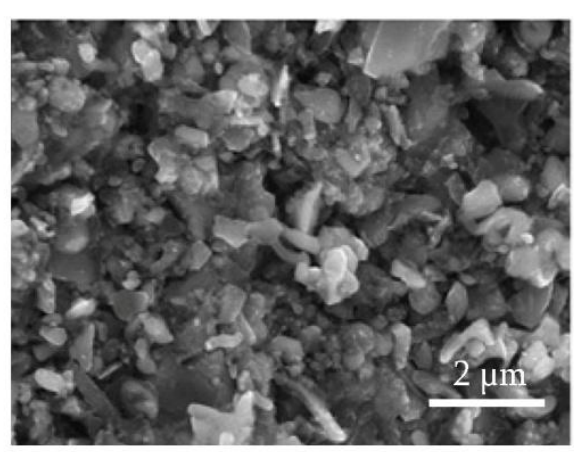

(c)

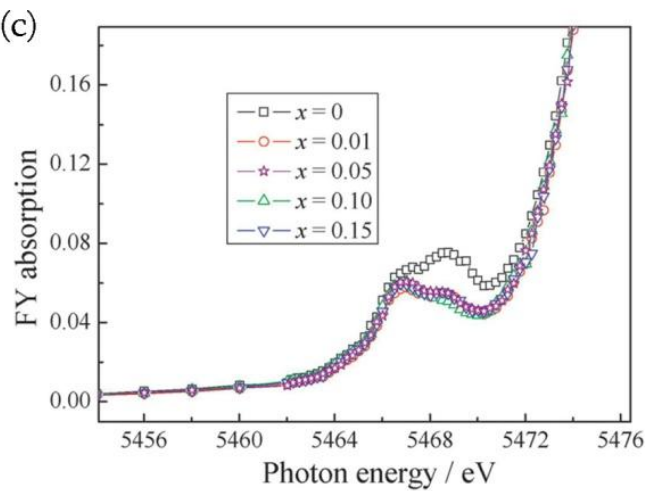

(b)

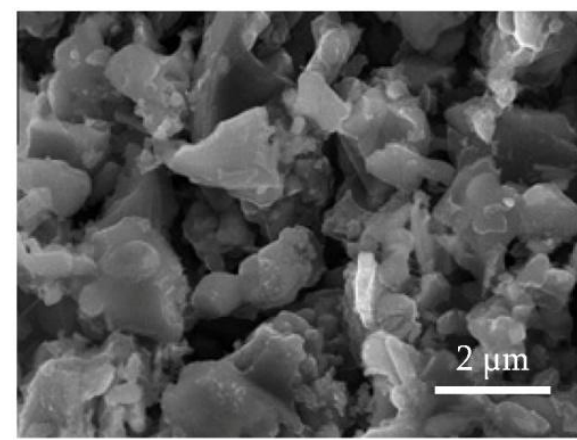

(d)

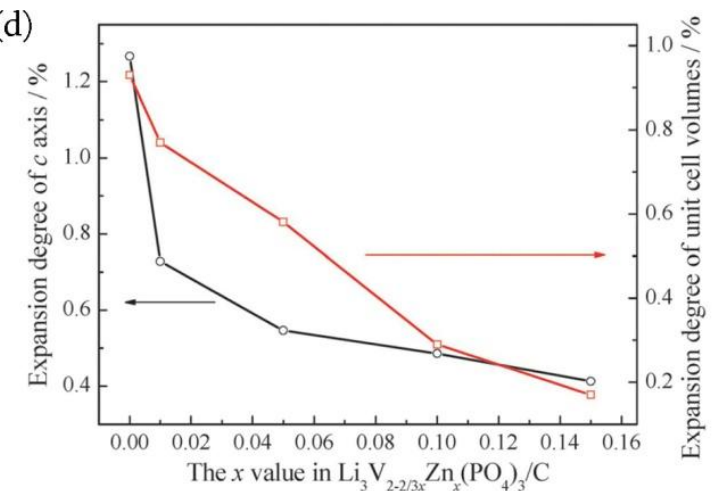

Figure 11. SEM images of (a) $\mathrm{Li}_{3} \mathrm{~V}_{1.9} \mathrm{Ti}_{0.05} \mathrm{Fe}_{0.05}\left(\mathrm{PO}_{4}\right)_{3}$ and (b) LVP [102]. Doped LVP has smaller particle sizes than the pristine LVP. The short diffusion path enhances the rate capability in doped LVP as verified in the original article. (c) The pre-edge features in the XANES spectra of the $\mathrm{Li}_{3} \mathrm{~V}_{2-2 / 3 x} \mathrm{Zn}_{x}\left(\mathrm{PO}_{4}\right)_{3} / \mathrm{C}$ samples and (d)The effect of the amount of zinc doping on the irreversible expansion of the $\mathrm{c}$ axis and the unit cell volume [115]. 


\subsubsection{Enhancing the Specific Capacity and Optimizing the Discharging Curve}

Three plateaus are displayed in the discharge curves of LVP within the electrochemical window of $3.0-4.3 \mathrm{~V}$ as shown in Figure 3. These characteristics derive from phase transitions at different potentials as described in section 1.1. In general, the theoretical capacity of electrode materials corresponds to the number of reactive electrons and the molar weight of the electrode materials as expressed with the following equation [5]:

$$
C_{t}=\frac{n F}{3.6 \times M}
$$

where $n$ is the number of reactive electrons per formula unit, $M$ is the molar weight of materials and $F$ is Faraday constant. On this basis, replacing $\mathrm{V}^{3+}$ with lighter elements increases the theoretical capacity of LVP. For example, $\mathrm{Li}_{3} \mathrm{~V}_{1.50} \mathrm{Al}_{0.50}\left(\mathrm{PO}_{4}\right)_{3}$ achieved a theoretical capacity as high as $203 \mathrm{mAh} / \mathrm{g}$ [83]. Generally, the electrochemical behavior in un-doped LVP can be described with the following reaction:

$$
\mathrm{Li}_{3} \mathrm{~V}_{2}^{3+}\left(\mathrm{PO}_{4}\right)_{3} \Leftrightarrow \mathrm{V}^{5+} \mathrm{V}^{4+}\left(\mathrm{PO}_{4}\right)_{3}+3 \mathrm{Li}^{+}+3 \mathrm{e}^{-}
$$

and corresponds to theoretical capacity of $197 \mathrm{mAh} / \mathrm{g}$. This accompanies a change in the average oxidation state from +3 to +4.5 . If, however, $\mathrm{V}^{3+}$ is partially replaced by $\mathrm{Mg}^{2+}$ to form $\mathrm{Li}_{3} \mathrm{~V}_{5 / 3} \mathrm{Mg}_{1 / 3}\left(\mathrm{PO}_{4}\right)_{3}$, a higher theoretical capacity is possible (202 $\mathrm{mAh} / \mathrm{g}$ ) [84], and the reaction can be described as follows:

$$
\mathrm{Li}_{3} \mathrm{~V}_{5 / 3}^{3+} \mathrm{Mg}_{1 / 3}^{2+}\left(\mathrm{PO}_{4}\right)_{3} \Leftrightarrow \mathrm{V}_{5 / 3}^{5+} \mathrm{Mg}_{1 / 3}^{2+}\left(\mathrm{PO}_{4}\right)_{3}+3 \mathrm{Li}^{+}+3 \mathrm{e}^{-}
$$

where vanadium is oxidized to +5 at the charged state. However, it is difficult to realize the goal because most foreign ions are electrochemically inactive $[115,118]$, which reduces the number of charges from $\mathrm{V}$ and thus reduces the number of removable $\mathrm{Li}$ ions in practice. Figure 12a shows the theoretical and practical capacities in $\mathrm{Li}_{3} \mathrm{~V}_{2-2 x} \mathrm{Ti}_{x} \mathrm{Mg}_{x}\left(\mathrm{PO}_{4}\right)_{3}$. As the titanium content increases, the difference 
between the theoretical and observed capacities becomes larger. Obviously, Ti and Mg co-doping has a negative effect on the capacity, which is attributed to decreasing small concentration of $\mathrm{V}^{3+}$. Further,as the dopant concentration increases, so does the voltage hysteresis [85]. However, $\mathrm{Ti}$ and $\mathrm{Mg}$ co-doping in LVP leads to excellent cycling stability at a high rate of $2 C$ (Figure 12b). By contrasting the XRD spectra before and after cycling, it is found that the cycled LVP $(x=0)$ cathode has the lowest and broadest peaks, but Ti and Mg co-doped cathodes displayed sharper and narrower patterns that indicates the foreign atoms relieved the structural change during the long-term cycling tests.

As discussed in section 3.1, replacements on Li site induce phase transitions from monoclinic to rhombohedral, which causes the plateaus in the voltage curves to gradually overlap and become indistinguishable with the change of phase components $[133,144]$. The same phenomenon was observed for atomic substitutions on V-site in LVP, as in the cases of Nb- [118] and Cr- [103] doped LVP. As seen in Figure 12c, the boundary of two plateaus presents near $3.5 \mathrm{~V}$ in LVP, but disappears with increasing $\mathrm{Nb}$ content. This characteristic is in accord with results obtained for $\mathrm{Zr}$ [139] and Ti- [85,101] doped LVP. Besides, the maximum specific capacity was achieved in the sample with $3 \% \mathrm{Nb}, 181.5 \mathrm{mAh} / \mathrm{g}$. This was higher than the capacity of LVP/C $(170.7 \mathrm{mAh} / \mathrm{g})$, obtained at $0.1 C$ in the potential range of $3.0-4.8 \mathrm{~V}$. Although the radius of $\mathrm{Nb}^{5+}$ is the same as that of $\mathrm{V}^{3+}$ with a six-fold coordination, the unit cell volume increases when $\mathrm{Nb}$ is incorporated. It is concluded that $\mathrm{Li}$ or $\mathrm{V}$ 
vacancies are introduced to achieve electroneutrality and also lead to the expansion of cell volume [82]. The expansion in the cell volume accelerates the Li ion diffusion to enhance the rate capability remarkably as shown in Figure $12 \mathrm{~d}$. At the same time a new phase $\beta-\mathrm{NbOPO}_{4}[118]$ formed in the final product is also believed as another factor for contributing to the improvements of capacity, rate capability and cycling performance. The magnetic and electrochemical properties were studied simultaneously in Nd-doped LVP, and the results demonstrated that magnetic susceptibility increases with the content of $\mathrm{Nd}$ in doped samples and the enhanced electrochemical properties derive from the expansion of lattice volume [119]. However, it is a pity that the relationship between the magnetic and electrochemical performances was not elucidated, albeit both properties were investigated in one work. Besides, the optimal composition is $\mathrm{Li}_{3} \mathrm{~V}_{1.95} \mathrm{Nb}_{0.05}\left(\mathrm{PO}_{4}\right)_{3}$ that differs from the results of $\mathrm{Li}_{3} \mathrm{~V}_{1.85} \mathrm{Nb}_{0.15}\left(\mathrm{PO}_{4}\right)_{3}$ in a previous work [82]. The impurity occurred at different $\mathrm{Nb}$ content in both studies, though the impurity was considered as the deteriorating factor to the electrochemical performances consentaneously. 

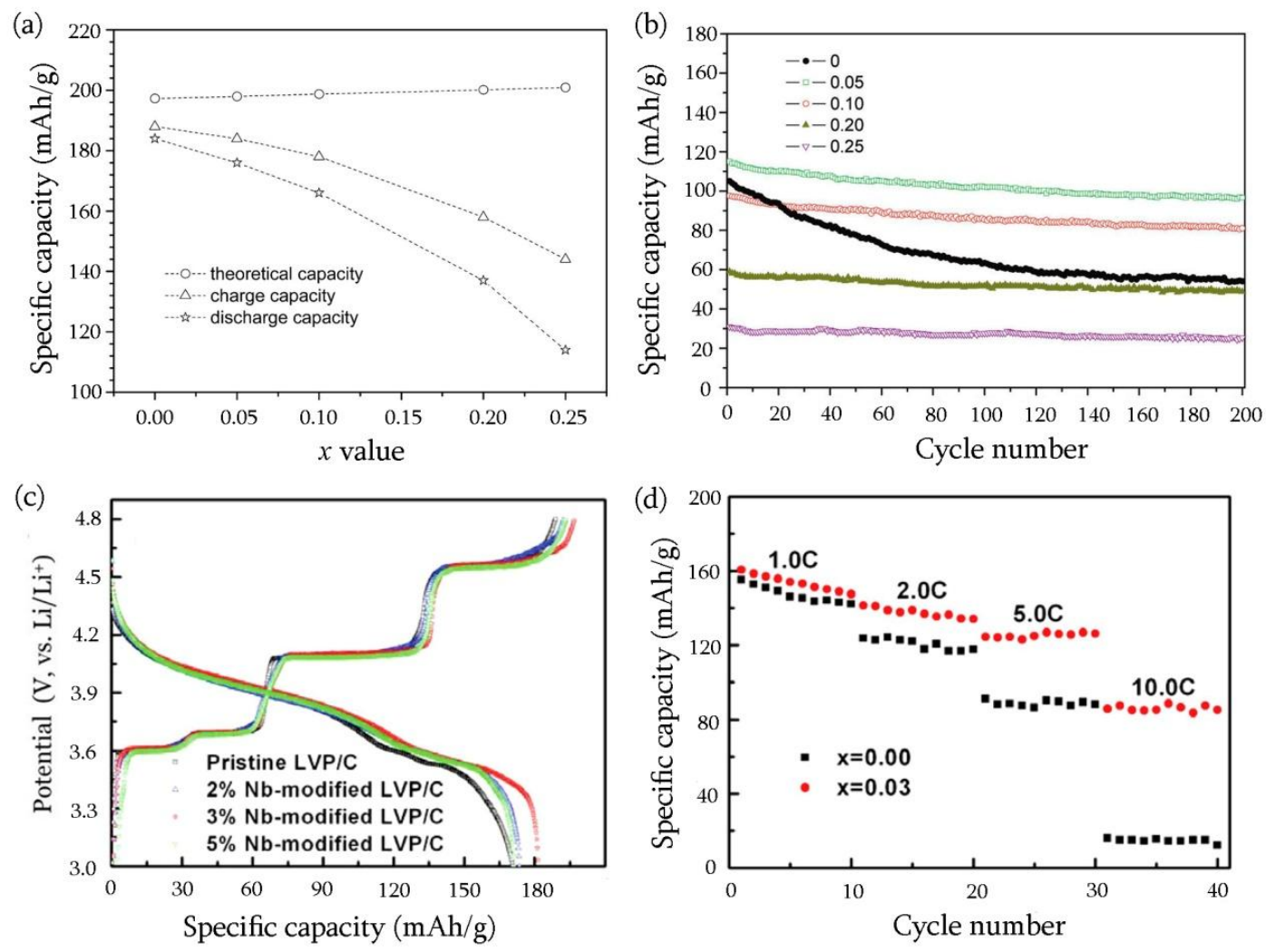

Figure 12. (a) First charge and discharge capacities compared to the theoretical capacity (based on the extraction of three lithium ions per formula unit) of the $\mathrm{Li}_{3} \mathrm{~V}_{2-2 x} \mathrm{Ti}_{x} \mathrm{Mg}_{x}\left(\mathrm{PO}_{4}\right)_{3}(x=0,0.05,0.1$, $0.2,0.25)$ samples at $0.2 C$ and (b) Long-term cycling performance of the $\mathrm{Li}_{3} \mathrm{~V}_{2-2 x} \mathrm{Ti}_{x} \mathrm{Mg}_{x}\left(\mathrm{PO}_{4}\right)_{3}(x$ $=0,0.05,0.1,0.2$, and 0.25 ) samples at the current densities of $2 C$ in the voltage of 3.0-4.8 V [85]. (c) The initial charge/discharge profiles of Nb-doped LVP and (d) cyclic performance of pristine and $\mathrm{Nb}$-incorporated LVP/C $(x=0.03)$ electrodes at $C$-rates varying from 1 to $10 C$ after ten cycles at each rate [118].

In addition to bulk defects, Fe-doped LVP not only creates defects that increase the number of $\mathrm{Li}$ ions in unit cell, but also forms a new phase on the surface of host that protects against side reactions between the electrode and electrolyte. First, the atomic radius for $\mathrm{Fe}^{2+}(75 \mathrm{pm})$ is close to that of $\mathrm{V}^{3+}(78 \mathrm{pm})$ so it is easy for $\mathrm{Fe}^{2+}$ to form $\mathrm{FeO}_{6}$ octahedra. Thus, it is reasonable to believe that $\mathrm{Fe}^{2+}$ can be doped at the $\mathrm{V}$-site in the LVP lattice. Considering the stability of $\mathrm{PO}_{4}$ tetrahedra, it is difficult to form an oxygen vacancy, so instead $\mathrm{Li}_{1+x} \mathrm{~V}_{2-y} \mathrm{Fe}_{y}\left(\mathrm{PO}_{4}\right)_{3}$ is formed to maintain the charge 
balance [109]. The increasing number of Li-ion sites increases the specific capacity in the host, but $\mathrm{Fe}$ has a heavier atomic weight that counteracts this positive effect. Secondly, Fe-doped LVP prefers to form $\mathrm{LiFePO}_{4}$ when the Fe content reaches its solubility limit in the LVP host lattice. During the charging process, Li ions are extracted and $\mathrm{Fe}$ is exposed on the surface. The $\mathrm{LiFePO}_{4}$ phase then becomes an amorphous $\mathrm{FePO}_{4}$ phase, which acts as a passivation layer to protect against oxidation of the electrolyte at high voltages [109]. The enhanced stability and reduced polarization at the particle surface benefit to improve the electrochemical performance of the host material. At the same time, incorporating Fe into the LVP lattice stabilizes the crystal structure during the Li ion extraction and insertion [104]. Based on the results of V-site substitution, three effects were observed and the electrochemical performances were enhanced in LVP as described above. In particular, $\mathrm{Zr}$ - and Nb-doped LVP produced new phases that have the positive effects, but the corresponding mechanisms are not clear. Great efforts are needed to explore the scientific foundations on the improvements and understand which element can induce the similar effects.

\subsection{Doping on $\left(\mathrm{PO}_{4}{ }^{3-}\right)$ Site}

Beyond cation doping on $\mathrm{Li}^{+}$or $\mathrm{V}^{3+}$ sites, anionic doping on the phosphate anion, such as with $\mathrm{F}^{-}[127]$ and $\mathrm{Cl}^{-}[99,128-130]$, is also an effective way to improve the electrochemical performance of LVP. Subjected to F-doped LVP, the electronic conductivity of $\mathrm{Li}_{3} \mathrm{~V}_{2}\left(\mathrm{PO}_{4}\right)_{2.9} \mathrm{~F}_{0.1}$ reaches $7.2 \times 10^{-6} \mathrm{~S} / \mathrm{cm}$, which is two orders 
magnitude higher than the conductivity of LVP $\left(3.7 \times 10^{-8} \mathrm{~S} / \mathrm{cm}\right)$ [127]. The substitution induces greater semiconductivity in LVP. Figure 13 a-b shows the discharge capacity and rate capability of F-doped LVP. The samples containing F ions delivered a higher capacity compared with that of LVP, and the highest capacity was observed for $\mathrm{Li}_{3} \mathrm{~V}_{2}\left(\mathrm{PO}_{4}\right)_{2.9} \mathrm{~F}_{0.1}$. In general, lithium ion insertion and extraction in LVP electrodes is accompanied by electron transfer not only on the particle surface but also inside the crystals. Thus, the enhanced electrical conductivity is helpful to modify the rate capability. Figure $13 \mathrm{~b}$ demonstrates that introduction of $\mathrm{F}$ ions at phosphate groups endows LVP with improved cyclability at $5 C . \mathrm{Li}_{3} \mathrm{~V}_{2}\left(\mathrm{PO}_{4}\right)_{2.9} \mathrm{~F}_{0.1}$ shows the best capacity retention of $93.6 \%$ after 30 cycles [127]. The similar results were also observed in Cl-doped LVP. With the increase of $\mathrm{Cl}^{-}$content, the specific discharge capacities of the materials increases and the highest value of $127.3 \mathrm{mAh} / \mathrm{g}$ is obtained for $x=0.12$ (Figure 13c). Compared with the profile of pristine LVP/C, the charge-discharge curves of $\mathrm{Li}_{3} \mathrm{~V}_{2}\left(\mathrm{PO}_{4}\right)_{2.88} \mathrm{Cl}_{0.12} / \mathrm{C}$ present the little longer and sloping profiles that may be attributed to the inductive effect of the stronger electronegative $\mathrm{Cl}^{-}$ion [130]. The substitution of the more electronegative $\mathrm{Cl}^{-}$ion for $\mathrm{PO}_{4}{ }^{3-}$ may decrease the Li-O bond energy and leads to easier extraction of lithium ions. The Li-ion diffusion coefficient calculated from electrochemical impedance spectroscopy (EIS) supports the explanation above, because $\mathrm{Li}_{3} \mathrm{~V}_{2}\left(\mathrm{PO}_{4}\right)_{2.88} \mathrm{Cl}_{0.12} / \mathrm{C}$ possesses the highest coefficient of $5.78 \times 10^{-10} \mathrm{~cm}^{2} / \mathrm{s}$ in the series of samples [130]. At the same time this sample delivered the highest discharge capacity of $123.8 \mathrm{mAh} / \mathrm{g}$ and only faded to $122.2 \mathrm{mAh} / \mathrm{g}(98.7 \%$ retention) after 50 cycles. Moreover, a capacity of 
113.6 $\mathrm{mAh} / \mathrm{g}$ was obtained after 80 cycles at $5 C$ rate, corresponding to $90.3 \%$ capacity retention. In comparison, the pristine LVP/C only achieved a capacity of $105.11 \mathrm{mAh} / \mathrm{g}$ after 80 cycles. When the rate was up to $8 C$, the capacities of the pristine $\mathrm{LVP} / \mathrm{C}$ and $\mathrm{Li}_{3} \mathrm{~V}_{2}\left(\mathrm{PO}_{4}\right)_{2.88} \mathrm{Cl}_{0.12} / \mathrm{C}$ after 80 cycles were found to be 90.6 and $107 \mathrm{mAh} / \mathrm{g}$, respectively (Figure 13d). The 10th charge-discharge curves of $\mathrm{Li}_{3} \mathrm{~V}_{2}\left(\mathrm{PO}_{4}\right)_{2.88} \mathrm{Cl}_{0.12} / \mathrm{C}$ at $5 \mathrm{C}$ and $8 \mathrm{C}$ is given in the inset of Figure 13d. A slight voltage polarization between the charge-discharge plateaus of $\mathrm{Li}_{3} \mathrm{~V}_{2}\left(\mathrm{PO}_{4}\right)_{2.88} \mathrm{Cl}_{0.12} / \mathrm{C}$ is observed as the rate increases but is mitigated by the reduced polarization within the host and faster lithium ion diffusion rate. More importantly, $\mathrm{Cl}^{-}$substitution in NASICON-type LVP also presented excellent performance under harsh conditions of $15 C$ rate and high temperature of $50{ }^{\circ} \mathrm{C}$ [99].

Anionic doping differs from cationic substitution, assuming that one phosphate group is replaced by three $\mathrm{F}^{-}$or $\mathrm{Cl}^{-}$ions, one oxygen vacancy must be created, at the same time there is no cation between anions, which could induce a strong electrostatic repulsion. Thus, what are the real chemical states between the groups or ions, and how does it affect the electrochemical performances in electrode materials? 

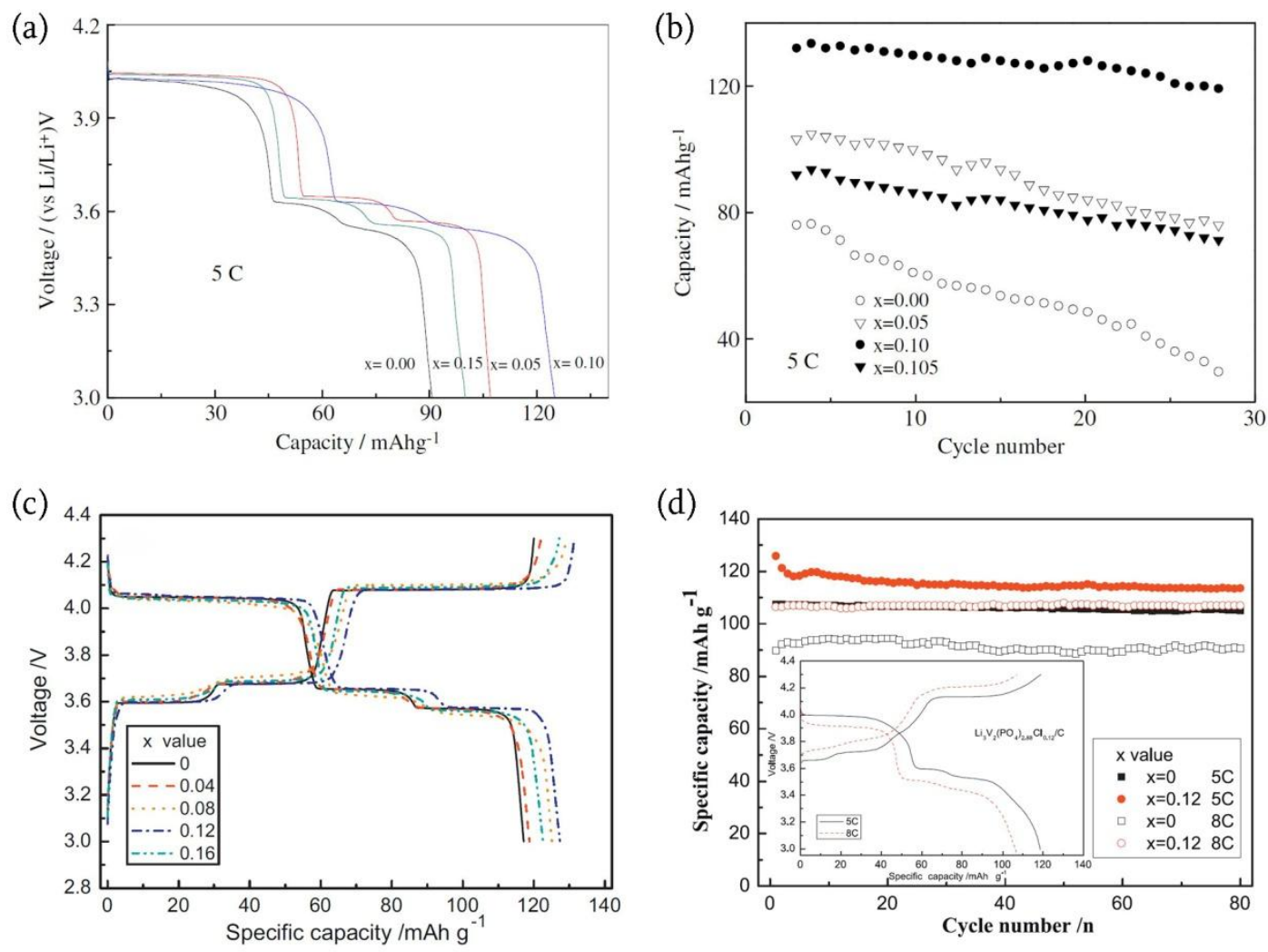

Figure 13. (a) The first discharge curves and (b) cycling performance of $\mathrm{Li}_{3} \mathrm{~V}_{2}\left(\mathrm{PO}_{4}\right)_{3-x} \mathrm{~F}_{x}(x=0.00$ - 0.15) at $5 C$ discharge rate [127]. (c) The initial charge-discharge curves of the $\mathrm{Li}_{3} \mathrm{~V}_{2}\left(\mathrm{PO}_{4}\right)_{3-x} \mathrm{Cl}_{x} / \mathrm{C}(x=0.00,0.04,0.08,0.12$ and 0.16$)$ at $0.2 C$ rate, and (d) The cycling performance of the pristine $\mathrm{LVP} / \mathrm{C}$ and $\mathrm{Li}_{3} \mathrm{~V}_{2}\left(\mathrm{PO}_{4}\right)_{2.88} \mathrm{Cl}_{0.12} / \mathrm{C}$ at high rates of 5 and $8 C$ (inset is the 10th charge-discharge profiles of $\mathrm{Li}_{3} \mathrm{~V}_{2}\left(\mathrm{PO}_{4}\right)_{2.88} \mathrm{Cl}_{0.12} / \mathrm{C}$ at 5 and 8 C) [130].

To briefly summarize, cationic or anionic doping of LVP induces defects in the host lattice and strength the crystal framework by enhancing the electrical and ionic conductivity and stabilizing the crystal structure in the charge/ discharge process of LVP. In particular, foreign atoms with a larger radius can expand the cell volume to facilitate Li-ion migration, which notably enhances the electrochemical performances of the LVP host, especially at high current rates (Table 3). The change in the charge/discharge curves provides a clue for understanding the voltage-composition mechanism in electrode materials, which is helpful to guide to the design and 
exploration of new materials with specific potential or potential plateau requirements. There are many questions needed to be explored, such as where does the doped ions occupy, and what are the determining factors that affect the electrochemical properties in doped materials?

\section{Composites Based on $\mathrm{Li}_{3} \mathrm{~V}_{2}\left(\mathrm{PO}_{4}\right)_{3}$}

Composites draw upon the strong points of a variety of materials to offset the individual weaknesses of any one material. As mentioned above, LVP has a three-dimensional path for Li-ion diffusion, but has poor electronic conductivity that originates from the separated $\mathrm{VO}_{6}$ octahedra. Thus, choosing conductive materials to compensate the disadvantages of LVP or combining the outstanding ionic conductivity of LVP with other high capacity compounds are two approaches to develop high-performance composites. Composites of LVP can be divided into five types: (1) carbon-coated LVP [70,145-160], (2) LVP combined with electrode materials, such as $\mathrm{LiFePO}_{4}$ [161-185], $\mathrm{LiVOPO}_{4}$ [186-188], $\mathrm{Li}_{4} \mathrm{Ti}_{5} \mathrm{O}_{12}$ [189], $\mathrm{LiMnPO}_{4}$ [190-193] and $\mathrm{LiCoO}_{2}$ [194]. (3) LVP with metals, for example, Ag [195,196] and $\mathrm{Cu}$ [197]. (4) LVP with conducting polymers [198-200], and (5) LVP with oxides, such as $\mathrm{SiO}_{2}$ [201], $\mathrm{MgO}$ [202] and $\mathrm{RuO}_{2}$ [203]. Among those composites, carbon coated LVP dominates this field because carbon possesses excellent electronic conductivity and low cost.

\subsection{LVP and Carbon Composites}


Carbon coatings possess excellent electronic conductivity which compensates for the inferior conductivity of all electrode materials in batteries. Coating carbon on the surface of electrode materials has been extensively adopted to enhance the electrical conductivities in electrode materials, especially transition metal oxides and polyanionic compounds (phosphates, silicates, sulfates). In view of the drawbacks of LVP, carbon derived from different sources is applied to enhance the comprehensive performance of LVP, especially the electronic conductivity. Besides, carbon coatings can hinder the growth of LVP grains, which correspondingly limits the distance for ion migration. Based on both effects, the following descriptions will be extended for amorphous carbon, carbon nanotubes or fibers and graphene.

Amorphous carbon coatings are introduced by simple and facile approaches on the surface of LVP particles. For example, carbon sources, such as glucose [204], polyvinyl alcohol (PVA) [148], stearic acid [147], glycine [205] or polyvinylpyrrolidone (PVP) [206] were added into the reactive solutions to generate carbon precursors on particle surfaces and the following heating treatment transformed the carbon precursors to the carbon coating that offer an electronic pathway between particles. In addition, carbon doped with heteroatoms provides a new feature to explore LVP matrix composites $[154,159]$. This section focuses on the effects of the carbon source and content on the electrochemical performance of LVP.

In most cases, carbon sources are added into the precursors before the final treatment 
during the synthesis process. For example, polyethylene glycol (PEG) was adopted as carbon source before a solid-state reaction to synthesize the LVP/C composite. Figure 14a shows the carbon coating is well-dispersed and covered the LVP particles, but also connects the particles and provides an electrical contact for electron transfer. The electronic conductivity of the LVP/C composite is $7.0 \times 10^{-1} \mathrm{~S} / \mathrm{cm}$, an increase of seven orders of magnitude compared with pristine LVP $\left(2.3 \times 10^{-8} \mathrm{~S} / \mathrm{cm}\right)$ [207]. Similar work studied PVA carbon coatings. The LVP composite obtained with this source possessed a higher electrical conductivity of $3.0 \times 10^{-1} \mathrm{~S} / \mathrm{cm}$, and the sample presents a high discharge capacity of $125.3 \mathrm{mAh} / \mathrm{g}$ at a low discharge rate of $0.3 C$, almost achieving the theoretical capacity $(133 \mathrm{mAh} / \mathrm{g})$ for the reversible cycling of two lithium ions [148]. In contrast, pristine LVP presents a capacity of only $83.7 \mathrm{mAh} / \mathrm{g}$ (Figure 14b). At a high rate of 5 , the capacity of the LVP/C composite remains almost constant over hundreds of cycles and decays slightly after the 1000th cycle, as shown in Figure 14c. The capacity still maintains $94.1 \mathrm{mAh} / \mathrm{g}$ after 2000 cycles, retaining approximately $90 \%$ of the initial capacity, indicating that high electrical conductivity improves the specific capacity and cycling stability in LVP. Similarly, a nanostructured LVP/C composite was successfully prepared by incorporating the precursor solution into a highly mesoporous carbon with an expanded pore structure. In the resulting composite, LVP was dispersed in the carbon matrix and particle sizes were around $50 \mathrm{~nm}$ (Figure 14d). More importantly, the composite delivered a reversible capacity of $122 \mathrm{mAh} / \mathrm{g}$ at $1 C$ and maintained a specific discharge capacity of $83 \mathrm{mAh} / \mathrm{g}$ at $32 \mathrm{C}$ within a voltage range of 3.0 to $4.3 \mathrm{~V}$ 
[39] (Figure 14e). Beyond the superior cycling stability and rate capacity, carbon-coated LVP also displayed an excellent performance at high temperature. Figure 14f shows the cyclic performance of the LVP electrode under different conditions within the voltage range of 3.0-4.3 V. During the electrochemical cycling, the sample displays a larger reversible capacity under the condition of smaller rate and higher temperature, i.e., it provides the largest reversible capacity in all 50 cycles at $0.1 C$ and at $55{ }^{\circ} \mathrm{C}$. The electrode presents similar capacity retention rates ( $\geqq 97 \%$ ) at 25 and $55{ }^{\circ} \mathrm{C}$ at relatively lower rates $(0.1$ and $1 \mathrm{C})$, and the corresponding retention rates at 25 and $55{ }^{\circ} \mathrm{C}$ at $2 C$ are $91 \%$ and $95 \%$, respectively[208]. These results demonstrate that the inherent structural characteristics of monoclinic LVP and the high electrical conductivity in the carbon coating are responsible for the excellent electrochemical cycling stability and shows great potential for use in high-power Li-ion batteries. 
(a)

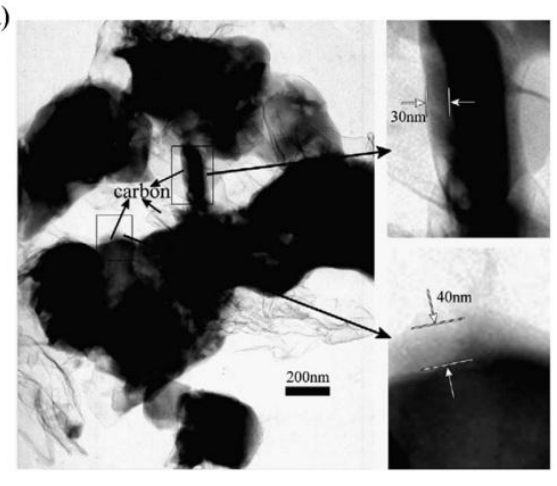

(c)
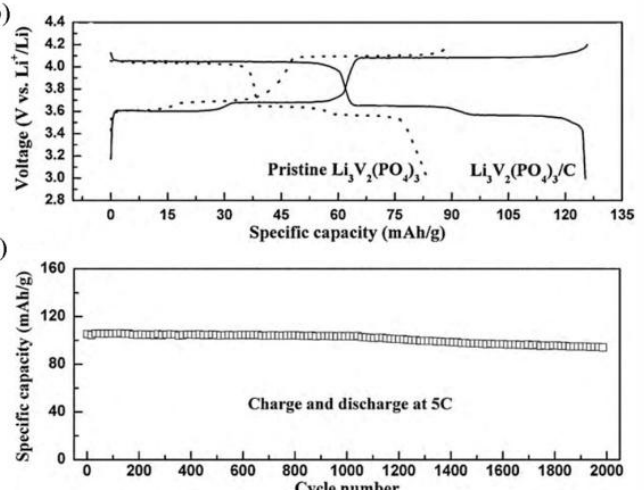
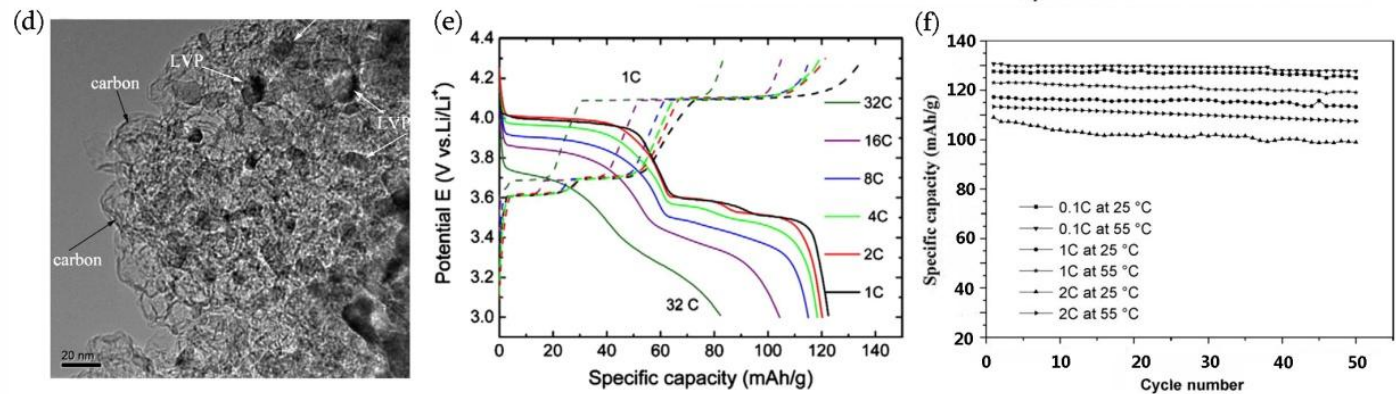

Figure 14. (a) TEM image of the LVP/C composite [207]. (b) The initial charge/discharge curves of the pristine LVP and LVP/C composite and (c) cyclic performance of LVP/C composite at $5 C$ in the potential window of 3.0-4.2 V [148]. (d) TEM images of the as-prepared LVP/C composite sample and (e) Discharge/charge curves of the LVP/C composite material at various discharge rates [39]. (f) Cyclic performance of the carbon coated LVP sample at different conditions in the voltage range of 3.0-4.3 $\mathrm{V}$ [208].

The sources and content of carbon affect the degree of graphitization and coverage rate on LVP particles surface. Both of them determine the continuity of electrons pathway that affect the cycling stability and rate capability of electrode materials. Figure 15a-b exhibits the differences from carbon source and content. Citric acid, glucose, PVDF and starch were used as carbon sources to synthesize the LVP/C composites, and the weight loss on the thermogravimetry (TG) curves (Figure 15a) indicates the percent carbon content in LVP/C composites is $1.3 \%, 13.3 \%, 12.7 \%$ and $10.5 \%$, respectively. The sample using citric acid as the carbon source has the lowest carbon content because the carboxyl groups in citric acid decompose to give 
off $\mathrm{CO}_{2}$ instead of contributing to residual carbon during the heat treatment process. The direct current (DC) resistances in a series of composites cells was measured as a function of potential (3.0-4.3 V) with a simultaneous current interruption method during the second cycle (Figure 15b). Three minimum resistance values appear around $3.55,3.65,4.05 \mathrm{~V}$ during the discharge process which is in accord with the three discharge plateaus in the voltage range from 3.0 to $4.3 \mathrm{~V}$. The resistances between two neighboring minimums are remarkably higher, which corresponds to the phase transition processes. Among all composites, the glucose sample displays the highest minimum resistance values, which causes the poorest rate performance. Although the citric acid sample has the lowest carbon content, it delivered the largest reversible capacity of $118 \mathrm{mAh} / \mathrm{g}$ with no capacity fading during 100 cycles at a rate of $0.2 C$ [209]. Based on the results from different carbon sources, the effect from the carbon content was investigated carefully by the same group [210]. Maltose was adopted as carbon source and samples with varied carbon content were synthesized. As shown in Figure 15c, an amorphous carbon layer covered the surface of LVP with a thickness of 3-4 nm. DC resistance measurements were also performed and the results are shown in Figure 15d. A similar resistance trend can be observed in the potential window of $3.0-4.3 \mathrm{~V}$ as introduced in Figure $15 \mathrm{~b}$, indicating that this simultaneous DC resistance measurement is very sensitive to the structural change of the electrode. The sample with $11.6 w t . \%$ carbon content displays the lowest resistance among the composites during the discharge process. When the cycling performance was tested at $0.5 C$, the sample with $5.7 \mathrm{wt} . \%$ carbon content delivered a 
discharge capacity of $128.4 \mathrm{mAh} / \mathrm{g}$ in the first cycle, but it decreased rapidly to 83.8 $\mathrm{mAh} / \mathrm{g}$ at the 50th-cycle (Figure 15e) [210]. However, excellent cycling performances are achieved with almost no capacity fading in the other three samples. These results imply that the carbon content must exceed a threshold value for ensuring continuous and complete conductive networking within the electrode. During the measurements of rate capability, the sample with $11.6 w t . \%$ carbon content exhibits the best rate capability and its discharge capacity slightly decreases by $7.2 \%$ from $125 \mathrm{mAh} / \mathrm{g}$ at $0.5 C$ to $116 \mathrm{mAh} / \mathrm{g}$ at $5 C$; a capacity of $82 \mathrm{mAh} / \mathrm{g}$ can be still obtained even at $10 C$. When the carbon content is increased to $15.3 \%$, however, the sample displays relatively poor rate performance because the carbon layer becomes too thick and impedes the diffusion of lithium ions. To compromise the electronic and ionic conductivities, an optimal carbon content of $\sim 11.6 w t . \%$, shows the best comprehensive performance in LVP/C electrodes[210]. In addition, biomass materials are used as carbon sources to load LVP active particles for improving its electrochemical performance. Zhang and coworkers reviewed the corresponding details carefully [211]. 
(a)

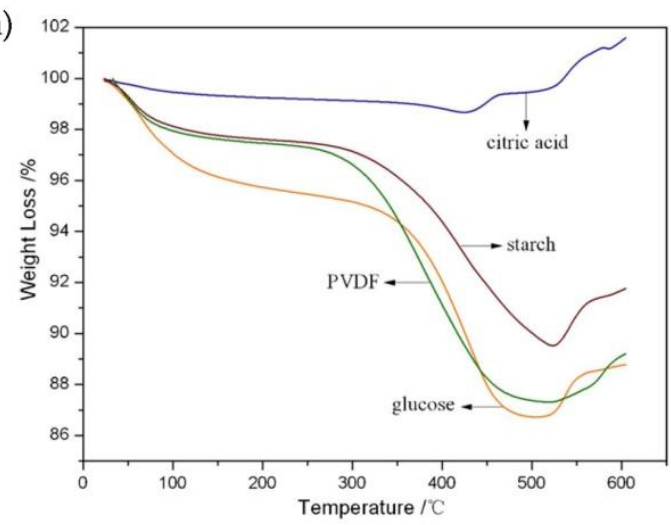

(c)

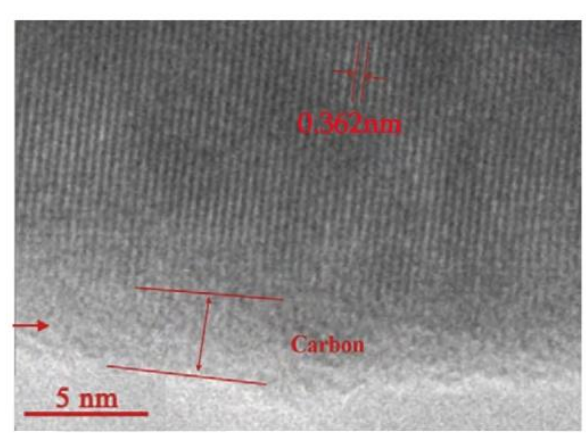

(e),

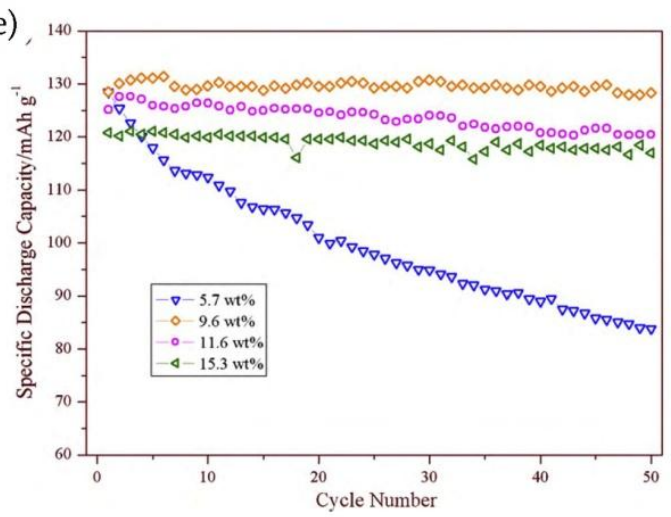

(b)

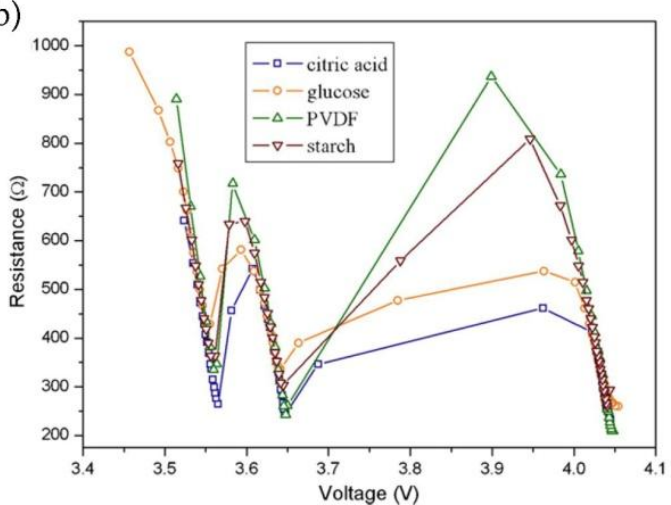

(d)

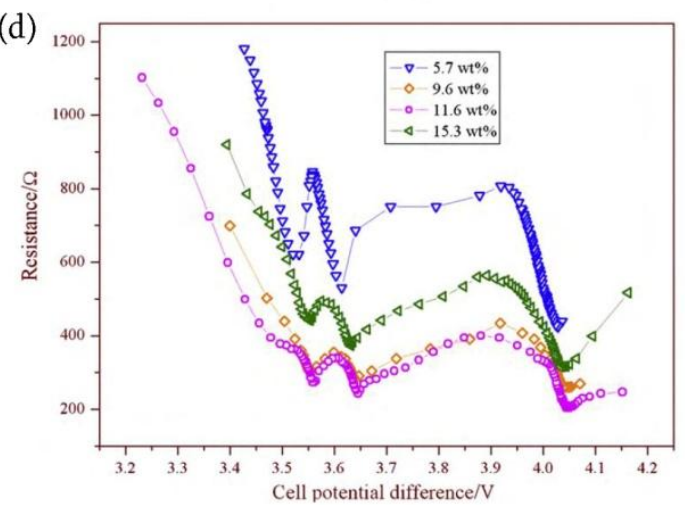

(f)

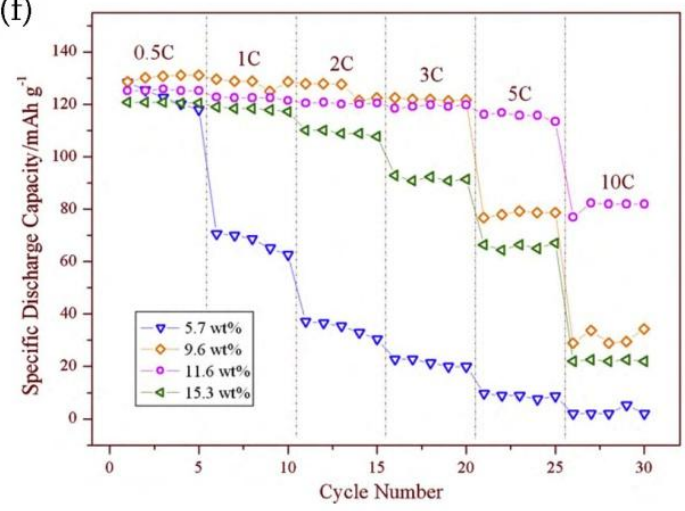

Figure 15. (a) TG curves of LVP/C composites synthesized with different carbon sources. (b) The DC resistance of the carbon-coated LVP/Li cells as a function of voltage (3.0-4.3 V) measured with a simultaneous current interruption method in the 2nd discharge process [209]. (c) HRTEM of LVP samples with $15.3 \mathrm{wt}$ \% carbon. (d) DC resistances of four samples with varied carbon content. (e) Cycling performance at the $0.5 C$ rate. (e) Rate capability of LVP/C samples with various carbon contents in the voltage range of 3.0-4.3 V [210].

Heteratom-doped carbon has very high electrical conductivity and functions as a coating layer on LVP that enhances the electrochemical performance $[154,159]$. Thus, choosing a reliable additive as the carbon source produces several positive effects on the host materials. For example, ionic liquids not only serve as soft templates to direct 
the morphology of product, but also work as excellent carbon precursors to build fast electron pathways after heat treatment [159]. Figure 16a illustrates the microstructure of carbon-coated LVP derived from a protic ionic liquid- (PIL) assisted solution reaction. LVP nanocrystals embedded in the $\mathrm{N}$ and $\mathrm{S}$ co-doped carbon matrix have a porous structure that favors the penetration of the electrolyte and charge transfer processes. The electronic conductivity of the LVP/C sample is in the range of $10^{-3}-10^{-2} \mathrm{~S} / \mathrm{cm}$, and higher than bare LVP $\left(10^{-6} \mathrm{~S} / \mathrm{cm}\right)$ in the same conditions [159]. Besides, the rate capability further supports the expected design. The sample delivers a specific capacity of $131 \mathrm{mAh} / \mathrm{g}$ at $1 \mathrm{C}$, which is very close to the theoretical capacity of $133 \mathrm{mAh} / \mathrm{g}$ within the potential range of $3.0-4.3 \mathrm{~V}$. When the rate increases to $10 C$, it has a specific capacity of $125 \mathrm{mAh} / \mathrm{g}$. At $100 C$, the electrode still achieves a capacity of $100 \mathrm{mAh} / \mathrm{g}$, which corresponds to $75 \%$ of the theoretical capacity (Figure 16b). The cycling performance is carried out at various C-rates and the results are shown in Figure 16c. The sample maintains the initial capacity over 100 cycles, and shows excellent cycling stability even after 2500 cycles at $50 C$. The results described above indicate that the ionic liquid-assisted reaction generates an $\mathrm{N}$ and $\mathrm{S}$ co-doped carbon matrix that encapsulates LVP, which in turn provides excellent rate capability and cycling stability because of the excellent electronic conductivity in the coating layer. In another work, benzyl disulfide $\left(\mathrm{C}_{14} \mathrm{H}_{14} \mathrm{~S}_{2}\right)$ is adopted as an additive to provide sulfur. When $\mathrm{S}$ is doped in the carbon matrix, sulfur is prone to occupy the edge and the defective sites of the carbon net as illustrated in Figure 16d. In other words, S-doping will produce defects in the carbon layer. The 
electronic conductivity of the LVP/C-S11.1\% powder that has a sulfur percentage of $11.1 \%$ reaches up to $2.083 \mathrm{~S} / \mathrm{cm}$, which is higher than all results mentioned above, indicating the strong positive effect S-doping has on the electric conductivity of the carbon-coated layer. Compared with bare LVP/C, sulfur-doped carbon-coated LVP exhibits an amazing electrochemical performance, especially with regard to the cyclic capability and rate stability (Figure 16e-f). For instance, when the discharge rate was increased from $0.5 C$ to $50 C$, the capacity of LVP/C-S11.1\% only decayed from $122.1 \mathrm{mAh} / \mathrm{g}$ to $106.4 \mathrm{mAh} / \mathrm{g}$, indicating an outstanding capacity retention of $87 \%$ [154]. It can be concluded that heteroatoms modulate the band gap and affect defective sites in carbon materials. The electronic difference between $\mathrm{S}$ and $\mathrm{C}$ in the matrix increases the electronic conductivity. The high electronic conductivity in carbon coating endows LVP with excellent rate capability and cycling stability, which provides a tool to modify and design electrode materials.
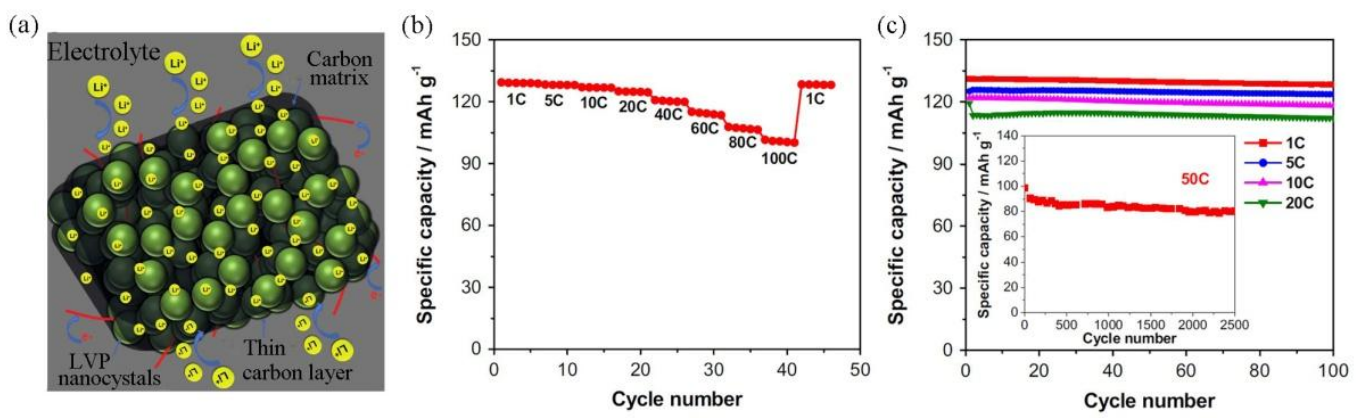

(d)

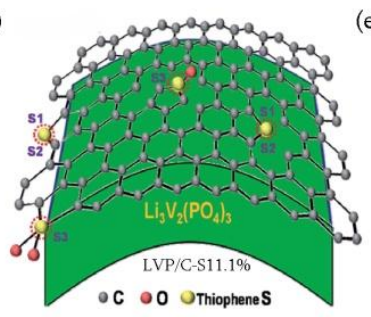

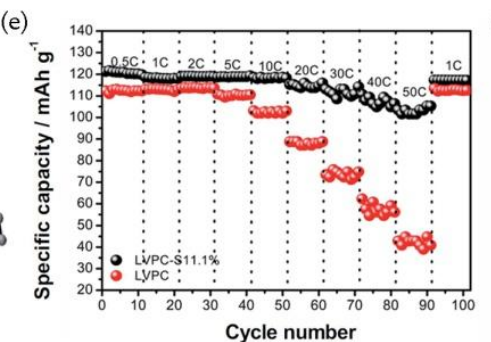

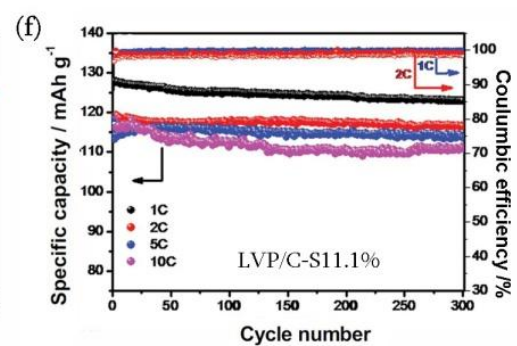

Figure 16. (a) Schematic representation of the LVP/PIL structure, illustrating the $\mathrm{Li}^{+}$ion and 
electron pathways, (b) Specific discharge capacity for a LVP/PIL electrode when discharged at various current densities in the range of 1 to $100 C$ with a constant charging rate of $0.1 C$ in the potential range of 3.0-4.3 V and (c) Specific capacity of LVP/PIL electrodes during cycling at different current densities. Inset: long-term cycling at $50 C$ [159]. (d) Schematic structures for the carbon coating on the surface of LVPC-S11.1\% particles.(e) Rate performance of LVP/C-S11.1\% and LVP/C. (f) coulombic efficiency at 1 and $2 C$ and cycle performances of LVP/C-S11.1\% and $\mathrm{LVP} / \mathrm{C}$ at various current densities in the potential window of 3.0-4.3 $\mathrm{V}$ [154].

More studies in LVP/C composites concentrate on the electrochemical performance at room temperature, whereas low temperature performance of LVP has recently attracted more attention for many advanced technology applications, such as military and aerospace missions, which require Li-ion batteries to operate at low-temperatures (e.g. $-20{ }^{\circ} \mathrm{C}$ or even lower) with appropriate energy density and power capability [157,204,212-214]. Thus, it is important to evaluate the low-temperature performance of electrode materials. Rui and coworkers contrasted the electrochemical performance of $\mathrm{LVP}$ and $\mathrm{LiFePO}_{4}$ (LFP) under various temperatures [212]. Figure 17a-b show the charge/discharge curves of electrodes at a rate of $0.3 C$ with different temperatures. As the operating temperature decreases, the capacity of LFP decreases and the electrical polarization increases, especially at -10 and $-20{ }^{\circ} \mathrm{C}$, as indicated by the voltage differences between the charge (increase) and discharge (decrease) plateaus (Figure 17a). Moreover, the LFP cell at $-20{ }^{\circ} \mathrm{C}$ only retains $32.9 \%(46.7 \mathrm{mAh} / \mathrm{g})$ of the discharge capacity obtained at $23{ }^{\circ} \mathrm{C}$. Similar to the case of the LFP/C sample, when the temperature decreases from $23{ }^{\circ} \mathrm{C}$ to $-20^{\circ} \mathrm{C}$, both the capacity and operating discharge voltage of the LVP/C sample are also reduced. However, compared with LFP/C, LVP/C exhibits a superior initial discharge capacity $(103.8 \mathrm{mAh} / \mathrm{g})$ at $-20{ }^{\circ} \mathrm{C}$, and maintains $81.7 \%$ capacity retention when the temperature is reduced from $23{ }^{\circ} \mathrm{C}$ 
to $-20{ }^{\circ} \mathrm{C}$ (Figure $17 \mathrm{~b}$ ). Moreover, the coulombic efficiency of LVP/C still reaches $96.2 \%$ at $-20{ }^{\circ} \mathrm{C}$, while LFP/C only achieves $61.3 \%$ efficiency. Thus, LVP/C is a more suitable cathode at $-20{ }^{\circ} \mathrm{C}$. At the same time, the LVP/C cell tested at $23{ }^{\circ} \mathrm{C}$, show only slight capacity fading, with $97.5 \%$ capacity retention after 100 cycles (Figure 17c). The Li-ion diffusion coefficients are presented in Figure 17d and the linear relationship is fit to both samples. Activation energies of ion migration for LFP and LVP are calculated to be 47.48 and $6.57 \mathrm{~kJ} / \mathrm{mol}$, respectively [212]. The activation energy of LVP is about one seventh that of LFP, indicating an easier Li diffusion. Based on the results above, the 3D framework in LVP crystal structure better facilitates Li-ions migration than other cathodes, and extending studies to low temperature performance is valuable applications in extreme conditions.
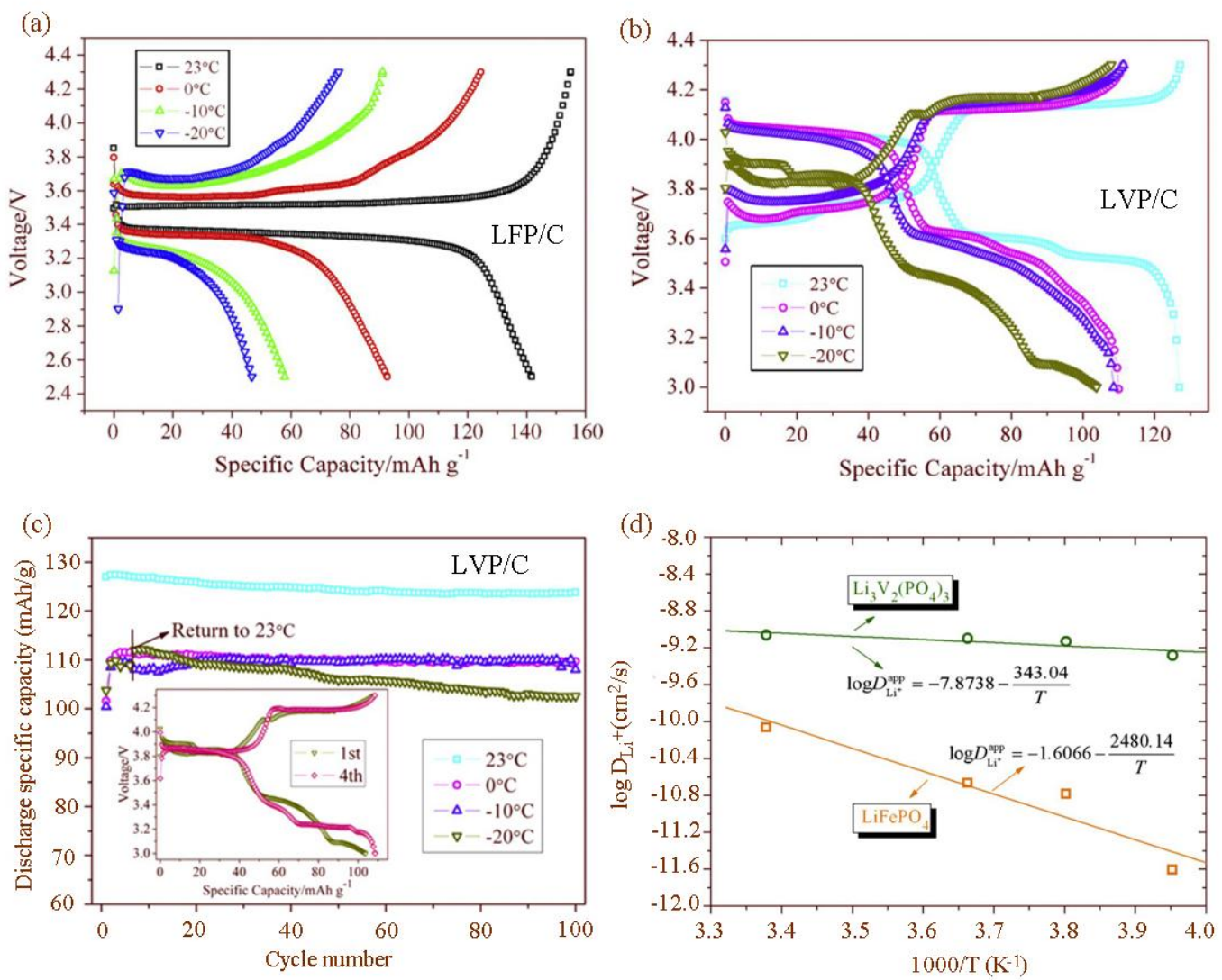
Figure 17. The initial charge-discharge curves of the LFP/C (a) and LVP/C (b) samples at various low temperatures $\left(23,0,-10\right.$ and $\left.-20{ }^{\circ} \mathrm{C}\right)$ under a $0.3 C$ rate. (c) The cycling performance of the $\mathrm{LVP} / \mathrm{C}$ sample at various low temperatures under a $0.3 C$ rate. Inset is the $1^{\text {st }}$ and $4^{\text {th }}$ charge-discharge curves at $-20{ }^{\circ} \mathrm{C}$. At $-20{ }^{\circ} \mathrm{C}$ (inset of c), there still exist three stable discharge plateaus at around $3.85,3.38$ and $3.22 \mathrm{~V}$ that cause a relatively high discharge capacity and good cycling performance. (d) Arrhenius plots of the apparent chemical diffusion coefficient of lithium ions of the LFP and LVP ( $E_{\mathrm{a}}=-R k \ln 10, k$ is the slope of the fitting line) [212].

One-dimensional carbon nanotubes (CNTs) exhibit exceptional electronic and mechanical properties [215], and has been usedas an additive to form composites with electrode materials that show improved electrochemical performance [216]. LVP is no exception to this trend; CNTs plays a crucial role in enhancing the electrical conductivity of electrode materials, which determines the rate capability and cycling stability as discussed in the previous section. Multi-wall CNT- (MWCNTs) modified LVP/C composite (labeled as LVP/C+MWCNTs) was prepared by a carbothermal reduction that used both PVA and MWCNTs as carbon sources for comparing the effect from MWCNTs [217]. The electrical conductivity of the as-prepared LVP/C+MWCNTs composite is $1.13 \mathrm{~S} / \mathrm{cm}$, which is orders of magnitude higher than the values of $\mathrm{LVP} / \mathrm{C}\left(4.95 \times 10^{-3} \mathrm{~S} / \mathrm{cm}\right)$ and $\operatorname{LVP}\left(2.3 \times 10^{-7} \mathrm{~S} / \mathrm{cm}\right)$. Figure 18a shows that the LVP particles link with MWCNTs to form a crosslinked conducting network with the carbon from pyrolyzed PVA, and gives the LVP/C+MWCNTs sample the highest electrical conductivity of the three materials. The EIS results measured at the charge potential of $3.6 \mathrm{~V}$ after 5 cycles also supports the discussion above. The Nyquist plots in Figure 18b present the charge-transfer resistance and ion diffusion impedance. Simulations are carried out and the simulated charge-transfer resistances 
$\left(\mathrm{R}_{\mathrm{ct}}\right)$ of LVP/C+MWCNTs and LVP/C are 22.36 and $41.12 \Omega$, respectively. Besides, the apparent diffusion coefficients of Li-ions, calculated from the Warburg regions in EIS spectra are $6.2 \times 10^{-9}$ and $2.4 \times 10^{-9} \mathrm{~cm}^{2} / \mathrm{s}$ for LVP/C+MWCNTs and LVP/C [217], respectively. It is concluded that adding MWCNTs can enhance the electrical conductivity of LVP, which then improves the ionic diffusion coefficient. In order to compare the difference between CNT and other carbon materials, super P, graphene and graphite were used as reducing agents and carbon sources to prepare LVP/carbon material composites. All the composites had approximately the same carbon content of $8.1 w t . \%$. The HRTEM image in Figure 18c clearly shows the LVP particle, CNTs, and boundary between the LVP particle and CNT. The lattice spacing of $0.43 \mathrm{~nm}$ corresponds to the (220) crystal planes in LVP and the interplanar distance of $0.35 \mathrm{~nm}$ matches the (002) planes of CNTs. The strong connection between LVP particle and CNT may be attributed to the in situ synthesis process that uses CNTs both as reducing agents and carbon sources. Thus, the interconnected CNTs build a charge transfer network between the LVP particles, which gives LVP@CNT the best rate capability among all of the LVP@C composites (Figure 18d). Obviously, the interconnected conducting pathway from CNT ensures fast charge transfer for the electrochemical reaction and enhances the rate and cycling performance of the LVP electrode. 
(a)

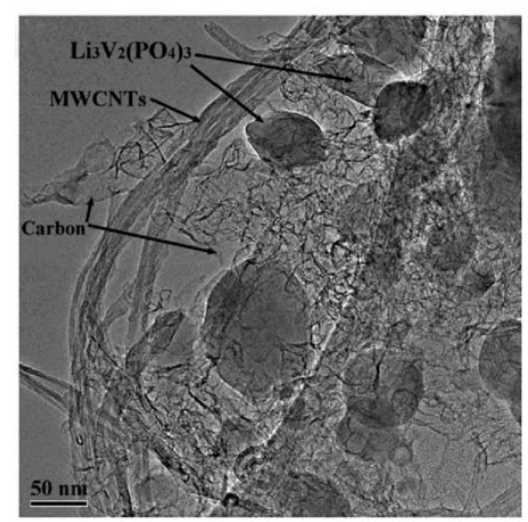

(c)

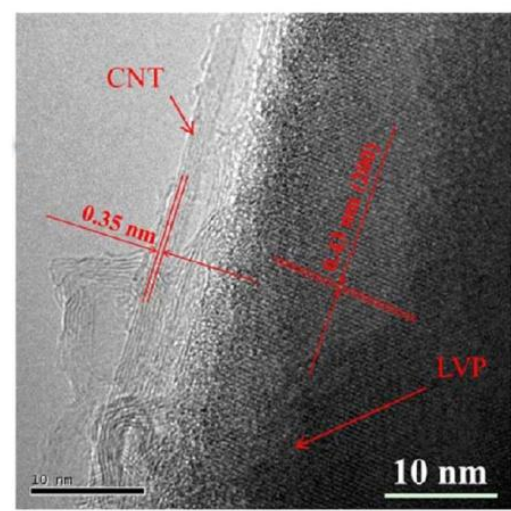

(b)

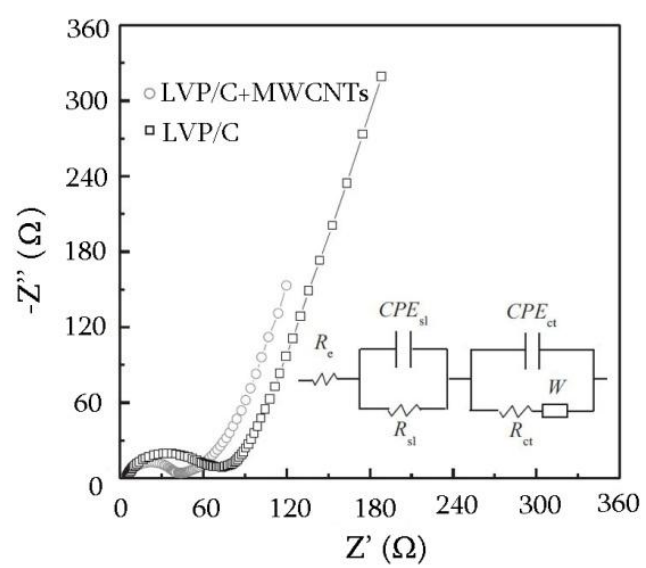

(d)

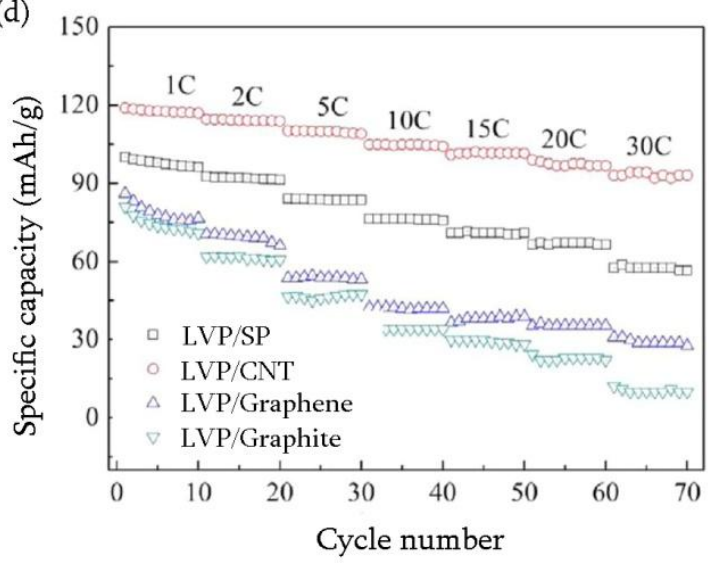

Figure 18. (a) TEM images of LVP/C+MWCNTs; (b) Nyquist plots of LVP/C+MWCNTs and LVP/C measured at the charge potential of $3.6 \mathrm{~V}$ (vs. $\mathrm{Li}^{2} / \mathrm{Li}^{+}$) [217]. (c) HRTEM images of LVP/CNT composites, and (d) Rate performance of LVP/SP, LVP/CNT, LVP/Graphene, and LVP/Graphite at different discharge rates ranging from 1 to $30 C$ in the potential window of 3.0-4.3 V [216].

In an alternative synthesis, carbon nanofibers $(\mathrm{CNF})$ is corroded and $\mathrm{V}_{2} \mathrm{O}_{3}$ nucleates at the generated defect sites, then $\mathrm{CH}_{3} \mathrm{COOLi}$ and $\mathrm{H}_{3} \mathrm{PO}_{4}$ are added and calcined to induce a phase transition that produces the expected LVP/CNF (Figure 19a). The close attachment between the LVP nanocrystals and the carbon surface improves the electronic conductivity and Li-diffusivity in the composite, at the same time the pillar effect of the impregnated LVP crystals build a mesoporous network to reserve electrolyte. This ideal LVP/CNF nanostructure achieved a $480 C$ rate (7.5 seconds) discharge with $83 \mathrm{mAh} / \mathrm{g}$, and $69 \%$ capacity retention relative to the slowest 
discharge rate (1 C) (Figure 19b). When cycling tests were carried out at $10 C$, the composite displays an excellent stability over 10,000 cycles, maintaining $85 \%$ of the initial capacity (Figure 19c) [218]. Electrospinning method was used to synthesize LVP/CNF, LVP particles grown outward from the CNF to guarantee an excellent electrical conductivity and the sufficient contact between LVP and electrolyte. The sample delivered a high specific capacity of $196 \mathrm{mAh} / \mathrm{g}$ at $0.1 C$ in the potential range of 3.0-4.8 V, and cycled at $20 C$ with a specific capacity of $127.5 \mathrm{mAh} / \mathrm{g}$ and displayed a high capacity retention of $80 \%$ after 1000 cycles [219]. One essential issue should be noted that the one-dimensional electrode materials present ideal electrical conductivity for fast redox reaction during the charge/discharge process, however, the tap density is relatively low and limits their practical applications. Thus, CNT or CNF composites supply a chance or perception to design electrode materials with high power density, but not a suitable choice for high energy density batteries. 
(a)

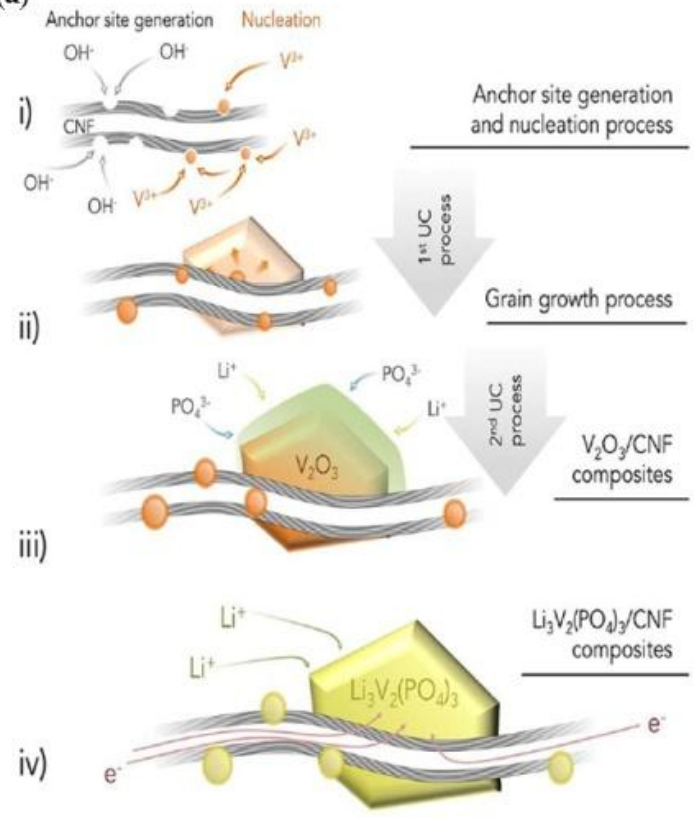

(b)

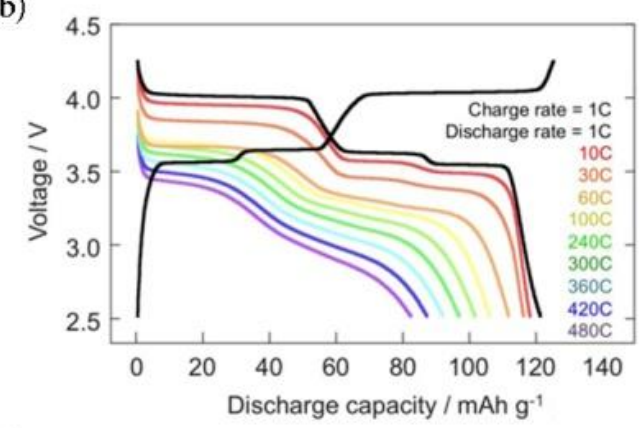

(c)

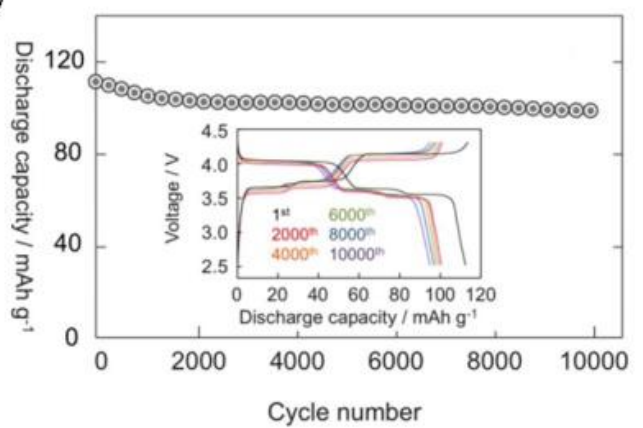

Figure 19. (a) Schematic illustration of the concept behind two-step LVP/CNF fabrication process. First, an ultracentrifugation (UC) treatment is carried out to synthesize nanoplate $\mathrm{V}_{2} \mathrm{O}_{3} / C N F$ composites. i) The $\mathrm{V}_{2} \mathrm{O}_{3}$ precursor can nucleate in the anchor sites of the CNF, this reaction occurs at a strongly basic conditions $\left(\mathrm{OH}^{-}\right)$; ii) The $\mathrm{V}_{2} \mathrm{O}_{3}$ precursor grown anisotropically to nanoplates $(20-200 \mathrm{~nm})$ due to the effects from ultracentrifugation at $75000 \mathrm{G}$ and the steric hindrance of the $\mathrm{CNF}$. The precursor was transformed into $\mathrm{V}_{2} \mathrm{O}_{3}$ nanocrystals after sintering at $800^{\circ} \mathrm{C}$ for $30 \mathrm{~min}$. A second UC treatment is used to synthesize the LVP nanoplate/CNF composites. iii) A mixture contained $\mathrm{V}_{2} \mathrm{O}_{3} / \mathrm{CNF}, \mathrm{CH}_{3} \mathrm{COOLi}$, and $\mathrm{H}_{3} \mathrm{PO}_{4}$ was treated by $\mathrm{UC}$, and subsequent sintered at $900{ }^{\circ} \mathrm{C}$ without holding time, iv) The designated LVP nanoplate/CNF composite is transformed from the $\mathrm{V}_{2} \mathrm{O}_{3}$ nanoplate/CNF without microstructure change. (b) Charge-discharge profiles of the sintered LVP/CNF composite at different discharge $C$-rates from 1 to $480 C$. (c) Results of the cycle tests for the LVP/CNF composite. Both the charge and discharge rates were fixed at $10 C$. The inset shows the charge-discharge profiles at the $1^{\text {st }}, 2000^{\text {th }}, 4000^{\text {th }}, 6000^{\text {th }}, 8000^{\text {th }}$, and $10000^{\text {th }}$ cycle [218].

Graphene, a two-dimensional carbon material, has a theoretical surface-to-mass ratio of $\sim 2600 \mathrm{~m}^{2} / \mathrm{g}$, which combined with its high electrical conductivity and flexibility, gives it the potential to store electric charge, ions, or hydrogen [220]. For these reasons, composites based on graphene have attracted attention, and has been used as a conductive component in electrode materials for energy storage [221]. As with other 
carbon materials, graphene is combined with LVP (LVP/G) to overcome the intrinsic poor electrical conductivity of LVP host [151,156,222-225]. Figure 20a shows an HRTEM image in which LVP nanoparticles are surrounded by multi-layer amorphous carbon on the graphene surface. The synergistic effect from amorphous carbon and graphene can describe in two aspects. On one hand, the carbon coating on the surface of the LVP primary particles limits the growth or prevents aggregation of LVP particles caused by volume shrinking and expanding in the charge-discharge process. On the other hand, the graphene tightly binds to LVP. The combination of high conductivity and excellent mechanical strength results in an electron-conducting skeleton for the composite [223]. The initial charge-discharge curves of the three composites are contrasted at $0.1 C$ in the voltage range of 3.0-4.3 V (Figure 20b). Three distinct potential plateaus are observed in the curves, as extensively reported $[15,86,132]$, exhibiting a sequence of phase transitions during the charge/discharge process. The discharge specific capacities of $\mathrm{LVP} / \mathrm{G}$ and $\mathrm{LVP} / \mathrm{C}+\mathrm{G}$ at $0.1 C$ rate are 125.2 and $131.4 \mathrm{mAh} / \mathrm{g}$, respectively, which are very close to the theoretical capacity (133 $\mathrm{mAh} / \mathrm{g}$ ) of LVP in this voltage range. However, the LVP/C delivers a discharge specific capacity of $111.8 \mathrm{mAh} / \mathrm{g}$ with only $80.4 \%$ coulombic efficiency at the initial cycle, which is much lower than that of the two former samples. This is attributed to the lower conductivity of the amorphous carbon-layer coating relative to graphene [223]. The high rate and low temperature performance of LVP/graphene composites are studied and the corresponding results are exhibited in Figure 20c-d. The composite shows excellent rate performance and delivered capacities of 104, 91 and 
$85 \mathrm{mAh} / \mathrm{g}$ at 5, 30 and $50 \mathrm{C}$ in the voltage range of 3.0-4.3 V, respectively. In addition, the contrast in normalized capacities is showed in Figure 20c, and obviously, $\mathrm{LVP} / \mathrm{C}+\mathrm{G}$ displays higher discharge capacities than those of $\mathrm{LVP} / \mathrm{C}$ at 30 and $50 C$, implying that adding graphene can further improve the rate capability of LVP/C. The specific capacities in low temperature tests demonstrate that the average capacities of $\mathrm{LVP} / \mathrm{C}+\mathrm{G}$ are 162,131 and $107 \mathrm{mAh} / \mathrm{g}$ at $20,-10$ and $-20{ }^{\circ} \mathrm{C}$, respectively, which are higher than those of LVP/C, whose average capacities were 151, 114, and $81 \mathrm{mAh} / \mathrm{g}$ at the same temperatures (Figure 20d). Beyond the effect of high electronic conductivity, graphene can also prevent grain growth of LVP during the synthesis process. When graphene oxide (GO) is adopted as precursor to prepare graphene/LVP composites, esterification occurs between GO and other organics, which can hinder the mass migration and separate LVP particles. Besides, the thermal reduction of GO originally tends to be wrinkle-like and curly and forms a tight contact between LVP and graphene. The average LVP particle size is smaller than $100 \mathrm{~nm}$ in the LVP/composites [151,225], but the size exceeds $500 \mathrm{~nm}$ in the conventional LVP/C composites $[100,153]$. The tight contact enhances the charge transfer and the reduced particle size shortens the ion diffusion pathway, which allows the LVP/graphene composites to achieve competitive rate capability, as widely reported [156,225].

The main contribution of carbonaceous materials, including amorphous carbon, carbon nanotube/ fiber and graphene, is to enhance the electrical conductivity of LVP for improving the rate capability and to hinder the particle growth in the 
high-temperature calcinations. Many articles involve carbonaceous materials- LVP composites, but have limited scientific contributions. The wettability and the linking way between the interfaces of two phases in composites should be explored further.

(a)

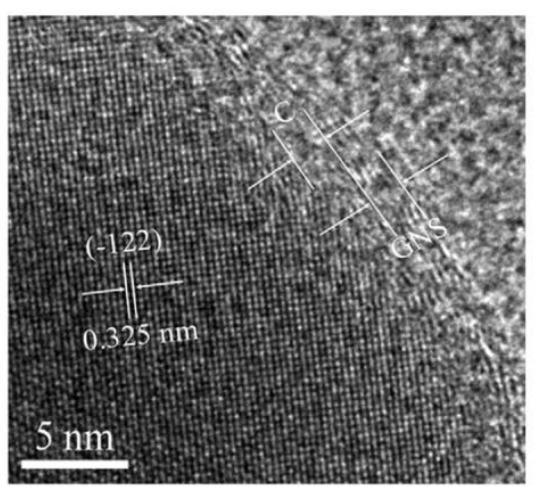

(c)

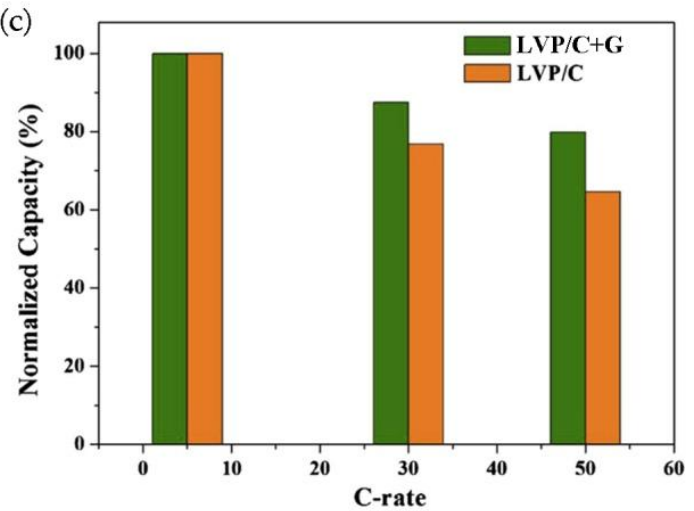

(b)

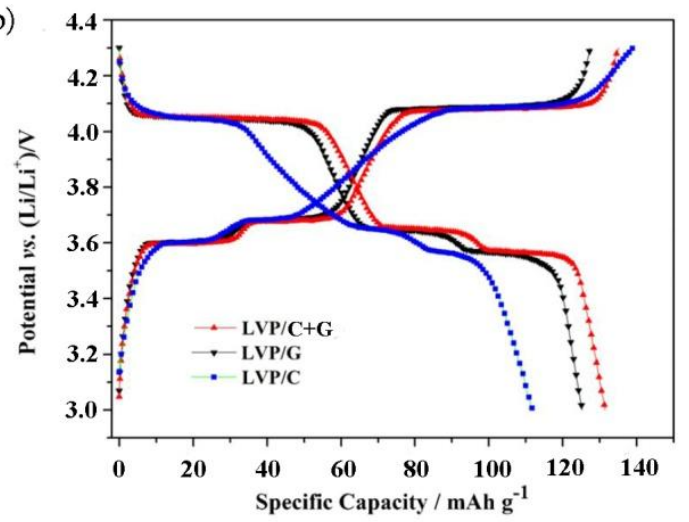

(d)

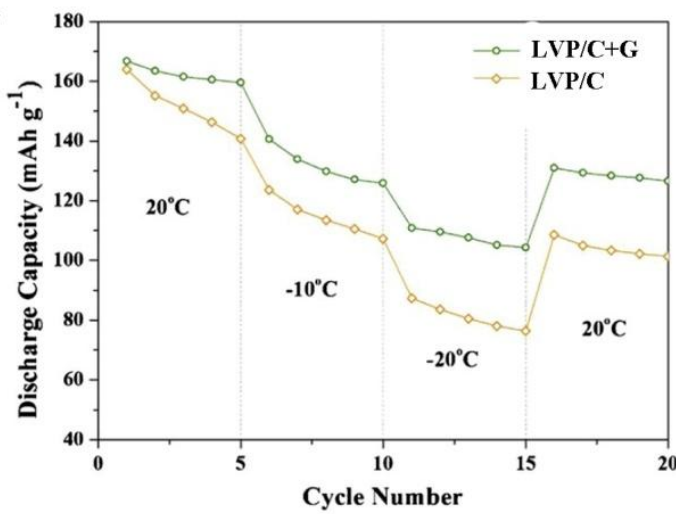

Figure 20. (a) High resolution TEM images of $L V P / C+G$ and (b) the initial charge-discharge curves of $\mathrm{LVP} / \mathrm{G}, \mathrm{LVP} / \mathrm{C}+\mathrm{G}$ and $\mathrm{LVP} / \mathrm{C}$ samples at $0.1 C$ rate in the voltage range of 3.0-4.3 V [223]. (c) Normalized capacities of LVP/C and LVP/C+G at different rates in the voltage range of 3.0-4.3 V and (d) Low-temperature performance of LVP/C and LVP/C+G at $1 C$ in the voltage range of 3.0-4.8 $\mathrm{V}$ [224].

\subsection{LVP Combined with Other Electrode Materials}

Each electrode material has its own merits. For example, phosphates have good cycling stability and ideal potential plateaus and layered materials possess high ionic and electrical conductivity. Analogous to $\mathrm{LiFePO}_{4}, \mathrm{LVP}$, display an excellent stability and discharge profile under a wide operating temperature, while its main drawback is 
its low electronic conductivity, stemming from the separated $\mathrm{VO}_{6}$ octahedrons within the LVP framework. Therefore, combining LVP with different conductive electrode materials can overcome the drawbacks in LVP and extend the applications under various conditions. $\mathrm{LiCoO}_{2}$ (LCO) has a layered structure in which $\mathrm{CoO}_{6}$ octahedrons are connected to each other through shared edges, resulting in a high electrical conductivity of $10^{-3} \mathrm{~S} / \mathrm{cm}$ [226]. It is milled with LVP to prepare composite cathodes in which LCO compensates the shortcomings LVP. Figure 21a displays the EIS spectra of LVP/C and LVP/LCO/C samples. The charge transfer resistance in the composite is smaller than that of LVP/C before and after cycling [194], indicating the expected gain in conductivity. In addition, the cycling performance at $50 C$ (Figure 21b) supports the EIS results because the high capacity at high rate is ensured by the low charge transfer resistance. Choosing a redox active electrode material for the composite allows both to participate in the (de)lithiation reaction simultaneously in a given potential window, which can maximize the specific capacity of the composite. The prerequisite is that the metal center ions in the components should have similar electrochemical redox potentials. As one example, $\mathrm{LiVPO}_{4} \mathrm{~F}$ fulfills this requirement and can be paired with LVP (Figure 21c). In the CV curve, oxidation peaks at 4.28 and $4.34 \mathrm{~V}$ correspond to the deintercalation process of $\mathrm{LiVPO}_{4} \mathrm{~F}$, and the peak resides at $4.17 \mathrm{~V}$ are related to reduction (intercalation). One reduction peak is missing, which is attributed to $\mathrm{Li}$ ion insertion at one particular site, though the extraction takes place at two Li ion sites whose energies differ. This gives rise to two oxidization peaks. The inserted $\mathrm{Li}$ ions will move from the occupied site to the other 
one automatically [188]. Interfacial bonding distinguishes a chemical composite from a physical mixture. A composite consisting of $\mathrm{LiMnPO}_{4}(\mathrm{LMP})$ and $\mathrm{Li}_{3} \mathrm{~V}_{2}\left(\mathrm{PO}_{4}\right)_{3}$ was synthesized using a solid-state reaction, and a transition layer appeared between both components (Figure 21d). It differs from LVP/LCO, which has a low chemical bond degree between two phases. The electrochemical performance differs between the chemical composite and physical mixture (Figure 21e). The discharge capacities in all the composites apparently exceed that of LMP/C at all rates. The $(1-x) \mathrm{LMP} \cdot x \mathrm{LVP} / \mathrm{C}$ composite with $x=0.4$ exhibits the highest discharge capacity of 125.9 and at $0.1 C$. Even at a high rate of $5 C$, the discharge capacity of sample with $x=0.4$ can still retains $74 \mathrm{mAh} / \mathrm{g}$, or approximately twice that of $\mathrm{LMP} / \mathrm{C}$. At the same time the rate capacity of the $0.6 \mathrm{LMP}+0.4 \mathrm{LVP} / \mathrm{C}$ mixture contrasted with the $0.6 \mathrm{LMP} \cdot 0.4 \mathrm{LVP} / \mathrm{C}$ composite; the composite exhibits much higher specific discharge capacities at all the rates studied. It is concluded that chemical bonding between both components benefits the composite by combining their strong points and counteract their shortcomings. Chemical bonding implies lattice mismatch and other interfacial defects which tune the energy level in the metal center ions, leading to improved electrochemical performance. It is hard to avoid generating impurity phases in the solid-state reaction, such as $\mathrm{LiVP}_{2} \mathrm{O}_{7}$ in LMP.LVP composites [192]. However, this is acceptable if the new phase has considerable ionic conductivity or ion storage capacity. Beyond the improvement of electronic conductivity and specific capacity in composites, ionic diffusion is another crucial factor in electrode materials, especially for high-power applications. $\mathrm{LiV}_{3} \mathrm{O}_{8}$ (LVO), an ionically conductive layered material, 
has been combined with LVP to enhance the ionic diffusion in the composites. Both components are synthesized using sol-gel methods and the composites are prepared through mechanical mixing [227] or solid-state reactions [228]. The Li-ion diffusion coefficient of the LVP/LVO composite, measured by GITT, are in the range of $10^{-11}$ to $10^{-9} \mathrm{~cm}^{2} / \mathrm{s}$ during the charge-discharge processes (Figure $21 \mathrm{f}$ ). These values are higher than those in $\operatorname{LVO}\left(10^{-14}\right.$ to $\left.10^{-10} \mathrm{~cm}^{2} / \mathrm{s}\right)$ and $\operatorname{LVP}\left(10^{-13}\right.$ to $\left.10^{-8} \mathrm{~cm}^{2} / \mathrm{s}\right)$ individually. It is found that the $\log \left(D_{\mathrm{Li}+}\right) v s$. potential plots show several valley at 2.6, 3.2, 3.8, and $4.0 \mathrm{~V}$, which correspond to $\mathrm{CV}$ redox peaks and charge-discharge voltage plateaus [228]. These potential plateaus in cathode materials are the regions where a two-phase transition occurs, which causes strong attractive interaction between intercalation species and the host matrix or some order-disorder transition during cycling [71].
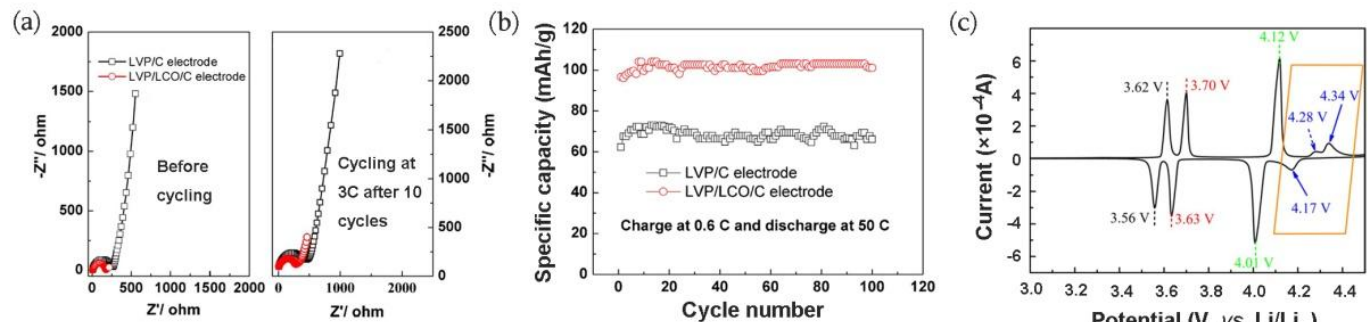

(d)

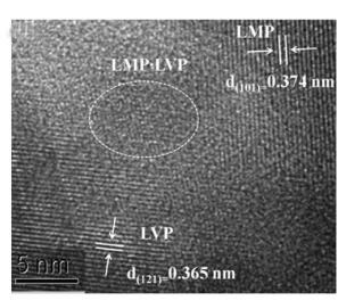

(e)
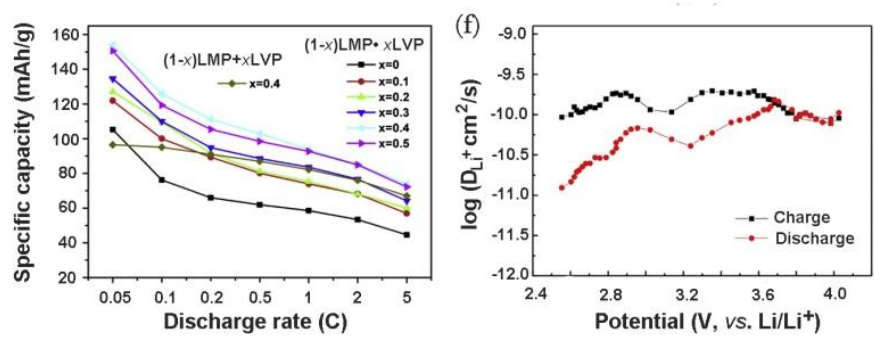

Figure 21. (a) Impedance spectra at different cycles and (b) cyclic performance with a charge rate of $0.6 C$ and discharge rate of $50 C$ in the range 3.0-4.3 V for LVP/C and LVP/LCO/C electrodes [194]. (c) CV curve at scan rate of $0.05 \mathrm{mV} / \mathrm{s}$ in the voltage range of 3.0-4.5 V [188]. (d) HRTEM image of 0.6LMP.0.4LVP, and (e) rate capacities of the as-prepared (1-x)LMP. $x \mathrm{LVP} / \mathrm{C}$ and the $(1-x) \mathrm{LMP}+x \mathrm{LVP} / \mathrm{C}$ physical mixture with $x=0.4$ [192]. (f) Li-ion diffusion coefficient calculated 
from GITT data for the 2LVP.LVO electrode as a function of potential during charge and discharge [228].

Among several electrode materials, $\mathrm{LiFePO}_{4}$ (LFP) was extensively studied as a component to combine with LVP. It is worth noting that the majority of LFP/LVP composite studies focus on improving the performance of LFP matrix by adding LVP $[167,172,174,177,183,212,229,230]$. This is because LVP allows for much faster lithium-ion migration $\left(\mathrm{D}_{\mathrm{Li}+}=10^{-10}\right.$ to $\left.10^{-9} \mathrm{~cm}^{2} / \mathrm{s}\right)$ than $\mathrm{LiFePO}_{4}\left(\mathrm{D}_{\mathrm{Li+}}=10^{-16}\right.$ to $10^{-14}$ $\mathrm{cm}^{2} / \mathrm{s}$ ), owing to its open three dimensional (3D) framework [177]. Besides, mutual cation doping $\left(\mathrm{Fe}^{2+}\right.$ and $\left.\mathrm{V}^{3+}\right)$ benefits to increases the conductivity of the materials [230]. Various approaches were adopted to prepare LVP/LFP composites, including solid-state reactions [174], and sol-gel [177], sol spray drying [178] and rheological phase reaction methods [183]. For example, 2 LFP.LVP/C composites were synthesized via spray drying as illustrated in Figure $22 \mathrm{a} . \mathrm{Fe}_{4}\left(\mathrm{VO}_{4}\right)_{4} \cdot 5 \mathrm{H}_{2} \mathrm{O}$ was first prepared via ultrasonic-aided precipitation, then mixed with a $\mathrm{Li}$ source $\left(\mathrm{LiH}_{2} \mathrm{PO}_{4}\right)$, glucose and oxalic acid for spray drying. Calcination decomposes the organic sources and completes the phase transition to form the carbon-encapsulated 2LFP/LVP/C composites [230]. TEM images show some lattice fringes corresponding to LFP and LVP in the composites, implying that LFP, LVP and LFP/LVP composite phases coexist in the material (Figure 22b). Coexisting LFP/LVP composite was also detected by XRD and consisted of both components as shown in Figure 22c. The charge/discharge curves vary with the component ratios (Figure 22d). As the LFP content increases, the potential profiles transform from the characteristic curve of LVP to LFP. In the composites, the curves contain characteristics of both phases 
because the $\mathrm{V}^{3+} / \mathrm{V}^{4+}$ and $\mathrm{Fe}^{2+} / \mathrm{Fe}^{3+}$ redox couples work together [184]. This is further verified from cyclic voltammetry $(\mathrm{CV})$ profiles of LFP/C, 3LFP.LVP/C, and LVP/C electrodes (Figure 22e). One (3.688/3.305 V) and three (3.650/3.521, 3.731/3.600, and 4.156/3.978 V) pairs of redox peaks are observed in LFP/C and LVP/C electrodes, respectively, while the 3LFP.LVP/C electrode contains all four redox couples (3.536/3.340 V from LFP, and 3.616/3.550, 3.700/3.631, and 4.116/4.012 $\mathrm{V}$ from LVP). It is noted that the redox peak separations for the 3LFP. LVP/C electrode are all lower than those of the single LFP/C and LVP/C electrodes, implying an improvement of the conductivity in this composite material [184]. A compilation of the results of more studies in LVP/LFP composites is given in Table 4 and includes the synthesis methods, and observed specific capacities and rate capabilities. Based on these results, LFP/LVP composites effectively integrate the strengths of both components and generate defects between the grain boundaries which provide fast pathways for Li-ion migration. In brief, composites are expected to synergistically provide a diversity of complex effects and complementary advantages. Controlling the formation of impurity phase and exploring the effects from interface defects are valuable and essential topic for the composites in the future studies. 
(a)

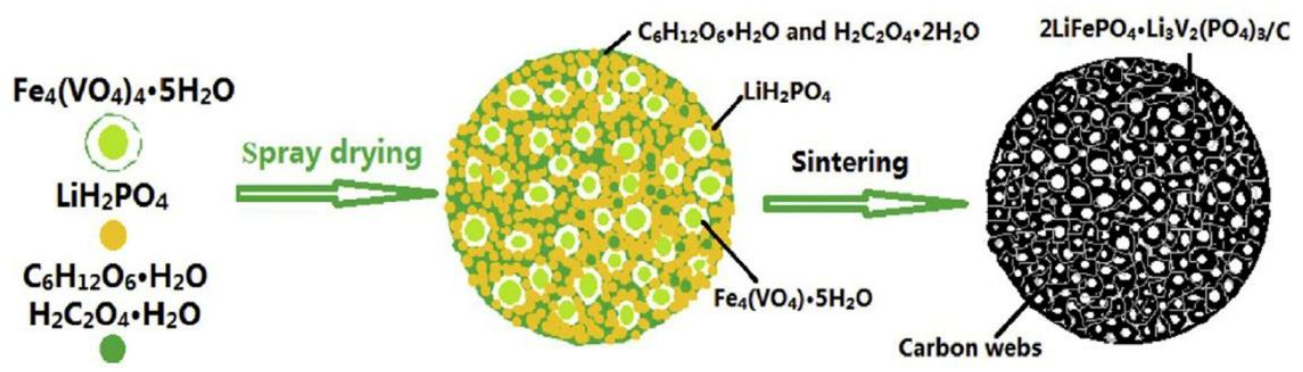

(b)

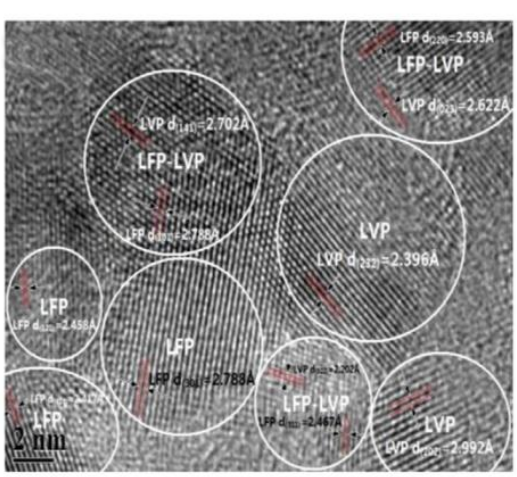

(d)

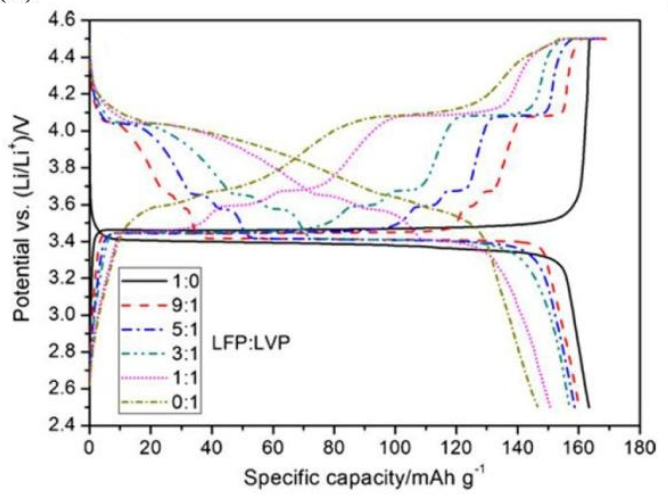

(c)

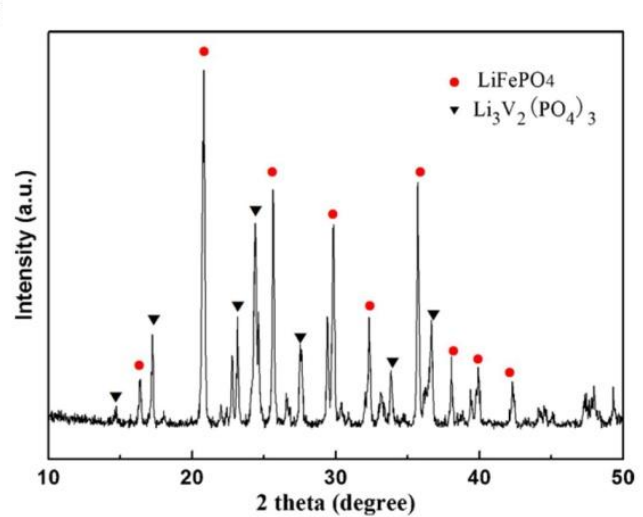

(e)

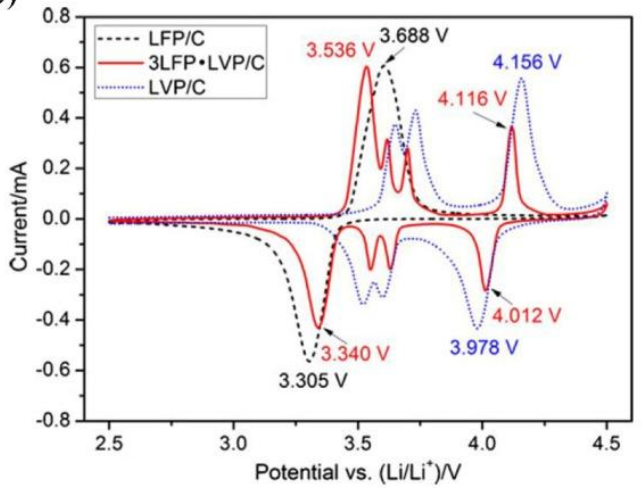

Figure 22. (a)Schematic illustration of the preparation process and microstructure characteristics of the 2LFP.LVP/C composites and (b) TEM image of 2LFP.LVP-S64 particles [230]. (c) XRD pattern of LFP.LVP synthesized at $700{ }^{\circ} \mathrm{C}$ for $12 \mathrm{~h}$ [172]. (d) Initial charge-discharge curves of $x \mathrm{LFP} \cdot y \mathrm{LVP} / \mathrm{C}$ composite materials at $0.1 C$ and (e) CV profiles of LFP/C, 3LFP. LVP/C, and LVP/C electrodes [184]. 
Table 4. The Synthesis Method and Electrochemical Performance of Composites Consisting of $\mathrm{Li}_{3} \mathrm{~V}_{2}\left(\mathrm{PO}_{4}\right)_{3}(\mathrm{LVP})$ and LiFePO $4(\mathrm{LFP})$

\begin{tabular}{|c|c|c|c|c|c|}
\hline $\begin{array}{l}\text { Optimized } \\
\text { Composites }\end{array}$ & Synthesized method & Initial discharge Capacity & Rate Capacity & Cyclic Performance & Reference \\
\hline LVP·LFP & Solution method & $127 \mathrm{mAh} / \mathrm{g}$ at $0.1 C$ in $2.5-4.3 \mathrm{~V}$ & $100 \mathrm{mAh} / \mathrm{g}$ at $10 \mathrm{C}$ & & [231] \\
\hline LVP·8LFP & $\begin{array}{l}\text { Rheological phase } \\
\text { reaction method }\end{array}$ & $129 \mathrm{mAh} / \mathrm{g}$ at $3 C$ in $2.0-4.4 \mathrm{~V}$ & $123 \mathrm{mAh} / \mathrm{g}$ at $5 \mathrm{C}$ & $\begin{array}{l}130 \mathrm{mAh} / \mathrm{g} \text { at } 3 C \text { and } 117 \mathrm{mAh} / \mathrm{g} \text { at } 5 \\
C \text { after } 100 \text { cycles }\end{array}$ & {$[183]$} \\
\hline LVP·5LFP & $\begin{array}{l}\text { Chemical reduction and } \\
\text { lithiation method }\end{array}$ & $165 \mathrm{mAh} / \mathrm{g}$ at $0.1 C$ in $2.5-4.5 \mathrm{~V}$ & & & [161] \\
\hline LVP·5LFP & $\begin{array}{l}\text { Chemical reduction and } \\
\text { lithiation method }\end{array}$ & $158 \mathrm{mAh} / \mathrm{g}$ at $0.1 \mathrm{C}$ in $2.5-4.5 \mathrm{~V}$ & $\begin{array}{l}153 \mathrm{mAh} / \mathrm{g} \text { at } 2 C, 124 \mathrm{mAh} / \mathrm{g} \text { at } 5 C \text { and } \\
114 \mathrm{mAh} / \mathrm{h} \text { at } 10 C\end{array}$ & & [185] \\
\hline LVP·9LFP & Thermal reaction & $168 \mathrm{mAh} / \mathrm{g}$ at $0.1 C$ in $2.5-4.5 \mathrm{~V}$ & $\begin{array}{l}143 \mathrm{mAh} / \mathrm{g} \text { at } 5 C, 131 \mathrm{mAh} / \mathrm{g} \text { at } 10 C \\
\text { and } 102 \mathrm{mAh} / \mathrm{g} \text { at } 15 C\end{array}$ & $\begin{array}{l}163 \mathrm{mAh} / \mathrm{g} \text { at } 1 C \text { after } 80 \text { cycles, } 125 \\
\mathrm{mAh} / \mathrm{g} \text { at } 10 C \text { after } 150 \text { cycles }\end{array}$ & [167] \\
\hline 3LVP.7LFP & Sol-gel method & $166 \mathrm{mAh} / \mathrm{g}$ at $0.1 C$ in $2.5-4.5 \mathrm{~V}$ & $\begin{array}{l}152 \mathrm{mAh} / \mathrm{g} \text { at } 1 C, 137 \mathrm{mAh} / \mathrm{g} \text { at } 10 C \text { and } \\
109 \mathrm{mAh} / \mathrm{g} \text { at } 20 C\end{array}$ & $125 \mathrm{mAh} / \mathrm{g}$ at $10 C$ after 1000 cycles & [171] \\
\hline LVP.9LFP & Sol-gel method & $161 \mathrm{mAh} / \mathrm{g}$ at $0.5 C$ in $2.5-4.5 \mathrm{~V}$ & $\begin{array}{l}154 \mathrm{mAh} / \mathrm{g} \text { at } 1 C, 149 \mathrm{mAh} / \mathrm{g} \text { at } 2 C \\
\text { and } 135 \mathrm{mAh} / \mathrm{g} \text { at } 5 C\end{array}$ & $99.25 \mathrm{mAh} / \mathrm{g}$ at $10 \mathrm{C}$ after 190 cycles & [182] \\
\hline LVP·5LFP & $\begin{array}{l}\text { Rheological phase } \\
\text { reaction method }\end{array}$ & $145.6 \mathrm{mAh} / \mathrm{g}$ at $0.1 C$ in $2.5-4.5 \mathrm{~V}$ & & $\begin{array}{l}138.6 \mathrm{mAh} / \mathrm{g} \text { at } 0.1 \mathrm{C} \text { after } 30 \text { cycles, } \\
134.8 \text { and } 129.9 \mathrm{mAh} / \mathrm{g} \text { at } 1 \text { and } 2 C \\
\text { after } 50 \text { cycles, respectively }\end{array}$ & [173] \\
\hline LVP·9LFP & Sol-gel method & $157.2 \mathrm{mAh} / \mathrm{g}$ at $0.1 C$ in $2.5-4.5 \mathrm{~V}$ & $\begin{array}{l}131.3 \text { and } 109.2 \mathrm{mAh} / \mathrm{g} \text { at } 10 \text { and } 20 \mathrm{C} \text {, } \\
\text { respectively }\end{array}$ & $\begin{array}{l}152.4 \text { and } 131.3 \mathrm{mAh} / \mathrm{g} \text { at } 1 \text { and } 10 \mathrm{C} \\
\text { after } 100 \text { cycles, respectively }\end{array}$ & [177] \\
\hline LVP·9LFP & $\begin{array}{l}\text { Spray-drying and } \\
\text { post-calcining method }\end{array}$ & $161.3 \mathrm{mAh} / \mathrm{g}$ at $0.1 C$ in $2.5-4.5 \mathrm{~V}$ & $\begin{array}{l}153.3,147.6,135.3 \text { and } 109.6 \mathrm{mAh} / \mathrm{g} \text { at } \\
1,2,5,10 \mathrm{C} \text {, respectively }\end{array}$ & $\begin{array}{l}130.1 \text { and } 102.7 \mathrm{mAh} / \mathrm{g} \text { at } 5 \text { and } 10 \mathrm{C} \\
\text { after } 100 \text { cycles, respectively }\end{array}$ & [175] \\
\hline 4LVP.6LFP & Polyol process & $140 \mathrm{mAh} / \mathrm{g}$ at $0.1 C$ in $2.5-4.5 \mathrm{~V}$ & $125 \mathrm{mAh} / \mathrm{g}$ at $5 C$ and $110 \mathrm{mAh} / \mathrm{g}$ at $10 C$ & $110 \mathrm{mAh} / \mathrm{g}$ at $10 \mathrm{C}$ after 50 cycles & [166] \\
\hline 3LVP.7LFP & $\begin{array}{l}\text { Spray-drying and } \\
\text { post-calcining method }\end{array}$ & $146 \mathrm{mAh} / \mathrm{g}$ at $30 \mathrm{~mA} / \mathrm{g}$ in $2.5-4.5 \mathrm{~V}$ & $120 \mathrm{mAh} / \mathrm{g}$ at $1.5 \mathrm{~A} / \mathrm{g}$ & & {$[178]$} \\
\hline
\end{tabular}




\begin{tabular}{|c|c|c|c|c|c|}
\hline LVP.9LFP & $\begin{array}{l}\text { Liquid-phase precipitation } \\
\text { reaction combined with } \\
\text { solid-state method }\end{array}$ & $153.1 \mathrm{mAh} / \mathrm{g}$ at $1 C$ in $2.4-4.2 \mathrm{~V}$ & $\begin{array}{l}137.7 \mathrm{mAh} / \mathrm{g} \text { at } 2 C, 113.6 \mathrm{mAh} / \mathrm{g} \text { at } 5 C \\
\text { and } 93.3 \mathrm{mAh} / \mathrm{g} \text { at } 10 C\end{array}$ & & [170] \\
\hline LVP·3LFP & Sol spray drying method & $152 \mathrm{mAh} / \mathrm{g}$ at $1 C$ in $2.5-4.5 \mathrm{~V}$ & $\begin{array}{l}143.6 \mathrm{mAh} / \mathrm{g} \text { at } 2 C, 134.3 \mathrm{mAh} / \mathrm{g} \text { at } 5 C \\
\text { and } 116.8 \mathrm{mAh} / \mathrm{g} \text { at } 10 C\end{array}$ & $151 \mathrm{mAh} / \mathrm{g}$ at $1 C$ after 100 cycles & [184] \\
\hline $\begin{array}{l}0.013 \mathrm{LVP} \cdot 0.987 \mathrm{LF} \\
\mathrm{P}\end{array}$ & $\begin{array}{l}\text { Modified solid-state } \\
\text { method }\end{array}$ & $165 \mathrm{mAh} / \mathrm{g}$ at $0.1 C$ in $2.5-4.2 \mathrm{~V}$ & $135.4 \mathrm{mAh} / \mathrm{g}$ at $1 C$ & $141.6 \mathrm{mAh} / \mathrm{g}$ at $1 C$ after 100 cycles & [174] \\
\hline $0.03 \mathrm{LVP} \cdot 0.97 \mathrm{LFP}$ & $\begin{array}{l}\text { Modified solid-state } \\
\text { method }\end{array}$ & $163.8 \mathrm{mAh} / \mathrm{g}$ at $1 C$ in $2.0-4.5 \mathrm{~V}$ & $\begin{array}{l}\sim 150 \mathrm{mAh} / \mathrm{g} \text { at } 2 C(\text { charge }) / 5 C \\
\text { (discharge) }\end{array}$ & $\sim 150 \mathrm{mAh} / \mathrm{g}$ at $5 C$ after 50 cycles & [229] \\
\hline
\end{tabular}

Note: $x$ LVP. $y$ LFP stands for LVP and LFP with the molar ratio of $x: y$. The theoretical capacity of $x$ LVP. $y$ LFP $=x \cdot$ theoretical capacity of LVP $+y \cdot$ theoretical capacity of LFP, where the theoretical capacity of LVP and LFP are 133 and $170 \mathrm{mAh} / \mathrm{g}$, respectively. 


\subsection{LVP-Metal Composites}

Metals have excellent electrical conductivities because of their delocalized valence electrons, and as a consequence they are promising candidates as coatings to improve the electronic conductivity of electrode materials. For instance, Au-coated $\mathrm{Li}_{4} \mathrm{Ti}_{5} \mathrm{O}_{12}$ displays a surprising rate capability [232] and Ag-modified $\mathrm{LiMn}_{2} \mathrm{O}_{4}$ reduces the cell polarization and improves the cycle-life at high rates [233]. In light of this, metals like $\mathrm{Cu}$ [197] and Ag [195,196] have been introduced to modify the electrochemical performances of LVP. The electronic conductivity of Cu-modified LVP (LVP-Cu) reaches $2.5 \times 10^{-4} \mathrm{~S} / \mathrm{cm}$, which is four orders magnitude higher than pristine LVP, i.e. $9 \times 10^{-8} \mathrm{~S} / \mathrm{cm}$ [197], demonstrating that metallic $\mathrm{Cu}$ drastically improves the electronic conductivity of LVP. Figure 23a shows the first charge-discharge curves of both materials in the potential window of 3.0-4.8 V. The LVP-Cu composite achieves an initial discharge capacity of $160 \mathrm{mAh} / \mathrm{g}$, which is much higher than that of LVP (132 $\mathrm{mAh} / \mathrm{g}$ ), suggesting that the LVP-Cu composite has faster electrochemical kinetics than LVP. Besides, LVP-Cu has the smaller charge transfer resistance of $198 \Omega$ compared to $492 \Omega$ in LVP (Figure 23b). At the same time the lithium diffusion coefficients are calculated from the Warburg region and the values are $2.8 \times 10^{-8}$ and $1.3 \times 10^{-9} \mathrm{~cm}^{2} / \mathrm{s}$ for pristine LVP-Cu and LVP, respectively [197]. A similar phenomenon was observed in $(\mathrm{Ag}+\mathrm{C})$-decorated LVP (labeled as LVP/(Ag+C)) [195]. As detailed in section 4.1, carbon coating is generally an effective approach to enhance the electronic conductivity of LVP but may be limited by inhomogeneous features in the materials. Therefore, introducing $\mathrm{Ag}$ particles to connect the 
carbon-coated LVP builds a three dimensional pathway for improved electron transfer [196]. Figure 23c shows the initial charge-discharge curves of the electrodes at $0.1 C$ $(1 C=197 \mathrm{~mA} / \mathrm{g})$ from 3.0 to $4.8 \mathrm{~V}$. The plateau voltage separations become lower in LVP/(Ag + C) sample, which indicates higher conductivity. The cycling performance in Figure 23d also shows improve electrochemical properties with Ag. After 50 cycles, $\mathrm{LVP}$ and LVP/(Ag + C) retain $94.3 \%(148.7 \mathrm{mAh} / \mathrm{g})$ and $95.0 \%(162.7 \mathrm{mAh} / \mathrm{g})$ of the capacity of the 1 st cycle at $0.1 C$, but the capacity of LVP decreases from 141.2 $\mathrm{mAh} / \mathrm{g}$ to $101.7 \mathrm{mAh} / \mathrm{g}$, only $72 \%$ capacity sustains. Moreover, the capacity of LVP fades drastically but LVP and LVP / $(\mathrm{Ag}+\mathrm{C})$ exhibit the considerable stability at $1 C$. As the current density increases to $5 C$, the capacity of LVP/C drops quickly, while the $\mathrm{LVP} /(\mathrm{Ag}+\mathrm{C})$ can still maintain $96.3 \%(120.5 \mathrm{mAh} / \mathrm{g})$ of the initial capacity [195]. On this basis, Ag and graphene co-modified LVP possessed enhanced conductivity that effectively increases the specific capacity and cycling stability for LVP [196]. Metals have noticeably high density that will reduce the energy density in a full battery. In addition, the chemical stability and cost would limit the choice of metals. However, the studies of metal-LVP composites are helpful in understandings of reaction mechanism, such as whether a metal oxide will be produced at the interface between metal and LVP, and what physical and chemical effects could be induced between two phases. 
(a)

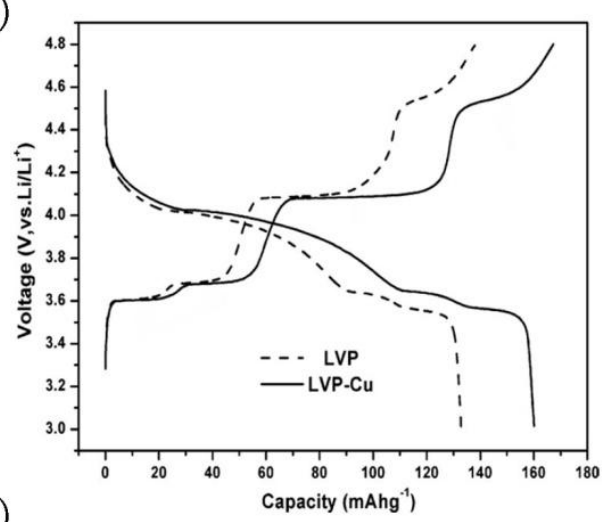

(c)

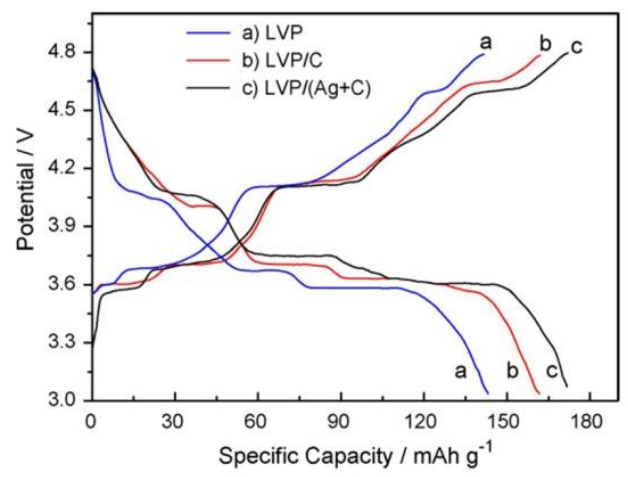

(b)

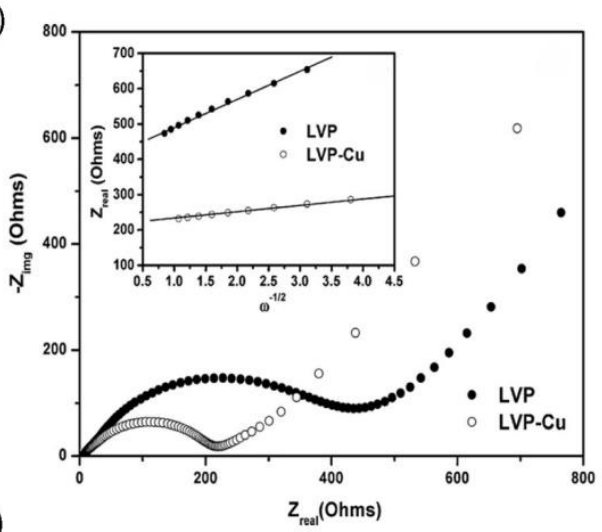

(d)

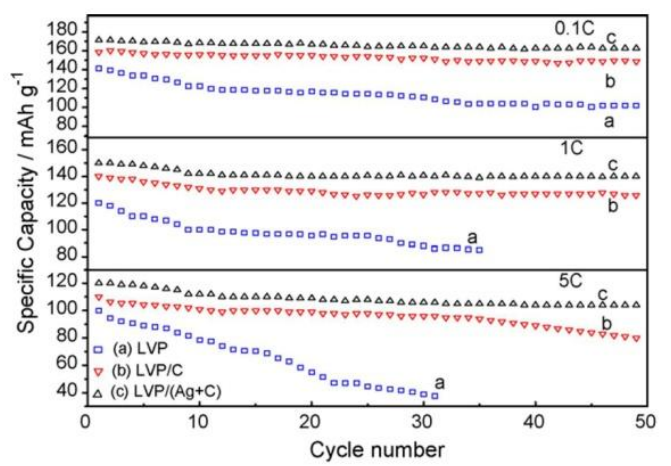

Figure 23. (a) First charge-discharge potential profiles of the LVP and LVP-Cu samples in the potential window of 3.0-4.8 V and (b) Nyquist plots of the LVP and LVP-Cu samples and linear fitting of the $Z_{\text {real }} v s . \omega^{-1 / 2}$ relationship [197]. (c) The first charge/discharge curves and (d) cycling performance of LVP, LVP/C and LVP/(Ag+C) electrodes at different current densities [195].

\subsection{LVP-Conductive Polymer Composites}

Conductive polymers are attractive coating components for surfaces modifications on inorganic electrodes. They improve not only electrical conductivity but also mechanical flexibility, which in turn favors to improved electrode kinetics and stability [234]. Besides, polymers can be coated through "softer" chemistry processes and conditions, such as low temperature and/or without harmful gases, than conventional carbon-coating processes [235]. The monomer 3,4-ethylenedioxythiophene (EDOT) was chosen to polymerize conductive stable 
films of poly(3,4-ethylenedioxythiophene) (PEDOT) on materials surface [235]. More importantly, EDOT monomers were polymerized on delithiated LVP surface by the reducing $\mathrm{V}^{4+}$ to $\mathrm{V}^{3+}$ coupled with $\mathrm{Li}^{+}$reinsertion. Figure $24 \mathrm{a}$ shows the schematic synthesis process for LVP/PEDOT composite. Polymerization of EDOT and the Li reinsertion occurred simultaneously in the absence of other oxidants or initiators and the reaction is described as [198]:

$$
\mathrm{Li}_{3-x} \mathrm{~V}_{2}\left(\mathrm{PO}_{4}\right)_{3}+x \mathrm{Li}^{+}+\text {EDOTs } \rightarrow \mathrm{Li}_{3} \mathrm{~V}_{2}\left(\mathrm{PO}_{4}\right)_{3} / \text { PEDOT composite. }
$$

Figure $24 \mathrm{~b}$ compares the discharge profiles and capacities in the LVP/PEDOT composite and LVP/carbon electrodes at various current rates in the 2.5-4.4 V potential window. At $1 C$, the LVP/PEDOT electrode delivered a specific capacity of $131 \mathrm{mAh} / \mathrm{g}$, closely approaching its theoretical capacity of $133 \mathrm{mAh} / \mathrm{g}$. When the rate is increased to $30 C$, the composite retained $83 \%$ of the theoretical capacity [198]. No additional conductive carbon agent was used for such a high-rate experiment on LVP/PEDOT, suggesting that PEDOT build a fast charge transfer pathway to enhance the rate capability of LVP. Beyond PEDOT, polyaniline (PANI) is another extensively studied conductive polymer used to coat electrode materials [199,236,237]. It boasts high conductivity, fast electrochemical switching and environmental stability [238]. LVP/PANI was synthesized through a microwave-assisted sol-gel method in which LVP powder was dispersed into diluted $\mathrm{HCl}$ solution and aniline (ANI) monomer was polymerized on the powder surface [200] (Figure 24c). PANI- coated LVP delivers a discharge capacity of $130.7 \mathrm{mAh} / \mathrm{g}$, which is again extremely close to the theoretical capacity of $133 \mathrm{mAh} / \mathrm{g}$, whereas 
LVP electrode only has a discharge capacity of $109.2 \mathrm{mAh} / \mathrm{g}$ at the same rate of $0.2 C$. After 30 cycles, the PANI-LVP electrode still achieves a high reversible discharge capacity of $128.5 \mathrm{mAh} / \mathrm{g}$. By contrast, the pristine LVP retains a discharge capacity of $101 \mathrm{mAh} / \mathrm{g}$ after the same cycles. The capacity retention of LVP and PANI-LVP is 92.1\% and $98.3 \%$, respectively. PANI-LVP composite presents stable capacities at various current densities (Figure 24d) and PANI-LVP electrode has a higher capacity retention of $93.9 \%$ when rate was turned back to $0.2 C$, compared to the LVP electrode $(80.0 \%)$ [200]. Figure 24e compares the Nyquist plots of electrodes before and after cycling tests. The charge transfer resistance of PANI-LVP shifts from 125 to $183 \Omega$ after 30 cycles, while that increases from 170 to $294 \Omega$ during the cycles in LVP. This implies that the conductive PANI coating on LVP can effectively increase the electrical conductivity between LVP nanoparticles and reduce the charge-transfer impedance [200]. Whether the polymer helps improve the wettability of LVP in nonaqueous electrolyte, and the solubility and electrochemical stability of polymer also need to be considered in the cycling tests. 
(a)

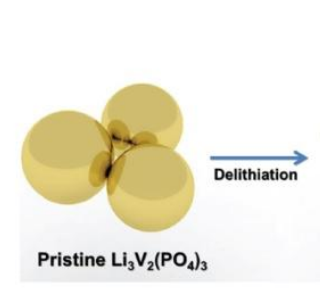

(c)

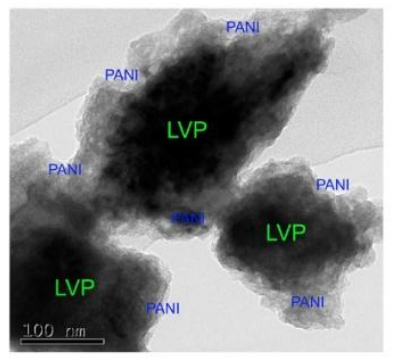

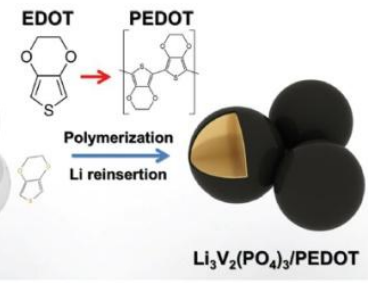

(b)

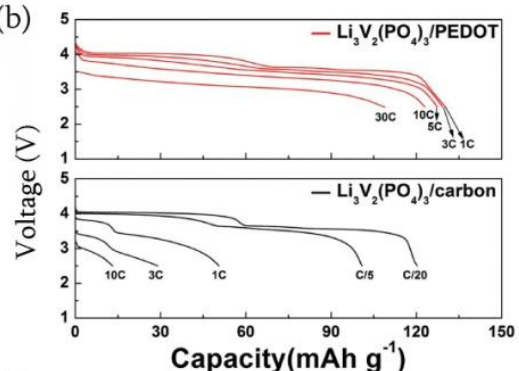

(d)

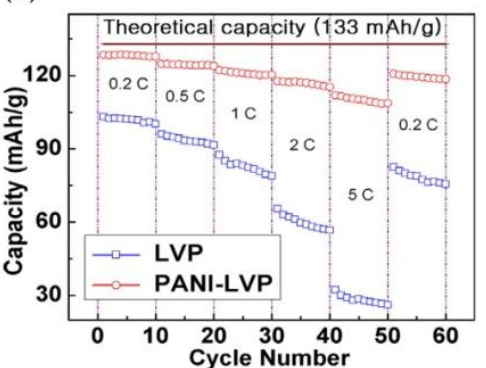

(e)

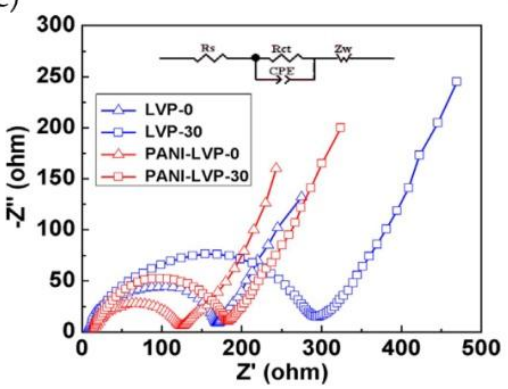

Figure 24. (a) Schematic illustration of the fabrication process of LVP/PEDOT composite and (b) specific discharge capacities of LVP/PEDOT and LVP/carbon in the voltage range 2.5-4.4 V with various current rates [198]. (c) TEM image of PANI-LVP powder, (d) comparison of the rate capability of LVP and PANI-LVP at different rates in the voltage range of 3.0-4.3 V $(1 C=133$ $\mathrm{mA} / \mathrm{g}$ ), and (e) EIS plots and equivalent circuit of LVP and PANI-LVP electrodes tested between $0.01 \mathrm{~Hz}$ and $100 \mathrm{kHz}$ [200]. Although the charge transfer resistance increases after 30 cycles in both samples, PANI-LVP has the smaller resistance than pristine LVP, indicating PANI improves the electrical conductivity in the electrode materials.

\subsection{LVP-Oxide Composites}

Electrolytes react with LVP at high potentials, especially above $4.6 \mathrm{~V}$ in the charged state, thus, surface modification is one of most effective approaches to avoid side reactions and enhance the cycling stability of LVP. Analogous to other cathode materials, metallic oxides coatings are chosen to overcome this instability. For example, $\mathrm{RuO}_{2}$ [203], $\mathrm{SiO}_{2}$ [201,239], $\mathrm{MgO}$ [202], $\mathrm{ZrO}_{2}$ [240], $\mathrm{Al}_{2} \mathrm{O}_{3}$ [241], $\mathrm{CeO}_{2}$ [242] and $\mathrm{MnO}$ [243] are used to modify the surface of LVP. Figure 25a shows the $\mathrm{CV}$ curves of LVP and $\mathrm{LVP}-\mathrm{SiO}_{2} / \mathrm{C}-800$ samples, herein, $\mathrm{LVP}^{-\mathrm{SiO}_{2}} / \mathrm{C}-800$ stands for this composite calcined at $800{ }^{\circ} \mathrm{C}$ in the synthesis process. Two oxidation peaks 
occurs around 3.8 and $4.2 \mathrm{~V}$ and two reduction peaks displays around 3.5 and $3.9 \mathrm{~V}$ in LVP. The $\mathrm{LVP}_{-} \mathrm{SiO}_{2} / \mathrm{C}-800$ electrode has three oxidation peaks around $3.65 \mathrm{~V}, 3.70 \mathrm{~V}$, and $4.12 \mathrm{~V}$ and three reduction peaks around $3.55 \mathrm{~V}, 3.62 \mathrm{~V}$, and $3.95 \mathrm{~V}$ at a scanning rate of $0.05 \mathrm{mV} / \mathrm{s}$. Obviously, the $\mathrm{LVP}-\mathrm{SiO}_{2} / \mathrm{C}-800$ material shows smaller peak separation than LVP at the same scanning rate [239], and smaller voltage polarization in the charge-discharge profiles (Figure 25b). Besides, the $\mathrm{SiO}_{2}$-modified LVP samples deliver higher discharge capacities and considerable cycling stability (Figure 25c). The enhanced electrochemical performance is attributed to the hybrid coating layer where carbon ensures the fast charge transfer and $\mathrm{SiO}_{2}$ hinders side reactions between electrolyte and LVP. In most cases, carbon or oxide coating induce changes in the $\mathrm{V}$ valance state. In order to distinguish between differences in the composite and the pristine sample, V K-edge X-ray absorption spectroscopy was employed to study LVP and $\mathrm{LVP}_{-} \mathrm{SiO}_{2}$. The K-edge energies are 5479.8 and $5480.2 \mathrm{eV}$ for LVP and $\mathrm{LVP}-\mathrm{SiO}_{2}$. These energies are almost identical to the trivalent $\mathrm{V}$ reference compounds, verifying that $\mathrm{SiO}_{2}$ incorporation into LVP/C does not change the valence state of $\mathrm{V}$ ions [201]. Compared with $\mathrm{SiO}_{2}, \mathrm{RuO}_{2}$ is electrochemically active and possesses high ionic and electrical conductivities, and fabricating a hybrid coating consisting of amorphous carbon and $\mathrm{RuO}_{2}$ enabled high conductivities in the LVP composite (Figure 25d). EIS shows that sample with 2.4 wt.\% Ru (sample b) exhibits the lowest interfacial resistance of $87.2 \Omega$ after the first charge, while the sample without $\mathrm{Ru}$ (sample a) shows the largest interfacial resistance of $191.6 \Omega$ (Figure 25e). Besides, the sample $\mathrm{b}$ also has twice the ionic conductivity of LVP/C. Figure $25 \mathrm{f}$ 
shows the cycling performance of the samples at $10 C . \mathrm{RuO}_{2}$ and C co-modified LVP present increased capacity and sample b exhibits the largest discharge capacity (102.5 $\mathrm{mAh} / \mathrm{g}$ ) and the best cyclic stability (98.5\% capacity retention after 100 cycles) among the three samples [203]. In general, oxides are less electrical conductive that would limit the rate capacity of the composites.
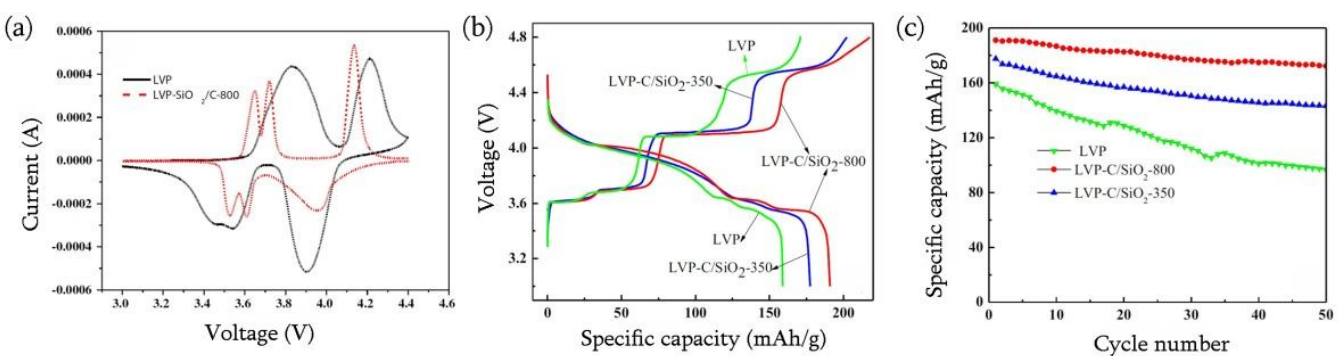

(d)

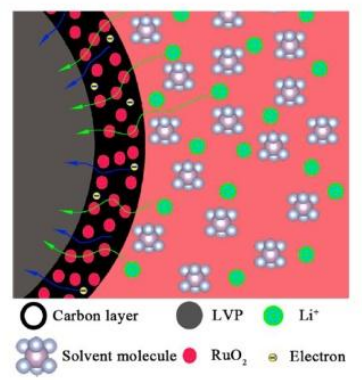

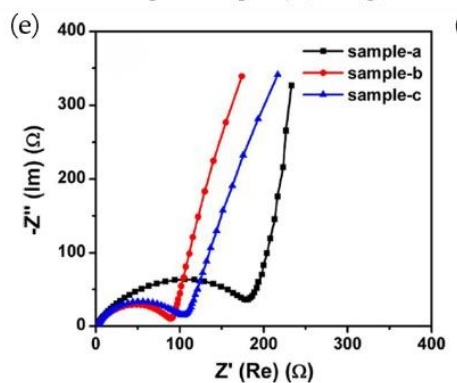

(f)

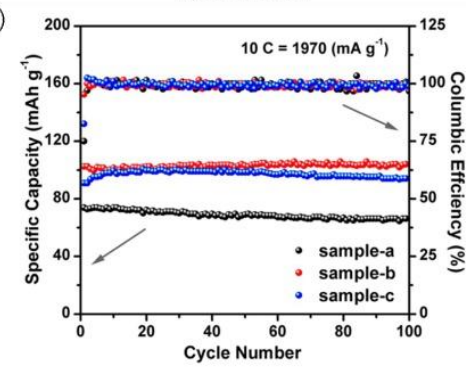

Figure 25. (a) $\mathrm{CV}$ profiles of $\mathrm{LVP}$ and $\mathrm{LVP}-\mathrm{SiO}_{2} / \mathrm{C}-800$ electrodes at the scanning rate of 0.05 $\mathrm{mV} / \mathrm{s}$, (b) charge and discharge capacity and (c) cycle performance of LVP, $\mathrm{LVP}-\mathrm{SiO}_{2} / \mathrm{C}-350$ and LVP-SiO $/ 2$ - -800 materials at $0.1 C$ [239]. (d) $\mathrm{C}+\mathrm{RuO}_{2}$ binary surface coating for the $\mathrm{LVP}$ cathode, (e) Nyquist plots of the $\mathrm{LVP} / \mathrm{C}$ and $\mathrm{LVP} / \mathrm{C}+\mathrm{RuO}_{2}$ samples after 1 cycle, and (f) cycling performance of the $\mathrm{LVP} / \mathrm{C}$ and $\mathrm{LVP} / \mathrm{C}+\mathrm{RuO}_{2}$ samples at a rate of $10 C$ rate [203]. Samples a, b and c stand for the LVP sample with $0,2.4$ and $5.1 \mathrm{wt} . \% \mathrm{Ru}$, respectively.

Composites integrate the advantages of disparate components to meet specified conditions. Two limitations, low electronic conductivity and side reactions at high voltage, deteriorate the cycling stability of the electrode and hinder large-scale applications for LVP cathodes. Thus, introducing a second phase with higher conductivity or chemical stability can improve the rate capability and cyclability in 
the wide potential window of 3.0-4.8 V. Attempts have been carried out that composites and some positive results were verified, but the effects from interfaces between two phases requires more future work.

\section{Designing and Controlling Microstructures}

Designing and controlling the size or dimension on electrode materials not only improves capacity and cycling performance, but also to enhance the rate capability because changing the surface area and reactivity determines the path of ions diffusion and rate of electrons transfer. In particular, the dimensional control of materials at the nanoscale leads to unexpected characteristics. This section is divided into four aspects: zero-, one-, two- and three dimensional structures, and discusses how the mophology of nanostructured LVP affects their electrochemical properties.

\subsection{Zero Dimensional (0D) LVP}

Zero dimensional LVP is primarily concerned with nanoparticles and spherical materials. Compared irregular particles, spherical particles has many advantages such as higher volumetric energy density, higher tap density, better fluidity charteristics and lower surface energy [244-248]. Up to now, several studies have focused on spherical LVP, including solid [249-251], hollow [252] and mesoporous [253-255] spheres, which display different enhanced properties. Single-phase, spherical and well-dispersed $\mathrm{Li}_{3} \mathrm{~V}_{2}\left(\mathrm{PO}_{4}\right)_{3}$ has been successfully synthesized by using $\mathrm{N}_{2} \mathrm{H}_{4}$ as the reducing agent and the initial discharge capacities at $0.5 C$ were $123 \mathrm{mAh} / \mathrm{g}$ in the 
voltage range of 3.0-4.3 $\mathrm{V}$ and $132 \mathrm{mAh} / \mathrm{g}$ in the voltage range of 3.0-4.8 $\mathrm{V}$ [249]. In addition, spray drying was adopted to synthesize spherical LVP, which exhibits the discharge capacities of $130 \mathrm{mAh} / \mathrm{g}$ at $0.2 C$ and $100 \mathrm{mAh} / \mathrm{g}$ at $20 C$ [251]. Besides, the cycling performance is also excellent; the charge-discharge plateaus of cell in the $1^{\text {st }}$ and $105^{\text {th }}$ cycles are similar and the cell delivers $97.7 \%$ of the $1^{\text {st }}$ discharge capacity, $127 \mathrm{mAh} / \mathrm{g}$, at $105^{\text {th }}$ cycle with $0.2 C$ rate in the voltage of $3.0-4.8 \mathrm{~V}$. In addition to the morphology of LVP, the coated carbon also ensures superior rate and cycling performance. Ultrasonic-assisted spray drying was used to synthesize regular spherical LVP (Figure 26) with carbon coating from sucrose [256]. The addition of sucrose in spray solution directly affects the formation of spherical LVP, irrespective of the amount of surcose added. The carbon from sucrose serves as a buffer coating that hinders the grain growth of LVP (Figure 26b). Interestingly, the adding sequence of raw materials determines the final morphology of LVP when the sodium salt of carboxy methyl cellulose (CMC) was added as carbon source [252]. SEM images (Figure 26 a-b) show the different morphologies: solid spherical particles are prepared by adding CMC after pre-sintering, and hollow LVP prepared by adding CMC before pre-sintering. The solid spheres present an initial charge capacity of $172.3 \mathrm{mAh} / \mathrm{g}$ and a related discharge capacity of $154.4 \mathrm{mAh} / \mathrm{g}$ with $89.6 \%$ coulombic efficiency at a current density of $0.1 C$, while the hollow electrode only delivers an initial discharge capacity of $132.4 \mathrm{mAh} / \mathrm{g}$ and $80.7 \%$ coulombic efficiency between 3.0-4.3 V (Figure 26 e). On the cycling, the solid LVP maintains a higher discharge capacity than that of hollow LVP (Figure $26 \mathrm{f}$ ). Both LVP composites show a new plateau around $3.85 \mathrm{~V}$ in 
the charge/discharge curves, which is caused by the formation of active $\mathrm{Na}^{+}$-containing compounds which were introduced by CMC. A microsphere LVP structure derived from yeast cells had a discharge capacity of about $126.7 \mathrm{mAh} / \mathrm{g}$ and only $2 \%$ capacity loss of the initial value after 50 cycles at $0.2 C$, and a high rate capacity of $100.5 \mathrm{mAh} / \mathrm{g}$ at $5 C$ in the region of 3.0-4.3 V[253]. Another similar work demonstrated a high capacity of $205 \mathrm{mAh} / \mathrm{g}$ at $0.2 C$ within the potential range of 3.0-4.8 V [257] which is not only better than the results of samples from spray drying [249,251], but also higher than the theoretical capacity of $197 \mathrm{mAh} / \mathrm{g}$. The remarkable results derive from the raw materials and the final structures of samples. During the synthesis (Figure $27 \mathrm{a}-\mathrm{b}$ ), the cations are electrostatically interact with the negatively charged hydrophilic groups and then self-assemble both on the yeast cell wall surface and inside the cell by metabolism regulation. After heat treatment, the carbon network formed on the surface of microsphere (Figure 27 c) supplies a condutive path for electrons transfer and the mesoporous micropheres allow the penetration of electrolyte. However, the samples have modest cycling stabilities due to the dissolution of $\mathrm{V}_{2}\left(\mathrm{PO}_{4}\right)_{3}$ and graphitization of biocarbon. Wu et al [254]. combined the two step ball-milling with spray drying to produce the single-phase LVP micropheres (diameter 1-3 $\mu \mathrm{m}$ ) consisted of uniformly distributed nanoparticles (diameter 50-200 nm). The sample delivers discharge capacities of 124.4 and $108.6 \mathrm{mAh} / \mathrm{g}$ at the current densities of 1 and $10 C$, respectively, in the potential range of 3.0-4.3 V. Besides, the tap density of the sample is as high as $1.49 \mathrm{~g} / \mathrm{cm}^{3}$ which is crucial for improving the enery density in pratical battery materials. Qiao et al [255]. employed hydrazine hydrate as 
the spheroidizing medium and 1,4-dihydroxy-2-butyne as the carbon source to fabricate a microspherical LVP/C composite that shows a high discharge capacity of 129.1 and $183.8 \mathrm{mAh} / \mathrm{g}$ at $0.2 C$ in the potential window of $3.0-4.3 \mathrm{~V}$ and $3.0-4.8 \mathrm{~V}$, respectively. The improved performace is attributed to the porous structure in the microspheres that provides good contact between electrolyte and electrode and supplies channels for fast Li-ion diffusion and electron transfer. Based on the results related to zero-dimensional LVP materials above, solid or porous spheres have improved specific capacities and the samples modified with carbon further have excellent rate capabilities and higher tap densities. According to "radial model" and "mosaic model" proposed by Andersson and Thomas [258], the smaller the particle, the faster the lithium ions and electrons extract, and hence the higher capacity. The reduced size of nanoparticles for assembled porous microspheres could improve the properties of LVP to move forward a new stage of research and development. 
(a)

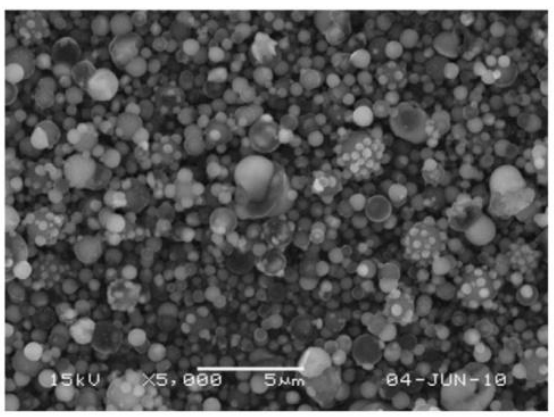

(c)

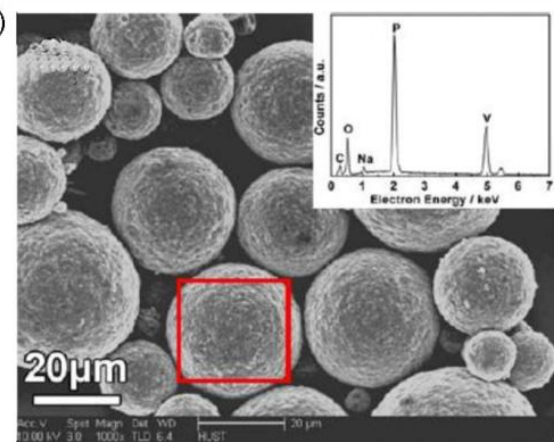

(e)

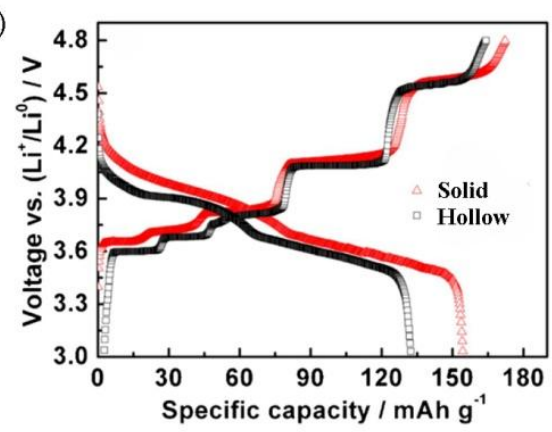

(b)

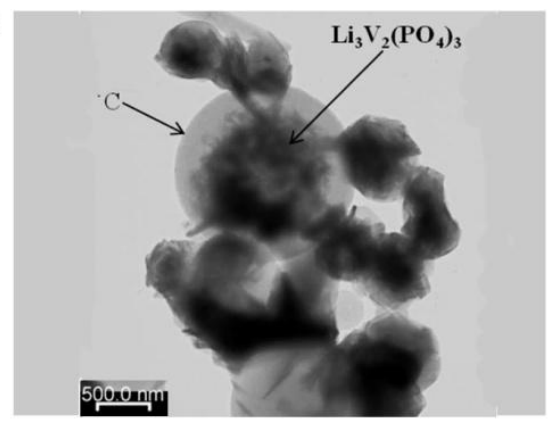

(d)
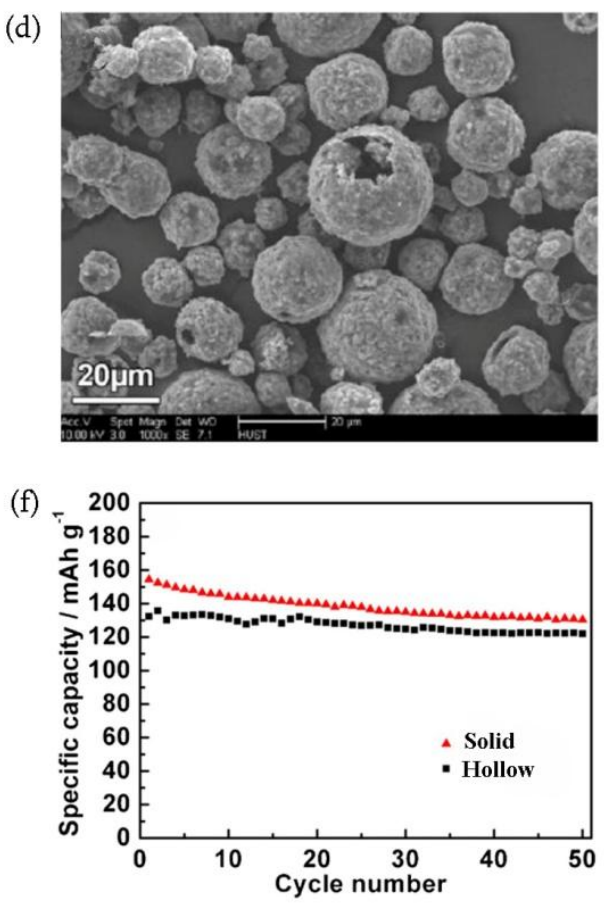

Figure 26. (a) SEM image and (b) TEM image of the post-treated powders prepared from the spray solution with $0.1 \mathrm{M}$ sucrose [256]. The carbon coating separates the grains of LVP and hinders grain growth. SEM images of solid LVP (c) and hollow LVP (d) samples. The spherical samples are actually an aggregation of smaller particles with sizes on the order of several hundreds of nanometers. The adding sequence of carboxy methyl cellulose (CMC) affects the amount of released gases and affects the morphology of the final sample. The initial charge/discharge profiles (e) and cyclic performance (f) for solid and hollow electrodes cycled at $0.1 C$ with a voltage range of 3.0-4.8 V. The solid spherical sample delivers higher capacity with higher coulombic efficiency compared to the hollow sample [252]. 
(a)

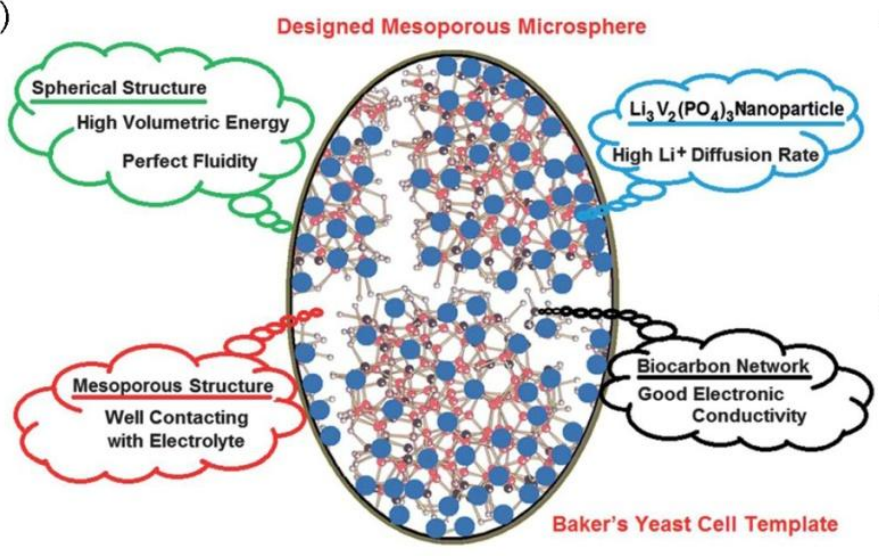

The metal ions absorb on the

(b) yeast cell and inside the cell

(c)

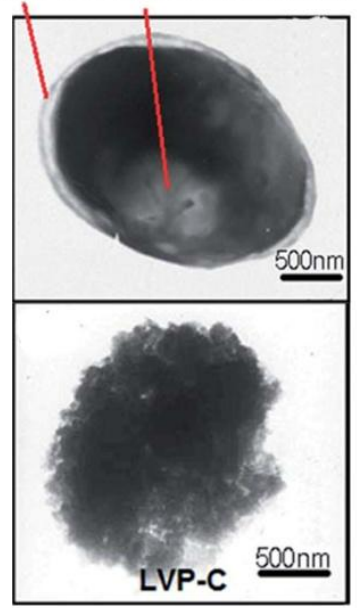

Figure 27. (a) Schematic representation of the microstructure of LVP-C synthesized by a yeast cell biotemplate. In this nanostructure, LVP nanoparticles effectively reduce the Li-ion diffusion distance and the inter-linked pores give a channel for wetting the electrode. Besides, the biocarbon network supplies an excellent conductive path that is beneficial to ensure the rate capability. (b) TEM image of yeast cell after adding $\mathrm{Li}^{+}, \mathrm{VO}^{2+}, \mathrm{PO}_{4}{ }^{3-}$ into the bioemulsion. The abundant surface charges on the cell wall provide nucleation sites for reactive ions. (c) TEM image of the final sample, LVP nanoparticles and interconnected carbon built the spherical porous framework [253].

\subsection{One Dimensional (1D) LVP}

One dimensional nanomaterials have unique electronic and structural properties that are attractive to the field of energy conversion and storage [259-265]. 1D LVP is no exception because the shorted ion diffusion distance and continuous electronic transfer path greatly benefits LVP as a Li-ion battery cathode [266-269]. Several methods have been used to obtain 1D LVP, such as hydrothermal [267,268], electrospining [269] and solid-state carbothermal reduction reactions [266]. Fei et al. combined ball-milling and solid-state carbothermal reduction to synthesize nano-flake carbon-entangled LVP nanorods which have high tap density and high specific capacity [266]. The composite material was obtained after ball milling the LVP precursor with sucrose and annealed in Ar (Figure 28a). The LVP rods ensure a higher 
tap density $\left(1.4 \mathrm{~g} / \mathrm{cm}^{3}\right)$ and continous carbon flakes provide fast charge transport (Figure 28b). The sample delivered an discharge capacities of $127.1(0.1 C), 123.8$ $(0.5 C), 122.0(1 C), 120.6(2 C), 117.9(5 C), 113.4(10 C) \mathrm{mAh} / \mathrm{g}$, and then back to 124.1 $\mathrm{mAh} / \mathrm{g}(0.1 C)$ in the voltage window of 3.0-4.3 V. This work not only combines the advantages of carbon and 1D LVP, but also avoids the drawback of low volumetric capacities in similar studies [270,271]. Electrospining is another effective way to obtain 1D inorganic materials [272] and LVP nanofibers (Figure 28c) were prepared in this way using $\mathrm{NH}_{4} \mathrm{VO}_{3}, \mathrm{NH}_{4} \mathrm{H}_{2} \mathrm{PO}_{4}, \mathrm{CH}_{3} \mathrm{COOLi}$, poly (4-vinyl) pyridine (PVP) and citric acid as raw materials in an aqueous solution [269]. The nanofibers possess excellent specific surface area $\left(160.75 \mathrm{~m}^{2} / \mathrm{g}\right)$ which facilitates much smaller local current densities, leading to smaller polarization. Besides, higher specific surface area also supplyies sufficient contact between the electrolyte and 1D disperive carbon nanofibers to compensate for the low electronic conductivity of LVP. Therefore, this sample exhibits a surprising discharge capacity of $190 \mathrm{mAh} / \mathrm{g}$ (Figure 28d) at a current density of $0.1 C$ in the potential window of 3.0-4.8 V, which is very close to the theoretical capacity of $197 \mathrm{mAh} / \mathrm{g}$. Even at a high rate of $20 C$, the sample presents the discharge capacity of $132 \mathrm{mAh} / \mathrm{g}$. 
(a)

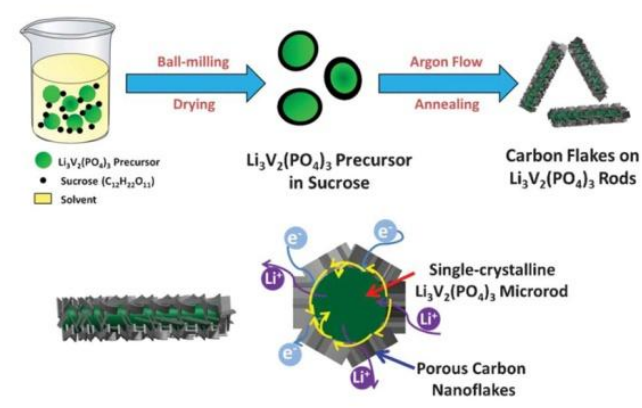

(c)

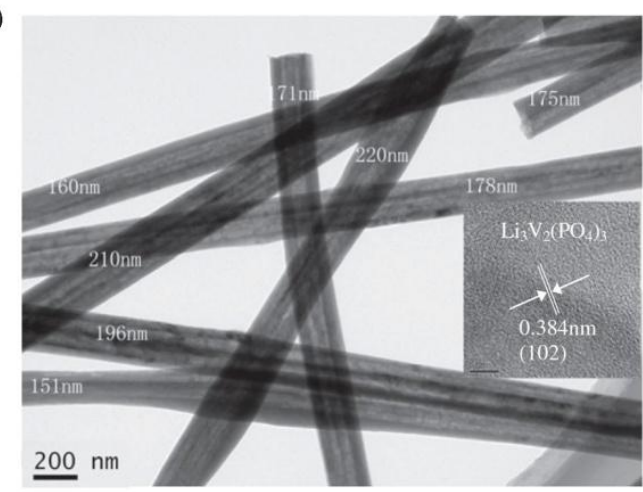

(b)

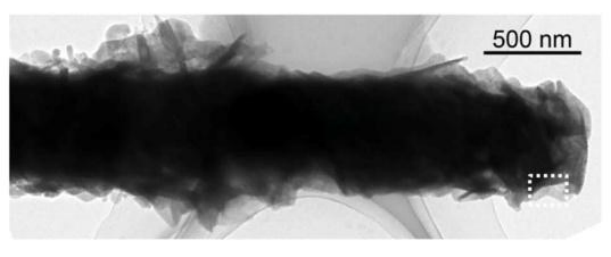

(d)

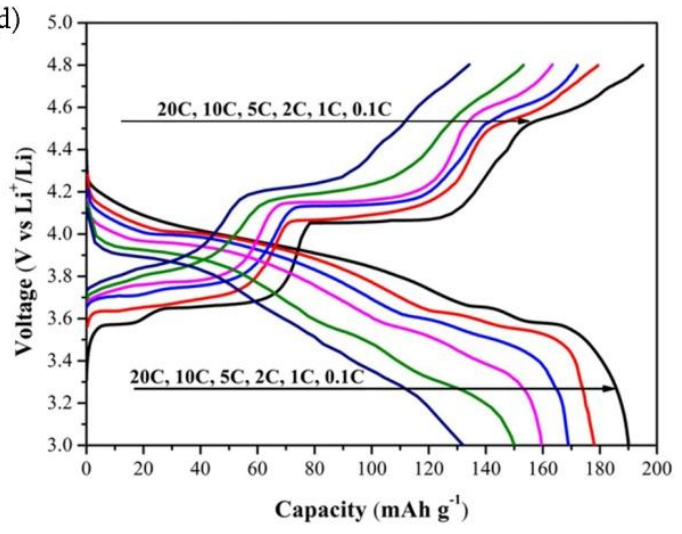

Figure 28. Schematic illustration of (a) synthesis of the heterostructured composite of carbon nanoflakes on LVP rods, sketched morphological features and proposed cross-sectional $\mathrm{Li}^{+} / \mathrm{e}^{-}$ transfer mechanism in LVP/C composite and TEM image of LVP/C composite [266]. (b, c) TEM images of LVP/C composite, (d) Charge/discharge curves of LVP/C nanofibers composite at different current rates $(1 C=197 \mathrm{~mA} / \mathrm{g}$ ) [269]. The initial discharge capacity reaches up to 190 $\mathrm{mAh} / \mathrm{g}$ (close to theoretical capacity of $197 \mathrm{mAh} / \mathrm{g}$ ) at $0.1 C$ and $132 \mathrm{mAh} / \mathrm{g}$ at $20 C$ in the potential window of 3.0-4.8 V.

Besides carbothermal and electrospining approaches mentioned above, hydrothermal methods are another effective way to synthesize 1D LVP. Defect-rich LVP nanorods have been preferentially growth along the [120] direction to lengths of several hundred nanometers and diameters of about $60 \mathrm{~nm}$ [267]. The nanorod discharge capacities are 141.6, 136.1, 134.6, 124.8 and $101.1 \mathrm{mAh} / \mathrm{g}$ at current densities of 0.5, 1, 2, 5 and $10 C$ rate, respectively $(1 C=180 \mathrm{~mA} / \mathrm{g})$ between 3.0 and $4.6 \mathrm{~V}$. These results represent an improvement compared to samples derived from conventional appoaches [273]. Besides, the defect-rich surface and suspension of structural changes 
endows considerable electrochemical performance, asverified in other work $[60,274]$. Another hydrothermal route to 1D LVPs used cetyltrimethylammonium bromide $(\mathrm{CTAB})$ and oxalic acid simultaneously as surfactant and carbon sources to form mesoporous carbon scaffolds and crystallize LVP [268] . According to other reported work [275-278], conductive mesoporous nanowires loaded with active nanocrystals (Schematic illustration in Figure 29a) provide fast ion or electron transfer, large surface area andgreat structural stability, leading to tremendous performance for Li-ion storage. During synthesis, organics not only play a role assembling nanocrystals along a preferential direction, but also act as carbon sources located in the voids of the nanowires. After heating, high-area $\left(67.5 \mathrm{~m}^{2} / \mathrm{g}\right)$ mesoporous nanowires consisting of nanocrystals of LVP and continuous carbon are formed (Figure 29b-d). The hierarchical nanowires display an initial discharge capacity of $120 \mathrm{mAh} / \mathrm{g}$ and delivers a outstanding capacity of $107 \mathrm{mAh} / \mathrm{g}$ after 1000 cycles at $5 \mathrm{C}$ in the potential range of 3.0-4.3 V. It is surprising that more than $80.0 \%$ capacity still remained after 3000 cycles, much higher than that of LVP $(39.2 \%)$. Besides, the diffusion coefficiency of $\mathrm{Li}^{+}$are also improved to $4.11 \times 10^{-9} \mathrm{~cm}^{2} / \mathrm{s}$, which is higher than OD LVP $\left(6.76 \times 10^{-10} \mathrm{~cm}^{2} / \mathrm{s}\right)$ [253]. Nanofiber-loaded LVP also displays high ionic and electrical conductivity which ensures excellent capability and cycling performance [158]. 

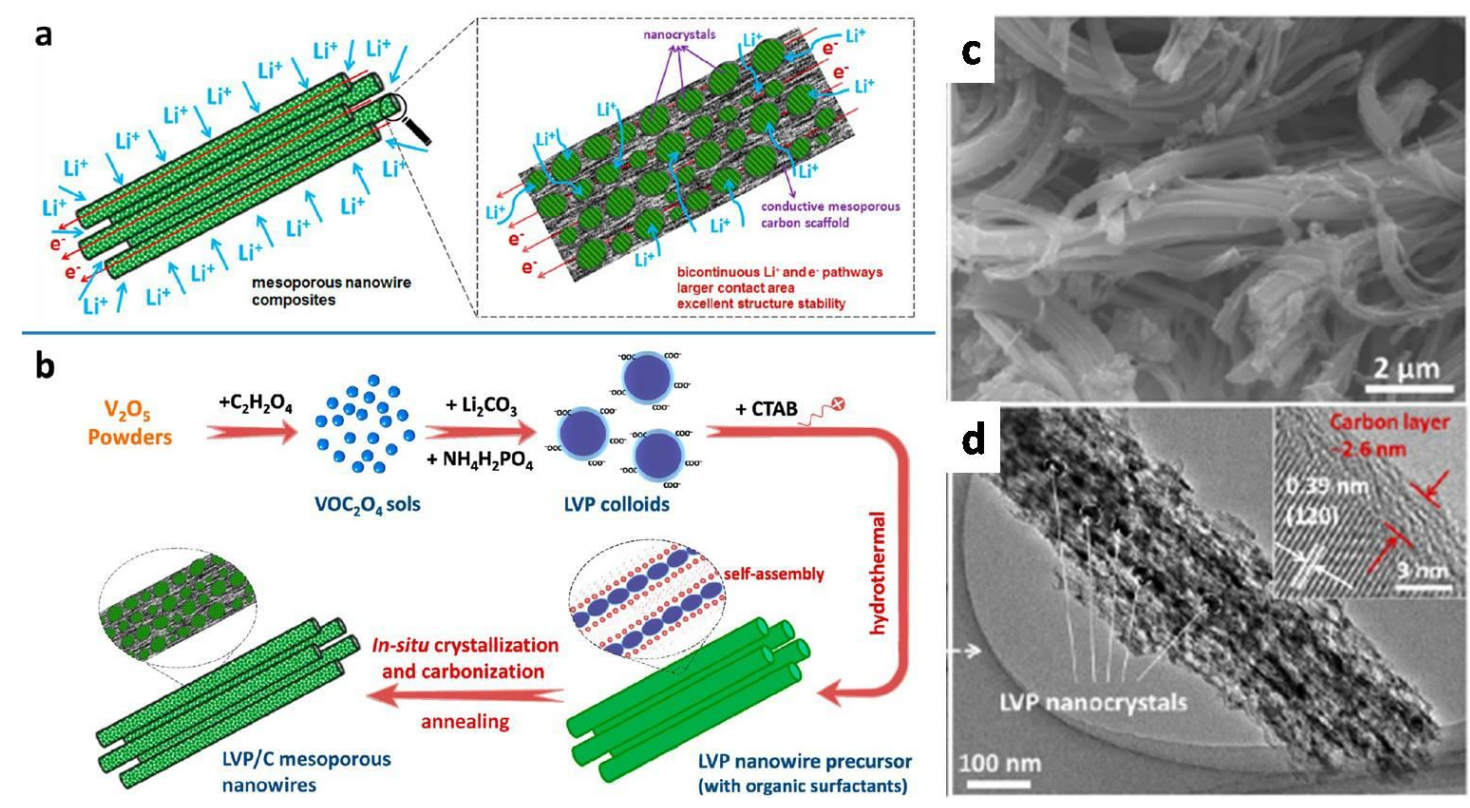

Figure 29. (a) Schematic illustration of the mesoporous nanowire composites with bicontinuous electron/ion transport pathways, larger electrode-electrolyte contact area, and facile strain relaxation during $\mathrm{Li}^{+}$extraction/insertion. (b) Schematic illustration of the fabrication steps and proposed formation mechanism for the LVP/C-M-NWs, (c) SEM image and (d) TEM image of mesowires of LVP [268].

These results demonstrate that 1D LVP possesses unique structural characteristics which provide channels for rapid ion or electron transport and high surface area for ensuring sufficient contact between the electrode and the electrolyte. Introducing mesopores and carbon scaffolds in 1D LVP to form hierarchical nanostructures may solve issues pertaining to aggregation of the active nanocrystals and stability during lattice expansion and contraction. Therefore, increasing the surface area, number of defects and continuity of the conductive framework, as well as tuning the size of active nanocrystals in 1D electrode materials, are all suitable ways for synthesizing the practical materials that simultaneously possess high capacity, excellent rate capability and stable cycling performance. 


\subsection{Two Dimensional (2D) LVP}

Two dimensional architectures are of great interest in many fields, such as optics [279], electronics [280,281], ion conduction [282], catalysis [283], energy storage [284-288] and so on. They are important to enegry storage because 2D structural materials can offer high active surface area and shortened paths for $\mathrm{Li}$ ion insertation/extraction [284,285,289-293]. Plate-like LVP/C composite has been synthesized [294] (Figure 30a), and it exhibits a specific capacity of $131.6 \mathrm{mAh} / \mathrm{g}$ (99 \% of the theoretical capacity) between $3.0-4.3 \mathrm{~V}$ and $193.7 \mathrm{mAh} / \mathrm{g}(98 \%$ of the theoretical capacity) between $3.0-4.8 \mathrm{~V}$ at a current density of $0.1 C$. When cycled at 3C, the sample delivers an initial discharge capacity of 125.2 and $133.3 \mathrm{mAh} / \mathrm{g}$ in the potential window of 3.0-4.3 and 3.0-4.8 V, respectively. After 500 cycles, the sample still delivers a discharge capacity of 111.8 and $97.8 \mathrm{mAh} / \mathrm{g}$ in $3.0-4.3$ and 3.0-4.8 V, respectively, displaying a good cycling performance. Based on the CV curve, the diffusion coefficient is calculated to be $2.7 \times 10^{-8} \mathrm{~cm}^{2} / \mathrm{s}$ that is higher than OD $\left(6.76 \times 10^{-10} \mathrm{~cm}^{2} / \mathrm{s}\right)$ [253] and 1D $\left(4.1 \times 10^{-9} \mathrm{~cm}^{2} / \mathrm{s}\right)$ [268] LVP morphologies. The competitive results originate from the structural characteristics of LVP which allow for fast ion transfer and uniform carbon coating (Figure 30b) for rapid electron transport. Nanobelts are another two dimensional shape. Pan et al [295]. have been employed a solid-state reaction in a molten hydrocarbon to prepare LVP nanobelts. The thickness and width of the nanobelts are around 50 and $200 \mathrm{~nm}$ (Figure 30c), respectively. During synthesis, oleic acid $\left[\left(\mathrm{CH}_{3}\left(\mathrm{CH}_{2}\right)_{7} \mathrm{CH} \mathrm{CH}\left(\mathrm{CH}_{2}\right)_{7} \mathrm{COOH}\right)\right]$ was adopted as the surface-capping precursor ligand, which sterically hinders 
agglomeration during the formation of LVP nanocrystals. Besides, the extend of tails of oleic acid in molten paraffin media act as a surfactant that directs the growth of LVP nanobelts. Furthermore, the decomposition of oleic acid produces carbon coated on the active materials, which facilitates electron transports in the final product. The electrochemical properties are outstanding for this LVP nanobelts. An initial discharge capacity of $131 \mathrm{mAh} / \mathrm{g}$ was measured at $0.1 C$ in the potential range of $3.0-4.3 \mathrm{~V}$, which is very close to the theoretical capacity of $133 \mathrm{mAh} / \mathrm{g}$. Even after 40 rate cycles, the specific discharge capacity of LVP electrode can return to $131 \mathrm{mAh} / \mathrm{g}$ at $0.1 C$ (Figure 30d). These properties are better than those of other 2D LVPs [294,296] disscussed in this section.

(a)

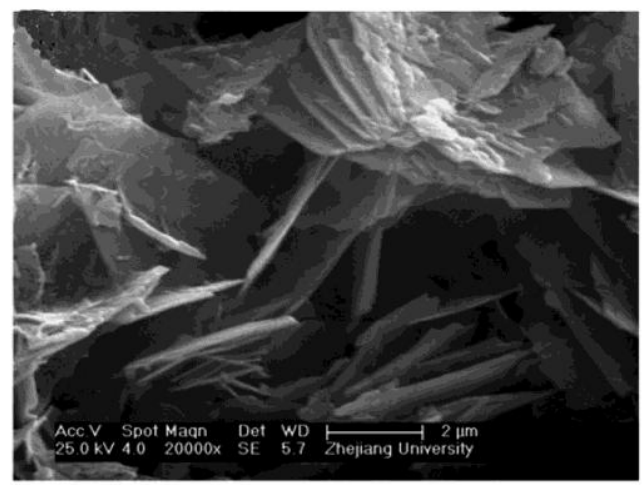

(b)

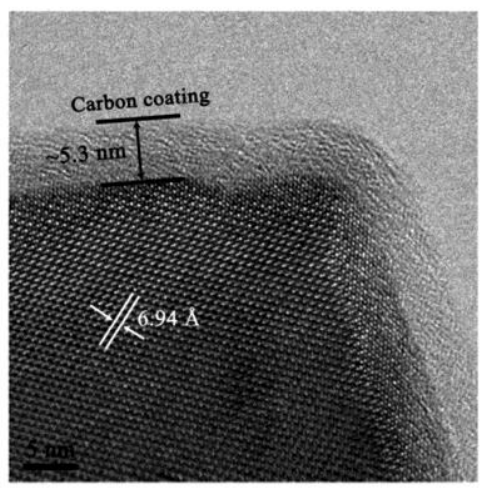

(c)

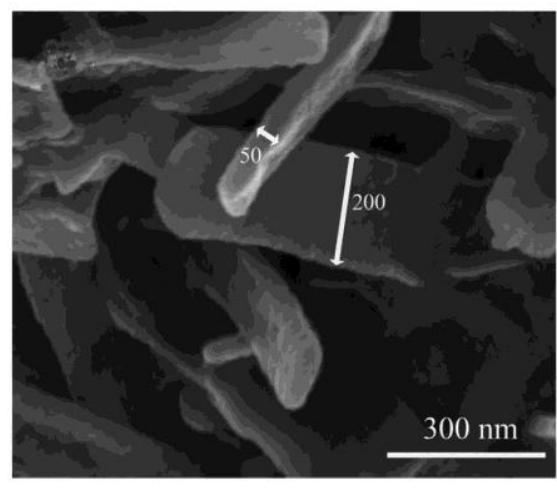

(d)

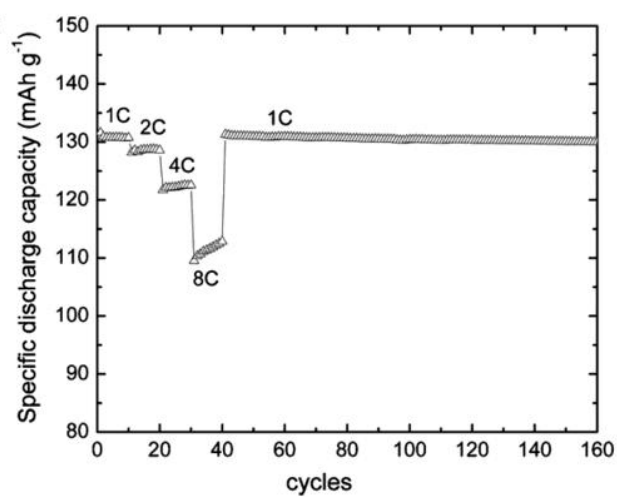

Figure 30.(a) Plate-like LVP/C composite after calcination; (b) HRTEM image showing a nearly 
$5.3 \mathrm{~nm}$ thick amorphous carbon layer on the surface and lattice fringes of monoclinic LVP. The carbon content is $3.23 \mathrm{wt} \%$ from the element analysis [294]. (c) FIB-SEM images of LVP nanobelts. Although LVP nanobelts aggregate, open spaces still remain. This structure allows easy penetration of electrolyte, which strongly affects the cycling and rate performance. (d) Cycling performance at various $\mathrm{C}$-rates followed by cycling with a constant $1 C$ charge/discharge rate. Here $1 C=132 \mathrm{~mA} / \mathrm{g}$ [295].

Hydrothermal synthesis was employed to prepare plate-like carbon-coated LVP [296] and the thickness of amorphous carbon coating is $5.6 \mathrm{~nm}$ (Figure 31a-b). The plate-like LVP delivers a capacity of $127.7 \mathrm{mAh} / \mathrm{g}$ in the initial discharge cycle and $124.5 \mathrm{mAh} / \mathrm{g}$ after 100 cycles (97.9\% capacity retention) at $0.1 C$ between 3.0 and 4.3 V. In the voltage range of 3.0-4.8 V, the sample displays $175.4 \mathrm{mAh} / \mathrm{g}$ in the initial discharge cycle and $140.7 \mathrm{mAh} / \mathrm{g}$ after 100 cycles $(80.2 \%$ capacity retention) at a current density of $0.2 C$. When cycled at $1 C$, its initial discharge capacity is 157.3 $\mathrm{mAh} / \mathrm{g}$ and $133.7 \mathrm{mAh} / \mathrm{g}$ for a capacity retention of $85 \%$ after 200 cycles. These results are remarkably higher than data from samples prepared by sol-gel [297] and solid state reaction [209]. As seen from Figure 31c, the rate capability for plate-like LVP in the 3.0-4.3 $\mathrm{V}$ range is better than that in the 3.0-4.8 $\mathrm{V}$ range. The advantages in 3.0-4.3 $\mathrm{V}$ derive from the unique structure in which rapid ion exchange and fast conductive path ensure fast kinetics at various rates. However, between 3.0 and $4.8 \mathrm{~V}$ oxidation of the electrolyte and overcharging causes the capacity to fade . 2D LVP also showed stable low-temperature performance. Below $-20^{\circ} \mathrm{C}$, the initial discharge capacity was $120.7 \mathrm{mAh} / \mathrm{g}$ and $117.4 \mathrm{mAh} / \mathrm{g}$ remained after 80 cycles at $0.1 C$. This is an important feature for practical applications like the winter performance of electric and hybrid electric vehicles (EVs and HEVs). 
From the previous results discussed above, 2D LVP has an outstanding merit most probably because the exposure surface has the preferential directions for $\mathrm{Li}$ ion diffusion. The reduced thickness provides ion channel for fast $\mathrm{Li}$ insertion/extraction, which can be verified by the Li-ion diffusion coefficient of 2D LVP compared to OD and 1D materials. When carbon is deposited on the surfaces of active materials as electron highway, both the rate and cycling performance are enhanced. Significantly, LVP has a three dimensional pathway for Li ion diffusion, as opposed to only one dimension for $\mathrm{LiFePO}_{4}[83,97,153]$, thus, controlling of crystalline preferential direction is not rigorous in LVP.
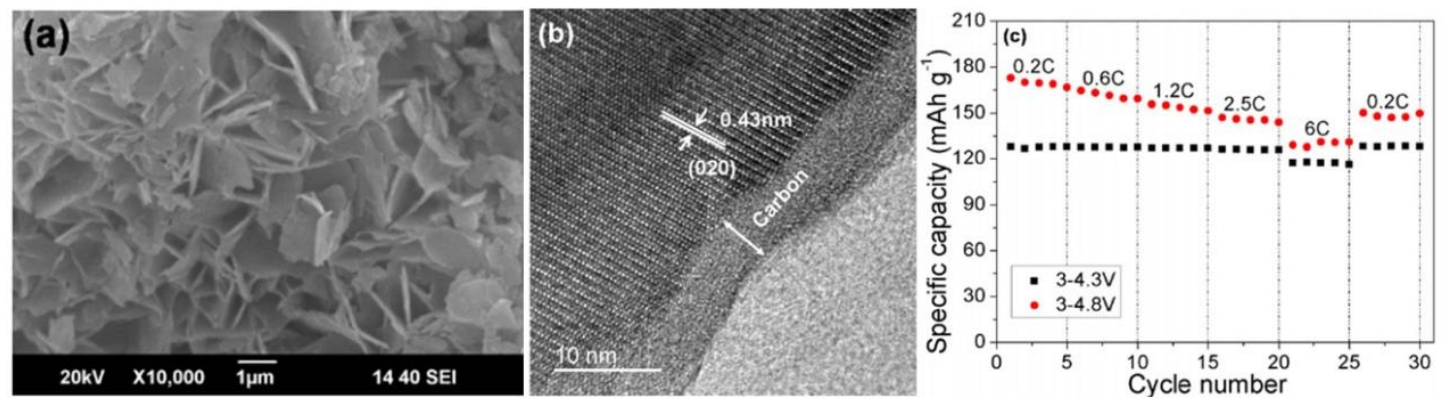

Figure 31. (a) SEM images of the intermediate product after hydrothermal synthesis. This shape could be remained after high-temperature calcination. (b) HRTEM images of a plate-like LVP/C particle. The amorphous carbon coating is uniform and the thickness is about $5.6 \mathrm{~nm}$. (c) The specific discharge capacity at different rates. It is worth noting that the discharge capacities of sample are stable at different rates in the potential window of 3.0-4.6 V, indicating that the carbon coating plate-like LVP possesses not only higher specific capacity, but also more stable rate capability [296].

\subsection{Three Dimensional (3D) LVP}

Three dimensional architectures for electrode materials can solve several issues related to fast charge/discharge in Li-ion battery and attract the attention of chemists 
and engineers [298-301]. Recently, several studies focused on 3D architectures for LVP, and both the rate capability and cycling performance were remarkably enhanced [301-306] compared to irregular LVP. For example, sol-gel combustion was employed to prepare a 3D porous $\mathrm{LVP} / \mathrm{C}$ composite [303] in which the content of amorphous carbon is $5.4 w t . \%$, as detected by element analysis. The porous microstructure accommodates penetration of electrolyte and the continuous framework provides pathway for fast charge transfer (Figure 32a). In the experimental process, citric acid and ethylene glycol were added as chelates that created pores in the precursor (Figure 32b) after combusting. Last, sucrose as carbon source was decomposed and deposited on the wall of pores and surface of active materials to build a 3D network. The Brunauer-Emmett-Teller (BET) adsorption measurements showed that the 3D porous LVP has a high specific surface area of $25.7 \mathrm{~m}^{2} / \mathrm{g}$ which provide abundant contact between the active materials and electrolyte to meet the requirements of fast ionic transportation. This 3D LVP/C sample delivers high capacities of 122, 114, 108 and $88 \mathrm{mAh} / \mathrm{g}$ at current densities of $10,20,40$, and $60 C$, respectively, after 100 cycles between 3.0 and $4.3 \mathrm{~V}$ (Figure 32c). This result is better than the discharge capacity of 91.5 mAh/g from macroporous LVP at $2 C$ after 20 cycles within 3.0-4.3 V [304] or $86 \mathrm{mAh} / \mathrm{g}$ of 3D network LVP at $10 C$ under same measured conditions [40]. Besides, $3 \mathrm{D}$ ordered macroporous $(3 \mathrm{DOM}) \mathrm{LVP} / \mathrm{C}$ cathode material is fabricated using a colloidal crystal array [306] that is illustrated in Figure 32d. The 3DOM architecture is constructed from densely sintered LVP/C composite with small pores of 50-140 nm (Figure 32e). The sample delivers a superior discharge capacity of $151 \mathrm{mAh} / \mathrm{g}$ at 0.1 
$C$ between 3.0 and $4.4 \mathrm{~V}$, which exceeds the theoretical capacity of $133 \mathrm{mAh} / \mathrm{g}$. Even at a high current density of $5 C$, its discharge capacity also reaches up to $132 \mathrm{mAh} / \mathrm{g}$. One explanation for this unexpected phenomenon is side reactions at high voltage. Uniformly ordered nanopores not only store electrolyte as reservoirs, but also increase the reaction area in the active solid material, causing the fraction of the measured capacity contributed by side reactions to increase relative to nontemplated LVP. The other reason may be surface storage or intercalation pseudocapacitance producing an additional capacity. As seen from Figure 32f, the LVP from the nontemplated method has a normal capacity of $124 \mathrm{mAh} / \mathrm{g}$, in agreement with the other reported results $[153,307,308]$. It is worth noting that the average capacity fading of 3DOM LVP is $0.08 \%$ per cycle, whereas nontemplated LVP suffered a capacity loss of $0.4 \%$ per cycle. When cycled at $20 C$, the capacity of 3 DOM LVP retains $70 \mathrm{mAh} / \mathrm{g}$, but nontemplated LVP is only $23 \mathrm{mAh} / \mathrm{g}$, indicating that the $3 \mathrm{DOM}$ LVP possessed considerable rate capability. However, it is less than $114 \mathrm{mAh} / \mathrm{g}$ obtained with nanoporous LVP [303] under same measured conditions. The difference comes from the size of active materials and smaller pores than in the 3DOM LVP. 
(a)

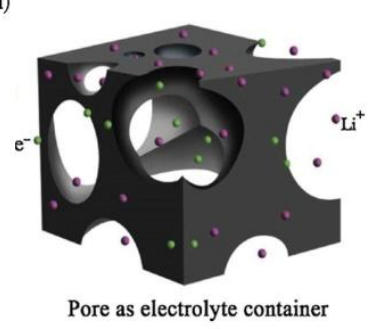

(d)

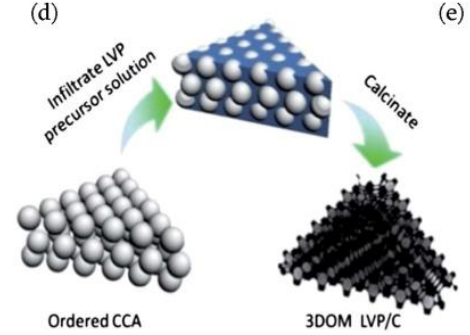

(b)

(e)
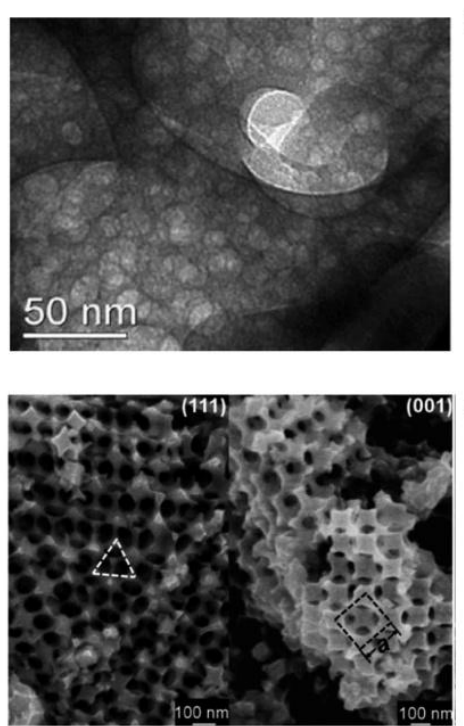

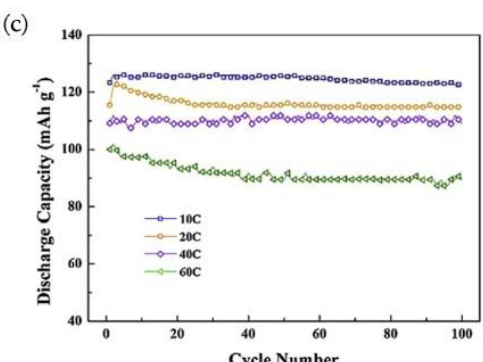

Cycle Numb

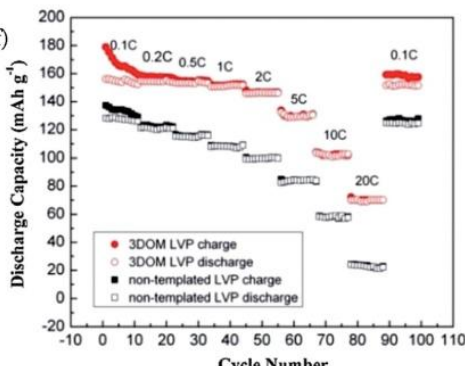

Figure 32. (a) Schematic of 3D-LVP framework. (b) TEM image of the precursor, (c) cycling performance at rates from 10 to $60 C$ between 3.0 and $4.3 \mathrm{~V}$ [303]. (d) The synthesis illustration of 3DOM LVP/C. (e) FESEM images showing FCC structure along the [111] and [001] directions, (f) cycling performance of the 3DOM LVP/C and LVP/C samples at different rates in the voltage range of 3.0-4.4 V. It is surprising that the initial discharge capacity of 3DOM $(155 \mathrm{mAh} / \mathrm{g})$ excesses the theoretical capacity of $133 \mathrm{mAh} / \mathrm{g}$ [306].

Continuous carbon coverage provides conductive electron paths for electrode materials, which is one of crucial factors for meeting the kinetic requirements in heavy duty power devices. When active materials form a continuous network with conductive carbon, the electrode kinetics is improved remarkably. A bicontinuous cathode with hierarchical carbon-decorated LVP was successfully designed and prepared (Figure 33a). It displayed a discharge capacity of $121 \mathrm{mAh} / \mathrm{g}$ (91\% of theoretical capacity) at a current density of $30 C$ [309], which is higher than what was obtained for 3D LVP with nanoporous [303] or ordered macroporous structures [306].

Figure $33 \mathrm{~b}$ shows cycling performance at different temperatures. The specific capacity decreases at low temperature due to the slow diffusion of $\mathrm{Li}$ ions. The sample exhibits a high initial capacity of $106 \mathrm{mAh} / \mathrm{g}$ and capacity retention of $88 \%$ 
after 450 cycles at $-20{ }^{\circ} \mathrm{C}$. Then, when the cell was heated back to $25{ }^{\circ} \mathrm{C}$ for subsequent tests the discharge capacity immediately returned to $117 \mathrm{mAh} / \mathrm{g}$. When the temperature increases to $60{ }^{\circ} \mathrm{C}$, a high discharge capacity of $125 \mathrm{mAh} / \mathrm{g}$ can be achieved. After hundreds of cycles at high and low temperatures, a discharge capacity of $108 \mathrm{mAh} / \mathrm{g}$ can still be delivered when the temperature turned back to $25^{\circ} \mathrm{C}$ [309]. This hierarchical carbon decorated LVP not only endows high rate and cycling performance, but also exhibits broad temperature adaptability. This superior performance of 3D LVP derived mainly from the carbon-confined bicontinuous structure. First, the dissolution of the active materials at high temperature is efficiently hindered by the protective carbon shell on the surface of LVP. Second, the slow kinetics of electrode at low temperatures are improved by virtue of the $3 \mathrm{D}$ carbon network. In addition, freeze drying was used to synthesize 3D LVP foam and the resulting sample is shown in Figure 33c. The discharge capacities of LVP were observed to be $121,112,105,91$, and $79 \mathrm{mAh} / \mathrm{g}$ at discharge rates of 5,10, 20, 50, and $100 C$ (Figure 33d). More significantly, the LVP 3D foam cathodes were able to achieve a capacity of $66 \mathrm{mAh} / \mathrm{g}$ ( $\sim 50 \%$ of its theoretical capacity) at an ultrahigh rate of $200 C$ - this corresponds $18 \mathrm{~s}$ for a full discharge [132]. The Ragone plot in Figure 33e exhibits the relationship between energy and power density for LVP electrode materials. It is able to achieve a specific energy density of $450 \mathrm{Wh} / \mathrm{kg}$ at a power density of $2.2 \mathrm{~kW} / \mathrm{kg}$, while maintaining an energy density of $205 \mathrm{Wh} / \mathrm{kg}$ at an ultrahigh power density of $41 \mathrm{~kW} / \mathrm{kg}$. 

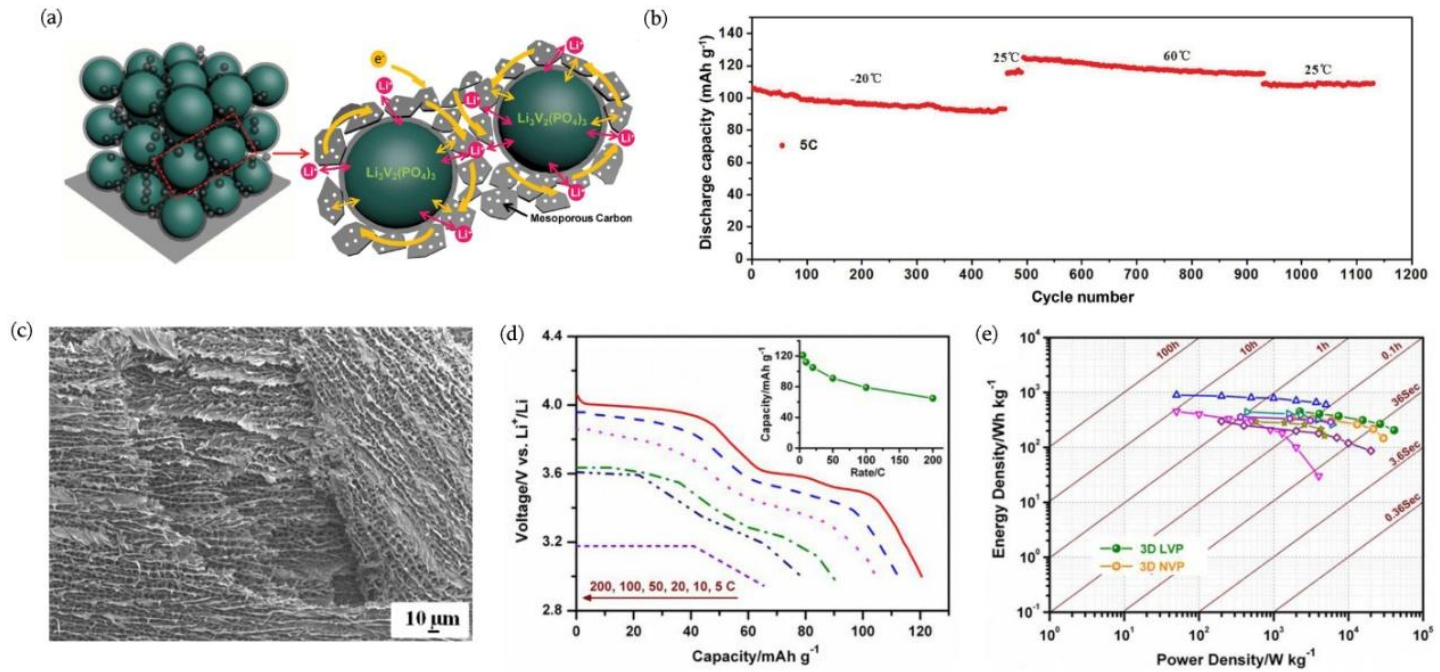

Figure 33. (a) Schematic of hierarchical carbon-decorated LVP with pathways for both electrons and lithium ions. (b) Charge-discharge cycling test of LVP/C cathode under various temperatures at $5 C$ [309]. (c) FESEM images of a sample obtained after freeze-drying. (d) Galvanostatic discharging profiles of LVP cathodes at current rates of 5 to 200 C. (e) Ragone plots of the 3D LVP cathodes compared with some advanced active materials [132].

On the foundation of reported results related to 3D LVP, both the rate capability and cycling performance of LVP are enhanced over a broad temperature range. Such performance is essential to pratical battery applications like EVs and HEVs. After examining the microstructure of 3D LVP, we conclude the continuous amorphous carbon and nano-sized LVP build a nanoporous network which combines high energy density with better power density because of the high active surface area and highways for rapid electron transportation.

\section{Application in an Energy Harvesting System}

Although LVP competes with currently commercialized or under developing cathodic materials for the next generation of Li-ion batteries with high energy and power density, its unique properties make it particularly suitable for some emerging 
applications, such as storing renewable energy. Currently, harvesting renewable energy copes with the challenge of increasing growing global energy demands. Solar cells, wind, biomass and geothermally driven renewable energy sources help human beings move energy harvesting and utilization away from fossil fuels [310,311]. However, the renewable energy commonly generate irregular current density, sometime with surging current and other time with low current, for example, when thick clouds block the sunshine and when the gusty wind blows. Beyond these energy harvesting applications, micro/nano-devices play a pivotal role in this information era, and the corresponding energy supply becomes a hot topic. Thus, various models have been fabricated to realize desirable functions [312], and there are more challenges in storing intermittent weak energy in the micro/nano-systems in comparison with solar cells and thermoelectrics. It is noticeable that many people try hard to increase the power conversion efficiency in the renewable sources, however, a very little attention is devoted to the energy storage efficiency of batteries. The low energy storage efficiency would not only loose a large fraction of energy, but also generate undesirable heat. Most recently, Nan et al. [313], has studied and compared four sets of $\mathrm{Li}$ ion half cells are fabricated using $\mathrm{LiFePO}_{4}(\mathrm{LFP}), \mathrm{LiMn}_{2} \mathrm{O}_{4}(\mathrm{LMO}), \mathrm{LiCoO}_{2}$ (LCO) and LVP as cathode materials. These four batteries collect the electricity generated by a triboelectric nanogenerator (TENG) that consisted of a rotator and stator as shown in Figure 34a. A flexible polytetrafluoroethylene (PTFE) film is pasted on fanned copper grids to build the rotator. Both stationary electrodes in the stator are composed of complementary-patterned copper sectors covered with a 
kapton layer. Each electrode is comprised of 180 sectors, and a stiff glass epoxy is used as base material. The electricity-generating mechanism in the TENG is based on the coupled effects of triboelectrification and electrostatic induction [312]. In order to collect the electricity from the TENG, a transformer, rectifier bridge and resistor are used to design a working circuit that outputs a persistent positive current and keeps the voltage within 3-5 V to guarantee safe battery charge (Figure 34b). As seen from Figure 34c-d, LVP not only delivers the largest energy density in output, but also displays the highest energy conversion efficiency $(\eta)$ in each cycle after being charged by the TENG for $30 \mathrm{~s}$. The conversion efficiency $(\eta)$ represents the ratio between output and input energy density. Table 5 shows the average values of input and output energy density and conversion efficiency in different batteries. Among all batteries, the battery with LVP cathode presents the highest average conversion efficiency (83.4\%) compared to LFP (74.4\%), LMO (73.6\%) and LCO (66.1\%). The difference is attributed to the three-dimension conducting network in LVP/C that facilitates fast transfer of both lithium ions and electrons during the process. In contrast, LFP has a relatively low $\mathrm{Li}^{+}$diffusion coefficient that restricts fast redox reactions in the battery and leads to lower energy conversion efficiency under high-frequency and high-current charging conditions. Although spinel structured LMO has a three dimensional $\mathrm{Li}$ ion diffusion path that endows LMO with superior rate performance, John-Teller distortion induces lattice strain that destroys the crystal structure, causing the decaying performances. For LCO, the crystal structure is intrinsically instable during the charge process at a large current density in high 
frequencies. The destruction of electrode structure and side reactions would lead to polarization of the cell, and the voltage will go up more rapidly than that in the conventional charge process. For the given charge energy, the charge current will be reduced when the voltage goes up quickly, limiting the deintercalation process in a given period ( $30 \mathrm{~s}$ in the present study). That might be the reason, at least partially, why LCO and LMO have relatively low energy conversion efficiency. As a result, the LVP battery exhibits the highest energy conversion efficiency because of its robust crystal structure and fast Li-ion diffusion channels. In addition, the commercial data in Table 6 compare the strengths of the cathodes in Li-ion full batteries. It is a pity that no commercial data on LVP electrode, but we can evaluate the relative values as shown in the table. The average voltage, cycling life and energy density are competitive for LVP, and the cost approximates to that of LFP because the abundant sources and the price of oxides in global market, implying LVP has the promising applications for renewable energy storage. 
(a)

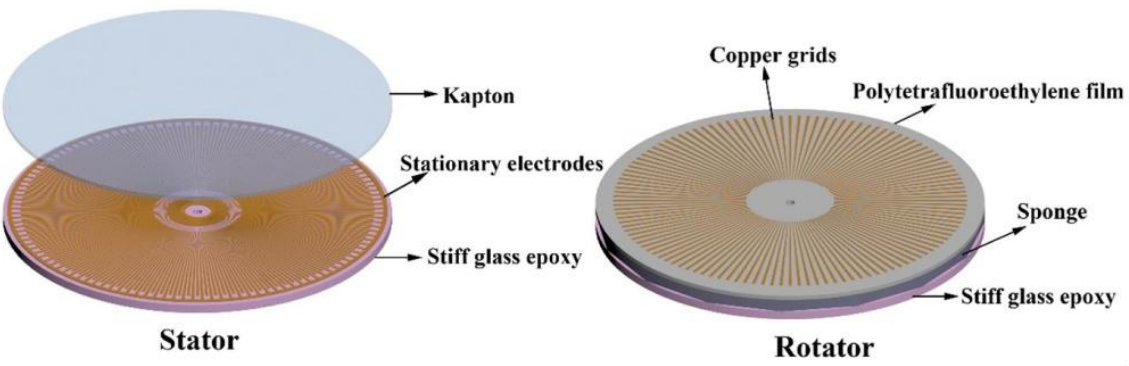

(b)

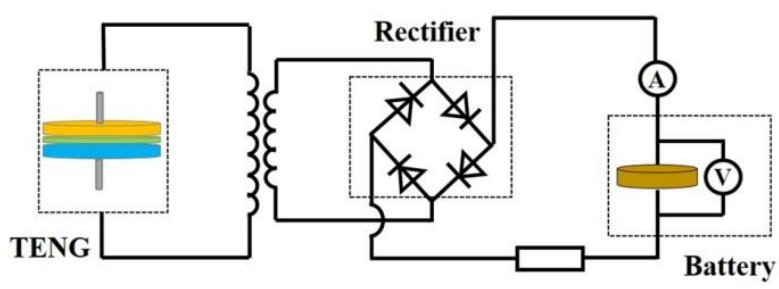

(c)

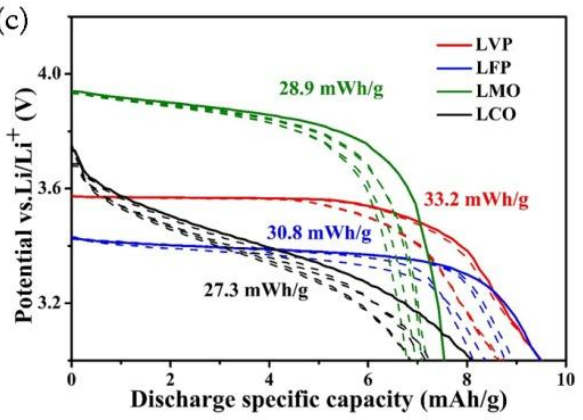

(d)

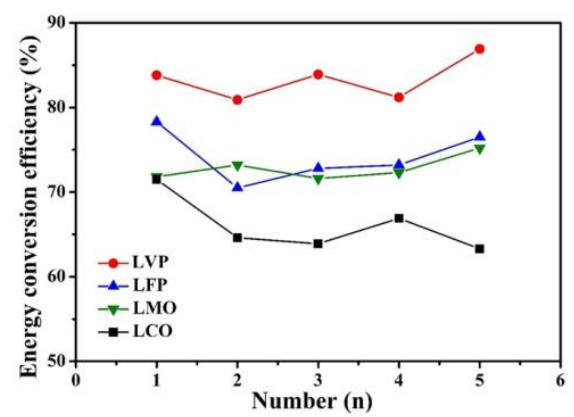

Figure 34. (a) The schematic illustration of the TENG. (b) Circuit diagram for rectifying the voltage output from the TENG to charge a battery. (c) The discharge curves of the four cathode materials after being charged by the triboelectric generator for 30s. The solid lines are discharge curves of the cathodes with the largest output energy density, the dash lines are the discharge curves of the cathodes that charged in the following four times. (d) The energy conversion efficiencies of different cathode materials in the charge/discharge process [313].

Table 5. Comparison of $\eta$ in Li-ion batteries with LFP, LMO, LCO and LVP as cathode materials [313]

\begin{tabular}{cccc}
\hline Electrode & $\begin{array}{c}\text { Input energy density } \\
(\mathrm{mWh} / \mathrm{g})\end{array}$ & $\begin{array}{c}\text { Output energy density } \\
(\mathrm{mWh} / \mathrm{g})\end{array}$ & $\begin{array}{c}\text { Energy conversion efficiency } \\
(\%)\end{array}$ \\
\hline LFP & $39.1 \pm 1.3$ & $29.1 \pm 1.3$ & $74.4 \pm 2.8$ \\
LMO & $37.5 \pm 0.9$ & $27.6 \pm 1.2$ & $73.6 \pm 1.5$ \\
LCO & $36.9 \pm 0.7$ & $24.4 \pm 1.5$ & $66.1 \pm 3.0$ \\
LVP & $37.3 \pm 1.3$ & $31.1 \pm 1.5$ & $83.4 \pm 2.2$ \\
\hline
\end{tabular}

Table 6. Comparison among Commercial Cathodes and LVP [314]

\begin{tabular}{lllll}
\hline Cathode materials & LCO & LMO & LFP & LVP \\
\hline Reversible capacity $(\mathrm{mAh} / \mathrm{g})$ & 140 & 100 & 145 & $>120$ \\
\hline
\end{tabular}




\begin{tabular}{lllll}
\hline Working voltage plateau (V) & 3.7 & 3.8 & 3.2 & $\sim 3.8$ \\
Charge termination voltage (V) & 4.25 & 4.35 & 4.2 & $\sim 4.8$ \\
Overcharge tolerance (V) & 0.1 & 0.1 & 0.7 & $\sim 1.0$ \\
R.T. Cycle life (cycles) & 400 & 300 & 1000 & $>1000$ \\
$55^{\circ} \mathrm{C}$ Cycle life (cycles) & 300 & 100 & 800 & $>500$ \\
Heat Flow by DSC (kJ/g) & 650 & 150 & 10 & - \\
Price (US $\$ \mathrm{~kg})$ & 30 & 15 & 12 & - \\
Battery energy density (Wh/kg) & 180 & 100 & 130 & $\sim 150$ \\
\hline
\end{tabular}

Note: The data of LCO, LMO and LFP are collected from the website of RONBEN Technology Co., Ltd. The data of LVP is evaluated by the reported results and the industrious criteria.

\section{Remarks and Outlooks}

Lithium vanadium phosphate is a competitive cathode candidate that stimulates great research interest because of its robust structure, fast ionic migration, high electrochemical potential and specific capacity. However, the intrinsically low electrical conductivity of $2.4 \times 10^{-7} \mathrm{~S} / \mathrm{cm}$ hinders the rate capability and cycling stability. Foreign atom doping, two-phase composites and tailored microstructures represent the three main approaches to improve the comprehensive performance. First, dopants can be introduced at three positions induce different effects. Doping on Li sites change the phase of host and therefore changes the electrochemical potential because the site energy of removable Li-ion is affected. While large cations can be substituted at $\mathrm{V}$ sites, which then expand the crystal lattice to improve $\mathrm{Li}$ ion migration. Anions substitutions affect the electrical conductivity because the inductive effect tunes the band gap for charge transfer. However, several valuable questions still remain. For example, what is the relationship between electronic structure of foreign atom or center cation and electrochemical potential of electrode material, and how can 
we predict and tailor electrical and/or ionic conductivities? Crystal field theory may help answer these questions. Second, additional phases are adopted to form composites with LVP in order to enhance the rate capability and cycling stability. Carbon materials are the main sources of second phases because of their excellent electrical conductivity. Coatings with suitable thickness and carbon content ensure fast charge transfer kinetics, which gives rise to high rate or cycling performance. Besides, an inert compound coated on the surface of LVP can stabilize the crystal structure when three $\mathrm{Li}$ ions are extracted. However, the interface between the two phases must be thoroughly studied, and the effect of interfaces on ionic migration and charge transfer also require careful exploration. The corresponding reaction mechanisms are helpful to investigations on all electrode materials. Third, reducing the size of LVP particles shortens the pathway for ionic migration, which benefits the rate capability. At the same time, combining the excellent electrical conductivity from carbon materials can further improve the comprehensive performance of LVP. Controlling the preferential growth of electrode materials to expose channels for ion migration is an important topic related to basic investigations on thermodynamics and kinetics of materials growth. Thus, fundamental studies of LVP can accelerate the design of electrode materials. Additionally, an LVP battery displayed the highest energy conversion efficiency in a renewable energy harvesting application. All the verified merits and controlled electrochemical properties make LVP a promising and competitive cathode candidate for secondary batteries powered devices or vehicles in the future market. 


\section{Acknowledgments}

This work was supported in part by the "thousands talents" program for the pioneer researcher and his innovation team, China, and by the National Science Foundation (NSF, CMMI-1030048 and DMR-1505902) and the University of Washington TGIF grant.

\section{References}

[1] Larcher, D.; Tarascon, J. M. Towards greener and more sustainable batteries for electrical energy storage. Nat. Chem. 7, 2015, 19-29.

[2] Tarascon, J. M.; Simon, P. Electrochemical Energy Storage; John Wiley \& Sons, Inc, 2015.

[3] Goodenough, J. B. Evolution of Strategies for Modern Rechargeable Batteries. Accounts Chem. Res. 46, 2012, 1053-1061.

[4] Melot, B. C.; Tarascon, J. M. Design and Preparation of Materials for Advanced Electrochemical Storage. Accounts Chem. Res. 46, 2013, 1226 -1238.

[5] Liu, C.; Neale, Z. G.; Cao, G. Understanding electrochemical potentials of cathode materials in rechargeable batteries. Mater. Today 2015. doi:10.1016/j.mattod.2015.10.009

[6] Islam, M. S.; Fisher, C. A. J. Lithium and sodium battery cathode materials: computational insights into voltage, diffusion and nanostructural properties. Chem. Soc. Rev. 43, 2014, 185-204.

[7] Chung, S. Y.; Bloking, J. T.; Chiang, Y. M. Electronically conductive phospho-olivines as lithium storage electrodes. Nat. Mater. 1, 2002, 123-128.

[8] Antolini, E. $\mathrm{LiCoO}_{2}$ : formation, structure, lithium and oxygen nonstoichiometry, electrochemical behaviour and transport properties. Solid State Ion. 170, 2004, 159-171.

[9] Park, J. K. Principles and Applications of Lithium Secondary Batteries; Wiley-VCH Germany, 2012. pp. 22-26.

[10] https://en.wikipedia.org/wiki/Vanadium.

[11] https://en.wikipedia.org/wiki/Abundance_of_elements_in_Earth\%27s_crust.

[12] Pan, A.; Zhang, J. G.; Cao, G.; Liang, S.; Wang, C.; Nie, Z.; Arey, B. W.; Xu, W.; Liu, D.; Xiao, J.; Li, G.; Liu, J. Nanosheet-structured $\operatorname{LiV}_{3} \mathrm{O}_{8}$ with high capacity and excellent stability for high energy lithium batteries. J. Mater. Chem. 21, 2011, 10077.

[13] Pan, A.; Liu, J.; Zhang, J. G.; Cao, G.; Xu, W.; Nie, Z.; Jie, X.; Choi, D.; Arey, B. W.; Wang, C.; Liang, S. Template free synthesis of $\mathrm{LiV}_{3} \mathrm{O}_{8}$ nanorods as a cathode material for high-rate secondary lithium batteries. J. Mater. Chem. 21, 2011, 1153-1161.

[14] Pan, A.; Zhang, J. G.; Nie, Z.; Cao, G.; Arey, B. W.; Li, G.; Liang, S. Q.; Liu, J. Facile 
synthesized nanorod structured vanadium pentoxide for high-rate lithium batteries. J. Mater. Chem. 2O, 2010, 9193-9199.

[15] Huang, H.; Yin, S. C.; Kerr, T.; Taylor, N.; Nazar, L. F. Nanostructured composites: A high capacity, fast rate $\mathrm{Li}_{3} \mathrm{~V}_{2}\left(\mathrm{PO}_{4}\right)_{3} /$ carbon cathode for rechargeable lithium batteries. $A d v$. Mater. 14, 2002, 1525-1528.

[16] Uchaker, E.; Zheng, Y. Z.; Li, S.; Candelaria, S. L.; Hu, S.; Cao, G. Z. Better than crystalline: amorphous vanadium oxide for sodium-ion batteries. J. Mater. Chem. A 2, 2014, 18208-18214.

[17] Raju, V.; Rains, J.; Gates, C.; Luo, W.; Wang, X.; Stickle, W. F.; Stucky, G. D.; Ji, X. Superior cathode of sodium-ion batteries: orthorhombic $\mathrm{V}_{2} \mathrm{O}_{5}$ nanoparticles generated in nanoporous carbon by ambient hydrolysis deposition. Nano Lett. 14, 2014, 4119-4124.

[18] Zhou, Y.; Rui, X.; Sun, W.; Xu, Z.; Zhou, Y.; Ng, W. J.; Yan, Q.; Fong, E. Biochemistry-Enabled 3D Foams for Ultrafast Battery Cathodes. ACS Nano 9, 2015, 4628-4635.

[19] Sai Gautam, G.; Canepa, P.; Abdellahi, A.; Urban, A.; Malik, R.; Ceder, G. The Intercalation Phase Diagram of $\mathrm{Mg}$ in $\mathrm{V}_{2} \mathrm{O}_{5}$ from First-Principles. Chem. Mater. 27, 2015, 3733-3742.

[20] Levi, E.; Gofer, Y.; Aurbach, D. On the Way to Rechargeable Mg Batteries: The Challenge of New Cathode Materials. Chem. Mater. 22, 2010, 860-868.

[21] Massé, R.; Uchaker, E.; Cao, G. Beyond Li-ion: electrode materials for sodium- and magnesium-ion batteries. Sci. China Mater. 58, 2015, 715-766.

[22] Delmas, C.; Cognac-Auradou, H.; Cocciantelli, J. M.; Ménétrier, M.; Doumerc, J. P. The $\mathrm{Li}_{\mathrm{x}} \mathrm{V}_{2} \mathrm{O}_{5}$ system: An overview of the structure modifications induced by the lithium intercalation. Solid State Ion. 69, 1994, 257-264.

[23] Yuan, L. X.; Wang, Z. H.; Zhang, W. X.; Hu, X. L.; Chen, J. T.; Huang, Y. H.; Goodenough, J. B. Development and challenges of $\mathrm{LiFePO}_{4}$ cathode material for lithium-ion batteries. Energy Environ. Sci. 4, 2011, 269-284.

[24] Vincent, C. A.; Scrosati, B. Modern Batteries: An Introduction to Electrochemical Power Sources, 2nd Edition; Butterworth-Heinemann, 1997.

[25] Landgrebe, A. R.; Klingler, R. J. Interfaces, Phenomena and Nanostructures in Lithium Batteries: Proceedings; Electrochemical Society, 2001.

[26] Li, H.; He, P.; Wang, Y.; Hosono, E.; Zhou, H. High-surface vanadium oxides with large capacities for lithium-ion batteries: from hydrated aerogel to nanocrystalline $\mathrm{VO}_{2}(\mathrm{~B})$, $\mathrm{V}_{6} \mathrm{O}_{13}$ and $\mathrm{V}_{2} \mathrm{O}_{5}$. J. Mater. Chem. 21, 2011, 10999-11009.

[27] Ding, Y. L.; Wen, Y.; Wu, C.; van Aken, P. A.; Maier, J.; Yu, Y. 3D V ${ }_{6} \mathrm{O}_{13}$ Nanotextiles Assembled from Interconnected Nanogrooves as Cathode Materials for High-Energy Lithium Ion Batteries. Nano Lett. 15, 2015, 1388-1394.

[28] Uchaker, E.; Gu, M.; Zhou, N.; Li, Y.; Wang, C.; Cao, G. Enhanced Intercalation Dynamics and Stability of Engineered Micro/Nano-Structured Electrode Materials: Vanadium Oxide Mesocrystals. Small 9, 2013, 3880-3886.

[29] Xia, X.; Chao, D.; Ng, C. F.; Lin, J.; Fan, Z.; Zhang, H.; Shen, Z. X.; Fan, H. J. VO $\mathrm{VO}_{2}$ nanoflake arrays for supercapacitor and Li-ion battery electrodes: performance enhancement by hydrogen molybdenum bronze as an efficient shell material. Mater. Horiz. 2, 2015, 237-244. 
[30] Zhang, C.; Song, H.; Zhang, C.; Liu, C.; Liu, Y.; Cao, G. Interface Reduction Synthesis of $\mathrm{H}_{2} \mathrm{~V}_{3} \mathrm{O}_{8}$ Nanobelts-Graphene for High-Rate Li-Ion Batteries. J. Phys. Chem. C 119, 2015, 11391-11399.

[31] Simoes, M.; Mettan, Y.; Pokrant, S.; Weidenkaff, A. Surface-Modified Lithiated $\mathrm{H}_{2} \mathrm{~V}_{3} \mathrm{O}_{8}$ : A Stable High Energy Density Cathode Material for Lithium-Ion Batteries with $\mathrm{LiPF}_{6}$ Electrolytes. J. Phys. Chem. C 118, 2014, 14169-14176.

[32] Tian, X.; Xu, X.; He, L.; Wei, Q.; Yan, M.; Xu, L.; Zhao, Y.; Yang, C.; Mai, L. Ultrathin pre-lithiated $\mathrm{V}_{6} \mathrm{O}_{13}$ nanosheet cathodes with enhanced electrical transport and cyclability. J. Power Sources 255, 2014, 235-241.

[33] Liu, C.; Gillette, E. I.; Chen, X.; Pearse, A. J.; Kozen, A. C.; Schroeder, M. A.; Gregorczyk, K. E.; Lee, S. B.; Rubloff, G. W. An all-in-one nanopore battery array. Nat. Nanotechnol. 9, 2014, 1031-1039.

[34] Yin, S. C.; Grondey, H.; Strobel, P.; Anne, M.; Nazar, L. F. Electrochemical property: Structure relationships in monoclinic $\mathrm{Li}_{3-\mathrm{y}} \mathrm{V}_{2}\left(\mathrm{PO}_{4}\right)_{3}$. J. Am. Chem. Soc. 125, 2003, 10402-10411.

[35] Yazami, R. Nanomaterials for Lithium-Ion Batteries: Fundamentals and Applications. CRC Press, Taylor \& Francis Group, 2013; pp. 227-251.

[36] Wang, Y.; Takahashi, K.; Lee, K.; Cao, G. Z. Nanostructured vanadium oxide electrodes for enhanced lithium-ion intercalation. Adv. Funct. Mater. 16, 2oo6, 1133-1144.

[37] Geckeler, K. E.; Nishide, H. Advanced Nanomaterials; Wiley-VCH, 2010. pp. 320.

[38] Song, H.; Liu, Y.; Zhang, C.; Liu, C.; Cao, G. Mo-doped $\mathrm{LiV}_{3} \mathrm{O}_{8}$ nanorod-assembled nanosheets as a high performance cathode material for lithium ion batteries. J. Mater. Chem. A 3, 2015, 3547-3558.

[39] Pan, A. Q.; Liu, J.; Zhang, J. G.; Xu, W.; Cao, G. Z.; Nie, Z. M.; Arey, B. W.; Liang, S. Q. Nano-structured $\mathrm{Li}_{3} \mathrm{~V}_{2}\left(\mathrm{PO}_{4}\right)_{3}$ /carbon composite for high-rate lithium-ion batteries. Electrochem. Commun. 12, 2010, 1674-1677.

[40] Xu, J. T.; Chou, S. L.; Zhou, C. F.; Gu, Q. F.; Liu, H. K.; Dou, S. X. Three-dimensional-network $\mathrm{Li}_{3} \mathrm{~V}_{2}\left(\mathrm{PO}_{4}\right)_{3} / \mathrm{C}$ composite as high rate lithium ion battery cathode material and its compatibility with ionic liquid electrolytes. J. Power Sources 246, 2014, 124-131.

[41] Masquelier, C.; Croguennec, L. Polyanionic (Phosphates, Silicates, Sulfates) Frameworks as Electrode Materials for Rechargeable Li (or Na) Batteries. Chem. Rev. 113, 2013, 6552-6591.

[42] Aravindan, V.; Gnanaraj, J.; Lee, Y. S.; Madhavi, S. LiMnPO 4 -A next generation cathode material for lithium-ion batteries. J. Mater. Chem. A 1, 2013, 3518-3539.

[43]Hu, M.; Pang, X. L.; Zhou, Z. Recent progress in high-voltage lithium ion batteries. $J$. Power Sources 237, 2013, 229-242.

[44] Karami, H.; Taala, F. Synthesis, characterization and application of $\mathrm{Li}_{3} \mathrm{Fe}_{2}\left(\mathrm{PO}_{4}\right)_{3}$ nanoparticles as cathode of lithium-ion rechargeable batteries. J. Power Sources 196, 2011, 6400-6411.

[45] Aatiq, A.; Menetrier, M.; Croguennec, L.; Suard, E.; Delmas, C. On the structure of $\mathrm{Li}_{3} \mathrm{Ti}_{2}\left(\mathrm{PO}_{4}\right)_{3}$. J. Mater. Chem. 12, 2002, 2971-2978.

[46] Zheng, J.; Qin, C.; Wu, T.; Xie, S.; Ni, L.; Peng, M.; Tang, Y.; Chen, Y. High-performance $\mathrm{LiMnPO}_{4} / \mathrm{C}$ nanoplates synthesized by negative pressure immersion and a 
solid state reaction using nanoporous $\mathrm{Mn}_{2} \mathrm{O}_{3}$ precursors. J. Mater. Chem. A 3, 2015, 15299-15306.

[47] Choi, D.; Wang, D.; Bae, I. T.; Xiao, J.; Nie, Z.; Wang, W.; Viswanathan, V. V.; Lee, Y. J.; Zhang, J.-G.; Graff, G. L.; Yang, Z.; Liu, J. LiMnPO 4 Nanoplate Grown via Solid-State Reaction in Molten Hydrocarbon for Li-Ion Battery Cathode. Nano Lett. 10, 2010, 2799-2805.

[48] Fujimoto, D.; Kuwata, N.; Matsuda, Y.; Kawamura, J.; Kang, F. Fabrication of solid-state thin-film batteries using $\mathrm{LiMnPO}_{4}$ thin films deposited by pulsed laser deposition. Thin Solid Films 579, 2015, 81-88.

[49] Luo, J. Y.; Chen, L. J.; Zhao, Y. J.; He, P.; Xia, Y. Y. The effect of oxygen vacancies on the structure and electrochemistry of $\mathrm{LiTi}_{2}\left(\mathrm{PO}_{4}\right)_{3}$ for lithium-ion batteries: A combined experimental and theoretical study. J. Power Sources 194, 2009, 1075-1080.

[50] Roh, H. K.; Kim, H. K.; Roh, K. C.; Kim, K. B. $\operatorname{LiTi}_{2}\left(\mathrm{PO}_{4}\right)_{3} /$ reduced graphene oxide nanocomposite with enhanced electrochemical performance for lithium-ion batteries. Rsc $A d v$ 4, 2014, $31672-31677$.

[51] Vijayan, L.; Cheruku, R.; Govindaraj, G. Structure and ion transport in $\mathrm{Li}_{3} \mathrm{Fe}_{2}\left(\mathrm{PO}_{4}\right)_{3}$ synthesized by solution combustion technique. J. Appl. Phys. 111, 2012, 064905.

[52] Malik, R.; Burch, D.; Bazant, M.; Ceder, G. Particle Size Dependence of the Ionic Diffusivity. Nano Lett. 1o, 2010, 4123-4127.

[53] Gaubicher, J.; Wurm, C.; Goward, G.; Masquelier, C.; Nazar, L. Rhombohedral form of $\mathrm{Li}_{3} \mathrm{~V}_{2}\left(\mathrm{PO}_{4}\right)_{3}$ as a cathode in Li-ion batteries. Chem. Mater. 12, 2000, 3240-3242.

[54] Patoux, S.; Wurm, C.; Morcrette, M.; Rousse, G.; Masquelier, C. A comparative structural and electrochemical study of monoclinic $\mathrm{Li}_{3} \mathrm{Fe}_{2}\left(\mathrm{PO}_{4}\right)_{3}$ and $\mathrm{Li}_{3} \mathrm{~V}_{2}\left(\mathrm{PO}_{4}\right)_{3}$. J. Power Sources 119-121, 2003, 278-284.

[55] Morcrette, M.; Leriche, J. B.; Patoux, S.; Wurm, C.; Masquelier, C. In situ X-ray diffraction during lithium extraction from rhombohedral and monoclinic $\mathrm{Li}_{3} \mathrm{~V}_{2}\left(\mathrm{PO}_{4}\right)_{3}$. Electrochem. Solid State 6, 2003, A80-A84.

[56] Burba, C. M.; Frech, R. Vibrational spectroscopic studies of monoclinic and rhombohedral $\mathrm{Li}_{3} \mathrm{~V}_{2}\left(\mathrm{PO}_{4}\right)_{3}$. Solid State Ionics 177, 2007, 3445-3454.

[57] Cahill, L. S.; Chapman, R. P.; Britten, J. F.; Goward, G. R. Li-7 NMR and two-dimensional exchange study of lithium dynamics in monoclinic $\mathrm{Li}_{3} \mathrm{~V}_{2}\left(\mathrm{PO}_{4}\right)_{3}$. J. Phys. Chem. B 110, 2006, 7171-7177.

[58] Yang, G.; Ji, H. M.; Liu, H. D.; Qian, B.; Jiang, X. F. Crystal structure and electrochemical performance of $\mathrm{Li}_{3} \mathrm{~V}_{2}\left(\mathrm{PO}_{4}\right)_{3}$ synthesized by optimized microwave solid-state synthesis route. Electrochim. Acta 55, 2010, 3669-3680.

[59] Yin, S. C.; Strobel, P. S.; Grondey, H.; Nazar, L. F. $\mathrm{Li}_{2.5} \mathrm{~V}_{2}\left(\mathrm{PO}_{4}\right)_{3}: \mathrm{A}$ room-temperature analogue to the fast-ion conducting high-temperature gamma-phase of $\mathrm{Li}_{3} \mathrm{~V}_{2}\left(\mathrm{PO}_{4}\right)_{3}$. Chem. Mater. 16, 2004, 1456-1465.

[6o] Yin, S. C.; Grondey, H.; Strobel, P.; Huang, H.; Nazar, L. F. Charge ordering in lithium vanadium phosphates: Electrode materials for lithium-ion batteries. J. Am. Chem. Soc. 125, 2003, 326-327.

[61] Van der Ven, A.; Bhattacharya, J.; Belak, A. A. Understanding Li Diffusion in Li-Intercalation Compounds. Accounts Chem. Res. 46, 2013, 1216-1225.

[62] Membreno, N.; Park, K.; Goodenough, J. B.; Stevenson, K. J. Electrode/Electrolyte 
Interface of Composite alpha- $\mathrm{Li}_{3} \mathrm{~V}_{2}\left(\mathrm{PO}_{4}\right)_{3}$ Cathodes in a Nonaqueous Electrolyte for Lithium Ion Batteries and the Role of the Carbon Additive. Chem. Mater. 27, 2015, 3332-3340.

[63] Lee, S.; Park, S. S. Atomistic Simulation Study of Monoclinic $\mathrm{Li}_{3} \mathrm{~V}_{2}\left(\mathrm{PO}_{4}\right)_{3}$ as a Cathode Material for Lithium Ion Battery: Structure, Defect Chemistry, Lithium Ion Transport Pathway, and Dynamics. J. Phys. Chem. C 116, 2012, 25190-25197.

[64] Sahu, G.; Rangasamy, E.; Li, J.; Chen, Y.; An, K.; Dudney, N.; Liang, C. A high-conduction Ge substituted $\mathrm{Li}_{3} \mathrm{AsS}_{4}$ solid electrolyte with exceptional low activation energy. J. Mater. Chem. A 2, 2014, 10396-10403.

[65] Zhu, Y.; Wang, C. Galvanostatic Intermittent Titration Technique for Phase-Transformation Electrodes. J. Phys. Chem. C 114, 2010, 2830-2841.

[66] Dees, D. W.; Kawauchi, S.; Abraham, D. P.; Prakash, J. Analysis of the Galvanostatic Intermittent Titration Technique (GITT) as applied to a lithium-ion porous electrode. $J$. Power Sources 189, 2009, 263-268.

[67] Weppner, W.; Huggins, R. A. Determination of the Kinetic Parameters of Mixed-Conducting Electrodes and Application to the System $\mathrm{Li}_{3} \mathrm{Sb}$. J. Electrochem. Soc. 124, 1977, 1569-1578.

[68] Xu, K. Electrolytes and Interphases in Li-Ion Batteries and Beyond. Chem. Rev. 114, 2014, 11503-11618.

[69] Chen, Y. S.; Zhang, D.; Bian, X. F.; Bie, X. F.; Wang, C. Z.; Du, F.; Jang, M.; Chen, G.; Wei, Y. J. Characterizations of the electrode/electrolyte interfacial properties of carbon coated $\mathrm{Li}_{3} \mathrm{~V}_{2}\left(\mathrm{PO}_{4}\right)_{3}$ cathode material in $\mathrm{LiPF}_{6}$ based electrolyte. Electrochim. Acta 79, 2012 , 95-101.

[70] Wang, W. H.; Zhang, J. L.; Lin, Y.; Jia, Z.; Dai, C. S. A compromise of electrochemical performances of $\mathrm{Li}_{3} \mathrm{~V}_{2}\left(\mathrm{PO}_{4}\right)_{3} / \mathrm{C}$ upon cycling within a suitable potential range. Electrochim. Acta 116, 2014, 490-494.

[71] Rui, X. H.; Ding, N.; Liu, J.; Li, C.; Chen, C. H. Analysis of the chemical diffusion coefficient of lithium ions in $\mathrm{Li}_{3} \mathrm{~V}_{2}\left(\mathrm{PO}_{4}\right)_{3}$ cathode material. Electrochim. Acta 55, 2010, 2384-2390.

[72] Nathiya, K.; Bhuvaneswari, D.; Gangulibabu; Kalaiselvi, N. Combustion synthesized nanocrystalline $\mathrm{Li}_{3} \mathrm{~V}_{2}\left(\mathrm{PO}_{4}\right)_{3} / \mathrm{C}$ cathode for lithium-ion batteries. Mater. Res. Bull. 47, 2012, 4300-4304.

[73] Yang, G.; Liu, H. D.; Ji, H. M.; Chen, Z. Z.; Jiang, X. F. Temperature-controlled microwave solid-state synthesis of $\mathrm{Li}_{3} \mathrm{~V}_{2}\left(\mathrm{PO}_{4}\right)_{3}$ as cathode materials for lithium batteries. $J$. Power Sources 195, 2010, 5374-5378.

[74] Yuan, W.; Yan, J.; Tang, Z. Y.; Sha, O.; Wang, J. M.; Mao, W. F.; Ma, L. Synthesis of $\mathrm{Li}_{3} \mathrm{~V}_{2}\left(\mathrm{PO}_{4}\right)_{3}$ cathode material via a fast sol-gel method based on spontaneous chemical reactions. J. Power Sources 201, 2012, 301-306.

[75] Zhu, X. J.; Liu, Y. X.; Geng, L. M.; Chen, L. B. Synthesis and performance of lithium vanadium phosphate as cathode materials for lithium ion batteries by a sol-gel method. $J$. Power Sources 184, 2008, 578-582.

[76] Zhang, W. J.; Liu, Q. J.; Feng, L. J.; Wang, S. P.; Yang, Y. Z.; Wei, H. Y. A simple and practical synthesis route for preparation of $\mathrm{Li}_{3} \mathrm{~V}_{2}\left(\mathrm{PO}_{4}\right)_{3} / \mathrm{C}$ by the rheological phase method using composite chelating reagents. New J. Chem. 38, 2014, 2265-2268.

[77] Chen, S. H.; Wu, J.; Su, Z. L.; Deng, L. Kinetic Studies on the Synthesis of 
Monoclinic $\mathrm{Li}_{3} \mathrm{~V}_{2}\left(\mathrm{PO}_{4}\right)_{3}$ via Solid-State Reaction. J. Phys. Chem. A 118, 2014, 3711-3716.

[78] Yang, C. C.; Kung, S. H.; Lin, S. J.; Chien, W. C. $\mathrm{Li}_{3} \mathrm{~V}_{2}\left(\mathrm{PO}_{4}\right)_{3} / \mathrm{C}$ composite materials synthesized using the hydrothermal method with double-carbon sources. J. Power Sources 251, 2014, 296-304.

[79] Niu, C. S.; Meng, J. S.; Wang, X. P.; Han, C. H.; Yan, M. Y.; Zhao, K. N.; Xu, X. M.; Ren, W. H.; Zhao, Y. L.; Xu, L.; Zhang, Q. J.; Zhao, D. Y.; Mai, L. Q. General synthesis of complex nanotubes by gradient electrospinning and controlled pyrolysis. Nat. Commun. 6, 2015. doi:10.1038/ncomms8402

[8o] Rui, X.; Yan, Q.; Skyllas-Kazacos, M.; Lim, T. M. $\mathrm{Li}_{3} \mathrm{~V}_{2}\left(\mathrm{PO}_{4}\right)_{3}$ cathode materials for lithium-ion batteries: A review. J. Power Sources 258, 2014, 19-38.

[81] Yuan, L. X.; Wang, Z. H.; Zhang, W. X.; Hu, X. L.; Chen, J. T.; Huang, Y. H.; Goodenough, J. B. Development and challenges of $\mathrm{LiFePO}_{4}$ cathode material for lithium-ion batteries. Energy Environ. Sci. 4, 2011, 269.

[82] Xia, Y.; Zhang, W.; Huang, H.; Gan, Y.; Li, C.; Tao, X. Synthesis and electrochemical properties of $\mathrm{Nb}$-doped $\mathrm{Li}_{3} \mathrm{~V}_{2}\left(\mathrm{PO}_{4}\right)_{3} / \mathrm{C}$ cathode materials for lithium-ion batteries. Mater. Sci. Eng. $B$ 176, 2011, 633-639.

[83] Barker, J.; Gover, R. K. B.; Burns, P.; Bryan, A. The effect of Al substitution on the electrochemical insertion properties of the lithium vanadium phosphate, $\mathrm{Li}_{3} \mathrm{~V}_{2}\left(\mathrm{PO}_{4}\right)_{3} . J$. Electrochem. Soc. 154, 2007, A307-A313.

[84] Dong, Y. Z.; Zhao, Y. M.; Duan, H. The effect of doping $\mathrm{Mg}^{2+}$ on the structure and electrochemical properties of $\mathrm{Li}_{3} \mathrm{~V}_{2}\left(\mathrm{PO}_{4}\right)_{3}$ cathode materials for lithium-ion batteries. $J$. Electroanal. Chem. 66o, 2011, 14-21.

[85] Deng, C.; Zhang, S.; Yang, S. Y.; Gao, Y.; Wu, B.; Ma, L.; Fu, B. L.; Wu, Q.; Liu, F. L. Effects of Ti and Mg Codoping on the Electrochemical Performance of $\mathrm{Li}_{3} \mathrm{~V}_{2}\left(\mathrm{PO}_{4}\right)_{3}$ Cathode Material for Lithium Ion Batteries. J. Phys. Chem. C 115, 2011, 15048-15056.

[86] Han, D. W.; Lim, S. J.; Kim, Y. I.; Kang, S. H.; Lee, Y. C.; Kang, Y. M. Facile Lithium Ion Transport through Superionic Pathways Formed on the Surface of $\mathrm{Li}_{3} \mathrm{~V}_{2}\left(\mathrm{PO}_{4}\right)_{3} / \mathrm{C}$ for High Power Li Ion Battery. Chem. Mater. 26, 2014, 3644-3650.

[87] Zhang, Y.; Nie, P.; Shen, L. F.; Xu, G. Y.; Deng, H. F.; Luo, H. F.; Zhang, X. G. Rhombohedral NASICON-structured $\mathrm{Li}_{2} \mathrm{NaV}_{2}\left(\mathrm{PO}_{4}\right)_{3}$ with single voltage plateau for superior lithium storage. $R s c A d v$ 4, 2014, 8627-8631.

[88] Wang, W. H.; Chen, Z. Y.; Zhang, J. L.; Dai, C. S.; Li, J. J.; Ji, D. L. A comparative structural and electrochemical study of monoclinic $\mathrm{Li}_{3} \mathrm{~V}_{2}\left(\mathrm{PO}_{4}\right)_{3} / \mathrm{C}$ and rhombohedral $\mathrm{Li}_{2.5} \mathrm{Na}_{0.5} \mathrm{~V}_{(2-2 \mathrm{x} / 3)} \mathrm{Nix}\left(\mathrm{PO}_{4}\right)_{3} / \mathrm{C}$. Electrochim. Acta 103, 2013, 259-265.

[89] Kuang, Q.; Zhao, Y. M.; Liang, Z. Y. Synthesis and electrochemical properties of Na-doped $\mathrm{Li}_{3} \mathrm{~V}_{2}\left(\mathrm{PO}_{4}\right)_{3}$ cathode materials for Li-ion batteries. J. Power Sources 196, 2o11, 10169-10175.

[90] Chen, Q. Q.; Qiao, X. C.; Wang, Y. B.; Zhang, T. T.; Peng, C.; Yin, W. M.; Liu, L. Electrochemical performance of $\mathrm{Li}_{3-\mathrm{x}} \mathrm{Na}_{\mathrm{x}} \mathrm{V}_{2}\left(\mathrm{PO}_{4}\right)_{3} / \mathrm{C}$ composite cathode materials for lithium ion batteries. J. Power Sources 201, 2012, 267-273.

[91] Wang, R. H.; Xiao, S. H.; Li, X. H.; Wang, J. X.; Guo, H. J.; Zhong, F. X. Structural and electrochemical performance of Na-doped $\mathrm{Li}_{3} \mathrm{~V}_{2}\left(\mathrm{PO}_{4}\right)_{3} / \mathrm{C}$ cathode materials for lithium-ion batteries via rheological phase reaction. J. Alloy Compd. 575, 2013, 268-272.

[92] Yan, J.; Yuan, W.; Xie, H.; Tang, Z. Y.; Liu, F. J.; Mao, W. F.; Xu, Q.; Zhang, X. H. 
Preparation and electrochemical performance of Na-doped $\mathrm{Li}_{3} \mathrm{~V}_{2}\left(\mathrm{PO}_{4}\right)_{3} / \mathrm{C}$ cathode material. $J$. Solid State Electr. 16, 2012, 3201-3206.

[93] Tang, Y. H.; Wang, C. Y.; Zhou, J. J.; Bi, Y. J.; Liu, Y.; Wang, D. Y.; Shi, S. Q.; Li, G. B. $\mathrm{Li}_{2} \mathrm{NaV}_{2}\left(\mathrm{PO}_{4}\right)_{3}$ : A novel composite cathode material with high ratio of rhombohedral phase. J. Power Sources 227, 2013, 199-203.

[94] Huang, J. S.; Yang, L.; Liu, K. Y.; Tang, Y. F. Synthesis and characterization of $\mathrm{Li}_{3} \mathrm{~V}_{(2-2 \mathrm{x} / 3)} \mathrm{Mg}_{\mathrm{x}}\left(\mathrm{PO}_{4}\right)_{3} / \mathrm{C}$ cathode material for lithium-ion batteries. J. Power Sources 195, 2010, $5013-5018$.

[95] Mateyshina, Y. G.; Uvarov, N. F. Electrochemical behavior of $\mathrm{Li}_{3-\mathrm{x}} \mathrm{M}_{\mathrm{x}}^{\prime} \mathrm{V}_{2-\mathrm{y}} \mathrm{M}_{\mathrm{y}}^{\prime \prime}\left(\mathrm{PO}_{4}\right)_{3}$ $\left(\mathrm{M}^{\prime}=\mathrm{K}, \mathrm{M}^{\prime \prime}=\mathrm{Sc}, \mathrm{Mg}+\mathrm{Ti}\right) / \mathrm{C}$ composite cathode material for lithium-ion batteries. J. Power Sources 196, 2011, 1494-1497.

[96] Zhang, B.; Liu, J. Q.; Zhang, Q.; Li, Y. H. Electrochemical performance of $\mathrm{Al}$-substituted $\mathrm{Li}_{3} \mathrm{~V}_{2}\left(\mathrm{PO}_{4}\right)_{3}$ cathode materials synthesized by sol-gel method. T. Nonferr. Metar. Soc. 2O, 2010, 619-623.

[97] Cho, A. R.; Son, J. N.; Aravindan, V.; Kim, H.; Kang, K. S.; Yoon, W. S.; Kim, W. S.; Lee, Y. S. Carbon supported, Al doped- $\mathrm{Li}_{3} \mathrm{~V}_{2}\left(\mathrm{PO}_{4}\right)_{3}$ as a high rate cathode material for lithium-ion batteries. J. Mater. Chem. 22, 2012, 6556-6560.

[98] Ai, D. J.; Liu, K. Y.; Lu, Z. G.; Zou, M. M.; Zeng, D. Q.; Ma, J. Aluminothermal synthesis and characterization of $\mathrm{Li}_{3} \mathrm{~V}_{2-\mathrm{x}} \mathrm{Al}_{\mathrm{x}}\left(\mathrm{PO}_{4}\right)_{3}$ cathode materials for lithium ion batteries. Electrochim. Acta 56, 2011, 2823-2827.

[99] Son, J. N.; Kim, S. H.; Kim, M. C.; Kim, G. J.; Aravindan, V.; Lee, Y. G.; Lee, Y. S. Superior charge-transfer kinetics of NASICON-type $\mathrm{Li}_{3} \mathrm{~V}_{2}\left(\mathrm{PO}_{4}\right)_{3}$ cathodes by multivalent $\mathrm{Al}^{3+}$ and $\mathrm{Cl}^{-}$substitutions. Electrochim. Acta 97, 2013, 210-215.

[100] Sun, C. W.; Rajasekhara, S.; Dong, Y. Z.; Goodenough, J. B. Hydrothermal Synthesis and Electrochemical Properties of $\mathrm{Li}_{3} \mathrm{~V}_{2}\left(\mathrm{PO}_{4}\right)_{3} / \mathrm{C}$-Based Composites for Lithium-Ion Batteries. ACS Appl. Mater. Interfaces 3, 2011, 3772-3776.

[101] Liu, S. Q.; Li, S. C.; Huang, K. L.; Chen, Z. H. Effect of doping $\mathrm{Ti}^{4+}$ on the structure and performances of $\mathrm{Li}_{3} \mathrm{~V}_{2}\left(\mathrm{PO}_{4}\right)_{3}$. Acta Phys-Chim Sin. 23, 2007, 537-542.

[102] Zhang, S.; Wu, Q.; Deng, C.; Liu, F. L.; Zhang, M.; Meng, F. L.; Gao, H. Synthesis and characterization of Ti-Mn and Ti-Fe codoped $\mathrm{Li}_{3} \mathrm{~V}_{2}\left(\mathrm{PO}_{4}\right)_{3}$ as cathode material for lithium ion batteries. J. Power Sources 218, 2012, 56-64.

[103] Yang, S. Y.; Zhang, S.; Fu, B. L.; Wu, Q.; Liu, F. L.; Deng, C. Effects of Cr doping on the electrochemical performance of $\mathrm{Li}_{3} \mathrm{~V}_{2}\left(\mathrm{PO}_{4}\right)_{3}$ cathode material for lithium ion batteries. $J$. Solid State Electr. 15, 2011, 2633-2638.

[104] Chen, Y. H.; Zhao, Y. M.; An, X. N.; Liu, J. M.; Dong, Y. Z.; Chen, L. Preparation and electrochemical performance studies on Cr-doped $\mathrm{Li}_{3} \mathrm{~V}_{2}\left(\mathrm{PO}_{4}\right)_{3}$ as cathode materials for lithium-ion batteries. Electrochim. Acta 54, 2009, 5844-5850.

[105] Chen, L.; Yan, B.; Xie, Y. F.; Wang, S. M.; Jiang, X. F.; Yang, G. Preparation and electrochemical properties of $\mathrm{Li}_{3} \mathrm{~V}_{1.8} \mathrm{Mn}_{0.2}\left(\mathrm{PO}_{4}\right)_{3}$ doped via different Mn sources. J. Power Sources 261, 2014, 188-197.

[106] Zhai, J.; Zhao, M. S.; Wang, D. D. Effect of Mn-doping on performance of $\mathrm{Li}_{3} \mathrm{~V}_{2}\left(\mathrm{PO}_{4}\right)_{3} / \mathrm{C}$ cathode material for lithium ion batteries. T. Nonferr. Metal Soc. 21, 2o11, 523-528.

[107] Chen, L.; Wang, C. G.; Wang, H. Y.; Qiao, E. B.; Wang, S. M.; Jiang, X. F.; Yang, G. 
Enhanced high-rate electrochemical performance of $\mathrm{Li}_{3} \mathrm{~V}_{1.8} \mathrm{Mn}_{0.2}\left(\mathrm{PO}_{4}\right)_{3}$ by atomic doping of $\mathrm{Mn}(\mathrm{III})$. Electrochim. Acta 125, 2014, 338-346.

[108] Ren, M. M.; Zhou, Z.; Li, Y. Z.; Gao, X. P.; Yan, J. Preparation and electrochemical studies of Fe-doped $\mathrm{Li}_{3} \mathrm{~V}_{2}\left(\mathrm{PO}_{4}\right)_{3}$ cathode materials for lithium-ion batteries. J. Power Sources 162, 2006, 1357-1362.

[109] Zhang, L. L.; Liang, G.; Peng, G.; Huang, Y. H.; Wang, L.; Qie, L.; Croft, M. C.; Ignatov, A.; Goodenough, J. B. Insight into Fe Incorporation in $\mathrm{Li}_{3} \mathrm{~V}_{2}\left(\mathrm{PO}_{4}\right)_{3} / \mathrm{C}$ Cathode Material. J. Electrochem. Soc. 159, 2012, A1573-A1578.

[110] Nathiya, K.; Bhuvaneswari, D.; Gangulibabu; Nirmala, D.; Kalaiselvi, N. $\mathrm{Li}_{3} \mathrm{M}_{\mathrm{x}} \mathrm{V}_{2-\mathrm{x}}\left(\mathrm{PO}_{4}\right)_{3} / \mathrm{C}(\mathrm{M}=\mathrm{Fe}, \mathrm{Co})$ composite cathodes with extended solubility limit and improved electrochemical behavior. Rsc Adv 2, 2012, 6885-6889.

[111] Kuang, Q.; Zhao, Y. M.; An, X. N.; Liu, J. M.; Dong, Y. Z.; Chen, L. Synthesis and electrochemical properties of Co-doped $\mathrm{Li}_{3} \mathrm{~V}_{2}\left(\mathrm{PO}_{4}\right)_{3}$ cathode materials for lithium-ion batteries. Electrochim. Acta 55, 2010, 1575-1581.

[112] Wu, W. L.; Liang, J.; Yan, J.; Mao, W. F. Synthesis of $\mathrm{Li}_{3} \mathrm{Ni}_{\mathrm{x}} \mathrm{V}_{2-\mathrm{x}}\left(\mathrm{PO}_{4}\right)_{3} / \mathrm{C}$ cathode materials and their electrochemical performance for lithium ion batteries. J. Solid State Electr. 17, 2013, 2027-2033.

[113] Zhang, Y.; Huo, Q. Y.; Lv, Y.; Wang, L. Z.; Zhang, A. Q.; Song, Y. H.; Li, G. Y.; Gao, H. L.; Xia, T. C.; Dong, H. C. Effects of nickel-doped lithium vanadium phosphate on the performance of lithium-ion batteries. J. Alloy Compd. 542, 2012, 187-191.

[114] Wang, J.; Zheng, S. Q.; Hojamberdiev, M.; Ren, B.; Xu, Y. H.; Shao, C. Y. Effect of $\mathrm{Ni}$ doping on electrochemical performance of $\mathrm{Li}_{3} \mathrm{~V}_{2}\left(\mathrm{PO}_{4}\right)_{3} / \mathrm{C}$ cathode material prepared by polyol process. Ceram. Int. 4O, 2014, 11251-11259.

[115] Wang, W. H.; Zhang, J. L.; Jia, Z.; Dai, C. S.; Hu, Y. F.; Zhou, J. G.; Xiao, Q. F. Enhancement of the cycling performance of $\mathrm{Li}_{3} \mathrm{~V}_{2}\left(\mathrm{PO}_{4}\right)_{3} / \mathrm{C}$ by stabilizing the crystal structure through $\mathrm{Zn}^{2+}$ doping. Phys. Chem. Chem. Phys. 16, 2014, 13858-13865.

[116] Liu, S. Q.; Li, S. C.; Huang, K. L.; Gong, B. L.; Zhang, G. Kinetic study on $\mathrm{Li}_{2.8}\left(\mathrm{~V}_{0.9} \mathrm{Ge}_{0.1}\right)_{2}\left(\mathrm{PO}_{4}\right)_{3}$ by EIS measurement. J. Alloy Compd. 45O, 2008, 499-504.

[117] Zhong, S. K.; Liu, L. T.; Jiang, J. Q.; Li, Y. W.; Wang, J.; Liu, J. Q.; Li, Y. H. Preparation and electrochemical properties of Y-doped $\mathrm{Li}_{3} \mathrm{~V}_{2}\left(\mathrm{PO}_{4}\right)_{3}$ cathode materials for lithium batteries. J. Rare Earth 27, 2009, 134-137.

[118] Zhang, L. L.; Zhang, X.; Sun, Y. M.; Luo, W.; Hu, X. L.; Wu, X. J.; Huang, Y. H. Improved Electrochemical Performance in $\mathrm{Li}_{3} \mathrm{~V}_{2}\left(\mathrm{PO}_{4}\right)_{3}$ Promoted by Niobium-Incorporation. J. Electrochem. Soc. 158, 2011, A924-A929.

[119] Liu, L. Y.; Qiu, Y. B.; Mai, Y. Z.; Wu, Q. B.; Zhang, H. Y. Influences of neodymium doping on magnetic and electrochemical properties of $\mathrm{Li}_{3} \mathrm{~V}_{2}\left(\mathrm{PO}_{4}\right)_{3} / \mathrm{C}$ synthesized via a sol-gel method. J. Power Sources 295, 2015, 246-253.

[120] Yuan, W.; Yan, J.; Tang, Z. Y.; Sha, O.; Wang, J. M.; Mao, W. F.; Ma, L. Mo-doped $\mathrm{Li}_{3} \mathrm{~V}_{2}\left(\mathrm{PO}_{4}\right)_{3} / \mathrm{C}$ cathode material with high rate capability and long term cyclic stability. Electrochim. Acta 72, 2012, 138-142.

[121] Liu, H. P.; Bi, S. F.; Wen, G. W.; Teng, X. G.; Gao, P.; Ni, Z. J.; Zhu, Y. M.; Zhang, F. Synthesis and electrochemical performance of Sn-doped $\mathrm{Li}_{3} \mathrm{~V}_{2}\left(\mathrm{PO}_{4}\right)_{3} / \mathrm{C}$ cathode material for lithium ion battery by microwave solid-state technique. J. Alloy Compd. 543, 2012, 99-104.

[122] Jiang, B. Q.; Hu, S. F.; Wang, M. W.; Ouyang, X. P.; Gong, Z. Y. Synthesis and 
electrochemical performance of La-doped $\mathrm{Li}_{3} \mathrm{~V}_{2-\mathrm{x}} \mathrm{La}_{\mathrm{x}}\left(\mathrm{PO}_{4}\right)_{3}$ cathode materials for lithium batteries. Rare Metals 3o, 2011, 115-119.

[123] Yao, J.; Wei, S.; Zhang, P.; Shen, C.; Aguey-Zinsou, K.-F.; Wang, L. Synthesis and properties of $\mathrm{Li}_{3} \mathrm{~V}_{2-\mathrm{x}} \mathrm{Ce}_{\mathrm{x}}\left(\mathrm{PO}_{4}\right)_{3} / \mathrm{C}$ cathode materials for Li-ion batteries. J. Alloy Compd. 532, 2012, 49-54.

[124] Dang, J. X.; Xiang, F.; Gu, N. Y.; Zhang, R. B.; Mukherjee, R.; Oh, I. K.; Koratkar, N.; Yang, Z. Y. Synthesis and electrochemical performance characterization of Ce-doped $\mathrm{Li}_{3} \mathrm{~V}_{2}\left(\mathrm{PO}_{4}\right)_{3} / \mathrm{C}$ as cathode materials for lithium-ion batteries. J. Power Sources 243, 2013 , 33-39.

[125] Zhang, L.; Yang, T.; Yang, Q.; Huang, Z. H.; Fang, M. H.; Liu, Y. G. Effects of Ta Ion Doping on Structure and Electrochemical Performances of $\mathrm{Li}_{3} \mathrm{~V}_{2}\left(\mathrm{PO}_{4}\right)_{3} / \mathrm{C}$ Cathode Materials. Key Eng. Mater. 519, 2012, 137-141.

[126] Yang, X. J.; Jun, L.; Jia, H. R. Study on structure and electrochemical performance of $\mathrm{Tm}^{3+}$-doped monoclinic $\mathrm{Li}_{3} \mathrm{~V}_{2}\left(\mathrm{PO}_{4}\right)_{3} / \mathrm{C}$ cathode material for lithium-ion batteries. Electrochim. Acta 15o, 2014, 62-67.

[127] Zhong, S. K.; Liu, L. T.; Liu, J. Q.; Wang, J.; Yang, J. W. High-rate characteristic of F-substitution $\mathrm{Li}_{3} \mathrm{~V}_{2}\left(\mathrm{PO}_{4}\right)_{3}$ cathode materials for Li-ion batteries. Solid State Commun. 149, 2009, 1679-1683.

[128] Yao, J. H.; Jia, Z. T.; Zhang, P. J.; Shen, C. Q.; Wang, J. B.; Aguey-Zinsou, K. F.; Ma, C. A.; Wang, L. B. Microwave assisted sol-gel synthesis of chlorine doped lithium vanadium phosphate. Ceram. Int. 39, 2013, 2165-2170.

[129] Lee, S. N.; Kim, H. S.; An, J. Y.; Amaresh, S.; Lee, Y. G.; Nam, K. W.; Lee, Y. S. Preparation and Characterization of Chlorine Doped $\mathrm{Li}_{3} \mathrm{~V}_{2}\left(\mathrm{PO}_{4}\right)_{3}$ as High Rate Cathode Active Material for Lithium Secondary Batteries. J. Nanosci. Nanotechnol. 14, 2014, 7516-7520.

[130] Yan, J.; Yuan, W.; Tang, Z. Y.; Xie, H.; Mao, W. F.; Ma, L. Synthesis and electrochemical performance of $\mathrm{Li}_{3} \mathrm{~V}_{2}\left(\mathrm{PO}_{4}\right)_{3-\mathrm{x}} \mathrm{Cl} / \mathrm{x} / \mathrm{C}$ cathode materials for lithium-ion batteries. J. Power Sources 209, 2012, 251-256.

[131] Cushing, B. L.; Goodenough, J. B. $\mathrm{Li}_{2} \mathrm{NaV}_{2}\left(\mathrm{PO}_{4}\right)_{3}:$ A 3.7 V Lithium-Insertion Cathode with the Rhombohedral NASICON Structure. J. Solid State Chem. 162, 2oo1, 176-181.

[132] Zhou, Y. P.; Rui, X. H.; Sun, W. P.; Xu, Z. C.; Zhou, Y.; Ng, W. J.; Yan, Q. Y.; Fong, E. Biochemistry-Enabled 3D Foams for Ultrafast Battery Cathodes. ACS Nano 9, 2015, 4628-4635.

[133] Shao, L. Y.; Shu, J.; Tang, Y. H.; Li, P.; Lin, X. T.; Shui, M.; Long, N. B.; Wang, D. Y. Phase diagram and electrochemical behavior of lithium sodium vanadium phosphates cathode materials for lithium ion batteries. Ceram. Int. 41, 2015, 5164-5171.

[134] Guo, X. D; Zhong, B. H; Tang, Y; Liao, W. H; Du. Q, W. Performance and structure of doped-Mg- $\mathrm{Li}_{3} \mathrm{~V}_{2}\left(\mathrm{PO}_{4}\right)_{3}$ cathode materialfor lithium ion batteries. Chem. Res. Appl. 2O, 2008, 625-627.

[135] Dai, C. S.; Chen, Z. Y.; Jin, H. Z.; Hu, X. G. Synthesis and performance of $\mathrm{Li}_{3}\left(\mathrm{~V}_{1-\mathrm{x}} \mathrm{Mg}_{\mathrm{x}}\right)_{2}\left(\mathrm{PO}_{4}\right)_{3}$ cathode materials. J. Power Sources 195, 2010, 5775-5779.

[136] Lu, Y. H.; Wang, L.; Song, J.; Zhang, D. W.; Xu, M. W.; Goodenough, J. B. Aluminum-stabilized NASICON-structured $\mathrm{Li}_{3} \mathrm{~V}_{2}\left(\mathrm{PO}_{4}\right)_{3}$. J. Mater. Chem. A 1, 2013, 68-72.

[137] Xiao, Z.; Xia, Y.; Ren, Z. H.; Xu, G.; Shen, G.; Han, G. R. Electrochemical 
Performance of $\mathrm{Li}_{3} \mathrm{~V}_{2-\mathrm{x}} \mathrm{Mn}_{\mathrm{x}}\left(\mathrm{PO}_{4}\right)_{3} / \mathrm{C}$ Cathode Materials Prepared by a Sol-Gel Method. Rare Metal Mater. Eng. 41, 2012, 681-685.

[138] Bini, M.; Ferrari, S.; Capsoni, D.; Massarotti, V. Mn influence on the electrochemical behaviour of $\mathrm{Li}_{3} \mathrm{~V}_{2}\left(\mathrm{PO}_{4}\right)_{3}$ cathode material. Electrochim. Acta 56, 2o11, 2648-2655.

[139] Sato, M.; Ohkawa, H.; Yoshida, K.; Saito, M.; Uematsu, K.; Toda, K. Enhancement of discharge capacity of $\mathrm{Li}_{3} \mathrm{~V}_{2}\left(\mathrm{PO}_{4}\right)_{3}$ by stabilizing the orthorhombic phase at room temperature. Solid State Ion. 135, 2000, 137-142.

[140] Zhang, L. L.; Liang, G.; Peng, G.; Jiang, Y.; Fang, H.; Huang, Y. H.; Croft, M. C.; Ignatov, $\mathrm{A}$. Evolution of electrochemical performance in $\mathrm{Li}_{3} \mathrm{~V}_{2}\left(\mathrm{PO}_{4}\right)_{3} / \mathrm{C}$ composites caused by cation incorporation. Electrochim. Acta 108, 2013, 182-190.

[141] Bruce, P. G.; Scrosati, B.; Tarascon, J. M. Nanomaterials for Rechargeable Lithium Batteries. Angew. Chem. Int. Edit 47, 2008, 2930-2946.

[142] Omenya, F.; Chernova, N. A.; Upreti, S.; Zavalij, P. Y.; Nam, K. W.; Yang, X. Q.; Whittingham, M. S. Can Vanadium Be Substituted into $\mathrm{LiFePO}_{4}$ ? Chem. Mater. 23, 2o11, 4733-4740.

[143] Chaurand, P.; Rose, J.; Briois, V.; Salome, M.; Proux, O.; Nassif, V.; Olivi, L.; Susini, J.; Hazemann, J. L.; Bottero, J. Y. New Methodological Approach for the Vanadium K-Edge X-ray Absorption Near-Edge Structure Interpretation: Application to the Speciation of Vanadium in Oxide Phases from Steel Slag. J. Phys. Chem. B 111, 2007, 5101-5110.

[144] Mao, J. L.; Shao, L. Y.; Li, P.; Lin, X. T.; Shui, M.; Long, N. B.; Shu, J. Comparison of phase composition, morphology and electrochemical property for $\mathrm{Li}_{3-\mathrm{x}} \mathrm{Na}_{\mathrm{x}} \mathrm{V}_{2}\left(\mathrm{PO}_{4}\right)_{3}(\mathrm{x}=0.5$, 1.5 and 2.0) as lithium storage cathode materials. Electrochim. Acta 173, 2015, 96-104.

[145] Jiang, T.; Pan, W. C.; Wang, J.; Bie, X. F.; Du, F.; Wei, Y. J.; Wang, C. Z.; Chen, G. Carbon coated $\mathrm{Li}_{3} \mathrm{~V}_{2}\left(\mathrm{PO}_{4}\right)_{3}$ cathode material prepared by a PVA assisted sol-gel method. Electrochim. Acta 55, 2010, 3864-3869.

[146] Liu, Q. J.; Yang, F.; Wang, S. P.; Feng, L. J.; Zhang, W. J.; Wei, H. Y. A simple diethylene glycol-assisted synthesis and high rate performance of $\mathrm{Li}_{3} \mathrm{~V}_{2}\left(\mathrm{PO}_{4}\right)_{3} / \mathrm{C}$ composites as cathode material for Li-ion batteries. Electrochim. Acta 111, 2013, 903-908.

[147] Qiao, Y. Q.; Wang, X. L.; Xiang, J. Y.; Zhang, D.; Liu, W. L.; Tu, J. P. Electrochemical performance of $\mathrm{Li}_{3} \mathrm{~V}_{2}\left(\mathrm{PO}_{4}\right)_{3} / \mathrm{C}$ cathode materials using stearic acid as a carbon source. Electrochim. Acta 56, 2011, 2269-2275.

[148] Wang, J. W.; Zhang, X. F.; Liu, J.; Yang, G. L.; Ge, Y. C.; Yu, Z. J.; Wang, R. S.; Pan, $\mathrm{X}$. M. Long-term cyclability and high-rate capability of $\mathrm{Li}_{3} \mathrm{~V}_{2}\left(\mathrm{PO}_{4}\right)_{3} / \mathrm{C}$ cathode material using PVA as carbon source. Electrochim. Acta 55, 2010, 6879-6884.

[149] Wang, L. A.; Jiang, X. Q.; Li, X.; Pi, X. Q.; Ren, Y.; Wu, F. Rapid preparation and electrochemical behavior of carbon-coated $\mathrm{Li}_{3} \mathrm{~V}_{2}\left(\mathrm{PO}_{4}\right)_{3}$ from wet coordination. Electrochim. Acta 55, 2010, 5057-5062.

[150] Zhang, B.; Zheng, J. C. Synthesis of $\mathrm{Li}_{3} \mathrm{~V}_{2}\left(\mathrm{PO}_{4}\right)_{3} / \mathrm{C}$ with high tap-density and high-rate performance by spray drying and liquid nitrogen quenching method. Electrochim. Acta 67, 2012, 55-61.

[151] Liu, H. D.; Yang, G.; Zhang, X. F.; Gao, P.; Wang, L.; Fang, J. H.; Pinto, J.; Jiang, X. F. Kinetics of conventional carbon coated $-\mathrm{Li}_{3} \mathrm{~V}_{2}\left(\mathrm{PO}_{4}\right)_{3}$ and nanocomposite $\mathrm{Li}_{3} \mathrm{~V}_{2}\left(\mathrm{PO}_{4}\right)_{3} /$ graphene as cathode materials for lithium ion batteries. J. Mater. Chem. 22, 2012, 
11039-11047.

[152] Wang, C.; Liu, H. M.; Yang, W. S. An integrated core-shell structured $\mathrm{Li}_{3} \mathrm{~V}_{2}\left(\mathrm{PO}_{4}\right)_{3} @ \mathrm{C}$ cathode material of LIBs prepared by a momentary freeze-drying method. $J$. Mater. Chem. 22, 2012, 5281-5285.

[153] Su, J.; Wu, X. L.; Lee, J. S.; Kim, J.; Guo, Y. G. A carbon-coated $\mathrm{Li}_{3} \mathrm{~V}_{2}\left(\mathrm{PO}_{4}\right)_{3}$ cathode material with an enhanced high-rate capability and long lifespan for lithium-ion batteries. J. Mater. Chem. A 1, 2013, 2508-2514.

[154] Wang, C.; Guo, Z. Y.; Shen, W.; Zhang, A. L.; Xu, Q. J.; Liu, H. M.; Wang, Y. G. Application of sulfur-doped carbon coating on the surface of $\mathrm{Li}_{3} \mathrm{~V}_{2}\left(\mathrm{PO}_{4}\right)_{3}$ composites to facilitate Li-ion storage as cathode materials. J. Mater. Chem. A 3, 2015, 6064-6072.

[155] Kuang, Q.; Zhao, Y. M. Two-step carbon coating of lithium vanadium phosphate as high-rate cathode for lithium-ion batteries. J. Power Sources 216, 2012, 33-35.

[156] Pei, B.; Jiang, Z. Q.; Zhang, W. X.; Yang, Z. H.; Manthiram, A. Nanostructured $\mathrm{Li}_{3} \mathrm{~V}_{2}\left(\mathrm{PO}_{4}\right)_{3}$ cathode supported on reduced graphene oxide for lithium-ion batteries. J. Power Sources 239, 2013, 475-482.

[157] Qiao, Y. Q.; Tu, J. P.; Wang, X. L.; Cu, C. D. The low and high temperature electrochemical performances of $\mathrm{Li}_{3} \mathrm{~V}_{2}\left(\mathrm{PO}_{4}\right)_{3} / \mathrm{C}$ cathode material for Li-ion batteries. J. Power Sources 199, 2012, 287-292.

[158] von Hagen, R.; Lepcha, A.; Song, X. F.; Tyrra, W.; Mathur, S. Influence of electrode design on the electrochemical performance of $\mathrm{Li}_{3} \mathrm{~V}_{2}\left(\mathrm{PO}_{4}\right)_{3} / \mathrm{C}$ nanocomposite cathode in lithium ion batteries. Nano Energy 2, 2013, 304-313.

[159] Zhang, X. F.; Kuhnel, R. S.; Hu, H. T.; Eder, D.; Balducci, A. Going nano with protic ionic liquids-the synthesis of carbon coated $\mathrm{Li}_{3} \mathrm{~V}_{2}\left(\mathrm{PO}_{4}\right)_{3}$ nanoparticles encapsulated in a carbon matrix for high power lithium-ion batteries. Nano Energy 12, 2015, 207-214.

[160] Duan, W. C.; Hu, Z.; Zhang, K.; Cheng, F. Y.; Tao, Z. L.; Chen, J. $\mathrm{Li}_{3} \mathrm{~V}_{2}\left(\mathrm{PO}_{4}\right)_{3} @ \mathrm{C}$ core-shell nanocomposite as a superior cathode material for lithium-ion batteries. Nanoscale $5, \mathbf{2 0 1 3}, 6485-6490$.

[161] Zheng, J. C.; Li, X. H.; Wang, Z. X.; Li, J. H.; Li, L. J.; Wu, L.; Guo, H. J. Characteristics of $\mathrm{xLiFePO}_{4} \cdot \mathrm{yLi}_{3} \mathrm{~V}_{2}\left(\mathrm{PO}_{4}\right)_{3}$ electrodes for lithium batteries. Ionics 15 , 2009, 753-759.

[162] Zheng, J. C.; Li, X. H.; Wang, Z. X.; Li, J. H.; Wu, L.; Li, L. J.; Guo, H. J. A Coalescence Mechanism for the Composite Cathode Material $x \mathrm{LiFePO}_{4} \cdot \mathrm{yLi}_{3} \mathrm{~V}_{2}\left(\mathrm{PO}_{4}\right)_{3}$. Acta Phys-Chim Sin. 25, 2009, 1916-1920.

[163] Jin, C.; Zhang, X. D.; He, W.; Wang, Y.; Li, H. M.; Wang, Z.; Bi, Z. Y. Effect of ion doping on the electrochemical performances of $\mathrm{LiFePO}_{4} \cdot \mathrm{Li}_{3} \mathrm{~V}_{2}\left(\mathrm{PO}_{4}\right)_{3}$ composite cathode materials. Rsc Adv 4, 2014, 15332-15339.

[164] Chen, Z. Y.; Yuan, G. H.; Dai, C. S.; Hu, X. G.; Luo, X. Y. Electrochemical behavior of $\mathrm{Mg}$-doped $7 \mathrm{LiFePO}{ }_{4} \cdot \mathrm{Li}_{3} \mathrm{~V}_{2}\left(\mathrm{PO}_{4}\right)_{3}$ composite cathode material for lithium-ion batteries. Ionics 19, 2013, 1077-1084.

[165] Guo, X. D.; Zhong, B. H.; Liu, H.; Song, Y.; Wen, J. J.; Tang, Y. Electrochemical performance of $\mathrm{LiFePO}_{4} \cdot \mathrm{Li}_{3} \mathrm{~V}_{2}\left(\mathrm{PO}_{4}\right)_{3}$ composite material prepared by solid-hydrothermal method. T. Nonferr. Metal Soc. 21, 2011, 1761-1766.

[166] Gao, C.; Liu, H.; Liu, G. B.; Zhang, J.; Wang, W. High-rate performance of $x \mathrm{LiFePO} \mathrm{H}_{4 \mathrm{y}} \cdot \mathrm{Li}_{3} \mathrm{~V}_{2}\left(\mathrm{PO}_{4}\right)_{3} / \mathrm{C}$ composite cathode materials synthesized via polyol process. Mater. 
Sci. Eng. B-Adv 178, 2013, 272-276.

[167] Xiang, J. Y.; Tu, J. P.; Zhang, L.; Wang, X. L.; Zhou, Y.; Qiao, Y. Q.; Lu, Y. Improved electrochemical performances of $9 \mathrm{LiFePO}_{4} \cdot \mathrm{Li}_{3} \mathrm{~V}_{2}\left(\mathrm{PO}_{4}\right)_{3} / \mathrm{C}$ composite prepared by a simple solid-state method. J. Power Sources 195, 2010, 8331-8335.

[168] Wang, L. Z.; Wang, K.; Zhang, Y.; Gu, S. H.; Zhang, K. Q. Improved electrode performance of $\mathrm{LiFePO}_{4}$ by using $\mathrm{Li}_{3} \mathrm{~V}_{2}\left(\mathrm{PO}_{4}\right)_{3}$ as an additive. Adv. Mater. Res-Switz 347-353, 2012, 3501-3505.

[169] Guo, X. D.; Zhong, B. H.; Tang, H.; Tang, Y.; Zhog, Y. J.; Song, Y. Influence of the Preparation Methods on $\mathrm{LiFePO}_{4} \cdot \mathrm{Li}_{3} \mathrm{~V}_{2}\left(\mathrm{PO}_{4}\right)_{3}$ Hybrid Material. Asian J. Chem. 23, 2o11, 3837-3840.

[170] Ma, Z. P.; Shao, G. J.; Wang, X.; Song, J. J.; Wang, G. L. $\mathrm{Li}_{3} \mathrm{~V}_{2}\left(\mathrm{PO}_{4}\right)_{3}$ modified $\mathrm{LiFePO}_{4} / \mathrm{C}$ cathode materials with improved high-rate and low-temperature properties. Ionics 19, 2013, 1861-1866.

[171] Tang, H.; Guo, X. D.; Zhong, B. H.; Liu, H.; Tang, Y.; Xu, R.; Li, L. Y. Mechanism studies and electrochemical performance optimization on $\mathrm{xLiFePO}_{4} \cdot(1-\mathrm{x}) \mathrm{Li}_{3} \mathrm{~V}_{2}\left(\mathrm{PO}_{4}\right)_{3}$ hybrid materials. J. Solid State Electr. 16, 2012, 1537-1543.

[172] Zheng, J. C.; Li, X. H.; Wang, Z. X.; Niu, S. S.; Liu, D. R.; Wu, L.; Li, L. J.; Li, J. H.; Guo, H. J. Novel synthesis of $\mathrm{LiFePO}_{4} \cdot \mathrm{Li}_{3} \mathrm{~V}_{2}\left(\mathrm{PO}_{4}\right)_{3}$ composite cathode material by aqueous precipitation and lithiation. J. Power Sources 195, 2010, 2935-2938.

[173] Zhong, S. K.; Chen, W.; Wu, L.; Liu, J. Q. A PEG-assisted rheological phase reaction synthesis of $5 \mathrm{LiFePO}_{4}<\ldots \mathrm{Li}_{3} \mathrm{~V}_{2}\left(\mathrm{PO}_{4}\right)_{3} / \mathrm{C}$ as cathode material for lithium ion cells. Ionics 18 , 2012, 523-527.

[174] Guo, Y.; Huang, Y. D.; Jia, D. Z.; Wang, X. C.; Sharma, N.; Guo, Z. P.; Tang, X. C. Preparation and electrochemical properties of high-capacity $\mathrm{LiFePO}_{4} \cdot \mathrm{Li}_{3} \mathrm{~V}_{2}\left(\mathrm{PO}_{4}\right)_{3} / \mathrm{C}$ composite for lithium-ion batteries. J. Power Sources 246, 2014, 912-917.

[175] Zhong, S. K.; Wu, L.; Zheng, J. C.; Liu, J. Q. Preparation of high tap-density $9 \mathrm{LiFePO}{ }_{4} \cdot \mathrm{Li}_{3} \mathrm{~V}_{2}\left(\mathrm{PO}_{4}\right)_{3} / \mathrm{C}$ composite cathode material by spray drying and post-calcining method. Powder Technol. 219, 2012, 45-48.

[176] Yang, G.; Jiang, C. Y.; He, X. M.; Ying, J. R.; Gao, J. Preparation of $\mathrm{Li}_{3} \mathrm{~V}_{2}\left(\mathrm{PO}_{4}\right)_{3} / \mathrm{LiFePO}_{4}$ composite cathode material for lithium ion batteries. Ionics 19, 2013, 1247-1253.

[177] Zhong, S. K.; Wu, L.; Liu, J. Q. Sol-gel synthesis and electrochemical properties of $9 \mathrm{LiFePO}{ }_{4} \cdot \mathrm{Li}_{3} \mathrm{~V}_{2}\left(\mathrm{PO}_{4}\right)_{3} / \mathrm{C}$ composite cathode material for lithium ion batteries. Electrochim. Acta 74, 2012, 8-15.

[178] Ma, P. P.; Hu, P.; Liu, Z. J.; Xia, J. H.; Xia, D. G.; Chen, Y.; Liu, Z. G.; Lu, Z. C. Structural and electrochemical characterization of $0.7 \mathrm{LiFePO}_{4} \cdot 0.3 \mathrm{Li}_{3} \mathrm{~V}_{2}\left(\mathrm{PO}_{4}\right)_{3} / \mathrm{C}$ cathode materials using PEG and glucose as carbon sources. Electrochim. Acta 106, 2013, 187-194.

[179] Zhang, B.; Zheng, J. C.; Yang, Z. H. Structural properties of composite cathode material $\mathrm{LiFePO}_{4} \cdot \mathrm{Li}_{3} \mathrm{~V}_{2}\left(\mathrm{PO}_{4}\right)_{3}$. Ionics 17, 2011, 859-862.

[180] Zhang, X. P.; Guo, H. J.; Li, X. H.; Wang, Z. X.; Peng, W. J.; Wu, L. Structure and Electrochemical Performance of $\mathrm{LiFePO}_{4}$ Cathode with Coating Super Iron Conductor $\mathrm{Li}_{3} \mathrm{~V}_{2}\left(\mathrm{PO}_{4}\right)_{3}$. Chem. J. Chinese U 33, 2012, 236-242.

[181] Zheng, J. C.; Zhang, B.; Yang, Z. H.; Ou, X.; Zhang, J. F. Studies of Composite Cathode Material $\mathrm{LiFePO}_{4} \cdot \mathrm{Li}_{3} \mathrm{~V}_{2}\left(\mathrm{PO}_{4}\right)_{3}$ and It's Precursor $\mathrm{FeVO}_{4-x} \mathrm{H}_{2} \mathrm{O}$. B Chem. Soc. Jpn. 86, 
2013, 376-381.

[182] Zhang, X. P.; Guo, H. J.; Li, X. H.; Wang, Z. X.; Wu, L. Studies of fast-ion conducting $\mathrm{Li}_{3} \mathrm{~V}_{2}\left(\mathrm{PO}_{4}\right)_{3}$ coated $\mathrm{LiFePO}_{4}$ via sol-gel method. Solid State Ion. 212, 2012 , 106-111.

[183] Wang, L.; Li, Z. C.; Xu, H. J.; Zhang, K. Studies of $\mathrm{Li}_{3} \mathrm{~V}_{2}\left(\mathrm{PO}_{4}\right)_{3}$ additives for the $\mathrm{LiFePO}_{4}$-based Li ion batteries. J. Phys. Chem.C 112, 2008, 308-312.

[184] Wu, L.; Lu, J. J.; Zhong, S. K. Studies of $\mathrm{xLiFePO}_{4} \cdot \mathrm{yLi}_{3} \mathrm{~V}_{2}\left(\mathrm{PO}_{4}\right)_{3} / \mathrm{C}$ composite cathode materials with high tap density and high performance prepared by sol spray drying method. J. Solid State Electr. 17, 2013, 2235-2241.

[185] Zheng, J. C.; Li, X. H.; Wang, Z. X.; Qin, D. M.; Guo, H. J.; Peng, W. J. Synthesis and Characterization of Composite Cathode Material $\mathrm{xLiFePO}_{4}{ }_{\mathrm{y}} \mathrm{Li}_{3} \mathrm{~V}_{2}\left(\mathrm{PO}_{4}\right)_{3}$. J. Inorg. Mater. 24, 2009, 143-146.

[186] Kosova, N. V.; Devyatkina, E. T.; Slobodyuk, A. B.; Gutakovskii, A. K. LiVPO $_{4}$ F/ $\mathrm{Li}_{3} \mathrm{~V}_{2}\left(\mathrm{PO}_{4}\right)_{3}$ nanostructured composite cathode materials prepared via mechanochemical way. J. Solid State Electr. 18, 2014, 1389-1399.

[187] Zhang, B.; Shen, C.; Zheng, J. C.; Han, Y. D.; Zhang, J. F.; Ming, L.; Wang, J. L.; Qin, S. E.; Li, H. Synthesis and Characterization of a Multi-Layer Core-Shell Composite Cathode Material LiVOPO ${ }_{4} \cdot \mathrm{Li}_{3} \mathrm{~V}_{2}\left(\mathrm{PO}_{4}\right)_{3}$. J. Electrochem. Soc. 161, 2014, A748-A752.

[188] Wang, J. X.; Wang, Z. X.; Li, X. H.; Guo, H. J.; Wu, X. W.; Zhang, X. P.; Xiao, W. X $\mathrm{Li}_{3} \mathrm{~V}_{2}\left(\mathrm{PO}_{4}\right)_{3} \cdot \mathrm{LiVPO}_{4} \mathrm{~F} / \mathrm{C}$ composite cathode materials for lithium ion batteries. Electrochim. Acta 87, 2013, 224-229.

[189] Wang, L. J.; Li, X. X.; Tang, Z. Y.; Zhang, X. H. Research on $\mathrm{Li}_{3} \mathrm{~V}_{2}\left(\mathrm{PO}_{4}\right)_{3} / \mathrm{Li}_{4} \mathrm{Ti}_{5} \mathrm{O}_{12} / \mathrm{C}$ composite cathode material for lithium ion batteries. Electrochem. Commun. 22, 2012, 73-76.

[190] Bi, Y. J.; Yang, W. C.; Yang, B. C.; Wang, C. Y.; Wang, D. Y.; Shi, S. Q. Influence of $\mathrm{Li}_{3} \mathrm{~V}_{2}\left(\mathrm{PO}_{4}\right)_{3}$ complexing on the performance of $\mathrm{LiMnPO}_{4}$ based materials utilized in lithium ion battery. Ceram. Int. 4O, 2014, 7637-7641.

[191] Wang, C. Y.; Bi, Y. J.; Liu, Y.; Qin, Y. P.; Fang, Y. Q.; Wang, D. Y. Investigation of (1-x)LiMnPO${ }_{4} \cdot{ }_{x} \mathrm{Li}_{3} \mathrm{~V}_{2}\left(\mathrm{PO}_{4}\right)_{3} / \mathrm{C}$ : Phase composition and electrochemical performance. J. Power Sources 263, 2014, 332-337.

[192] Qin, L. F.; Xia, Y. G.; Qiu, B.; Cao, H. L.; Liu, Y. Z.; Liu, Z. P. Synthesis and electrochemical performances of (1-x) $\mathrm{LiMnPO}_{4} \cdot{ }_{\mathrm{x}} \mathrm{Li}_{3} \mathrm{~V}_{2}\left(\mathrm{PO}_{4}\right)_{3} / \mathrm{C}$ composite cathode materials for lithium ion batteries. J. Power Sources 239, 2013, 144-150.

[193] Yun, J. S.; Kim, S.; Cho, B. W.; Lee, K. Y.; Chung, K. Y.; Chang, W. Synthesis and Electrochemical Properties of $\mathrm{Li}_{3} \mathrm{~V}_{2}\left(\mathrm{PO}_{4}\right)_{3} \cdot \mathrm{LiMnPO}_{4}$ Composite Cathode Material for Lithium-ion Batteries. B Korean Chem. Soc. 34, 2013, 433-436.

[194] Wang, L. J.; Du, C. Q.; Tang, Z. Y.; Zhang, X. H.; Xu, Q. Improvement of electrochemical performance for $\mathrm{Li}_{3} \mathrm{~V}_{2}\left(\mathrm{PO}_{4}\right)_{3} / \mathrm{C}$ electrode using $\mathrm{LiCoO}_{2}$ as an additive. Electrochim. Acta 98, 2013, 218-224.

[195] Zhang, L.; Wang, X. L.; Xiang, J. Y.; Zhou, Y.; Shi, S. J.; Tu, J. P. Synthesis and electrochemical performances of $\mathrm{Li}_{3} \mathrm{~V}_{2}\left(\mathrm{PO}_{4}\right)_{3} /(\mathrm{Ag}+\mathrm{C})$ composite cathode. J. Power Sources 195, 2010, 5057-5061.

[196] Choi, M. S.; Kim, H. S.; Lee, Y. M.; Jin, B. S. Enhanced electrochemical performance of $\mathrm{Li}_{3} \mathrm{~V}_{2}\left(\mathrm{PO}_{4}\right)_{3} / \mathrm{Ag}$-graphene composites as cathode materials for Li-ion batteries. 
J. Mater. Chem. A 2, 2014, 7873-7879.

[197] Jiang, T.; Wei, Y. J.; Pan, W. C.; Li, Z.; Ming, X.; Chen, G.; Wang, C. Z. Preparation and electrochemical studies of $\mathrm{Li}_{3} \mathrm{~V}_{2}\left(\mathrm{PO}_{4}\right)_{3} / \mathrm{Cu}$ composite cathode material for lithium ion batteries. J. Alloy Compd. 488, 2009, L26-L29.

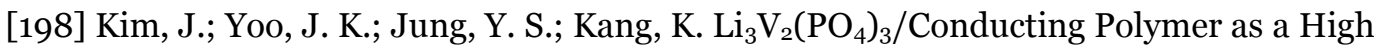
Power 4 V-Class Lithium Battery Electrode. Adv. Energy Mater. 3, 2013, 1004-1007.

[199] Zhang, G. Q.; Li, X. X.; Jia, H. T.; Pang, X. X.; Yang, H. W.; Wang, Y. H.; Ding, K. Q. Preparation and Characterization of Polyaniline (PANI) doped- $\mathrm{Li}_{3} \mathrm{~V}_{2}\left(\mathrm{PO}_{4}\right)_{3}$. Int. $J$. Electrochem. Soc. 7, 2012, 830-843.

[200] Yan, H. Y.; Chen, W. X.; Wu, X. M.; Li, Y. F. Conducting polyaniline-wrapped lithium vanadium phosphate nanocomposite as high-rate and cycling stability cathode for lithium-ion batteries. Electrochim. Acta 146, 2014, 295-300.

[201] Zhang, L. L.; Liang, G.; Peng, G.; Zou, F.; Huang, Y. H.; Croft, M. C.; Ignatov, A. Significantly Improved Electrochemical Performance in $\mathrm{Li}_{3} \mathrm{~V}_{2}\left(\mathrm{PO}_{4}\right)_{3} / \mathrm{C}$ Promoted by $\mathrm{SiO}_{2}$ Coating for Lithium-Ion Batteries. J. Phys. Chem. C 116, 2012, 12401-12408.

[202] Zhai, J.; Zhao, M. S.; Wang, D. D.; Qiao, Y. Q. Effect of MgO nanolayer coated on $\mathrm{Li}_{3} \mathrm{~V}_{2}\left(\mathrm{PO}_{4}\right)_{3} / \mathrm{C}$ cathode material for lithium-ion battery. J. Alloy Compd. 502, 2010, 401-406.

[203] Zhang, R.; Zhang, Y.; Zhu, K.; Du, F.; Fu, Q.; Yang, X.; Wang, Y.; Bie, X.; Chen, G.; Wei, Y. Carbon and $\mathrm{RuO}_{2}$ Binary Surface Coating for the $\mathrm{Li}_{3} \mathrm{~V}_{2}\left(\mathrm{PO}_{4}\right)_{3}$ Cathode Material for Lithium-Ion Batteries. ACS Appl. Mater. Interfaces 6, 2014, 12523-12530.

[204] Secchiaroli, M.; Nobili, F.; Tossici, R.; Giuli, G.; Marassi, R. Synthesis and electrochemical characterization of high rate capability $\mathrm{Li}_{3} \mathrm{~V}_{2}\left(\mathrm{PO}_{4}\right)_{3} / \mathrm{C}$ prepared by using poly(acrylic acid) and D-(+)-glucose as carbon sources. J. Power Sources 275, 2015, 792-798.

[205] Wang, L. J.; Tang, Z. Y.; Ma, L.; Zhang, X. H. High-rate cathode based on $\mathrm{Li}_{3} \mathrm{~V}_{2}\left(\mathrm{PO}_{4}\right)_{3} / \mathrm{C}$ composite material prepared via a glycine-assisted sol-gel method. Electrochem. Commun. 13, 2011, 1233-1235.

[206] Wang, H.; Li, Y. J.; Huang, C. H.; Zhong, Y. D.; Liu, S. Q. High-rate capability of $\mathrm{Li}_{3} \mathrm{~V}_{2}\left(\mathrm{PO}_{4}\right)_{3} / \mathrm{C}$ composites prepared via a polyvinylpyrrolidone-assisted sol-gel method. $J$. Power Sources 208, 2012, 282-287.

[207] Wang, J. W.; Liu, J.; Yang, G. L.; Zhang, X. F.; Yan, X. D.; Pan, X. M.; Wang, R. S. Electrochemical performance of $\mathrm{Li}_{3} \mathrm{~V}_{2}\left(\mathrm{PO}_{4}\right)_{3} / \mathrm{C}$ cathode material using a novel carbon source. Electrochim. Acta 54, 2009, 6451-6454.

[208] Chen, Q. Q.; Wang, J. M.; Tang, Z.; He, W. C.; Shao, H. B.; Zhang, J. Q. Electrochemical performance of the carbon coated $\mathrm{Li}_{3} \mathrm{~V}_{2}\left(\mathrm{PO}_{4}\right)_{3}$ cathode material synthesized by a sol-gel method. Electrochim. Acta 52, 2007, 5251-5257.

[209] Rui, X. H.; Li, C.; Chen, C. H. Synthesis and characterization of carbon-coated $\mathrm{Li}_{3} \mathrm{~V}_{2}\left(\mathrm{PO}_{4}\right)_{3}$ cathode materials with different carbon sources. Electrochim. Acta 54, 2009, 3374-3380.

[210] Rui, X. H.; Li, C.; Liu, J.; Cheng, T.; Chen, C. H. The $\mathrm{Li}_{3} \mathrm{~V}_{2}\left(\mathrm{PO}_{4}\right)_{3} / \mathrm{C}$ composites with high-rate capability prepared by a maltose-based sot-gel route. Electrochim. Acta 55, 2010, 6761-6767.

[211] Zhang, X. D.; Hou, Y. K.; He, W.; Yang, G. H.; Cui, J. J.; Liu, S. K.; Song, X.; Huang, Z. Fabricating high performance lithium-ion batteries using bionanotechnology. Nanoscale 7 , 2015, 3356-3372. 
[212] Rui, X. H.; Jin, Y.; Feng, X. Y.; Zhang, L. C.; Chen, C. H. A comparative study on the low-temperature performance of $\mathrm{LiFePO}_{4} / \mathrm{C}$ and $\mathrm{Li}_{3} \mathrm{~V}_{2}\left(\mathrm{PO}_{4}\right)_{3} / \mathrm{C}$ cathodes for lithium-ion batteries. J. Power Sources 196, 2011, 2109-2114.

[213] Chen, Z. Y.; Dai, C. S.; Wu, G.; Nelson, M.; Hu, X. G.; Zhang, R. X.; Liu, J. S.; Xia, J. C. High performance $\mathrm{Li}_{3} \mathrm{~V}_{2}\left(\mathrm{PO}_{4}\right)_{3} / \mathrm{C}$ composite cathode material for lithium ion batteries studied in pilot scale test. Electrochim. Acta 55, 2010, 8595-8599.

[214] Liu, Z. Q.; Kang, X. Y.; Li, C. F.; Hua, N.; Wumair, T.; Han, Y. Low-temperature behavior of $\mathrm{Li}_{3} \mathrm{~V}_{2}\left(\mathrm{PO}_{4}\right)_{3} / \mathrm{C}$ as cathode material for lithium ion batteries. J. Solid State Electr. 16, 2012, 1917-1923.

[215] De Volder, M. F. L.; Tawfick, S. H.; Baughman, R. H.; Hart, A. J. Carbon Nanotubes: Present and Future Commercial Applications. Science 339, 2013, 535-539.

[216] Mao, W. F.; Fu, Y. B.; Zhao, H.; Ai, G.; Dai, Y. L.; Meng, D. C.; Zhang, X. H.; Qu, D. Y.; Liu, G.; Battaglia, V. S.; Tang, Z. Y. Rational Design and Facial Synthesis of $\mathrm{Li}_{3} \mathrm{~V}_{2}\left(\mathrm{PO}_{4}\right)_{3} @ \mathrm{C}$ Nanocomposites Using Carbon with Different Dimensions for Ultrahigh-Rate Lithium-Ion Batteries. ACS Appl. Mater. Interfaces 7, 2015, 12057-12066.

[217] Qiao, Y. Q.; Tu, J. P.; Mai, Y. J.; Cheng, L. J.; Wang, X. L.; Gu, C. D. Enhanced electrochemical performances of multi-walled carbon nanotubes modified $\mathrm{Li}_{3} \mathrm{~V}_{2}\left(\mathrm{PO}_{4}\right)_{3} / \mathrm{C}$ cathode material for lithium-ion batteries. J. Alloy Compd. 509, 2011, 7181-7185.

[218] Naoi, K.; Kisu, K.; Iwama, E.; Sato, Y.; Shinoda, M.; Okita, N.; Naoi, W. Ultrafast Cathode Characteristics of Nanocrystalline- $\mathrm{Li}_{3} \mathrm{~V}_{2}\left(\mathrm{PO}_{4}\right)_{3} /$ Carbon Nanofiber Composites. $J$. Electrochem. Soc. 162, 2015, A827-A833.

[219] Yan, B.; Chen, L.; Wang, T.; Xu, J.; Wang, H. Y.; Yang, G. Preparation and characterization of $\mathrm{Li}_{3} \mathrm{~V}_{2}\left(\mathrm{PO}_{4}\right)_{3}$ grown on carbon nanofiber as cathode material for lithium-ion batteries. Electrochim. Acta 176, 2015, 1358-1363.

[220] Bonaccorso, F.; Colombo, L.; Yu, G.; Stoller, M.; Tozzini, V.; Ferrari, A. C.; Ruoff, R. S.; Pellegrini, V. Graphene, related two-dimensional crystals, and hybrid systems for energy conversion and storage. Science 347, 2015.1246501

[221] Chang, H.; Wu, H. Graphene-based nanocomposites: preparation, functionalization, and energy and environmental applications. Energy Environ. Sci. 6, 2013, 3483-3507.

[222] Liu, H. D.; Gao, P.; Fang, J. H.; Yang, G. $\mathrm{Li}_{3} \mathrm{~V}_{2}\left(\mathrm{PO}_{4}\right)_{3} /$ graphene nanocomposites as cathode material for lithium ion batteries. Chem. Commun. 47, 2011, 9110-9112.

[223] Jiang, Y.; Xu, W. W.; Chen, D. D.; Jiao, Z.; Zhang, H. J.; Ma, Q. L.; Cai, X. H.; Zhao, B.; Chu, Y. L. Graphene modified $\mathrm{Li}_{3} \mathrm{~V}_{2}\left(\mathrm{PO}_{4}\right)_{3}$ as a high-performance cathode material for lithium ion batteries. Electrochim. Acta 85, 2012, 377-383.

[224] Zhang, L.; Wang, S. Q.; Cai, D. D.; Lian, P. C.; Zhu, X. F.; Yang, W. S.; Wang, H. H. $\mathrm{Li}_{3} \mathrm{~V}_{2}\left(\mathrm{PO}_{4}\right)_{3} @ \mathrm{C} /$ graphene composite with improved cycling performance as cathode material for lithium-ion batteries. Electrochim. Acta 91, 2013, 108-113.

[225] Cheng, B.; Zhang, X. D.; Ma, X. H.; Wen, J. W.; Yu, Y.; Chen, C. H. Nano$\mathrm{Li}_{3} \mathrm{~V}_{2}\left(\mathrm{PO}_{4}\right)_{3}$ enwrapped into reduced graphene oxide sheets for lithium-ion batteries. J. Power Sources 265, 2014, 104-109.

[226] Tukamoto, H.; West, A. R. Electronic Conductivity of $\mathrm{LiCoO}_{2}$ and Its Enhancement by Magnesium Doping. J. Electrochem. Soc. 144, 1997, 3164-3168.

[227] Li, Y.; Xie, D.; Zhang, Y. D.; Zhou, D.; Niu, X. Q.; Tong, Y. Y.; Wang, D. H.; Wang, X. L.; Gu, C. D.; Tu, J. P. Synthesis and electrochemical performance of $\mathrm{xLiV}_{3} \mathrm{O}_{8} \cdot \mathrm{y}$ 
$\mathrm{Li}_{3} \mathrm{~V}_{2}\left(\mathrm{PO}_{4}\right)_{3} / \mathrm{rGO}$ composite cathode materials for lithium ion batteries. J. Mater. Chem. A 3 , 2015, 14731-14740.

[228] Li, Y.; Bai, W. Q.; Zhang, Y. D.; Niu, X. Q.; Wang, D. H.; Wang, X. L.; Gu, C. D.; Tu, J. P. Synthesis and electrochemical performance of lithium vanadium phosphate and lithium vanadium oxide composite cathode material for lithium ion batteries. J. Power Sources 282, 2015, 100-108.

[229] Sarkar, S.; Mitra, S. $\mathrm{Li}_{3} \mathrm{~V}_{2}\left(\mathrm{PO}_{4}\right)_{3}$ Addition to the Olivine Phase: Understanding the Effect in Electrochemical Performance. J. Phys. Chem. C 118, 2014, 11512-11525.

[230] Zhang, J. F.; Shen, C.; Zhang, B.; Zheng, J. C.; Peng, C. L.; Wang, X. W.; Yuan, X. B.; Li, H.; Chen, G. M. Synthesis and performances of $2 \mathrm{LiFePO}_{4} \cdot \mathrm{Li}_{3} \mathrm{~V}_{2}\left(\mathrm{PO}_{4}\right)_{3} / \mathrm{C}$ cathode materials via spray drying method with double carbon sources. J. Power Sources 267, 2014, 227-234.

[231] Yang, M. R.; Ke, W. H.; Wu, S. H. Improving electrochemical properties of lithium iron phosphate by addition of vanadium. J. Power Sources 165, 2007, 646-650.

[232] Wang, W.; Guo, Y.; Liu, L.; Wang, S.; Yang, X.; Guo, H. Gold coating for a high performance $\mathrm{Li}_{4} \mathrm{Ti}_{5} \mathrm{O}_{12}$ nanorod aggregates anode in lithium-ion batteries. J. Power Sources 245, 2014, 624-629.

[233] Son, J. T.; Park, K. S.; Kim, H. G.; Chung, H. T. Surface-modification of $\mathrm{LiMn}_{2} \mathrm{O}_{4}$ with a silver-metal coating. J. Power Sources 126, 2004, 182-185.

[234] Park, K. S.; Schougaard, S. B.; Goodenough, J. B. Conducting-Polymer/ Iron-Redox-Couple Composite Cathodes for Lithium Secondary Batteries. Adv. Mater. 19, 2007, 848-851.

[235] Lepage, D.; Michot, C.; Liang, G.; Gauthier, M.; Schougaard, S. B. A Soft Chemistry Approach to Coating of $\mathrm{LiFePO}_{4}$ with a Conducting Polymer. Angew. Chem. Int. Edit 5o, 2011, 6884-6887.

[236] Karthikeyan, K.; Amaresh, S.; Aravindan, V.; Kim, W. S.; Nam, K. W.; Yang, X. Q.; Lee, Y. S. $\mathrm{Li}\left(\mathrm{Mn}_{1 / 3} \mathrm{Ni}_{1 / 3} \mathrm{Fe}_{1 / 3}\right) \mathrm{O}_{2}$-Polyaniline hybrids as cathode active material with ultra-fast charge-discharge capability for lithium batteries. J. Power Sources 232, 2013, 240-245.

[237] Gao, X. W.; Wang, J. Z.; Chou, S. L.; Liu, H. K. Synthesis and electrochemical performance of $\mathrm{LiV}_{3} \mathrm{O}_{8} /$ polyaniline as cathode material for the lithium battery. J. Power Sources 220, 2012, 47-53.

[238] Wang, Y. J.; Wang, X. H.; Li, J.; Mo, Z. S.; Zhao, X. J.; Jing, X. B.; Wang, F. S. Conductive polyaniline/silica hybrids from sol-gel process. Adv. Mater. 13, 2001, 1582-1585.

[239] Lai, C. Y.; Wei, J. J.; Wang, Z.; Xu, Q. J.; Lu, Y. F.; Li, H. X. $\mathrm{Li}_{3} \mathrm{~V}_{2}\left(\mathrm{PO}_{4}\right)_{3} /\left(\mathrm{SiO}_{2}+\mathrm{C}\right)$ composite with better stability and electrochemical properties for lithium-ion batteries. Solid State Ion. 272, 2015, 121-126.

[240] Han, H.; Qiu, F.; Liu, Z. T.; Han, X. E. $\mathrm{ZrO}_{2}$-coated $\mathrm{Li}_{3} \mathrm{~V}_{2}\left(\mathrm{PO}_{4}\right)_{3} / \mathrm{C}$ nanocomposite: A high-voltage cathode for rechargeable lithium-ion batteries with remarkable cycling performance. Ceram. Int. 41, 2015, 8779-8784.

[241] Zhai, J.; Zhao, M. S.; Wang, Y. Z. Effect of $\mathrm{Al}_{2} \mathrm{O}_{3}$-coating on the electrochemical performances of $\mathrm{Li}_{3} \mathrm{~V}_{2}\left(\mathrm{PO}_{4}\right)_{3} / \mathrm{C}$ cathode material. J. Solid State Electr. 18, 2014, 2857-2862.

[242] Yang, Y. X.; Guo, R. S.; Cai, G. L.; Zhang, C.; Liu, L.; Wang, S. S.; Wu, C.; Wan, Y. Z. Preparation and Electrochemical Properties of Ceria Coated $\mathrm{Li}_{3} \mathrm{~V}_{2}\left(\mathrm{PO}_{4}\right)_{3} / \mathrm{C}$ Cathode Materials for Lithium-Ion Batteries. J. Electrochem. Soc. 161, 2014, A2153-A2159. 
[243] Yang, Z. Z.; Huang, C. X.; Ke, R. P.; Xi, J. C.; Guo, Y. L. Effects of MnO nanolayer coating on $\mathrm{Li}_{3} \mathrm{~V}_{2}\left(\mathrm{PO}_{4}\right)_{3} / \mathrm{C}$ cathode material for lithium-ion batteries. Mater. Chem. Phys. 151, 2015, 259-266.

[244] Guo, Y. G.; Hu, J. S.; Wan, L. J. Nanostructured Materials for Electrochemical Energy Conversion and Storage Devices. Adv. Mater. 20, 2oo8, 2878-2887.

[245] Xiao, X.; Lu, J.; Li, Y. $\mathrm{LiMn}_{2} \mathrm{O}_{4}$ microspheres: Synthesis, characterization and use as a cathode in lithium ion batteries. Nano Res. 3, 2010, 733-737.

[246] Xie, H. M.; Wang, R. S.; Ying, J. R.; Zhang, L. Y.; Jalbout, A. F.; Yu, H. Y.; Yang, G. L.; Pan, X. M.; Su, Z. M. Optimized $\mathrm{LiFePO}_{4}-$ Polyacene Cathode Material for Lithium-Ion Batteries. Adv. Mater. 18, 2006, 2609-2613.

[247] He, X.; Li, J.; Cai, Y.; Wang, Y.; Ying, J.; Jiang, C.; Wan, C. Preparation of co-doped spherical spinel $\mathrm{LiMn}_{2} \mathrm{O}_{4}$ cathode materials for Li-ion batteries. J. Power Sources 15O, 2005, 216-222.

[248] Yu, F.; Zhang, J. J.; Yang, Y. F.; Song, G. Z. Up-scalable synthesis, structure and charge storage properties of porous microspheres of $\mathrm{LiFePO}_{4} @ \mathrm{C}$ nanocomposites. J. Mater. Chem. 19, 2009, 9121.

[249] Wang, X. Y.; Yin, S. Y.; Zhang, K. L.; Zhang, Y. X. Preparation and characteristic of spherical $\mathrm{Li}_{3} \mathrm{~V}_{2}\left(\mathrm{PO}_{4}\right)_{3}$. J. Alloy Compd. 486, 2009, L5-L9.

[250] Yang, G.; Ying, J. R.; Gao, J.; Jiang, C. Y.; Wan, C. R. Preparation and Characterization of Spherical $\mathrm{Li}_{3} \mathrm{~V}_{2}\left(\mathrm{PO}_{4}\right)_{3} / \mathrm{C}$ Cathode Material for Lithium-ion Batteries. $J$. New Mater. Electr. Sys. 12, 2009, 201-205.

[251] Huang, B.; Fan, X. P.; Zheng, X. D.; Lu, M. Synthesis and rate performance of lithium vanadium phosphate as cathode material for Li-ion batteries. J. Alloy Compd. 509, 2011, $4765-4768$.

[252] Zhang, L. L.; Peng, G.; Liang, G.; Zhang, P. C.; Wang, Z. H.; Jiang, Y.; Huang, Y. H.; Lin, H. Controllable synthesis of spherical $\mathrm{Li}_{3} \mathrm{~V}_{2}\left(\mathrm{PO}_{4}\right)_{3} / \mathrm{C}$ cathode material and its electrochemical performance. Electrochim. Acta 9o, 2013, 433-439.

[253] Du, X. Y.; He, W.; Zhang, X. D.; Yue, Y. Z.; Liu, H.; Zhang, X. G.; Min, D. D.; Ge, X. $\mathrm{X}$; $\mathrm{Du}, \mathrm{Y}$. Enhancing the electrochemical performance of lithium ion batteries using mesoporous $\mathrm{Li}_{3} \mathrm{~V}_{2}\left(\mathrm{PO}_{4}\right)_{3} / \mathrm{C}$ microspheres. J. Mater. Chem. 22, 2012, 5960-5969.

[254] Wu, L.; Zhong, S. K.; Lu, J. J.; Lv, F.; Liu, J. Q. $\mathrm{Li}_{3} \mathrm{~V}_{2}\left(\mathrm{PO}_{4}\right)_{3} / \mathrm{C}$ microspheres with high tap density and high performance synthesized by a two-step ball milling combined with the spray drying method. Mater. Lett. 115, 2014, 60-63.

[255] Qiao, Y. Q.; Tu, J. P.; Wang, X. L.; Zhang, D.; Xiang, J. Y.; Mai, Y. J.; Gu, C. D. Synthesis and improved electrochemical performances of porous $\mathrm{Li}_{3} \mathrm{~V}_{2}\left(\mathrm{PO}_{4}\right)_{3} / \mathrm{C}$ spheres as cathode material for lithium-ion batteries. J. Power Sources 196, 2011, 7715-7720.

[256] Ko, Y. N.; Koo, H. Y.; Kim, J. H.; Yi, J. H.; Kang, Y. C.; Lee, J. H. Characteristics of $\mathrm{Li}_{3} \mathrm{~V}_{2}\left(\mathrm{PO}_{4}\right)_{3} / \mathrm{C}$ powders prepared by ultrasonic spray pyrolysis. J. Power Sources 196, 2o11, $6682-6687$.

[257] He, W.; Zhang, X. D.; Du, X. Y.; Zhang, Y.; Yue, Y. Z.; Shen, J. X.; Li, M. Bio-assisted synthesis of mesoporous $\mathrm{Li}_{3} \mathrm{~V}_{2}\left(\mathrm{PO}_{4}\right)_{3}$ for high performance lithium-ion batteries. Electrochim. Acta 112, 2013, 295-303.

[258] Andersson, A. S.; Thomas, J. O. The source of first-cycle capacity loss in $\mathrm{LiFePO}_{4}$. J. Power Sources 97-98, 2001, 498-502. 
[258] Bruce, P. G.; Scrosati, B.; Tarascon, J. M. Nanomaterials for rechargeable lithium batteries. Angew. Chem. 47, 2008, 2930-2946.

[260] Hochbaum, A. I.; Yang, P. Semiconductor Nanowires for Energy Conversion. Chem. Rev. 110, 2009, 527-546.

[261] Zhu, C.; Yu, Y.; Gu, L.; Weichert, K.; Maier, J. Electrospinning of highly electroactive carbon-coated single-crystalline $\mathrm{LiFePO}_{4}$ nanowires. Angew. Chem. 5o, 2o11, 6278-6282.

[262] Zhang, X.; Cheng, F.; Yang, J.; Chen, J. $\mathrm{LiNi}_{0.5} \mathrm{Mn}_{1.5} \mathrm{O}_{4}$ porous nanorods as high-rate and long-life cathodes for Li-ion batteries. Nano Lett. 13, 2013, 2822-2825.

[263] Mai, L.; Wei, Q.; An, Q.; Tian, X.; Zhao, Y.; Xu, X.; Xu, L.; Chang, L.; Zhang, Q. Nanoscroll Buffered Hybrid Nanostructural VO2(B) Cathodes for High-Rate and Long-Life Lithium Storage. Adv. Mater. 25, 2013. 2969-2973.

[264] Niu, C.; Meng, J.; Han, C.; Zhao, K.; Yan, M.; Mai, L. $\mathrm{VO}_{2}$ nanowires assembled into hollow microspheres for high-rate and long-life lithium batteries. Nano Lett. 14, 2014, 2873-2878.

[265] Xu, J.; Wu, H.; Wang, F.; Xia, Y.; Zheng, G. $\mathrm{Zn}_{4} \mathrm{Sb}_{3}$ Nanotubes as Lithium Ion Battery Anodes with High Capacity and Cycling Stability. Adv. Energy Mater. 3, 2013, 286-289.

[266] Fei, L. F.; Lu, W.; Sun, L.; Wang, J. P.; Wei, J. B.; Chan, H. L. W.; Wang, Y. Highly entangled carbon nanoflakes on $\mathrm{Li}_{3} \mathrm{~V}_{2}\left(\mathrm{PO}_{4}\right)_{3}$ microrods for improved lithium storage performance. Rsc Adv 3, 2013, 1297-1301.

[267] Liu, H. W.; Cheng, C. X.; Huang, X. T.; Li, J. L. Hydrothermal synthesis and rate capacity studies of $\mathrm{Li}_{3} \mathrm{~V}_{2}\left(\mathrm{PO}_{4}\right)_{3}$ nanorods as cathode material for lithium-ion batteries. Electrochim. Acta 55, 2010, 8461-8465.

[268] Wei, Q. L.; An, Q. Y.; Chen, D. D.; Mai, L. Q.; Chen, S. Y.; Zhao, Y. L.; Hercule, K. M.; Xu, L.; Minhas-Khan, A.; Zhang, Q. J. One-Pot Synthesized Bicontinuous Hierarchical $\mathrm{Li}_{3} \mathrm{~V}_{2}\left(\mathrm{PO}_{4}\right)_{3} / \mathrm{C}$ Mesoporous Nanowires for High-Rate and Ultralong-Life Lithium-ion Batteries. Nano Lett. 14, 2014, 1042-1048.

[269] Chen, Q. Q.; Zhang, T. T.; Qiao, X. C.; Li, D. Q.; Yang, J. W. $\mathrm{Li}_{3} \mathrm{~V}_{2}\left(\mathrm{PO}_{4}\right)_{3} / \mathrm{C}$ nanofibers composite as a high performance cathode material for lithium-ion battery. $J$. Power Sources 234, 2013, 197-200.

[270] Fu, P.; Zhao, Y. M.; Dong, Y. Z.; Hou, X. M. Synthesis of high tap density $\mathrm{Li}_{3} \mathrm{~V}_{2}\left(\mathrm{PO}_{4}\right)_{3}$ cathode materials using mixed lithium precursors. J. Phys. Chem. Solids 71, 2010 , 394-399.

[271] Sun, Y. K.; Oh, S. M.; Park, H. K.; Scrosati, B. Micrometer-sized, nanoporous, high-volumetric-capacity $\mathrm{LiMn}_{0.85} \mathrm{Fe}_{0.15} \mathrm{PO}_{4}$ cathode material for rechargeable lithium-ion batteries. Adv. Mater. 23, 2011, 5050-5054.

[272] Nie, G. D.; Li, S. K.; Lu, X. F.; Wang, C. Progress on Applications of Inorganic Nanofibers Synthesized by Electrospinning Technique. Chem. J. Chinese U 34, 2013, 15-29.

[273] Ren, M. M.; Zhou, Z.; Gao, X. P.; Peng, W. X.; Wei, J. P. Core-Shell $\mathrm{Li}_{3} \mathrm{~V}_{2}\left(\mathrm{PO}_{4}\right)_{3} @ \mathrm{C}$ Composites as Cathode Materials for Lithium-Ion Batteries. J. Phys. Chem. C 112, 2008, 5689-5693.

[274] Liu, D.; Liu, Y.; Pan, A.; Nagle, K. P.; Seidler, G. T.; Jeong, Y.-H.; Cao, G. Enhanced Lithium-Ion Intercalation Properties of $\mathrm{V}_{2} \mathrm{O}_{5}$ Xerogel Electrodes with Surface Defects. J. Phys. 
Chem. C 115, 2011, 4959-4965.

[275] Wang, G.; Liu, H.; Liu, J.; Qiao, S.; Lu, G. M.; Munroe, P.; Ahn, H. Mesoporous $\mathrm{LiFePO}_{4} / \mathrm{C}$ nanocomposite cathode materials for high power lithium ion batteries with superior performance. Adv. Mater. 22, 2010, 4944-4948.

[276] Shen, L.; Zhang, X.; Uchaker, E.; Yuan, C.; Cao, G. $\mathrm{Li}_{4} \mathrm{Ti}_{5} \mathrm{O}_{12}$ Nanoparticles Embedded in a Mesoporous Carbon Matrix as a Superior Anode Material for High Rate Lithium Ion Batteries. Adv. Energy Mater. 2, 2012, 691-698.

[277] Liu, H.; Su, D.; Zhou, R.; Sun, B.; Wang, G.; Qiao, S. Z. Highly Ordered Mesoporous $\mathrm{MoS}_{2}$ with Expanded Spacing of the (002) Crystal Plane for Ultrafast Lithium Ion Storage. Adv. Energy Mater. 2, 2012, 970-975.

[278] Shi, Y.; Hua, C.; Li, B.; Fang, X.; Yao, C.; Zhang, Y.; Hu, Y.-S.; Wang, Z.; Chen, L.; Zhao, D.; Stucky, G. D. Highly Ordered Mesoporous Crystalline $\mathrm{MoSe}_{2}$ Material with Efficient Visible-Light-Driven Photocatalytic Activity and Enhanced Lithium Storage Performance. Adv Funct. Mater. 23, 2013, 1832-1838.

[279] Rao, C. N.; Matte, H. S.; Maitra, U. Graphene analogues of inorganic layered materials. Angew. Chem. 52, 2013, 13162-13185.

[280] Huang, X.; Tan, C.; Yin, Z.; Zhang, H. 25th anniversary article: hybrid nanostructures based on two-dimensional nanomaterials. Adv. Mater. 26, 2014, 2185-2204.

[281] Xu, M.; Liang, T.; Shi, M.; Chen, H. Graphene-like two-dimensional materials. Chem. Rev.113, 2013, 3766-3798.

[282] Guo, X.; Maier, J. Ionically Conducting Two-Dimensional Heterostructures. Adv. Mater. 21, 2009, 2619-2631.

[283] Pacchioni, G. Two-dimensional oxides: multifunctional materials for advanced technologies. Chemistry 18, 2012, 10144-10158.

[284] Liu, J.; Liu, X. W. Two-dimensional nanoarchitectures for lithium storage. Adv. Mater. 24, 2012, 4097-4111.

[285] Peng, X.; Peng, L.; Wu, C.; Xie, Y. Two dimensional nanomaterials for flexible supercapacitors. Chem. Soc. Rev. 43, 2014, 3303-3323.

[286] Chhowalla, M.; Shin, H. S.; Eda, G.; Li, L. J.; Loh, K. P.; Zhang, H. The chemistry of two-dimensional layered transition metal dichalcogenide nanosheets. Nat. Chem. 5, $\mathbf{2 0 1 3}$, 263-275.

[287] Sun, Y.; Wu, Q.; Shi, G. Graphene based new energy materials. Energy Environ. Sci. 4, 2011, 1113-1132.

[288] Han, S.; Wu, D.; Li, S.; Zhang, F.; Feng, X. Graphene: a two-dimensional platform for lithium storage. Small 9, 2013, 1173-1187.

[289] Saravanan, K.; Ramar, V.; Balaya, P.; Vittal, J. J. Li( $\left.\mathrm{Mn}_{\mathrm{x}} \mathrm{Fe}_{1-\mathrm{x}}\right) \mathrm{PO}_{4} / \mathrm{C}(\mathrm{x}=0.5,0.75$ and 1) nanoplates for lithium storage application. J. Mater. Chem. 21, 2011, 14925.

[290] Choi, D.; Wang, D.; Bae, I. T.; Xiao, J.; Nie, Z.; Wang, W.; Viswanathan, V. V.; Lee, Y. J.; Zhang, J. G.; Graff, G. L.; Yang, Z.; Liu, J. LiMnPO 4 nanoplate grown via solid-state reaction in molten hydrocarbon for Li-ion battery cathode. Nano Lett. 1O, 2010, 2799-2805.

[291] Saravanan, K.; Balaya, P.; Reddy, M. V.; Chowdari, B. V. R.; Vittal, J. J. Morphology controlled synthesis of $\mathrm{LiFePO}_{4} / \mathrm{C}$ nanoplates for Li-ion batteries. Energy Environ. Sci. 3, 2010, 457.

[292] Saravanan, K.; Vittal, J. J.; Reddy, M. V.; Chowdari, B. V. R.; Balaya, P. Storage 
performance of $\mathrm{LiFe}_{1-\mathrm{x}} \mathrm{Mn}_{\mathrm{x}} \mathrm{PO}_{4}$ nanoplates (x = 0, 0.5, and 1). J. Solid State Electr. 14, 2010, 1755-1760.

[293] Saravanan, K.; Reddy, M. V.; Balaya, P.; Gong, H.; Chowdari, B. V. R.; Vittal, J. J. Storage performance of $\mathrm{LiFePO}_{4}$ nanoplates. J. Mater. Chem. 19, 2009, 605.

[294] Qiao, Y. Q.; Wang, X. L.; Mai, Y. J.; Xiang, J. Y.; Zhang, D.; Gu, C. D.; Tu, J. P. Synthesis of plate-like $\mathrm{Li}_{3} \mathrm{~V}_{2}\left(\mathrm{PO}_{4}\right)_{3} / \mathrm{C}$ as a cathode material for Li-ion batteries. J. Power Sources 196, 2011, 8706-8709.

[295] Pan, A. Q.; Choi, D. W.; Zhang, J. G.; Liang, S. Q.; Cao, G. Z.; Nie, Z. M.; Arey, B. W.; Liu, J. High-rate cathodes based on $\mathrm{Li}_{3} \mathrm{~V}_{2}\left(\mathrm{PO}_{4}\right)_{3}$ nanobelts prepared via surfactant-assisted fabrication. J. Power Sources 196, 2011, 3646-3649.

[296] Teng, F.; Hu, Z. H.; Ma, X. H.; Zhang, L. C.; Ding, C. X.; Yu, Y.; Chen, C. H. Hydrothermal synthesis of plate-like carbon-coated $\mathrm{Li}_{3} \mathrm{~V}_{2}\left(\mathrm{PO}_{4}\right)_{3}$ and its low temperature performance for high power lithium ion batteries. Electrochim. Acta 91, 2013, 43-49.

[297] Hao, W. J.; Zhan, H. H.; Yu, J. Construction of carbon coating and multi-dimensional networks for $\mathrm{Li}_{3} \mathrm{~V}_{2}\left(\mathrm{PO}_{4}\right)_{3}$ nanoparticles by polyvinyl alcohol and graphene sheets. Mater. Lett. 83, 2012, 121-123.

[298] Rolison, D. R.; Long, J. W.; Lytle, J. C.; Fischer, A. E.; Rhodes, C. P.; McEvoy, T. M.; Bourg, M. E.; Lubers, A. M. Multifunctional $3 \mathrm{D}$ nanoarchitectures for energy storage and conversion. Chem. Soc. Rev. 38, 2009, 226-252.

[299] Long, J. W.; Dunn, B.; Rolison, D. R.; White, H. S. Three-Dimensional Battery Architectures. Chem. Rev. 104, 2004, 4463-4492.

[300] Zhang, H.; Yu, X.; Braun, P. V. Three-dimensional bicontinuous ultrafast-charge and -discharge bulk battery electrodes. Nat. Nanotechnol. 6, 2011, 277-281.

[301] Liu, G. C.; Liu, Y. N.; Liu, S. Q. Grinding-sol-gel synthesis and electrochemical performance of mesoporous $\mathrm{Li}_{3} \mathrm{~V}_{2}\left(\mathrm{PO}_{4}\right)_{3}$ cathode materials. T. Nonferr. Metal Soc. 23, 2013, 439-444.

[302] Wang, S. L.; Zhang, Z. X.; Jiang, Z. T.; Deb, A.; Yang, L.; Hirano, S. I. Mesoporous $\mathrm{Li}_{3} \mathrm{~V}_{2}\left(\mathrm{PO}_{4}\right)_{3} @ \mathrm{CMK}-3$ nanocomposite cathode material for lithium ion batteries. J. Power Sources 253, 2014, 294-299.

[303] Zhang, L.; Xiang, H. F.; Li, Z.; Wang, H. H. Porous $\mathrm{Li}_{3} \mathrm{~V}_{2}\left(\mathrm{PO}_{4}\right)_{3} / \mathrm{C}$ cathode with extremely high-rate capacity prepared by a sot-gel-combustion method for fast charging and discharging. J. Power Sources 203, 2012, 121-125.

[304] Zhang, X.; Liu, S. Q.; Huang, K. L.; Zhuang, S. X.; Guo, J.; Wu, T.; Cheng, P. Synthesis and characterization of macroporous $\mathrm{Li}_{3} \mathrm{~V}_{2}\left(\mathrm{PO}_{4}\right)_{3} / \mathrm{C}$ composites as cathode materials for Li-ion batteries. J. Solid State Electr. 16, 2012, 937-944.

[305] Wang, S. L.; Zhang, Z. X.; Fang, S. H.; Yang, L.; Yang, C. C.; Hirano, S. Synthesis and electrochemical properties of ordered macroporous $\mathrm{Li}_{3} \mathrm{~V}_{2}\left(\mathrm{PO}_{4}\right)_{3}$ cathode materials for lithium ion batteries. Electrochim. Acta 111, 2013, 685-690.

[306] Li, D. L.; Tian, M.; Xie, R.; Li, Q.; Fan, X. Y.; Gou, L.; Zhao, P.; Ma, S. L.; Shi, Y. X.; Yong, H. T. H. Three-dimensionally ordered macroporous $\mathrm{Li}_{3} \mathrm{~V}_{2}\left(\mathrm{PO}_{4}\right)_{3} / \mathrm{C}$ nanocomposite cathode material for high-capacity and high-rate Li-ion batteries. Nanoscale 6, 2014, 3302-3308.

[307] Yang, G.; Liu, H. D.; Ji, H. M.; Chen, Z. Z.; Jiang, X. F. Microwave solid-state synthesis and electrochemical properties of carbon-free $\mathrm{Li}_{3} \mathrm{~V}_{2}\left(\mathrm{PO}_{4}\right)_{3}$ as cathode materials for 
lithium batteries. Electrochim. Acta 55, 2010, 2951-2957.

[308] Cao, X. Y.; Zhang, J. J. Rheological phase synthesis and characterization of $\mathrm{Li}_{3} \mathrm{~V}_{2}\left(\mathrm{PO}_{4}\right)_{3} / \mathrm{C}$ composites as cathode materials for lithium ion batteries. Electrochim. Acta 129, 2014, 305-311.

[309] Luo, Y.; Xu, X.; Zhang, Y.; Pi, Y.; Zhao, Y.; Tian, X.; An, Q.; Wei, Q.; Mai, L. Hierarchical Carbon Decorated $\mathrm{Li}_{3} \mathrm{~V}_{2}\left(\mathrm{PO}_{4}\right)_{3}$ as a Bicontinuous Cathode with High-Rate Capability and Broad Temperature Adaptability. Adv. Energy Mater. 4, 2014, 1400107.

[310] Li, K.; Bian, H.; Liu, C.; Zhang, D.; Yang, Y. Comparison of geothermal with solar and wind power generation systems. Renew. Sust. Energy Rev. 42, 2015, 1464-1474.

[311] Singh, R.; Setiawan, A. D. Biomass energy policies and strategies: Harvesting potential in India and Indonesia. Renew. Sust. Energy Rev. 22, 2013, 332-345.

[312] Wang, Z. L.; Chen, J.; Lin, L. Progress in triboelectric nanogenerators as a new energy technology and self-powered sensors. Energy Environ. Sci. 8, 2015, 2250-2282.

[313] Nan, X.; Zhang, C.; Liu, C.; Liu, M.; Wang, Z. L.; Cao, G. Highly efficient storage of pulse energy produced by triboelectric nanogenerator in $\mathrm{Li}_{3} \mathrm{~V}_{2}\left(\mathrm{PO}_{4}\right)_{3} / \mathrm{C}$ cathode $\mathrm{Li}$-ion batteries. ACS Appl. Mater. Interfaces 8, 2015. 862-870.

[314] http://www.ronbenmultimedia.com/support/the-basic-knowledge-about-tabletpc-battery.htm. 